Portland State University

PDXScholar

Master of Environmental Management Project

Reports

Environmental Science and Management

2018

\title{
Assessing Effort Shifts and Familial Succession in Oregon's Nearshore Fisheries
}

Bryn Ellen Hudson

Portland State University

Follow this and additional works at: https://pdxscholar.library.pdx.edu/mem_gradprojects

Part of the Environmental Studies Commons, and the Natural Resources Management and Policy Commons

Let us know how access to this document benefits you.

\section{Recommended Citation}

Hudson, Bryn Ellen, "Assessing Effort Shifts and Familial Succession in Oregon's Nearshore Fisheries" (2018). Master of Environmental Management Project Reports. 33.

https://pdxscholar.library.pdx.edu/mem_gradprojects/33

https://doi.org/10.15760/mem.4

This Project is brought to you for free and open access. It has been accepted for inclusion in Master of Environmental Management Project Reports by an authorized administrator of PDXScholar. Please contact us if we can make this document more accessible: pdxscholar@pdx.edu. 
Assessing Effort Shifts and Familial Succession in Oregon's Nearshore Fisheries

By

Bryn Ellen Hudson

A project submitted in partial fulfillment of the requirements for the degree of

\author{
Profession Science Master \\ in \\ Environmental Science and Management
}

Project Committee:

Dr. Elise Granek, Chair

Dr. Max Nielsen-Pincus

Dr. Thomas Swearingen, ODFW

Portland State University

2018 


\begin{abstract}
Since the industrial revolution, natural resource systems have rapidly modernized and globalized. Commercial fishing industries have expanded and optimized resource extraction but have often times exceeded sustainable levels of harvest. In the Pacific Northwestern United States, the commercial fishing industry is one of particular economic and cultural importance. Due to reduced yield of many native fish stocks, marine reserves have been implemented in Oregon's nearshore waters in an effort to conserve biodiversity. While spatial closures of marine reserves seek to preserve and stabilize Oregon's ocean ecosystems, adverse socioeconomic implications are inevitably created when profitable waters are set aside. A main challenge of marine policy is achieving conservation goals while simultaneously protecting and maintaining the socioeconomic livelihood of ocean users. As policy makers push for aggressive conservation policy, it is imperative to understand the ways in which different groups of stakeholders will be impacted by regulation.

The objectives of this study were to (1) assess potential fishing displacement from marine reserve designation and identify internal and external socioeconomic factors explaining variability in fishing behavior, and (2) evaluate shifting familial succession patterns across fisheries and port groups within Oregon's nearshore fisheries. A mail survey dispersed to permit holders in Oregon's commercial Dungeness crab, salmon, and groundfish fisheries (total permit $\mathrm{N}=1,371$ ) contained questions regarding spatial and temporal shifts in fishing behavior, operating expenditures, as well as demographic information. A total of 205 surveys were returned, representing 270 individual permits $(20 \%$ response rate).
\end{abstract}


The first study objective was to assess impacts of marine reserve designation on the ways that fishing effort is exerted and how efforts differ between fishing communities and fleets in Oregon's nearshore environment over time. Quantitative and spatial measurements of fishing effort can help determine which areas are most heavily fished, which areas are collectively perceived to be the best and worst fishing grounds and how fisher's behaviors are responding to market, regulatory, ecological, and climatic variability. A repeated measures analysis of variance revealed that fishing effort was not reduced or displaced by marine reserve implementation, but rather driven by fishery closures resulting from low stock health linked to climatic variability. Linear mixed effects models revealed that large-scale fishing operations are more resilient and flexible to climatic, regulatory, economic, and ecological variability.

The second study objective evaluated familial succession in Oregon's nearshore fisheries. Many rural industries, such as agriculture, timber and commercial fishing, are experiencing reduced youth recruitment and participation. Rural to urban migration patterns and large barriers to entry have been cited as reasons for the graying of Oregon's commercial fishing industry. It is important to understand which socioeconomic factors drive recruitment into the fishery in order to successfully manage and communicate with fishery participants. A binomial logistic regression model revealed that fishers with largescale fishing operations are much more likely to participate in familial succession within the industry, compared to a fisher with a relatively small business. Chi-squared goodness of fit analyses indicated that in some regions along the coast, succession often mirrors the health and economic viability of a fishery and dynamics of local economies. 
In order to holistically quantify and assess fishery dynamics, social, ecological, climatic, and economic factors need to be considered and incorporated into models that aim to explain human behavior. 


\section{ACKNOWLEDGEMENTS}

I would first like to thank Dr. Elise Granek, Dr. Max Nielsen-Pincus, and Dr. Thomas Swearingen of ODFW for serving on my committee and providing guidance and patience through this entire process. The mentorship, advice and inspiration that you three have provided me with is absolutely priceless. I would also like to thank Dr. Yangdong Pan for offering invaluable knowledge regarding statistical analysis and for his patience. I would also like to recognize Shannon Davis and The Research Group LLC for obtaining vital fisheries data and performing extensive representative analyses for this study.

This research would not have been possible without the constant support and efficient envelope stuffing from Casey Lewis, Amy Ehrhart, Britta Baechler, Dorothy Horn, Kaegan Scully-Engelmeyer, Amy Hemingway, Anna Bolm and Sabra Comet in the Applied Coastal Ecology Lab at PSU along with Emma Huston, Mom, Luke and Justin.

Thank you to the Fishermen Involved in Natural Energy (FINE), Fishermen Advisory Committee for Tillamook County (FACT), Port Orford Ocean Resource Team (POORT), the ODFW Shellfish Program, the Dungeness Crab Commission, the Salmon Troll Commission, and the Association of Trawlers for their extensive collaboration to create and advertise the survey and overall study objectives. Further thanks to all of the fishers who took the time to complete this study's survey.

Finally, this study would not have been possible without the generous funding opportunities provided by the Oregon Department of Fish and Wildlife, the Ed and Olive Bushby Foundation and The Institute for Sustainable Solutions. 
ABSTRACT.

TABLE OF CONTENTS

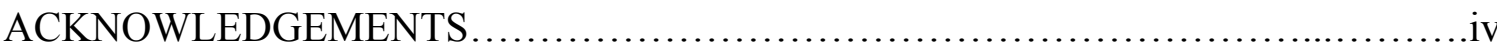

CHAPTER 1: Introduction......................................................

1.1 Commercial Fishing in the Pacific Northwest............................2

1.2 Marine Reserves in Oregon............................................ 3

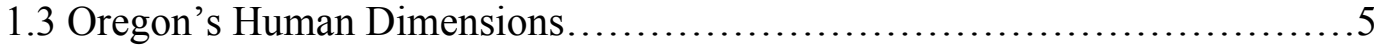

1.4 Research Overview and Context..........................................6 6

CHAPTER 2: Assessing Effort Shifts in Oregon Nearshore Fisheries....................8

2.1 Introduction........................................................... 8

2.1.1 Effort Shifts.............................................. 9

2.1.2 Socioeconomic Variability................................ 10

2.1.3 Oceanic and Climatic Variability..................................12

2.1.3 Research Objectives............................................13

2.2 Methods........................................................... 13

2.2.1 Survey Design.............................................. 13

2.2.2 Sampling and Survey Implementation............................17

2.2.3 Data Analysis............................................... 19

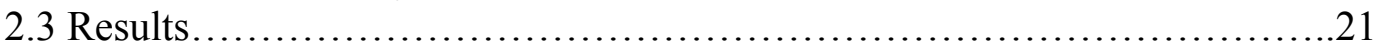

2.3.1 Descriptive Analyses.....................................21

2.3.2 Effort Shifts and Marine Reserves...............................25

2.3.3 Socioeconomic Drivers of Catch Per Unit Effort....................33

2.4 Discussion....................................................... 38

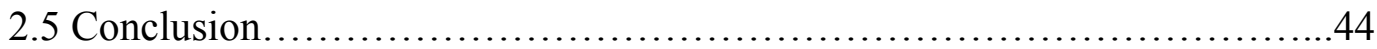

CHAPTER 3: Familial Succession in Oregon's Nearshore Fisheries......................45

3.1 Introduction....................................................... 45

3.1.1 Natural Resource-Dependent Communities......................46

3.1.2 Urban Migration and Barriers to Entry..........................47

3.1.3 Research Objectives.........................................48

3.2 Methods............................................................ 49

3.2.1 Survey Design............................................49

3.2.2 Sampling and Survey Implementation........................52

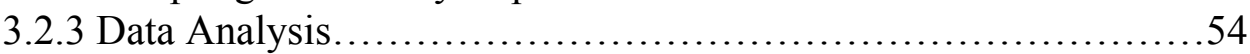

3.3 Results.......................................................... 56

3.3.1 Descriptive Analyses......................................56

3.3.2 Socioeconomic Drivers of Familial Succession....................59

3.3.3 Actual vs. Expected Generation Classes.........................60

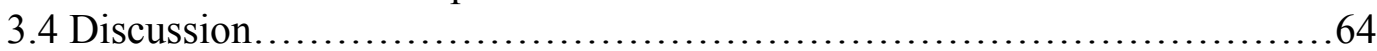

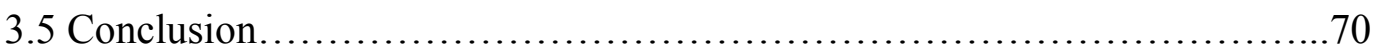

CHAPTER 4: Conclusions....................................................... 72

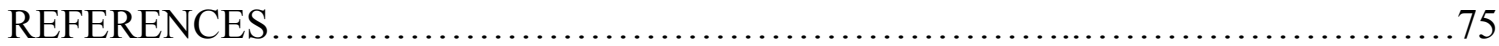

APPENDIX A: Survey Instrument......................................... 85

APPENDIX B: Summary Report............................................93

APPENDIX C: Representative Analysis Summary Report.........................211

APPENDIX D: Human Subjects Approval.......................................248 
APPENDIX E: Community Partner Reflection...............................249 


\section{CHAPTER 1: INTRODUCTION}

Industrialization is typically characterized by rapid modernization of production that ultimately shifts people from producers to consumers (Meszaros 1970). As economies globalize, diversification of economic niches allows humans to specialize and accelerate growth. Rapid population increases have pushed food production and natural resource extraction industries to modernize and maximize operations. The vast availability and accessibility of food in the Global North has allowed for the development of diverse and plentiful markets in urban areas away from fertile agricultural land. Mass distributional operations have allowed for human migrations from rural to urban areas in order to increase economic, social, and cultural connectivity (Mabogunje 1970).

As humans have industrialized, urbanized and globalized, a rift between labor and land has formed and the majority of people have become alienated from the food production processes (Meszaros 1970; McClintock 2010). Industrialized production has resulted in mass rural to urban migration patterns and shifts from production industries to consumerism. The separation of urban populations and the environment has made garnering public support and interest behind sustainable natural resource management difficult and cultural norms surrounding consumption have also resulted in the degradation of many common pool resources, such as air, water and soil (McClintock 2010).

Because many humans have historically detached themselves from food production, it is important to recognize and understand the places and ways in which they still interact with natural ecosystems. Social ecology reintroduces human systems and natural systems in order to holistically frame and assess ecosystems (Glaser 2008). 
Human dimensions research focuses primarily on the ways in which humans value, use, depend on and coexist with their natural environments (Gibson 2000). One of these interactions is the ability to maintain resiliency and adapt in a changing environment. Adaptation is typically defined as the "adjustment in ecological, social, or economic systems in response to changes in processes, practices, or structures to moderate or offset potential damages due to variability" (McCarthy 2001). Because the global ecosystem is susceptible to climatic, economic and societal variability, it is imperative to identify vulnerable communities and mitigate potential risks.

In Oregon, one aspect of human dimensions research focuses on the ways in which ocean user perceptions and behaviors are impacted by climatic and economic variability, as well as ocean conservation policy and shifting social structures (ODFW 2017a). Due to the economic and cultural importance, evaluating behavioral dynamics in Oregon's nearshore fisheries is a high priority to ocean policy makers (OPAC 2008).

\subsection{COMMERCIAL FISHING IN THE PACIFIC NORTHWEST}

Native American tribes have utilized the coastal Pacific Northwest for natural resource extraction for centuries, mainly in the form of fishing for salmon and a plethora of shellfish species (Comet 2017). As Europeans began to settle, canneries and processing plants were established in fishing port communities to support population growth and economic demand. As the demand for marine resources grew, markets were pushed to industrialize (Gabriel et al. 2008). Rapid modernization of boats, fishing gear and technology has allowed fishers to travel farther and with greater extraction capacity (Kroodsma et al. 2018). While expansive industrialization has resulted in diversifying markets and productive economic niches, aquatic ecosystems have been severely 
degraded due to overcapitalization, poor stock management, habitat loss, and climatic variability (World Bank 2009). Globally, 31\% of fish stocks are considered overfished and $58 \%$ of stocks are considered fully fished and several economically important fisheries in Oregon have experienced reduced stock health (FAO 2016; ODFW 2016). In order to preserve scarce natural resources, it is imperative that aggressive conservation policy is utilized (Anticamara et al. 2011). Reduced catch and trip limits as well as organism size and gear restrictions are commonly used fisheries management practices; however, ecosystem-based approaches, such as the application of marine protected areas and reserves, have emerged at the forefront of ocean conservation policy (Grafton et al. 2006).

\subsection{MARINE RESERVES IN OREGON}

Due to the rapid industrialization of modern commercial fishing and increasing climatic volatility, the need to aggressively conserve remaining marine resources is imperative (Pauly et al. 2005). In the state of Oregon, marine reserves are areas designated in state waters (0-3 miles from shore) that prohibit all fishing or organism collection, except for scientific monitoring/research. Marine reserves have been shown to enhance biomass and biodiversity due to the heavy protection inside their boundaries (Gell and Roberts 2003; Halpern 2003). As these protected areas reach carrying capacity, spillover of biomass occurs into surrounding, unprotected areas, and enhances the productivity of adjacent ecosystems and nearshore fisheries (McClanahan and Mangi 2000; Roberts et al. 2001).

In 2008, Governor Theodore Kulongoski signed Executive Order 08-07 declaring that marine reserve designations in Oregon's Territorial Sea have the potential to provide 
coastal communities and other ocean users with opportunities for continued economic growth and prosperity. Soon after, the Ocean Policy Advisory Council (OPAC) comprised of representatives from state agencies, non-governmental organizations, fishers and local coastal groups began the planning process for marine reserve designations.

Shortly after Executive Order 08-07, OPAC released objectives, principles and guidelines. The overall goal of the reserve system was to "conserve marine habitats and biodiversity; provide a framework for scientific research and effective monitoring; and avoid significant adverse social and economic impacts on ocean users and coastal communities" (OPAC 2008). Key recommendations highlighted collaborative methods that utilize local knowledge by heavily engaging with communities of interest. During the planning process, priority was given to proposals submitted by groups that worked collaboratively with coastal community members, ocean users, and other interested parties (OPAC 2008). Following OPAC recommendations, House Bill 3013 in 2009 and Senate Bill 1510 in 2012, put forth procedures for adopting rules to establish, study, monitor, evaluate, and enforce marine reserves at Otter Rock, Redfish Rocks, Cape Falcon, Cascade Head, and Cape Perpetua.

From 2012 to 2016, five marine reserves were established within Oregon's Territorial Sea: Otter Rock and Redfish Rocks were established in 2012, Cascade Head and Cape Perpetua in 2014 and Cape Falcon in 2016. These marine reserves were proposed and selected as ideal reserve sites based on ecological data and relative community and cultural importance. Each marine reserve is unique in its geomorphic and ecological composition as well as the ocean users which each supports. While marine 
reserves and protected areas have been shown to be beneficial for aquatic systems, longterm, social controversies surrounding these policies have limited widespread implementation (Klein et al. 2008a, 2008b; Pollnac et al. 2010). Currently, there are few quantitative studies regarding how commercial fishing effort has responded to regulatory, climatic, ecological and economic variability within the nearshore system, however, some qualitative efforts have been made (Marino 2015).

\subsection{OREGON'S MARINE RESERVES HUMAN DIMENSIONS PROGRAM}

The primary goal of the ODFW Marine Reserves Program is to evaluate how ecological and socioeconomic systems are responding to marine reserve implementation (ODFW 2017a). ODFW's human dimensions research continuously seeks to understand how different groups of ocean users depend on and interact with the ocean and its economy in Oregon. While reserves have been shown to enhance localized biodiversity and adjacent fishery production, eliminating fishing grounds has the potential for shortterm negative socioeconomic impacts.

Economic variability and societal perceptions of reserves are at the forefront of ODFW's human dimensions research agenda. Spatial analyses and stakeholder perception surveys before and during reserve implementation have found a suite of positive and negative beliefs about marine reserves. Fishers predicted decreases in revenue from commercial fishing and recreational fishing, while revenue from tourism was predicted to increase (The Research Group LLC and Golden Marine Consulting 2012; The Research Group LLC 2013a). Coastal business and resident surveys found that a majority of coastal communities did not feel that the reserves would have an economic impact on the local economy (Needham et al. 2016; Epperly et al. 2017). Visitor intercept 
surveys have revealed overall positive perceptions of the marine reserve system by ocean users not from the Oregon coast (Swearingen et al. 2016; Swearingen and Epperly 2016). There has also been extensive research effort to develop community profiles of several relevant fishing port towns in order to understand demographics and cultural attributes (Package and Conway 2010a, 2010b, 2010 c; Hall and Murphy 2012; Eardley and Murphy 2013; Murphy and Hall 2013). The actual economic and social impacts of marine reserves, however, are still largely unknown. Data gaps remain in understanding how commercial fishing behaviors and dynamics have shifted in response to marine reserve designation.

Other research goals for the Human Dimensions program highlight familial succession patterns and youth recruitment. Oregon's commercial fleets are experiencing consolidation of resources and are shifting towards larger, conglomerate-type fishing operations (The Research Group 2013b). Other research uncovered that the workforce is aging and younger generations are opting out of participation in the fishing industry (Cramer \& Conway 2016). The ways in which fishing families either consolidate resources or exit the industry partially determine how conservation policy will impact fleets. Furthermore, understanding workforce dynamics can aid policy makers in developing regulations that appropriately address fishing behaviors of the industry. However, quantitative familial succession data in Oregon is lacking.

\subsection{RESEARCH OVERVIEW AND CONTEXT}

The objective of this research is to assess shifts in fishing efforts and familial successional dynamics in Oregon's nearshore commercial fisheries. In order to most equitably manage fishery participants, it is imperative to understand how the behaviors 
and perceptions of individuals within each stakeholder group are changing over time.

Factors such as climatic variability, market dynamics, conservation policy and demographics have the potential to impact the ways in which ocean users interact with and rely on commercial fishing. An investigation into shifting behaviors and community dynamics will provide local policy makers with a socioecological framework to assess the best ways to engage with stakeholders and the ways in which future policy may impact them.

The overarching research objectives of this project are to (1) identify and assess which internal and external factors, including marine reserve designation, explain variability observed in fishing effort and success in Oregon's nearshore fisheries, and (2) evaluate familial succession patterns within different fishing communities. These objectives are evaluated in the following two chapters. Chapter two considers numerically measurable fishery dynamics, operating expenses, vessel capacity, and levels of investment as each relate to total fishing effort and catch per unit effort (CPUE). Effort is quantified by the total number of hours fished annually. CPUE is defined as the annual landings (in pounds) per hours fished per year. Chapter three addresses the second research objective, regarding community generational structures and familial succession among fisheries and operating port groups. More specifically, patterns in familial succession were analyzed relative to levels of investment and dependence, operating expenses, vessel capacity as well as fishery and geographic location. 


\section{CHAPTER 2: ASSESSING EFFORT SHIFTS IN OREGON'S NEARSHORE FISHERIES}

\subsection{INTRODUCTION}

Globally, $31 \%$ of fish stocks are considered overfished and $58 \%$ are considered fully fished, and in Oregon several economically and culturally important fisheries have experienced declines in stock health (FAO 2016; ODFW 2016). Reduced catch and trip limits as well as organism size and gear restrictions are commonly used fisheries management practices; however, broad ecosystem-based approaches, such as the application of marine protected areas and reserves, have emerged at the forefront of ocean conservation policy (Grafton et al. 2006; Monaco et al. 2007; Anticamara et al. 2011). Marine protected areas and reserves impose varying degrees of restriction on collection and aim to conserve localized biomass and diversity (Gell and Roberts 2003; Halpern 2003). As these protected environments reach carrying capacity, spillover of biomass occurs into surrounding areas, thus enhancing the productivity of adjacent ecosystems and nearshore fisheries (McClanahan and Mangi 2000; Roberts et al. 2001).

When waters are set aside for conservation, socioeconomic repercussions may arise for some stakeholders. A main challenge of marine conservation is achieving conservation goals while simultaneously protecting and maintaining the socioeconomic livelihood of ocean users. As decision makers push for more aggressive policy, it is imperative to understand the ways in which different groups will be impacted by regulations. In Oregon, the commercial fishing sector is of particular economic importance. This study aims to assess whether nearshore commercial fishing effort has 
shifted in response to the designation of marine reserves and how fisher behaviors are driven by socioeconomic factors.

\subsubsection{EFFORT SHIFTS}

Fishing effort is a measurement of the resources required for fishing, such as time, capital, labor, or gear (Pascoe and Robinson 1996; Del Valle et al. 2003; Ruttan 2003). Catch per unit effort, typically measured by weight of catch per a certain time period or specific type of gear is an effective measurement used to quantify effort. This measurement is an important tool that aids fishery managers in evaluating fish stocks and managing participants by estimating areas that are most heavily fished and fisher behavioral responses to market, ecological, and climatic variability (Branch et al. 2006; McCluskey and Lewison 2008). If the total effort of a fleet increases and landings remain constant, fish stocks may be declining and profitable extraction may be more difficult.

Since the turn of the century, several of Oregon's fisheries have experienced lower yield (ODFW 2016; Richardson et al. 2018). In an effort to conserve and enhance nearshore ecosystems and biodiversity, five marine reserves were designated within Oregon's nearshore state waters (0-3 nautical miles from shore) from the years 20122016. A main criticism of marine reserves is that spatial closures displace fishing effort and relocate it to other areas or eliminate it entirely (World Conservation Congress 2008). Displaced fishing effort can result in increased operating expenses, increased competition of fishing grounds and more overall fishing pressure (Pollnac et al. 2010; Bastardie et al. 2014). While the preservation of marine resources is necessary, the economic impacts to stakeholders who derive economic livelihood from the ocean are important to socioecological sustainability. During the marine reserves planning process, Oregon 
Department of Fish and Wildlife (ODFW) utilized a bottom up spatial planning approach, which relied heavily on fisher participation and incorporated social, cultural, and community dynamics (OPAC 2008). This type of bottom-up, community driven strategy has proven to be the best implementation method in regards to minimizing fishing displacement and maximizing community support (Klein et al. 2008a, 2008b; Pollnac et al. 2010).

\subsubsection{SOCIOECONOMIC VARIABILITY}

Three ODFW-managed commercial fisheries account for a majority of Oregon's nearshore fishing effort: Dungeness crab, salmon trolling, and nearshore groundfish. While each fishery participates in offshore fishing as well, these three groups of fishers are the most likely to experience displacement from reserve designation if any has occurred. Dungeness crab and salmon troll fishers are estimated to exert $54 \%$ and $35 \%$ of total effort within the nearshore, respectively, while nearshore groundfish operate almost exclusively in nearshore waters (The Research Group LLC 2018). Because each fishery utilizes differing gear types and target species, each marine reserve has the potential to impact effort disproportionately (Bellman et al. 2005). For example, a marine reserve protecting mostly sandy bottom habitat, may impact Dungeness crab fishers adversely compared to a reserve that protects rocky bottom substrate, which is more likely to impact the groundfish fishers. Furthermore, market prices for each fishery tend to fluctuate overtime. While the price per pound for Dungeness crab and salmon have remained relatively constant since 2011 , peaking in 2014, market prices for many important species of groundfish have been on the decline (ODFW 2016). This fluctuation 
may cause fishers to shift effort from one fishery to another, and in more extreme cases, cause a fisher to sell his/her permit and relevant gear.

"Sense of place" is a common factor that helps shape a person's perceptions of the socioeconomic impacts of marine reserves (Dalton 2004). Sense of place is often defined as a symbolic relationship to a specific place, derived from shared cultural, behavioral or emotional experiences of a group of people (Low 1992; Cross 2001). Coastal community profiles, visitor intercept surveys and commercial fishery evaluations in Oregon have revealed that sense of place shapes patterns of ocean usage and opinions on conservation and marine reserves (Package and Conway 2010a, 2010b, 2010c; Hall and Murphy 2012; Eardley and Murphy 2013; Murphy and Hall 2013). Differing opinions exist ranging from perceiving that fishing effort will be directly displaced by reserves to resenting the idea of government interference in the commercial fishing industry (Marino 2015). Furthermore, the general proximity to a reserve has the potential to disproportionately impact fishers based on their geographic location along the coast. Because of the spectrum of perceptions surrounding reserves, port of operation was a variable of observation.

While marine reserve designation may offer one explanation for shifts in fishing effort, several other socioeconomic drivers have been shown to impact fishing behaviors. Fishing capacity and scale of business operation are frequently cited factors that heavily impact a fisher's ability to participate in the fishing industry (Kirkley et al. 2001; Smith et al. 2010; Davis et al. 2017). Larger fishing vessels are typically indicative of scaled-up businesses because fishers are able to increase fishing capacity and maintain resiliency to oceanic variability. These larger business operations, however, are also often associated 
with higher operating costs in terms of fuel, crew and insurance expenditures (Davis et al. 2017). In order to effectively manage fishery participants, it is imperative to understand differing business operations and fishing success dynamics when evaluating the effort and fishing pressure that each fishery is supporting.

\subsubsection{OCEANIC AND CLIMATIC VARIABILITY}

Oceanic and climatic variability drive fishery participation and revenue (McCabe et al. 2016; McKibben et al. 2017; Richardson et al. 2018). Since 1900, accelerated fossil fuel combustion and global carbon dioxide emissions have resulted in increases in atmospheric and sea surface temperatures (IPCC 2015). Continuously increasing temperatures have led to a suite of negative impacts on the long-term health of coastal ecosystems, including sea-level rise, ocean acidification, invasive species, and more frequent and intense storms (Bindoff et al. 2007). Over the last century, salmon populations in the Northwestern United States and Canada have experienced declines, mainly linked to habitat loss and climatic variability (Lawson 1993). Decadal scale climatic fluctuations, such as the Pacific Decadal and El Nino Southern Oscillations, characterized by wide variability in sea surface temperatures, have been cited as major influencers on these population declines and are increasing in intensity (Mantua et al. 1997; Drake and Naiman 2007). Since 2006, low stock assessments have resulted in five spatial closures for Oregon's commercial salmon troll fishery leading to millions of dollars in lost revenue (Richardson et al. 2018). The most recent spatial closure (the first since 2010) occurred south of the city of Florence during the 2017-fishing season. Largescale warming events have negatively impacted other commercial fisheries as well.

Domoic acid-producing algal blooms led to delays in the 2016 and 2017 Dungeness crab 
fishing seasons (McCabe et al. 2016; McKibben et al. 2017). As climatic variability continues on current trajectories, more fishery closures and ultimately mass reductions in fishery revenue are sure to follow.

\subsubsection{RESEARCH OBJECTIVES}

This study aims to identify and explain observed behaviors in Oregon's commercial fishing communities and evaluate whether or not fishing effort has been displaced by marine reserve designation. The results will provide policy makers with a socioecological framework for identifying whether and how conservation policy may disproportionally impact specific communities. These evaluation criteria can provide a socioecological framework for both Oregon and other regions attempting to identify community-specific vulnerabilities and potential implications of conservation policy. The research objectives for this chapter are as follows: (1) determine whether or not fishing effort has been displaced by marine reserve designation, (2) identify differences in fishing effort based on temporal and spatial factors, and (3) test the influence of several socioeconomic factors on catch per unit effort (CPUE).

\subsection{METHODS}

\subsubsection{SURVEY DESIGN}

A mail questionnaire was used to conduct a survey for this study. Mail surveys are often used over other commonly used survey methods, such as telephone and face-toface interviews, due to low associated costs and simplicity (Dillman 2011). Portland State University Institutional Review Board approval was achieved to ensure study integrity while evaluating human subjects (Appendix D). In order to ensure consistent language and tone palatable for Oregon fishers, survey questions were developed in collaboration 
with members of the commercial fishing community. The Dungeness crab and salmon commissions, as well as the Oregon Trawlers Association, and volunteers within the fishing community provided feedback regarding survey structure and content. Furthermore, meetings with Fishermen Involved in Natural Energy (FINE), Fishermen's Advisory Committee for Tillamook County (FACT), Port Orford Ocean Resource Team (POORT), ODFW fishery managers, and several other fishers along the coast helped streamline questions to collect relevant information that would effectively quantify fishing effort.

The survey contained 15 questions and addressed the following subject matter: fisher demographics (fishery, port, familial information), perceptions of management, drivers of profit, landing and effort variability, operating expense breakdown, fishing effort logistics, and perceptions of marine reserves (Appendix A). The survey used 5point-Likert scale, multiple choice, ranking, and open-ended responses. In order to reduce respondent burden, fishers that held permits in more than two fisheries were instructed to select the two that contributed the most to their household income and complete the survey with respect to those two fisheries. It was assumed that two fisheries captured most of household income. This assumption may have created modest limitations to the collected data. Fishers were also instructed to choose their primary port of operation from seven fishing port groups. Grouping fishers by operating port group is a commonly used aggregation method when collecting fisheries data. The groupings used in this study are based on ODFW groups (Figure 2.1; Rodomsky \& Calavan 2015; Rodomsky et al. 2016; Rodomsky and Calavan 2017). Florence and Winchester Bay are not located in exclusively coastal counties and for simplicity, were aggregated into the Lincoln and 
Coos County groups, respectively. Brookings, while in Curry County, was separated based on recommendations from several fishing community members. The following data were used for this analysis: fisher demographics, operating expense breakdown, fishing effort logistics and drivers, and perceptions of marine reserves. 


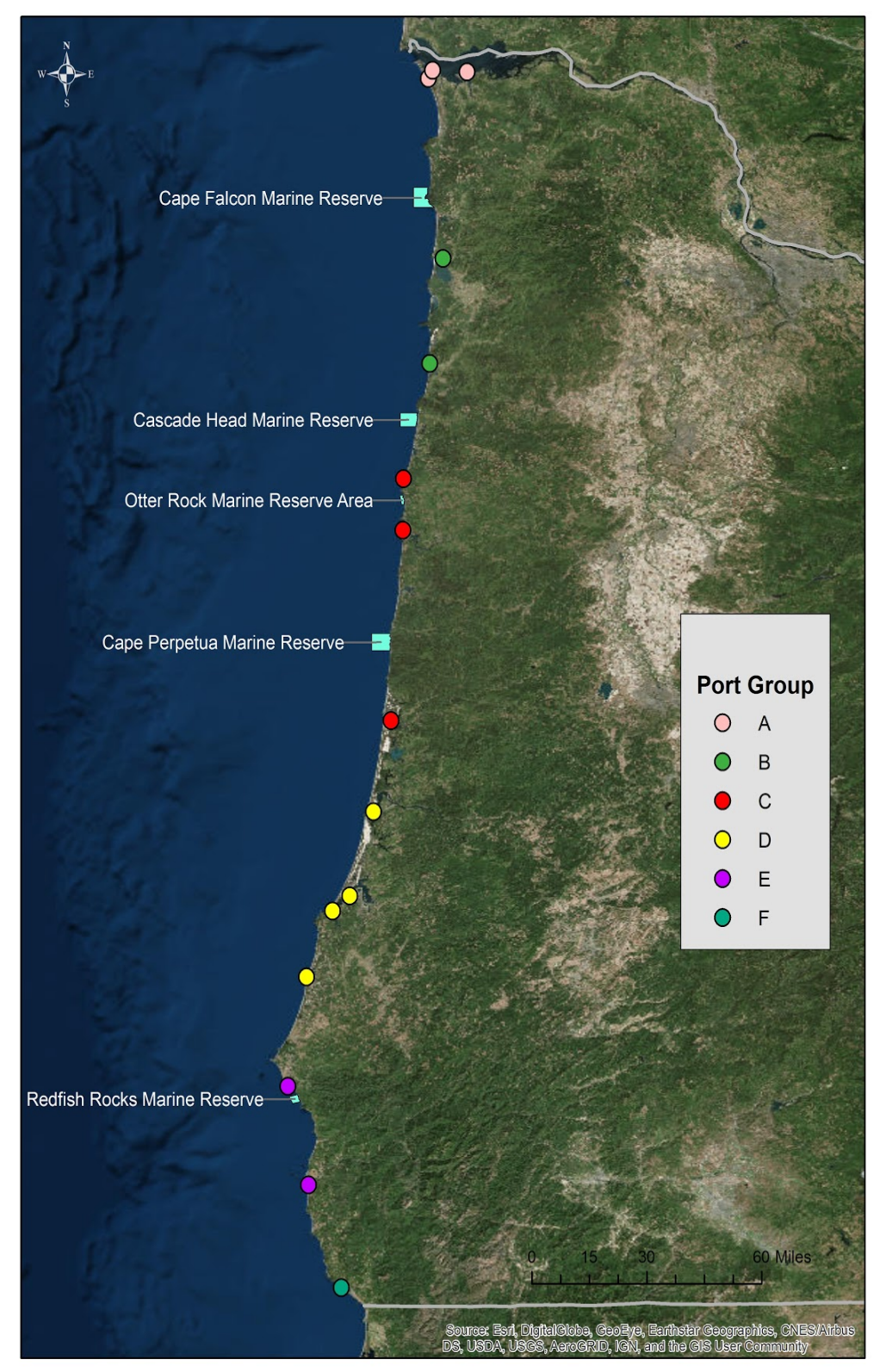

Figure 2.1. Primary operating port group distribution $(A=$ Clatsop County: Astoria, Warrenton, and Hammond, $\mathrm{B}=$ Tillamook County: Garibaldi and Pacific City, $\mathrm{C}=$ Lincol County: Newport, Depoe Bay, and Florence, $\mathrm{D}=$ Coos County: Coos Bay, Bandon, Charleston and, Winchester Bay, E= Curry County: Port Orford and Gold Beach, and F= Brookings) and general proximity to marine reserves.

Fishing effort was assessed for 2011, 2014, and 2017 by asking fishers to report the percentage of their household income that was derived from the fishery (financial dependence), total number of days fished, total number of days fished in the nearshore (0- 
3 miles from shore), total hours gear was deployed each day, total hours gear was deployed in the nearshore each day, miles traveled before deploying fishing gear per day, days fished in an area that is now a marine reserve, and percentage of fishery-related income generated by catch from areas that are now marine reserves. An operating expenditure profile was constructed by asking fishers to report the approximate percentage of operating expenses for fuel, crew, and other expenses for the years 2011, 2014, and 2017. Note that the first marine reserves were established in 2012 and the last was established in 2016. The questionnaire attempted to capture effort and operating expenditures before, during, and after marine reserve implementation. Landing, revenue and vessel feature data were obtained from ODFW (2017b) and the Pacific Fisheries Information Network (2017) for each permit that responded to the survey. Fishers also selected the top three drivers of their personal fishing effort from a list of eight options: ocean conditions, weather conditions, catch limits, market prices, operating expenses, catch per unit effort, regulations (open-ended), and other (open-ended). Finally, fishers reported on positive or negative implications of marine reserves and indicated the top impacts of designation: increased travel distances to fish, increased spatial competition with other fishers, fishing ground displacement, other (open-ended) and no clear impacts.

\subsubsection{SAMPLING AND SURVEY IMPLEMENTATION}

Using current permit lists provided by the Oregon Department of Fish and Wildlife, mail questionnaires were sent to current permit holders in the Dungeness crab, salmon, and groundfish fisheries (total permit $\mathrm{N}=1,371$ ). Permit holders in the charter fishery were also surveyed (total permit $\mathrm{N}=75$ ), however, due to the vast differences in 
fishery dynamics, responses were not comparable to the other commercial fisheries surveyed. Charter fishery data summaries can be found in in Appendix B.

Permit holders received five items via mail during the two-month sampling period. Permit holders received an announcement post card two weeks prior, then a reminder postcard two weeks after receiving the first survey. Non-respondents were mailed a replacement survey, with a financial incentive (2.00 USD bill) enclosed, four weeks after receiving the initial survey. A reminder postcard was sent six weeks after receiving the initial survey (Teske et al. 1983). A total of 230 surveys were returned, representing 270 individual permits. Of the 270 responses, 91 were completed to a degree that was usable for the repeated measures ANOVA and 117 were completed to a degree that was usable for the linear mixed effects models. Respondents that did not complete the survey mainly skipped questions regarding operating expenditures, fishing effort logistics, or marine reserve perceptions.

An external comparative analysis revealed that survey respondents were representative of the entire sampling frame (The Research Group LLC 2018; Appendix C). The review for representativeness was primarily based on landed value distribution. Other measures reviewed for representativeness were vessel size, operating port, and permit owner residency. Permit identification numbers and associated characteristics were cross-referenced with survey respondents and compared to the characteristics of the sampling frame (Figure 2.2). The analysis concluded that respondents for this study closely adhered to known survey frame characteristics suggesting that calibration schemes to improve representation were not needed; however, an analysis of nonrespondents, though beyond the scope of the study, would strengthen the conclusions. 


\begin{tabular}{|c|c|c|}
\hline \multicolumn{3}{|c|}{ Representative Measures } \\
\hline Measure & Survey Frame & Respondents \\
\hline $\begin{array}{l}\text { Survey size } \\
\text { including charter } \\
\text { boats }\end{array}$ & 1,161 & 229 \\
\hline $\begin{array}{l}\text { Commercial } \\
\text { fishing vessel } \\
\text { count }\end{array}$ & 1,106 & 212 \\
\hline $\begin{array}{l}\text { Landed value of } \\
\text { three fisheries in } \\
2016\end{array}$ & $\begin{array}{l}\$ 52.0 \text { million in } \\
2016,85 \% \\
\text { onshore }\end{array}$ & $\begin{array}{l}\$ 11.4 \text { million in } \\
2016,22 \% \text { frame }\end{array}$ \\
\hline $\begin{array}{l}\text { Mean per vessel } \\
\text { landed value of } \\
\text { three fisheries in } \\
2016\end{array}$ & $\begin{array}{l}107 \% \text { of } \\
\text { onshore }\end{array}$ & $94 \%$ of frame \\
\hline $\begin{array}{l}\text { Mean per vessel } \\
\text { trip counts in } 2016\end{array}$ & $\begin{array}{l}106 \% \text { of } \\
\text { onshore }\end{array}$ & $111 \%$ of frame \\
\hline Vessel length & average 41 feet & average 39 feet \\
\hline $\begin{array}{l}\text { Permit owner } \\
\text { residency in } 2016\end{array}$ & $\begin{array}{l}\text { Oregon for } 68 \% \\
\text { of permittees }\end{array}$ & $\begin{array}{l}\text { Oregon for } 75 \% \\
\text { of permittees }\end{array}$ \\
\hline $\begin{array}{l}\text { Principal delivery } \\
\text { port area in } 2016\end{array}$ & $\begin{array}{l}\text { Newport highest } \\
\text { number of } \\
\text { vessels }\end{array}$ & $\begin{array}{l}\text { Newport highest } \\
\text { number of } \\
\text { vessels }\end{array}$ \\
\hline $\begin{array}{l}\text { ote: The three fis } \\
\text { earshore groundf }\end{array}$ & es are D. crab, se & mon troll, and \\
\hline
\end{tabular}

Figure 2.2. Summary of measurements and fleet characteristics comparing representativeness of survey respondents to the sampling frame. Values over $100 \%$ indicate that the survey frame or respondents had slightly higher measurements than overall onshore fleet or survey frame, respectively. A full summary of the representative analysis can be viewed in Appendix C (The Research Group 2018).

\subsubsection{DATA ANALYSIS}

The first and second objectives were achieved by summarizing survey responses to questions about drivers of fishing effort and perceptions of marine reserves and using repeated measures analysis of variance (ANOVA) to evaluate effort within each year and between fisheries and port groups. The third objective was achieved by utilizing a linear mixed effects model that aimed to capture implications of socioeconomic variability on observed catch per unit fishing effort.

Total fishing effort was calculated by multiplying the total days fished in a year by the average number of hours that fishing gear was deployed per day to give the total hours that fishing gear was deployed per year for 2011, 2014, and 2017. Repeated 
measures two-way ANOVAs were calculated using R Studio version 1.1.383 package "ez" in order to analyze for differences in fishing effort (Lawrence 2016; R Development Core Team 2016). Fishery, operating port group, and sampling year were factors with respondent identification number included as an error term to account for the nonindependence between temporal samples. The assumption of sphericity, equal variance between all possible pairs of within-subject conditions, was tested for each parameter using the Mauchly test and adjusted using Greenhouse-Geisser corrections. Because several parameters did not meet the assumption of sphericity and were adjusted using Greenhouse-Geisser corrections, Bonferroni-Holm correction pair-wise comparisons between fisheries, operating ports and sampling year were preformed where significant differences in effort were observed. Normality and equal variance assumptions of repeated measures ANOVA were assessed via inspection of model residuals and total fishing effort values were square-rooted in order to meet assumptions.

CPUE was calculated by dividing a fisher's total annual landings (in pounds) by the reported total annual effort (hours fished). The repeated measures ANOVA revealed no significant variability in CPUE over time between 2011, 2014, and 2017 (with the exception of one year in the salmon fishery, which was excluded from analyses). As a result, CPUE measurements from each year were averaged to create a single CPUE value for each survey respondent. Linear mixed effects models were generated using R Studio version 1.1.383 package "nlme" to analyze which socioeconomic drivers contributed to variability in CPUE (Pinheiro et al., 2016; R Core Development Team 2016). Due to the differences in fishing methods between each fishery, data were separated by fishery in order to generate three unique models. Vessel length, number of vessels owned, average 
nearshore effort (measured in total annual hours fished in the nearshore), average fuel expenditure ratio, reserve effort (average number of days fished in what is now a marine reserve), reserve revenue (average percentage of income derived from marine reserves), seasonal delays/closures, and an average financial dependence on fishing were used as fixed effects while operating port and respondent identification number were used as random effects. Averages were obtained using measurements collected from the years 2011, 2014, and 2017. In order to incorporate seasonal delays and closures, each delay in the years 2011 to 2017 was given a value of 0.5 and each closure was given a value of 1 . If the seasonal delay or closure was not spatially distributed evenly, only port groups directly adjacent to closures received those values. All closures/delays for each fishery from 2011 to 2017 were added and applied as one value.

Backwards-stepwise Akaike Information Criterion (AIC) model selection was used in order to eliminate fixed effects that did not contribute to variability in average CPUE and a variance inflation factor (VIF) analysis evaluated predictor variables for multicollinearity. All independent variables were standardized to make regression coefficients more easily comparable.

\subsection{RESULTS}

\subsubsection{DESCRIPTIVE ANALYSES}

In total, 1,086 surveys, representing 1,371 unique permit holders (some fishers owned more than one permit in multiple fisheries) were mailed. After allowing seven months for respondents to return their survey, 205 surveys, representing 270 permits were received. A $20 \%$ response rate was achieved for this study, which is comparable to other survey studies conducted with commercial fishing communities (Himes-Cornell and Kent 
2014; Rodomsky and Calavan 2017). In total, 46 surveys were undeliverable and 18 potential respondents were either deceased or retired and were removed from the sample when calculating response rates (Table 2.1; Table 2.2). Fishers from the groundfish fishery responded at the highest rates, however, salmon fishers comprised the majority of survey respondents. Each designated port group received survey responses, including some respondents who landed consistently outside of Oregon (excluded from analyses).

Table 2.1. Survey Response by mailing round, non-response, and permit representation.

\begin{tabular}{|cc|}
\hline Response & $\mathrm{N}$ \\
\hline Total Surveys Mailed to Unique Addresses & 1086 \\
Total Permits Represented in Surveys Mailed & 1371 \\
to Unique Addresses & 115 \\
$1^{\text {ST }}$ Round Returned Surveys & 90 \\
$2^{\text {nd }}$ Round Returned Surveys & 205 \\
Total Returned Surveys $^{2}$ & 270 \\
Total Permits Represented in Returned Surveys $^{*}$ Undeliverable & 46 \\
Retired/Deceased $^{*}$ & 18 \\
Non-Response Surveys & 817 \\
\hline
\end{tabular}

*Removed from total $\mathrm{N}$ when calculating response rates

Table 2.2. Respondent distribution by fishery affiliation and by port group.

\begin{tabular}{|ccccc|}
\hline County (Group*) & $\begin{array}{c}\text { Dungeness } \\
\text { crab }\end{array}$ & Groundfish & Salmon & Total \\
\hline Clatsop (A) & 22 & 3 & 18 & 43 \\
Tillamook (B) & 10 & 7 & 19 & 36 \\
Lincoln (C) & 20 & 8 & 23 & 51 \\
Coos (D) & 9 & 5 & 22 & 36 \\
Curry (E) & 9 & 13 & 3 & 25 \\
Brookings (F) & 8 & 5 & 7 & 20 \\
Not in Oregon (H) & 16 & 1 & 21 & 38 \\
No Port & 4 & 2 & 15 & 21 \\
Total Permits Represented in & 98 & 44 & 128 & 270 \\
study & 378 & 101 & 892 & 1371 \\
Total \# Permits Contacted & $\mathbf{2 6 \%}$ & $\mathbf{4 4 \%}$ & $\mathbf{1 4 \%}$ & $\mathbf{2 0 \%}$ \\
Fishery Response Rate & $\mathbf{3 6 \%}$ & $\mathbf{1 6 \%}$ & $\mathbf{4 7 \%}$ & $\mathbf{1 0 0 \%}$ \\
\% Survey Respondents & & & & \\
\hline
\end{tabular}


Dungeness crab fishers fished the most hours per day (23 hours) and displayed the highest economic dependence up on that fishery (60\%) compared to the other fisheries, which appear to have more diverse economic profiles. Salmon fishers spent the most days fishing offshore (63\% outside three miles), while the other fisheries spent a majority of days fishing nearshore (inside three miles). Dungeness crab fishers traveled the farthest distances in order to fish and fished the most days in areas that are now marine reserves (15 miles, 15 days, respectively; Table 2.3). The fuel expenditure ratio was the lowest for Dungeness crab fishers and roughly equal for the groundfish and salmon fishers $(16 \%$, $25 \%, 26 \%$, respectively).

Table 2.3. Fishing effort logistics, separated by fishery affiliation: Dungeness crab $(\mathrm{N}=65)$, groundfish $(\mathrm{N}=28)$, and salmon $(\mathrm{N}=56)$. Summary of mean, standard deviation and \pm standard error of mean for untransformed data.

\begin{tabular}{|c|c|c|c|c|c|c|c|c|c|}
\hline \multirow[b]{2}{*}{ Effort Logistic } & \multicolumn{3}{|c|}{ Dungeness crab } & \multicolumn{3}{|c|}{ Groundfish } & \multicolumn{3}{|c|}{ Salmon } \\
\hline & Mean & SD & $\mathrm{SE}$ & Mean & $\mathrm{SD}$ & SE & Mean & $\mathrm{SD}$ & SE \\
\hline $\begin{array}{c}\text { \%Financial } \\
\text { Dependence* }\end{array}$ & 60 & 23.8 & 1.71 & 28 & 29.1 & 3.17 & 36 & 32.3 & 2.48 \\
\hline Days Fished/Year ${ }^{+}$ & 67 & 48.8 & 3.50 & 43 & 44.8 & 4.90 & 58 & 59.9 & 4.60 \\
\hline $\begin{array}{c}\text { Days Fished/Year } \\
\text { (nearshore)* }\end{array}$ & 52 & 38.6 & 2.77 & 43 & 47.4 & 5.17 & 21 & 32.8 & 2.52 \\
\hline $\begin{array}{l}\text { Hours Fished/ } \\
\text { Day }^{+}\end{array}$ & 23 & 3.10 & 0.22 & 8 & 5.10 & 0.56 & 10 & 4.60 & 0.36 \\
\hline $\begin{array}{l}\text { Hours Fished/Day } \\
\text { (nearshore)* }\end{array}$ & 21 & 6.90 & 0.49 & 6 & 3.40 & 0.37 & 6 & 6.20 & 0.48 \\
\hline $\begin{array}{c}\text { Miles Traveled to } \\
\text { Fish* }\end{array}$ & 15 & 17.1 & 1.23 & 7 & 5.80 & 0.63 & 14 & 25.8 & 1.98 \\
\hline $\begin{array}{l}\text { Days Fished/Year } \\
\text { (marine reserve)* }\end{array}$ & 13 & 28.0 & 2.01 & 3 & 10.0 & 1.10 & 2 & 8.30 & 0.64 \\
\hline $\begin{array}{c}\text { Financial } \\
\text { Dependence } \\
\text { (Marine Reserve)* }\end{array}$ & 5 & 10.7 & 0.76 & 4 & 10.5 & 1.15 & 4 & 15.7 & 1.20 \\
\hline $\begin{array}{c}\% \text { Fuel } \\
\text { Expenditure* }\end{array}$ & 16 & 10.2 & 1.30 & 25 & 21.6 & 3.51 & 26 & 26.4 & 2.64 \\
\hline
\end{tabular}

* Data were standardized when used in analyses

+ Data were square rooted when used in analyses 
Overall, fishing effort and catch per unit effort was the highest among Dungeness crab fishers (1289 annual hours and 40 pounds per hours, respectively). Fishing effort decreased for all fisheries from 2014 to 2017. CPUE was the highest for Dungeness crabbers and groundfish fishers in 2014 and for salmon fishers in 2017 (Table 2.4).

Table 2.4. Aggregated fishing effort (in hours fished per year) and catch per unit effort (pounds/hour) measurements aggregated and separated by fishery affiliation and sampling year. Summary of mean, standard deviation and \pm standard error of mean for untransformed data.

\begin{tabular}{|c|c|c|c|c|c|c|c|c|c|c|c|c|c|}
\hline \multirow[b]{3}{*}{ Fishery } & & \multirow{2}{*}{\multicolumn{3}{|c|}{$\begin{array}{c}\text { Aggregated } \\
\text { Average }\end{array}$}} & \multicolumn{9}{|c|}{ Sampling Year } \\
\hline & & & & & \multicolumn{3}{|c|}{2011} & \multicolumn{3}{|c|}{2014} & \multicolumn{3}{|c|}{2017} \\
\hline & & Mean & $\mathrm{SD}$ & SE & Mean & $\mathrm{SD}$ & SE & Mean & $\mathrm{SD}$ & SE & Mean & $\mathrm{SD}$ & $\mathrm{SE}$ \\
\hline \multirow{2}{*}{$\begin{array}{l}\text { Dungeness } \\
\text { crab }\end{array}$} & $\begin{array}{l}\text { Effort* } \\
(\mathrm{N}=48)\end{array}$ & 1289 & 686 & 99 & 1340 & 791 & 114 & 1309 & 717 & 103 & 1221 & 648 & 93 \\
\hline & $\begin{array}{l}\mathrm{CPUE}^{+} \\
(\mathrm{N}=45)\end{array}$ & 40 & 52 & 8 & 48 & 63 & 11 & 33 & 54 & 9 & 48 & 55 & 9 \\
\hline \multirow[b]{2}{*}{ Salmon } & $\begin{array}{l}\text { Effort* } \\
(\mathrm{N}=26)\end{array}$ & 638 & 515 & 71 & 724 & 542 & 106 & 758 & 536 & 105 & 432 & 583 & 114 \\
\hline & $\begin{array}{l}\mathrm{CPUE}^{+} \\
(\mathrm{N}=51)\end{array}$ & 10 & 21 & 11 & 5 & 8 & 14 & 13 & 13 & 15 & 14 & 78 & 16 \\
\hline \multirow{2}{*}{ Groundfish } & $\begin{array}{l}\text { Effort* } \\
(\mathrm{N}=23)\end{array}$ & 361 & 339 & 101 & 395 & 453 & 94 & 389 & 475 & 99 & 300 & 274 & 57 \\
\hline & $\begin{array}{l}\mathrm{CPUE}^{+} \\
(\mathrm{N}=26)\end{array}$ & 36 & 56 & 2.9 & 41 & 62 & 1.5 & 34 & 68 & 1.9 & 49 & 47 & 8.3 \\
\hline
\end{tabular}

* Data were square rooted when used in analyses

${ }^{+}$Data were log-transformed when used in analyses

Fishing vessels were the largest among Dungeness crab fishers and the smallest among groundfish fishers (43 feet, 28 feet, respectively). For each fishery, the median number of vessels owned was one (Table 2.5). The Clatsop and Lincoln County port groups had the largest average vessel while Tillamook and Curry county vessels were the smallest (44 feet, 42 feet, respectively; 24 feet, 27 feet respectively). For each port group the median number of vessels owned was one (Table 2.6). 
Table 2.5. Fishing vessel feature aggregated $(\mathrm{N}=168)$ and separated by fishery affiliation; Dungeness crab $(\mathrm{N}=66)$, salmon $(\mathrm{N}=71)$ and groundfish $(\mathrm{N}=31)$. Vessel length in feet. Summary of mean, median (med), standard deviation and \pm standard error of mean for untransformed data.

\begin{tabular}{|cccccccccccccc|}
\hline & \multicolumn{3}{c}{ Aggregated } & \multicolumn{4}{c}{ Dungeness crab } & \multicolumn{3}{c|}{ Salmon } & \multicolumn{3}{c|}{ Groundfish } \\
\cline { 2 - 13 } $\begin{array}{c}\text { Vessel } \\
\text { Feature }\end{array}$ & Mean & SD & SE & Mean & SD & SE & Mean & SD & SE & Mean & SD & SE \\
\hline $\begin{array}{c}\text { Length } \\
*\end{array}$ & 36 & 13 & 1.0 & 43 & 15 & 1.8 & 33 & 9.5 & 1.0 & 28 & 9.8 & 1.8 \\
\hline & Med & SD & SE & Med & SD & SE & Med & SD & SE & Med & SD & SE \\
\hline $\begin{array}{c}\# \\
\text { Owned }\end{array}$ & 1 & 0.34 & 0.02 & 1 & 0.4 & 0.05 & 1 & 0.26 & 0.03 & 1 & 0.4 & 0.07 \\
\hline
\end{tabular}

* Data were standardized when used in analyses

Table. 2.6. Fishing vessel feature aggregated $(\mathrm{N}=168)$ and separated by port group; Clatsop ( $\mathrm{N}=32)$, Tillamook $(\mathrm{N}=21)$, Lincoln $(\mathrm{N}=46)$, Coos $(\mathrm{N}=27)$, Curry $(\mathrm{N}=24)$ and Brookings $(\mathrm{N}=18)$. Vessel length in feet. Summary of mean, median, standard deviation and \pm standard error of mean for untransformed data.

\begin{tabular}{|cccccccccc|}
\hline Port & \multicolumn{3}{c}{ Clatsop } & \multicolumn{3}{c|}{ Tillamook } & \multicolumn{3}{c|}{ Lincoln } \\
\hline Vessel Feature & Mean & SD & SE & Mean & SD & SE & Mean & SD & SE \\
Length* & 44.1 & 16.1 & 2.85 & 23.9 & 3.56 & 0.78 & 41.9 & 12.1 & 1.78 \\
& Median & SD & SE & Median & SD & SE & Median & SD & SE \\
\# Owned & 1 & 0.4 & 0.07 & 1 & 0 & 0 & 1 & 0.35 & 0.051 \\
\hline Port & & Coos & & & Curry & \multicolumn{4}{c|}{ Brookings } \\
\hline & Mean & SD & SE & Mean & SD & SE & Mean & SD & SE \\
Length* & 35.0 & 10.3 & 1.97 & 27.2 & 5.89 & 1.20 & 35.3 & 12.2 & 2.88 \\
& Median & SD & SE & Median & SD & SE & Median & SD & SE \\
\# Owned & 1 & 0.3 & 0.051 & 1 & 0.46 & 0.095 & 1 & 0 & 0 \\
\hline
\end{tabular}

* Data were standardized when used in analyses

\subsubsection{EFFORT SHIFTS AND MARINE RESERVES}

Repeated measure analyses of variance were performed in order to identify how fishing effort varied over time between different subgroups of fishers. Statistical significance was determined by a $p$-value $<0.05$ for each fishery examined. Sampling year, fishery affiliation, and the interaction between sampling years within fisheries were factors that exhibited significant differences in fishing effort (Table 2.7). Because fishery affiliation was indicated as a significant factor, data were separated by fishery and 
analyzed, with repeated measures ANOVA, for differences between sampling year and operating port. Dungeness crab fishers exhibited the most overall effort for each of the years sampled, followed by the salmon and then groundfish fishers. Overall effort within Dungeness crab and groundfish fisheries appeared to decrease marginally in 2017 while effort in the salmon fishery experienced a much larger decrease (Figure 2.3).

Table 2.7. Repeated measures analysis of variance results for average fishing effort within individual survey respondents $(\mathrm{N}=91)$. Significant factors indicated in bold, marginally significant factors indicated in italics, $\wedge$ indicates Greenhouse-Geisser corrected $\mathrm{P}$ value, * interaction (Factor column). $\mathrm{SS}=$ sum of squares, $\mathrm{MS}=$ multiple squares, $\mathrm{df}=$ degrees of freedom, $\mathrm{F}=$ test statistic.

\begin{tabular}{|cccccc|}
\hline Factor & SS & MS & df & F & P \\
\hline Fishery & $\mathbf{1 5 8 0 5}$ & $\mathbf{7 9 0 3}$ & $\mathbf{2}$ & $\mathbf{1 8 . 7}$ & $\mathbf{2 . 8 3 E - 0 7}$ \\
Port & 965 & 193 & 5 & 0.544 & 0.741 \\
^Year & $\mathbf{5 9 1}$ & $\mathbf{2 9 6}$ & $\mathbf{2}$ & $\mathbf{1 0 . 1 6}$ & $\mathbf{0 . 0 0 0 7}$ \\
Fishery*Port & 4681 & 468 & 10 & 1.74 & 0.087 \\
^Fishery*Year & $\mathbf{3 8 3}$ & $\mathbf{9 6}$ & $\mathbf{4}$ & $\mathbf{3 . 8}$ & $\mathbf{0 . 0 1 6}$ \\
^Port*Year & 224 & 22 & 10 & 0.7 & 0.663 \\
^Fishery*Port*Year & 760 & 38 & 20 & 1.58 & 0.104 \\
Error between participants & 29765 & 431 & 69 & - & - \\
Error within participants & 3615 & 26 & 138 & - & - \\
\hline
\end{tabular}




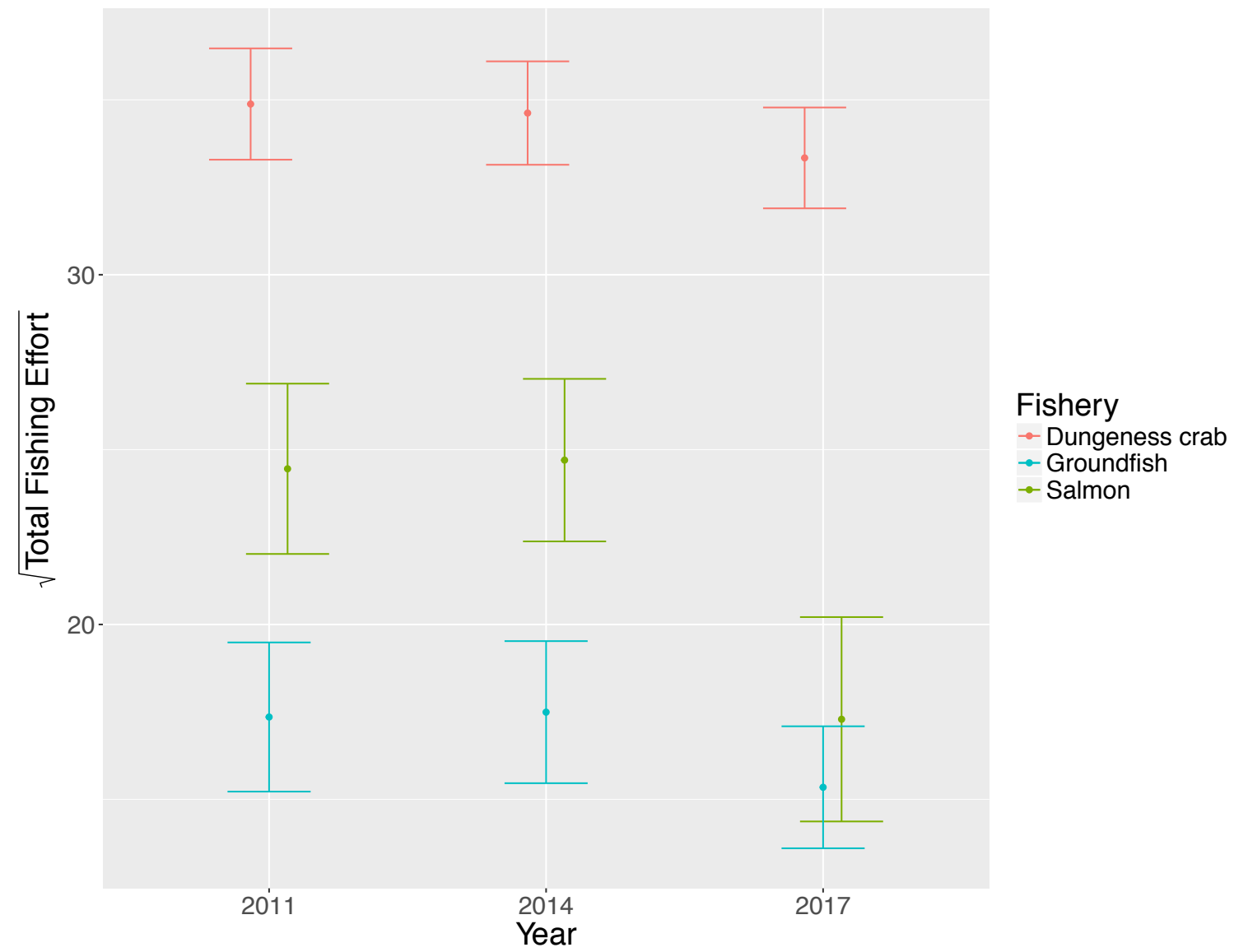

Figure 2.3. Average total fishing effort measurements for 2011, 2014, 2017 for Dungeness crab $(\mathrm{N}=45)$, groundfish $(\mathrm{N}=22)$ and salmon $(\mathrm{N}=24)$ fisheries. Error bars represent \pm standard error of the mean.

Data were separated by fishery and analyzed for patterns between sampling year and operating port group. ANOVA results indicated that effort between years and operating ports did not vary significantly with the exception of the sampling year in the salmon fishery, $\mathrm{F}=7.35, \mathrm{p}=0.01$ (Table 2.8). A Bonferroni-Holm pairwise test indicated that there was significantly higher fishing effort in the years 2011 and 2014 than in the year 2017 within the salmon fishery (Table 2.9, Figure 2.4). There also appeared to be a gradual increase in groundfish effort occurring in tandem with a gradual decrease in salmon effort for the Coos County port group; however, further repeated measures 
ANOVA testing revealed that there was no statistically significant difference in fishing

effort between sampling year or fishery for that port group (Figure 2.4; Table 2.10).

Table 2.8. Repeated measures analysis of variance results for average fishing effort within each fishery; Dungeness crab $(\mathrm{N}=45)$, salmon $(\mathrm{N}=24)$ and groundfish $(\mathrm{N}=22)$. Significant factors indicated in bold, ^ indicates Greenhouse-Geisser corrected P value, * interaction (Factor column). $\mathrm{SS}=$ sum of squares, $\mathrm{MS}=$ multiple squares, $\mathrm{df}=$ degrees of freedom, $\mathrm{F}=$ test statistic.

\begin{tabular}{|c|cccccc|}
\hline \multicolumn{1}{|c}{ Fishery } & Factor & SS & MS & df & F & P \\
\hline \multirow{4}{*}{$\begin{array}{c}\text { Dungeness } \\
\text { crab }\end{array}$} & Port & 2239 & 448 & 5 & 1.72 & 0.152 \\
& $\wedge$ Year & 61 & 31 & 2 & 2.14 & 0.132 \\
& $\wedge$ Year*Port & 182 & 18 & 10 & 1.57 & 0.146 \\
& Error between participants & 10128 & 260 & 39 & - & - \\
& Error within participants & 906 & 12 & 78 & - & - \\
\hline \multirow{5}{*}{ Salmon } & Port & 2636 & 527 & 5 & 1.5 & 0.237 \\
& ^Year & $\mathbf{8 4 9}$ & $\mathbf{4 2 5}$ & $\mathbf{2}$ & $\mathbf{7 . 3 5}$ & $\mathbf{0 . 0 1}$ \\
& $\wedge$ Year*Port & 454 & 45 & 10 & 1.04 & 0.426 \\
& Error between participants & 6303 & 350 & 18 & - & - \\
& Error within participants & 1571 & 44 & 36 & - & - \\
\hline \multirow{5}{*}{ Groundfish } & Port & 771 & 154 & 5 & 0.76 & 0.592 \\
& ^Year & 63 & 32 & 2 & 0.759 & 0.540 \\
& $\wedge$ Year*Port & 349 & 35 & 10 & 0.426 & 0.412 \\
& Error between participants & 3249 & 203 & 16 & - & - \\
& Error within participants & 1042 & 33 & 32 & - & - \\
\hline
\end{tabular}

Table 2.9. Bonferroni-Holm pairwise comparison tests between sampling years in overall fishing effort for the salmon fishery ( $\mathrm{N}=24)$. Significant factors indicated in bold.

\begin{tabular}{|c|cc|}
\hline \multicolumn{2}{|c|}{ Pairwise Comparisons } & P \\
\hline Sampling Year & 2011 & 2014 \\
\hline 2014 & 0.762 & - \\
$\mathbf{2 0 1 7}$ & $\mathbf{0 . 0 1 2}$ & $\mathbf{0 . 0 0 8}$ \\
\hline
\end{tabular}




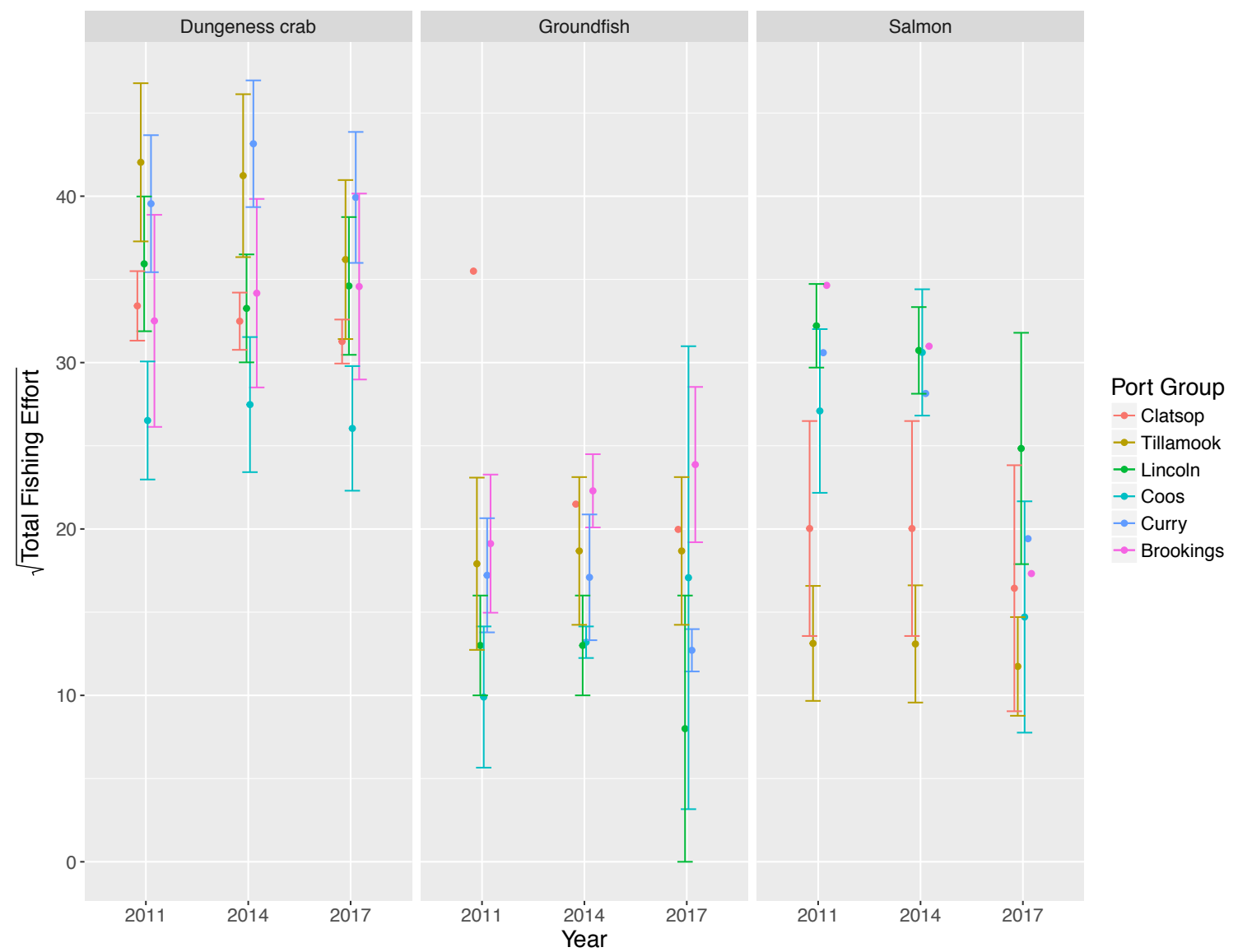

Figure 2.4. Average total fishing effort for 2011, 2014 and 2017 for Dungeness crab $(\mathrm{N}=45)$, groundfish $(\mathrm{N}=22)$ and salmon $(\mathrm{N}=24)$ fisheries separated by primary operating port group. Error bars represent \pm standard error of the mean.

Table 2.10. Repeated measures analysis of variance results for average fishing effort within the Coos County port group for salmon $(\mathrm{N}=18)$ and groundfish $(\mathrm{N}=6)$ fisheries. ${ }^{\wedge}$ Indicates Greenhouse-Geisser corrected $\mathrm{P}$ value, * interaction (Factor column). SS=sum of squares, $\mathrm{MS}=$ multiple squares, $\mathrm{df}=$ degrees of freedom, $\mathrm{F}=$ test statistic.

\begin{tabular}{|cccccc|}
\hline Factor & SS & MS & df & F & P \\
\hline Fishery & 5120 & 520 & 1 & 1.6 & 0.252 \\
Year^ $^{\wedge}$ & 502 & 250 & 2 & 0.60 & 0.485 \\
Fishery*Year^$^{\wedge}$ & 387 & 193 & 2 & 2.13 & 0.191 \\
Error between participants $^{\text {Error within participants }}$ & 1942 & 323 & 6 & - & - \\
Erom & 1090 & 91 & 12 & - & - \\
\hline
\end{tabular}

Fishers indicated a wide variety of factors that drive their personal fishing effort and explain the observed variability. When separated by fishery, weather conditions, market prices, and ocean conditions, were the top drivers of effort within the Dungeness 
crab fishery $(21 \%, 20 \%, 17 \%$ respectively). Groundfish fishers indicated that catch limits, ocean conditions, and weather conditions primarily drove their effort $(22 \%, 17 \%$, $14 \%$, respectively). Regulations, ocean conditions, and operating expenses were the largest drivers of effort among salmon fishers $(24 \%, 17 \%, 16 \%$ respectively; Table 2.11 ; Figure 2.5). When fishers were asked to indicate which regulations drove effort, seasonal fishery closures were the most commonly stated responses, followed by personal reasons, such as health or family obligations $(61 \%, 10 \%$, respectively; Table 2.12$)$. Not one fisher mentioned marine reserves as a driver of personal effort.

Table 2.11. Participant selections of top three drivers of personal fishing effort ( $\mathrm{N}=548$ ), separated by fishery affiliation; Dungeness crab $(\mathrm{N}=220)$, groundfish $(\mathrm{N}=90)$ and salmon $(\mathrm{N}=238)$. Each participant was directed to select up to three drivers. Top three drivers are indicated in bold.

\begin{tabular}{|cccc|}
\hline & \multicolumn{3}{c|}{ Percent of Responses } \\
\cline { 2 - 4 } Driver of Effort & Dungeness crab & Groundfish & Salmon \\
\hline Regulations & $10 \%$ & $11 \%$ & $\mathbf{2 4 \%}$ \\
Ocean Conditions & $\mathbf{1 7 \%}$ & $\mathbf{1 7 \%}$ & $\mathbf{1 7 \%}$ \\
Weather Conditions & $\mathbf{2 1 \%}$ & $\mathbf{1 4 \%}$ & $14 \%$ \\
Catch Limits & $2 \%$ & $\mathbf{2 2 \%}$ & $11 \%$ \\
Operating Expenses & $16 \%$ & $12 \%$ & $\mathbf{1 6 \%}$ \\
Market Prices & $\mathbf{2 0 \%}$ & $11 \%$ & $6 \%$ \\
Catch Per Unit Effort & $9 \%$ & $8 \%$ & $8 \%$ \\
Other & $4 \%$ & $4 \%$ & $3 \%$ \\
\hline
\end{tabular}




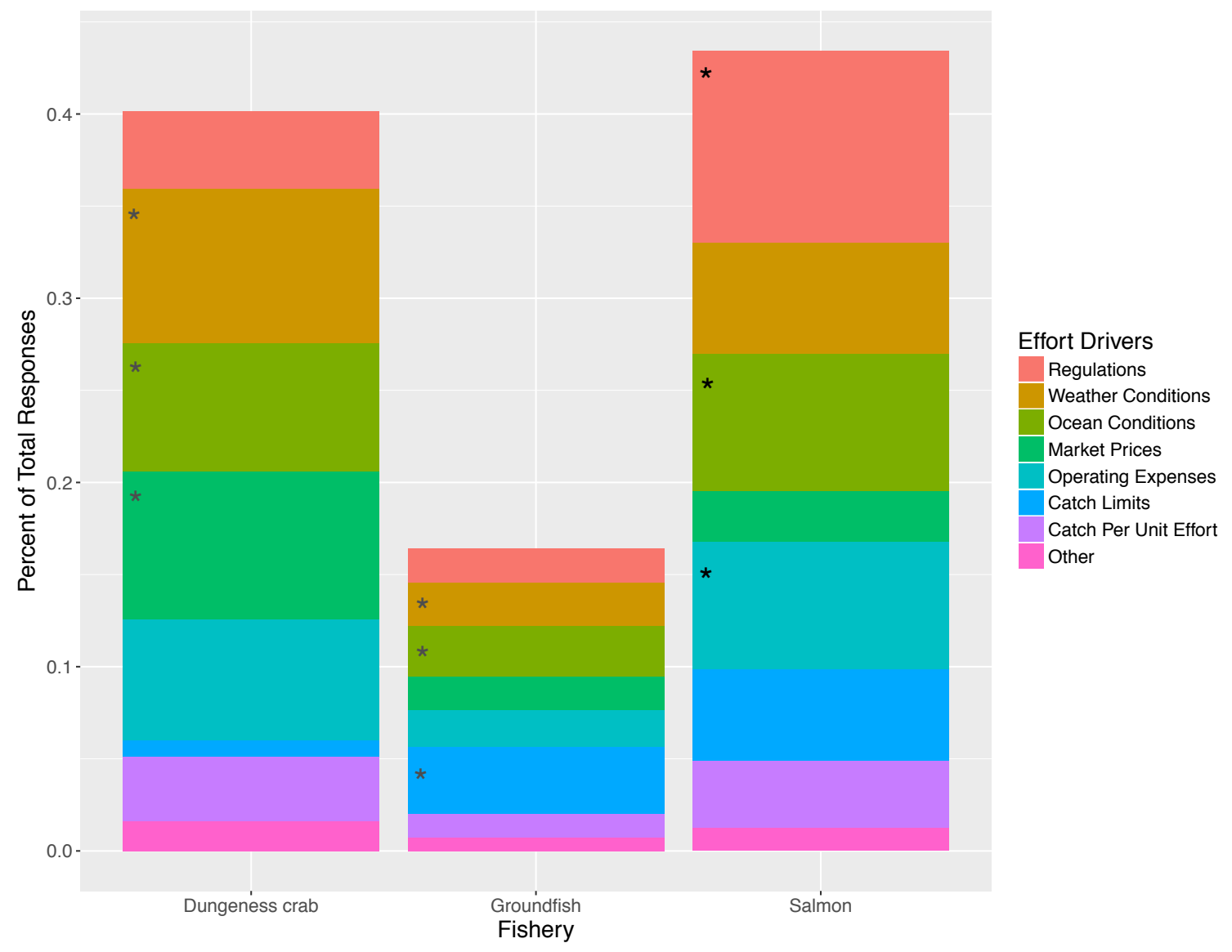

Figure 2.5. Participant selections of top three drivers of personal fishing effort $(\mathrm{N}=548)$ separated by fishery affiliation; Dungeness crab $(\mathrm{N}=220)$, groundfish $(\mathrm{N}=90)$ and salmon $(\mathrm{N}=238)$. Each participant was directed to select up to three drivers, ${ }^{*}$ indicates one of the top three drivers for each fishery.

Table 2.12. Open-ended response proportions for fishers that indicated "regulations" as a driver of person fishing effort. Percent of responses were calculated by dividing the number of times each driver was selected by the total $\mathrm{N}(\mathrm{N}=89)$.

\begin{tabular}{|cc|}
\hline Regulation & Percentage of Responses \\
\hline Seasonal Fishery Closures & $61 \%$ \\
Other & $12 \%$ \\
Personal reasons & $10 \%$ \\
Low Fish Stocks & $7 \%$ \\
Vessel Limitations & $6 \%$ \\
Gear/Catch Restrictions & $4 \%$ \\
Marine Reserves & $0 \%$ \\
\hline
\end{tabular}

No clear impacts of marine reserve designation were further reinforced when

fishers were prompted to indicate whether or not marine reserves have had an impact on 
fishery participation. The general consensus was that marine reserve implementation has had no clear impact. When separated by fishery affiliation, fishers still indicated that reserves have had no clear impact on fishery participation, with very small leanings towards negative impacts (Table 2.13). When asked to select the top impacts experienced by marine reserve implementation, the overwhelming response was no clear impact (61\%; Table 2.14). Indications of displacement of fishing, increased spatial competition and increased travel distances to fish were evenly distributed among aggregate responses as well as fishery dependent responses.

Table 2.13. Perceived impacts of marine reserve implementation aggregated $(\mathrm{N}=168)$ and separated by fishery affiliation; Dungeness crab $(\mathrm{N}=54)$, groundfish $(\mathrm{N}=23)$ and salmon $(\mathrm{N}=76)$. Summary of median, mean, standard deviation and \pm standard error of mean.

\begin{tabular}{|ccccc|}
\hline Fishery & Median $^{*}$ & Mean $^{*}$ & SD & SE \\
\hline Aggregated & 0 & -0.5 & 0.78 & 0.06 \\
Dungeness crab & 0 & -0.4 & 0.81 & 0.11 \\
Groundfish & 0 & -0.5 & 0.94 & 0.2 \\
Salmon & 0 & -0.5 & 0.72 & 0.08 \\
\hline
\end{tabular}

* Median and mean response scale: $(-2=$ Largely Negative, $-1=$ Moderately Negative, $0=$ No Clear Impacts, $+1=$ Moderately Positive,$+2=$ Largely Positive)

Table 2.14. Impacts of marine reserve implementation on fishery participation, aggregated ( $\mathrm{N}=445)$ and separated by fishery affiliation; Dungeness crab $(\mathrm{N}=155)$, groundfish $(\mathrm{N}=65)$ and salmon $(\mathrm{N}=225)$. Each participant was directed to select up to three impacts. The top impact for each fishery is indicated in bold.

\begin{tabular}{|ccccc|}
\hline & \multicolumn{3}{c|}{ Percent of Responses } \\
\cline { 2 - 5 } Impact of Marine Reserve & Aggregated & $\begin{array}{c}\text { Dungeness } \\
\text { crab }\end{array}$ & Groundfish & \multirow{2}{*}{ Salmon } \\
\hline Displacement of Fishing & $14 \%$ & $18 \%$ & $14 \%$ & $12 \%$ \\
Increased Spatial Competition & $13 \%$ & $17 \%$ & $12 \%$ & $12 \%$ \\
Increased Travel Distance to Fish & $12 \%$ & $14 \%$ & $12 \%$ & $12 \%$ \\
No Impact & $\mathbf{6 1 \%}$ & $\mathbf{5 2 \%}$ & $\mathbf{6 2 \%}$ & $\mathbf{6 4 \%}$ \\
\hline
\end{tabular}




\subsubsection{SOCIOECONOMIC DRIVERS OF CATCH PER UNIT EFFORT}

A linear mixed effects model was produced for each fishery. The Dungeness crab fishery had the largest coefficient (2.92), indicating the highest CPUE, followed by the groundfish (2.41) and then the salmon fishery (0.414). In the Dungeness crab fishery, backwards-stepwise AIC model selection indicated vessel length (in feet) acted as a positive predictor of CPUE, while nearshore fishing effort, marine reserve revenue and fuel expenditure ratios were selected as negative predictors. Backward-stepwise AIC selection eliminated number of vessels owned, miles traveled to fish, marine reserve effort, financial dependence and seasonal delays from the final regression model. Because the Dungeness crab season was partially delayed in 2016 and 2017 for all fishers, the seasonal delay variable did not have any variability ( 1 for all fishers) and did not have a final intercept or p-value. The final regression model, including only fixed effects, resulted in an Adjusted $\mathrm{R}^{2}$ value $=0.409$. The addition of survey respondent port group as a random effect (in order to account for variability explained by unquantifiable differences between individual respondents) resulted in an intra-class correlation coefficient $($ ICC $)=0.990$ (Table 2.15). The ICC value enhances the explanatory power of the model and indicates that other variables contribute to variability in fishing success. The Clatsop County port group had the highest CPUE measurement (74 lbs/hour; Figure 2.6). All other port groups were within 0.2 units of each other (2.82-3.06). The final model explaining variability in CPUE for Dungeness crab fishers is as follows:

$$
\begin{gathered}
\mathrm{Y}(\text { CPUE })=2.92+0.323(\text { Vessel Length })-0.368(\text { Nearshore Effort })-0.693(\text { Reserve Revenue }) \\
-0.641(\text { Fuel Expenditure Ratio })+\text { Error }(\text { Port Group })
\end{gathered}
$$


In the salmon fishery, number of vessels owned by the fisher and miles traveled before launching fishing gear were selected as fixed effects that acted as positive predictors of CPUE, while fuel expenditure ratios were selected as negative predictor. A fisher owning one vessel, rather than two vessels, was predicted to exhibit higher CPUE. Fishers than spent a larger percentage of operating expenditures on fuel, were predicted to have lower CPUE. Backward-stepwise AIC selection eliminated vessel length, financial dependence, nearshore and marine reserve effort, marine reserve revenue, and seasonal delays from the final regression model. The final regression model, including only fixed effects, resulted in an Adjusted $\mathrm{R}^{2}$ value $=0.319$ and the addition of survey respondent port group as a random effect resulted in an ICC value $=0.990$ (Table 2.15). Lincoln and Clatsop County port groups had the highest CPUE measurements (17 lbs/hour and $16.5 \mathrm{lbs} /$ hour) while the Coos County group had the lowest (5 lbs/hour; Figure 2.6). Random intercepts were distributed within 0.3 units of each other (1.782.08). The final model explaining variability in CPUE for salmon fishers is as follows:

$$
\begin{aligned}
\mathrm{Y}(C P U E) & =1.58+4.58\left(2^{\text {nd }} \text { Vessel Owned }\right)+0.618(\text { Miles Traveled }) \\
& -0.232 \text { (Fuel Expenditure })+\operatorname{Error}(\text { Port Group })
\end{aligned}
$$

In the groundfish fishery backwards-stepwise AIC selection eliminated number of vessels owned, vessel length, miles traveled to fish, financial dependence, nearshore and marine reserve effort, reserve revenue, fuel expenditure ratios and seasonal delays from the final regression model. Because there were no unexpected seasonal delays or closures in the groundfish fishery, the seasonal delay variable did not have any variability and did not have a final intercept or p-value. All variables were eliminated during the model selection process and for that reason no Adjusted $\mathrm{R}^{2}$ value was produced. The addition of 
survey respondent as a random effect resulted in an ICC value=0.681 (Table 2.15).

Clatsop and Curry County port groups had the highest CPUE measurements (149

lbs/hour and $52 \mathrm{lbs} /$ hour) while Lincoln and Coos counties had the lowest measurements (5 lbs/hour and $8 \mathrm{lbs} /$ hour; Figure 2.6).

ANOVA revealed that all final models were significantly different when

compared to null models and that there were no significant differences between the full and reduced models. 
Table 2.15. Predictors for catch per unit effort for Dungeness crab $(\mathrm{N}=44)$, salmon $(\mathrm{N}=47)$ and groundfish $(\mathrm{N}=26)$ fishers. Fixed effects contributing to observed variability in CPUE are indicated in bold. P-value indicates that slope of line differs from zero. Coefficients are standardized, $\mathrm{SE}= \pm$ standard error.

\begin{tabular}{|c|c|c|c|c|c|}
\hline Fishery & Fixed Effects & Estimate & SE & $\mathbf{P}$ & $\begin{array}{c}\text { Random Effects } \\
\text { (ICC) }\end{array}$ \\
\hline \multirow{11}{*}{$\begin{array}{c}\text { Dungeness } \\
\text { crab }\end{array}$} & Intercept & 2.92 & 0.260 & $1.22 \mathrm{E}-14$ & \multirow{11}{*}{$\begin{array}{l}\text { Port Group } \\
\mathrm{ICC}=0.990\end{array}$} \\
\hline & 2 Vessels Owned & 0.579 & 0.537 & 0.288 & \\
\hline & Vessel length & 0.323 & 0.145 & 0.031 & \\
\hline & $\begin{array}{c}\text { Financial } \\
\text { Dependence }\end{array}$ & 0.111 & 0.224 & 0.622 & \\
\hline & Nearshore Effort & -0.368 & 0.14 & 0.013 & \\
\hline & Miles Traveled & -0.129 & 0.122 & 0.298 & \\
\hline & Reserve Effort & 0.487 & 0.445 & 0.282 & \\
\hline & Reserve Revenue & -0.693 & 0.24 & 0.007 & \\
\hline & Fuel Expenditure & -0.641 & 0.32 & 0.052 & \\
\hline & Seasonal Delay & - & - & - & \\
\hline & \multicolumn{4}{|c|}{ Adjusted $\mathrm{R}^{2}=0.409$} & \\
\hline \multirow{11}{*}{ Salmon } & Intercept & 0.41 & 0.131 & $1.40 \mathrm{E}-15$ & \multirow{11}{*}{$\begin{array}{l}\text { Port Group } \\
\mathrm{ICC}=0.990\end{array}$} \\
\hline & 2 Vessels Owned & 1.84 & 0.375 & 0.0004 & \\
\hline & Vessel Length & 0.193 & 0.234 & 0.414 & \\
\hline & $\begin{array}{c}\text { Financial } \\
\text { Dependence }\end{array}$ & -0.033 & 0.155 & 0.833 & \\
\hline & Nearshore Effort & 0.152 & 0.706 & 0.830 & \\
\hline & Miles Traveled & 0.400 & 0.196 & 0.04 & \\
\hline & Reserve Effort & 0.264 & 0.261 & 0.318 & \\
\hline & Reserve Revenue & -0.133 & 0.171 & 0.443 & \\
\hline & Fuel Expenditure & -0.232 & 0.112 & 0.045 & \\
\hline & Seasonal Delays & -0.350 & 0.27 & 0.205 & \\
\hline & \multicolumn{4}{|c|}{ Adjusted $\mathrm{R}^{2}=0.319$} & \\
\hline \multirow{10}{*}{ Groundfish } & Intercept & 2.41 & 1.07 & 0.039 & \multirow{10}{*}{$\begin{array}{l}\text { Port Group } \\
\mathrm{ICC}=0.681\end{array}$} \\
\hline & 2 Vessels Owned & -0.854 & 1.20 & 0.486 & \\
\hline & Vessel Length & -0.146 & 0.663 & 0.828 & \\
\hline & $\begin{array}{c}\text { Financial } \\
\text { Dependence }\end{array}$ & 0.722 & 0.683 & 0.305 & \\
\hline & Nearshore Effort & -2.03 & 1.45 & 0.180 & \\
\hline & Miles Traveled & -0.136 & 1.54 & 0.931 & \\
\hline & Reserve Effort & 2.39 & 1.65 & 0.164 & \\
\hline & Reserve Revenue & -1.87 & 2.02 & 0.367 & \\
\hline & Fuel Expenditure & -0.172 & 0.33 & 0.613 & \\
\hline & Seasonal Delays & - & - & - & \\
\hline
\end{tabular}



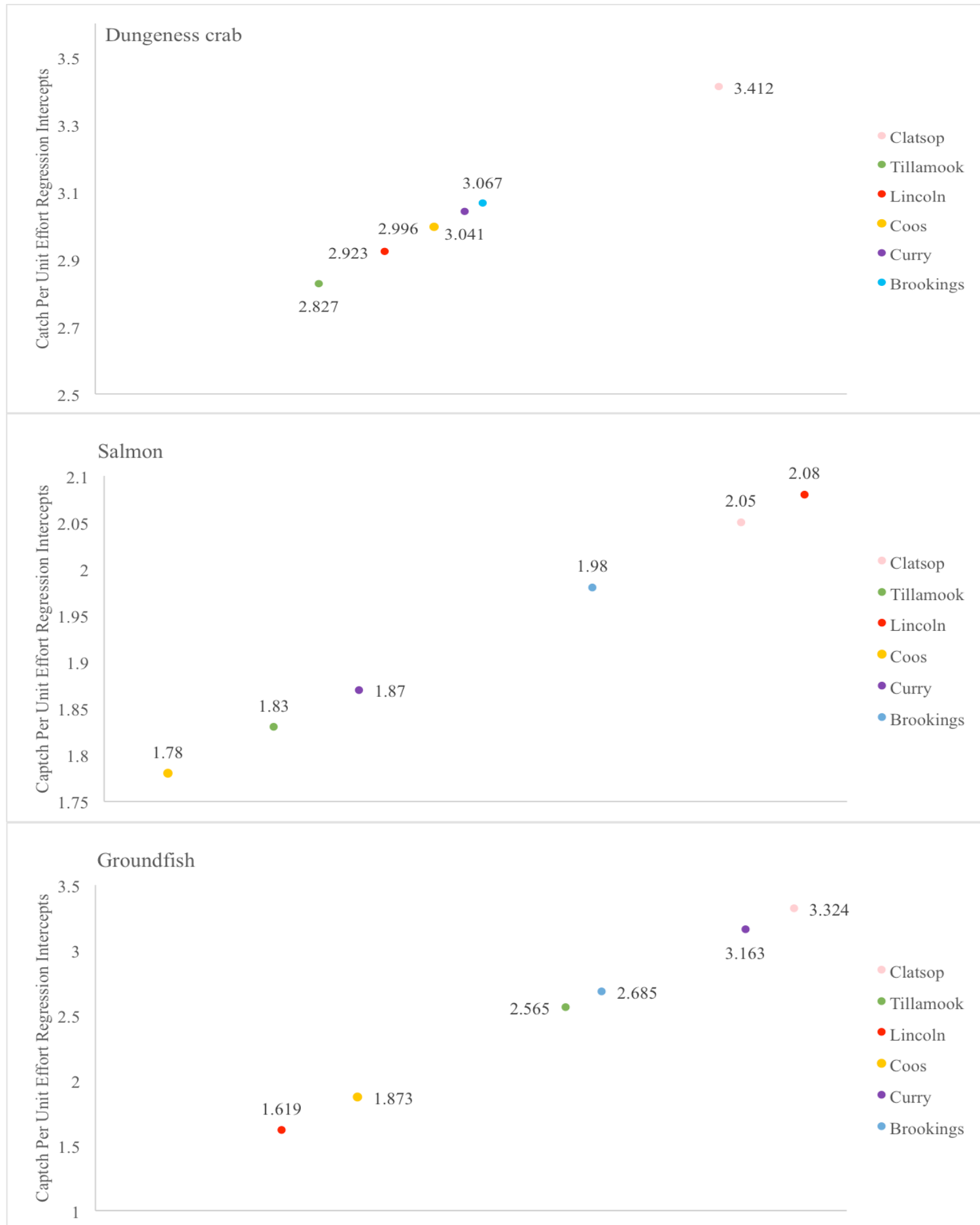

Figure 2.6. Catch per unit effort regression intercepts display CPUE measurements for each port group by fishery affiliation; Dungeness crab (top), salmon (middle) and groundfish (bottom). Intercept coefficients are log-transformed. Higher intercept values indicate higher CPUE measurements for a given port group. 


\subsection{DISCUSSION}

This study determined that marine reserve designation has not displaced commercial fishing for any of the examined fisheries. Most fishers indicated that seasonal closures, resulting from climatic variability, or economic fluctuations ultimately drove personal fishing effort. Marine reserve designation was never specifically referred to as a driver of effort and an overwhelming proportion of responses indicated that reserves have had no clear impact on fishery participation. Driving factors of effort (seasonal closures, oceanic/weather variability, and market price fluctuations) were further reinforced by observed shifts in fishing effort. High CPUE values typically corresponded to large-scale fishing operations that proved to be overall more resilient and flexible to market, oceanic, and regulatory variability.

Regulatory responses to climatic variability and market price fluctuation were indicated as the primary drivers of effort by Dungeness crab fishers and were reflected in effort measurements. Large-scale warming events resulting in domoic acid-producing algal blooms led to delayed openings for the 2016 and 2017 fishing seasons (McCabe et al., 2016; McKibben et al, 2017). Variability in fishing effort is likely a reaction to truncated fishing seasons. In the words of one fisher:

"My effort has been impacted greatly by changing ocean conditions. Climate change has led to warmer oceans that produce more algal blooms that ultimately cause seasonal delays."

Furthermore, patterns in fishing effort correspond strongly with Dungeness crab market price fluctuations, i.e., peak prices in 2014 followed by gradual declines (Davis et al. 2017). While establishment of the Cape Falcon Marine Reserve (most northern reserve) 
in 2016 may serve as a partial explanation to the small reduction of effort by the Tillamook County port group in 2017, this trend is not observed anywhere else during years that correspond with the implementation of other marine reserves and is likely not an explanatory reason for marginal declines in fishing effort. Furthermore, marine reserves were never specified as a driver of effort. For this reason, this study concludes that effort within the Dungeness crab fishery is primarily driven by climatic and market fluctuation.

In the Dungeness crab fishery, high fishing success (CPUE) appeared to be largely indicative of scale of business. Larger fishing operations, typically characterized by greater vessel size, allow for more gear storage than smaller vessels (i.e., more crab pots) and are typically able to travel farther and fish for longer periods of time in highly variable weather conditions, due to increased fuel capacity and durability (Le Pape and Vigneau 2001). Smaller fishing operations are less likely to employ and support large crews and will likely spend a higher proportion of operating expenses on fuel, as opposed to employment or insurance expenses. Fewer workers on a vessel will ultimately result in reduced fishing capacity. These large-scale operations are also often associated with high operating costs, which push fishers to increase effort in order to maximize profit margins (Smith et al. 2010; Davis et al. 2017). One surveyed fisher reflected on how vessel size has impacted his/her overall effort:

"Effort in the crab fishery is mainly due to the state giving large vessels a competitive edge on smaller boats. It is becoming very difficult for boats under 50 feet to compete." 
Negative relationships between CPUE and nearshore and marine reserve fishing effort indicate that nearshore fishing fleets are typically characterized by smaller fishing vessels that have a lower fishing capacity relative to larger vessels (Davis et al. 2017). The Dungeness crab fishery was the only fishery in which nearshore and reserve fishing effort partially determined CPUE. This might suggest that nearshore regulations, such as marine reserves, could disproportionately impact nearshore crabbers. Ultimately, smaller fishing operations are less flexible and resilient to regulatory, climatic and market variability (Rijnsdrop et al. 2000; Le Pape and Vigneau 2001; Stewart et al. 2010; Anticamara et al. 2011).

Similar to the Dungeness crab fishery, variability in fishing effort within the salmon fishery was driven by spatial closures correlating with poor oceanic conditions. Since 2006, low stock assessments have resulted in five spatial closures for Oregon's commercial salmon troll fishery that have led to millions of dollars in lost revenue (Richardson et al. 2018). The most recent spatial closure (the first since 2010), occurring south of Florence during the 2017 fishing season explains the significant drop in effort between 2014 and 2017 in southern port groups.

Due to the relatively volatile nature of salmon populations off the Oregon coast, it appears that many salmon fishers have diversified business to reduce vulnerabilities that often accompany homogenous income sources (Salas and Gaertner 2004). Business diversification ultimately distributes risk in order to ensure financial stability (Rumelt 1982). Lower annual effort and CPUE, relative to other comparable fisheries, might indicate that salmon fishers are financially dependent on multiple fisheries. One fisher expressed the great importance of fishery flexibility: 
"I have three boats and multiple permits in multiple fisheries. Any opportunity a fisherman has is vital to financial survival. Whether used or not they are important due to fishery fluctuation. [Other permits] could be needed when other fisheries are in a down cycle."

Information regarding primary gear type (fixed, hook and line, etc.) would further support this conclusion.

The scale of a fishing operation also characterized CPUE in the salmon fishery. Due to the transient nature of target salmon species, vessels with increased travel capacity can more efficiently locate and pursue fish (Le Pape and Vigneau 2001). Smaller boats may be limited by the traveling capacity required to locate anadromous fish species. One surveyed fisher distinctly reflected on this trend:

"I have a smaller boat (36 feet) that made it hard to travel and fish successfully.

For that reason, I lost interest and sold my salmon permit."

Trends within the salmon fishery were similar to those observed in the Dungeness crab fishery. Fishing effort was ultimately driven by fishery closures resulting from climatic variability, and CPUE was determined by a fisher's ability to scale-up operations and diversify his/her income sources.

Explanation of effort within the groundfish fishery was difficult due to the lack of consistency in study results. The fishery is limited entry, which reduces the number of participating vessels and offers two types of permits. A Blue/Black rockfish permit limits the flexibility for catch of other nearshore species, such as sculpin, greenling and rockfish. The addition of a Nearshore Endorsement allows for collection of an additional 20 other nearshore species (ODFW 2018). Potential profit is heavily constrained for 
vessels without the Nearshore Endorsement due to the narrow limit of species that can be extracted. While measures of effort could be indicative of nearshore permit profiles, observed patterns in this study do not correlate with the geographic distribution of Nearshore Endorsements (Rodomsky and Calavan 2017). For this reason, interactions with other fisheries must be taken into account. Variability in effort may be indicative of fishers shifting from one fishery to another due to internal volatility or stability. While not statistically significant, increases in groundfish fishing effort appeared to be marginally mirrored by declining effort exerted by salmon fishers for corresponding port groups. Due to low salmon stocks, a shift from salmon trolling to groundfish fishing may be occurring in some areas along the coast. Fishers primarily indicated that catch limits and oceanic variability ultimately drove fishing effort, further suggesting that a shift from salmon to groundfish fishing may be occurring. Because model selection eliminated all socioeconomic drivers of effort, it can be suggested that fishing success or effort within the groundfish fishery is not driven by scale of operation, but rather climatic or regulatory restrictions in nearshore ecosystems.

The study results are limited for several reasons. This study did not specifically target and separate permits that operated primarily in the nearshore for this would have delayed research substantially. For that reason, offshore fishers may have returned surveys with responses that may have skewed the data and nearshore effort measurements. A comparative analysis revealed that annual landings and revenue values for survey respondents were representative of the entire sample (The Research Group LLC 2018). Further analysis of opinions of non-respondents, though beyond the scope of the study, would strengthen the conclusions. 
Overall, study results indicate that climatic, economic, ecological, and regulatory variability will disproportionately impact smaller fishing operations due to their lack of flexibility and vulnerability to volatility. Similar studies in New Zealand, France, and The Netherlands have also found that smaller fishing vessels experience less fishing success due to mobility and fishing capacity limitations and are ultimately unable to stay competitive in the industry (Rignsdrop et al. 2000; Le Pape and Vigneau 2001; Stewart et al. 2010). Furthermore, global fishing effort analyses have found that developed nations, with industrialized fishing fleets are able to consistently exert high levels of effort, while developing nations in Central and South America are unable to achieve similar fishing effort activity due to reduced fleet size (Anticamapa et al. 2011).

There was little evidence indicating that marine reserves have led to reductions or displacement in fishing effort. Observed trends in fishing did correspond with fishery closures resulting from climatic variability and for the Dungeness crab fishery, market fluctuations. Other analyses have found that collaborative reserve designation in California, similar to the planning process used in Oregon, resulted in minimized fishing effort displacement (Klein et al. 2008a, 2008b). Furthermore, a synthesis study of global fishing effort found that historically, large-scale policy changes, El Nino events, in the Indian and Pacific Oceans, and cultural holidays ultimately shape fishing effort (Kroodsma et al. 2018). This supports previous conclusions that fishery dynamics are largely driven by climate and culture, rather than small-scale area closures (Kroodsma et al. 2018; Sala et al. 2018). 


\subsection{CONCLUSIONS}

Because marine protected areas and reserves are emerging to the forefront of ecosystem-based management, the social controversies of these policies are pervasive wherever there is ocean resource extraction. The results from this study provide a socioecological framework for identifying community specific vulnerabilities and potential implications of conservation policy. Together, socio-ecological and economic patterns paint a picture of social resiliency; however, natural ecosystems shift and respond to environmental pressures that inevitably drive and limit the ways in which humans interact with them. It is important to understand the aggregate impacts of economic, climatic, ecological, and societal variability on the financial viability and sustainability of natural resource industries in order to identify vulnerable populations and evaluate emerging stakeholder and market characteristics. 


\section{CHAPTER 3: FAMILIAL SUCCESSION IN OREGON'S NEARSHORE FISHERIES}

\subsection{INTRODUCTION}

The United States baby boom era (1946-1964) was characterized by a large population increase that resulted in uneven age class distributions. Studies project that by the year 2030, 20\% of the national population will be over the age of 65 (Sade 2012). "Graying" is a commonly used term to describe the shift within the workforce in which the average age of participants increases in tandem with the decrease of youth recruitment. Rural industries, such as timber, agriculture, and commercial fishing have experienced this graying effect (Cramer and Conway 2016; Gale 2003; NASS 2013). Urban migration and socioeconomic barriers of entry into these industries have largely contributed to the decline in participation of younger generations (Heberle 1938; Mabogunje 1970). Commercial fishing industries are observing a steady global decrease in youth recruitment and participation; this issue is particularly pervasive in many of Oregon's commercial fleets along with massive consolidations of resources (Caracciolo 2017; Cramer \& Conway 2016; Donkersloot 2011; Saputra 2016; The Research Group 2013b). In assessing the overall socioeconomic profiles of certain natural resource industries, it is important to understand the demographics of its participants. Age structure and youth recruitment are two important demographics that allow managers to evaluate how the workforce is growing or shrinking and predict workforce dynamics. Furthermore, as these industries continue to gray, the economic viability of many smallscale natural resource operations are called into question (MacCannell 1988; Swanson 1988; Wani 2011). The goal of this research is to identify patterns of youth recruitment 
from fisher families within Oregon's nearshore commercial fisheries and to evaluate drivers of familial succession.

\subsubsection{NATURAL RESOURCE-DEPENDENT COMMUNITIES}

Natural resource-dependent communities display similar economic and social patterns (Christensen and Donoghue 2001). As the average age of workers in the commercial agriculture, timber harvest, and fishing industries increases, younger generations are choosing to opt-out of these trades (Caracciolo 2017; Donkersloot 2011; NASS 2013). This large decrease in participation casts uncertainty over the next generation of food producers and calls into question the economic viability of many small-scale production operations (MacCannell 1988; Swanson 1988; Wani 2011). In communities heavily reliant on resource extraction, the natural environment and social, economic, and cultural facets are deeply intertwined (Graham and St. Martin 1990; Wilkinson 1991). Natural resource-dependent regions that have balanced social resiliency and economic stability support high quality of life for local communities; however, the inverse is true when operations scale-up, consolidate, and neglect investment towards community social programs (Flint and Luloff 2005; Flora and Flora 1991; Selznick 1987). The industrialization of agricultural and timber industries has largely enhanced profitability for some, but has also limited growth for smaller operations and degraded the overall quality of life for local communities (Kusel and Fortmann 1991; MacCannell 1988; Swanson 1988). Reduced employment opportunities as well as economic instability have pushed many participants to exit these rural industries and the communities that have historically supported them (Christensen and Donoghue 2001; Murray 2009). Similar trends in industrialization and resource consolidation have been 
observed within commercial fishing communities (Caracciolo 2017; Donkersloot 2011; Stewart et al. 2006; The Research Group 2013b). As the current workforce continues to age, the uncertainty surrounding the next generation of food producers calls for more research regarding youth participation and familial succession. This study focused on the socioeconomic factors that drive patterns of participation and consolidation within Oregon's nearshore fishing industry.

\subsubsection{URBAN MIGRATION AND BARRIERS TO ENTRY}

Human migration is defined as groups of people moving from one place to another and typically occurs in four different ways; rural-rural, rural-urban, urban-rural, and urban-urban. The reasons why people choose to migrate from one community to another are defined as "push-pull" factors (Heberle 1938). Urban areas are typically associated with higher wages and standards of living as well as enhanced social connectivity. In conjunction with the technological revolution, urban areas have increased mid-level career opportunities that have typically been eliminated in rural economies, such as industrial or agricultural markets (Heberle 1938; Mabogunje 1970). This type of rural to urban migration has had a direct impact on the commercial fishing industry and has ultimately contributed to decreases in fisheries participation over time (Caracciolo 2017; Donkersloot 2011).

Another commonly cited reason for decreased participation in rural, labor intensive industries are large barriers to entry. Barriers to entry are typically defined as high financial start-up costs that prevent feasible entrance of newer competitors (Demsetz 1982). Industries, such as fishing or agriculture, require large sums of upfront capital or resource investment; i.e. large swaths of land or a fishing vessel. If not inherited, the 
burden falls upon the new competitor to acquire sufficient capital needed to enter the market. In the fishing industry, the implementation of catch share programs (purchased rights to take a finite number of fish) has increased values of individual take quotas, posing a massive up-front financial burden and access issue for many new fishers (Caracciolo 2017; Carothers 2011; Carothers and Chambers 2012). An increase in operating expenses and risk associated with fishing may limit new or ongoing investments (Davis et al. 2017). While overall vessel revenue has been increasing since the 1960s, the number of fishing vessels has drastically decreased, indicating wealth accumulation among those who have been able to afford to participate and scale business operations (The Research Group 2013b). For younger generations, fishing as a profession is perceived to be incapable of supporting families in the modern economy due to low yields and lack of quality and quantity of jobs (Power et al. 2014). Due to these massive barriers of entry and infeasibility as a reliable career path, the commercial fishing industry on the West Coast is likely to experience decreases in youth recruitment and retention.

\subsubsection{RESEARCH OBJECTIVES}

Due to the economic importance of commercial fishing in Oregon, understanding which workforce dynamics impact succession within the industry is critical. The goal of this research is to provide evaluation criteria for generational structures and familial succession patterns associated with fishing success and business scale. The research objectives for this study are as follows: (1) identify patterns between familial succession and scale of business operations, and (2) evaluate patterns in familial succession across fishery affiliations and geographic location. 


\subsection{METHODS}

\subsubsection{SURVEY DESIGN}

A mail questionnaire was used to conduct a survey for this study. Mail surveys are often used over other commonly used survey methods, such as telephone and face-toface interviews, due to low associated costs and simplicity (Dillman 2011). Portland State University Institutional Review Board approval was achieved to ensure study integrity while evaluating human subjects (Appendix C). In order to ensure consistent language and tone palatable for Oregon fishers, survey questions were developed in collaboration with members of the commercial fishing community. The Dungeness crab and salmon commissions, as well as the Oregon Trawlers Association, and volunteers within the fishing community provided feedback regarding survey structure and content. Furthermore, meetings with Fishermen Involved in Natural Energy (FINE), Fishermen's Advisory Committee for Tillamook County (FACT), Port Orford Ocean Resource Team (POORT), ODFW fishery managers, and several other fishers along the coast helped streamline questions to collect relevant information that would effectively quantify fishing effort.

The survey contained 15 questions and used 5-point-Likert scale, multiple choice, ranking, and open-ended responses (Appendix A). The following sections were used for this analysis: fisher demographics and fishing effort logistics. In order to reduce respondent burden, fishers that held permits in more than two fisheries were instructed to select the two that contributed the most to their household income and complete the survey with respect to those two fisheries. It was assumed that two fisheries captured most of the household income. This assumption may have created modest limitations to 
the collected data. Fishers were also instructed to choose their primary port of operation from seven fishing port groups. Grouping fishers by operating port group is a commonly used aggregation method when collecting fisheries data. The groupings used in this study are based on ODFW groups (Figure 3.1; Rodomsky \& Calavan 2015; Rodomsky and Calavan 2017; Rodomsky et al. 2016). Florence and Winchester Bay are not located in exclusively coastal counties and for simplicity, were aggregated into the Lincoln and Coos County groups, respectively. Brookings, while in Curry County, was separated based on recommendations from several fishing community members. Fishers were then asked to identify which generation of fisher he/she was and to state whether or not his/her children planned to continue in the commercial fishing industry. 


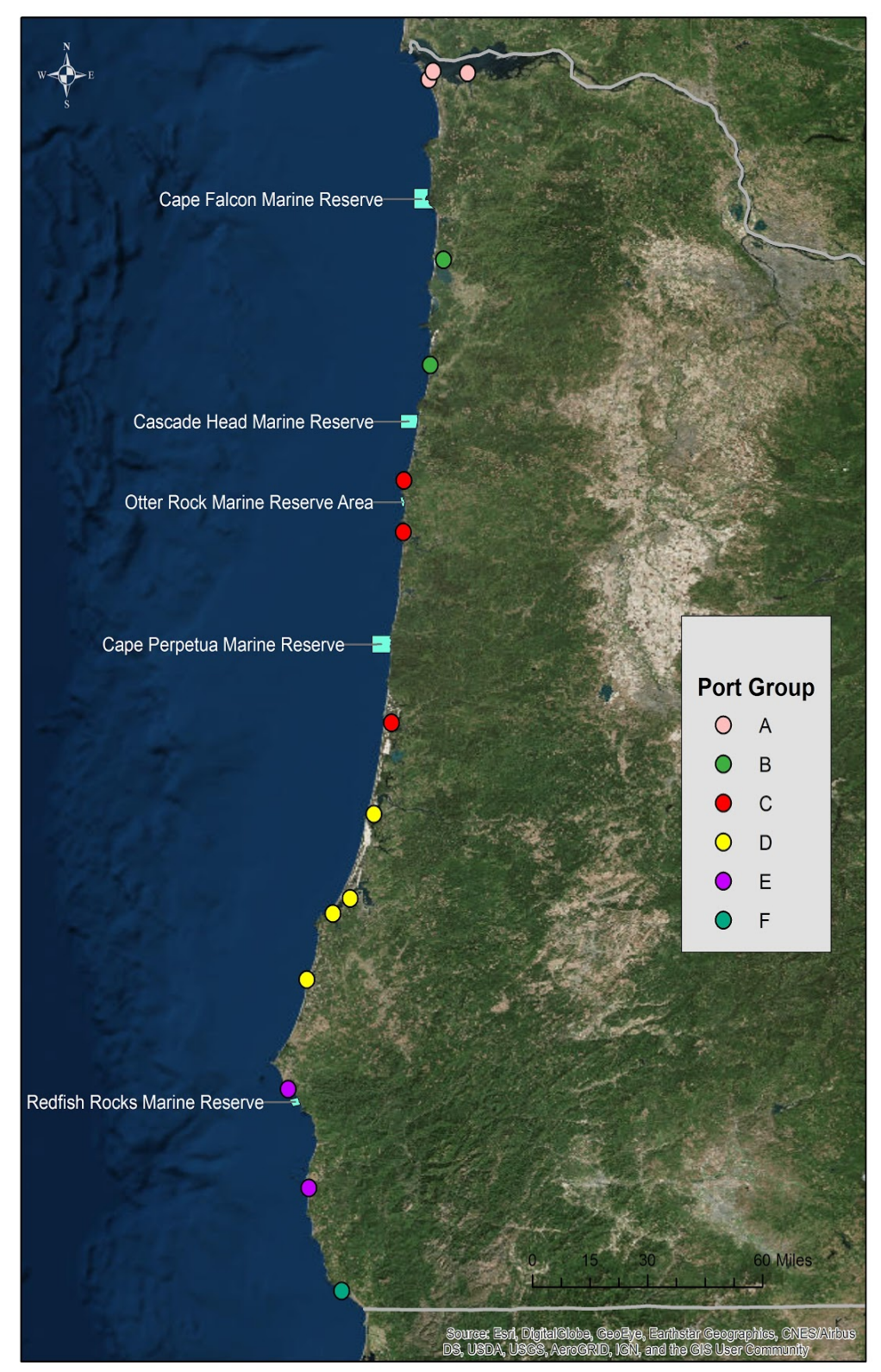

Figure 3.1. Primary operating port group distribution $(\mathrm{A}=$ Clatsop County: Astoria, Warrenton, and Hammond, $\mathrm{B}=$ Tillamook County: Garibaldi and Pacific City, $\mathrm{C}=$ Lincoln County: Newport, Depoe Bay, and Florence, $\mathrm{D}=$ Coos County: Coos Bay, Bandon, Charleston and, Winchester Bay, E= Curry County: Port Orford and Gold Beach, and $\mathrm{F}=$ Brookings) and general proximity to marine reserves.

Fishing effort was assessed for 2011, 2014, and 2017 by asking fishers to report the percentage of household income that was derived from the fishery, total number of days fished and total hours gear was deployed each day. Catch per unit effort was 
calculated by dividing annual landing weight by the number of hours gear was deployed per year. Landing, revenue, and vessel length were obtained from ODFW (2017b) and the Pacific Fisheries Information Network (2017) for each permit that responded to the survey.

\subsubsection{SAMPLING AND SURVEY IMPLEMENTATION}

Using current permit lists provided by the Oregon Department of Fish and Wildlife, mail questionnaires were sent to current permit holders in the Dungeness crab, salmon, and groundfish fisheries (total permit $\mathrm{N}=1,371$ ). Permit holders in the charter fishery were also surveyed (total permit $\mathrm{N}=75$ ), however, due to the vast differences in fishery dynamics, responses were not comparable to the other commercial fisheries surveyed. Charter fishery data summaries can be found in in Appendix B.

Permit holders received five items via mail during the two-month sampling period. Permit holders received an announcement post card two weeks prior, then a reminder postcard two weeks after receiving the first survey. Non-respondents were mailed a replacement survey, with a financial incentive (2.00 USD bill) enclosed, four weeks after receiving the initial survey. A reminder postcard was sent six weeks after receiving the initial survey (Teske et al. 1983). A total of 205 surveys were returned, representing 270 individual permits. Of the 270 responses, 127 were completed to a degree that was usable for the binomial logistic regression analysis and 246 were completed to a degree that was usable for the Chi-Squared tests. Respondents that did not complete the survey mainly skipped questions regarding fishing effort logistics.

An external comparative analysis revealed that survey respondents were representative of the entire sampling frame (The Research Group LLC 2018; Appendix 
C). The review for representativeness was primarily based on landed value distribution.

Other measures reviewed for representativeness were vessel size, operating port, and permit owner residency. Permit identification numbers and associated characteristics were cross-referenced with survey respondents and compared to the characteristics of the sampling frame (Figure 3.2). The analysis concluded that respondents for this study closely adhered to known survey frame characteristics suggesting that calibration schemes to improve representation were not needed; however, an analysis of nonrespondents, though beyond the scope of the study, would strengthen the conclusions.

\begin{tabular}{|c|c|c|}
\hline \multicolumn{3}{|c|}{ Representative Measures } \\
\hline Measure & Survey Frame & Respondents \\
\hline $\begin{array}{l}\text { Survey size } \\
\text { including charter } \\
\text { boats }\end{array}$ & 1,161 & 229 \\
\hline $\begin{array}{l}\text { Commercial } \\
\text { fishing vessel } \\
\text { count }\end{array}$ & 1,106 & 212 \\
\hline $\begin{array}{l}\text { Landed value of } \\
\text { three fisheries in } \\
2016\end{array}$ & $\begin{array}{l}\$ 52.0 \text { million in } \\
2016,85 \% \\
\text { onshore }\end{array}$ & $\begin{array}{l}\$ 11.4 \text { million in } \\
2016,22 \% \text { frame }\end{array}$ \\
\hline $\begin{array}{l}\text { Mean per vessel } \\
\text { landed value of } \\
\text { three fisheries in } \\
2016\end{array}$ & $\begin{array}{l}107 \% \text { of } \\
\text { onshore }\end{array}$ & $94 \%$ of frame \\
\hline $\begin{array}{l}\text { Mean per vessel } \\
\text { trip counts in } 2016\end{array}$ & $\begin{array}{l}106 \% \text { of } \\
\text { onshore }\end{array}$ & $111 \%$ of frame \\
\hline Vessel length & average 41 feet & average 39 feet \\
\hline $\begin{array}{l}\text { Permit owner } \\
\text { residency in } 2016\end{array}$ & $\begin{array}{l}\text { Oregon for } 68 \% \\
\text { of permittees }\end{array}$ & $\begin{array}{l}\text { Oregon for } 75 \% \\
\text { of permittees }\end{array}$ \\
\hline $\begin{array}{l}\text { Principal delivery } \\
\text { port area in } 2016\end{array}$ & $\begin{array}{l}\text { Newport highest } \\
\text { number of } \\
\text { vessels }\end{array}$ & $\begin{array}{l}\text { Newport highest } \\
\text { number of } \\
\text { vessels }\end{array}$ \\
\hline \multicolumn{3}{|c|}{$\begin{array}{l}\text { Note: The three fisheries are D. crab, salmon troll, and } \\
\text { nearshore groundfish. }\end{array}$} \\
\hline
\end{tabular}

Figure 3.2. Summary of measurements and fleet characteristics comparing representativeness of survey respondents to the sampling frame. Values over $100 \%$ indicate that the survey frame or respondents had slightly higher measurements than overall onshore fleet or survey frame, respectively. A full summary of the representative analysis can be viewed in Appendix C (The Research Group 2018). 


\subsubsection{DATA ANALYSIS}

The first research objective was to evaluate which fishery dynamics impact the probability of familial succession. A binomial logistic regression model was used with probability of familial succession as the dependent variable and a suite of business characteristics as independent, predictor variables. The second research objective utilized a series of Chi-Squared goodness of fit analyses to evaluate trends of familial succession in specific populations, such as fishery affiliation and operating port group.

Familial succession was evaluated using a success-failure binomial probability, with 1 indicating succession of offspring in the fishing business and 0 indicating no succession of offspring. A binomial logistic regression model using R Studio version 1.1.383 package "car" evaluated the impacts of fishery dynamics and scale of business operations on the probability of familial continuation in the commercial fishing industry (Fox and Weisberg 2011; R Core Team 2016). Fishery affiliation, primary operating port group, average annual catch per unit effort (landings per total hours fished for years 2011, 2014, and 2017), respondent's generational standing within the fishery, financial dependence on fishery income (percentage of household income), vessel length, and number of vessels owned were used as predictor variables for succession probability. Backwards-stepwise Akaike information criterion (AIC) model selection was used to eliminate variables that did not contribute to familial succession and a variance inflation factor (VIF) analysis evaluated predictor variables for multicollinearity.

Model fit was assessed using a Chi Squared p-value of the deviance of the residuals where a p-value $<0.05$ indicated that the model fit the data well. The McFadden and Nagelkerke $\mathrm{R}^{2}$ values were calculated to further evaluate model fit compared to a 
null model. An analysis of variance (ANOVA) was used to compare the full logistic model to the final logistic model. Continuous predictor variables were standardized to make coefficients more comparable. In order to keep familial succession responses binomial, respondents that indicated "Maybe" for familial succession were combined with respondents that indicated "No". Respondents who did not have children were excluded from the analysis, as they do not take part in familial successional planning.

The chi-squared goodness of fit test was conducted using R Studio version 1.1.383 package "MASS” (R Core Team 2016; Venables \& Ripley 2002). A series of goodness of fit tests (separated by fishery affiliation and operating port groups) were conducted in order to identify differences between expected and actual generational proportions. Expected generation class proportions were based on the current generational standing indicated by the survey respondent. Actual generation class proportions were based on fisher responses to the fate of their offspring within the industry. For example, a current first-generation fisher that indicated his/her offspring would continue in the fishing industry would correlate to an actual second-generation fisher. These tests aimed to evaluate if and how generational class proportions are changing over time in different communities. There were no projected data for actual first-generation fishers and for that reason it was assumed that the number of first generation fishers remained the same for expected and actual proportions. The combination scheme for "Maybe", "No" and "No Children" responses that was used for the binomial logistic regression was used in these analyses as well. 


\subsection{RESULTS}

\subsubsection{DESCRIPTIVE ANALYSES}

In total, 1086 surveys, representing 1371 unique permit holders (some fishers owned more than one permit in multiple fisheries). After allowing seven months for respondents to return their survey, 205 surveys, representing 270 permits were received. A $20 \%$ response rate was achieved for this study, which is comparable to other survey studies conducted with commercial fishing communities (Himes-Cornell and Kent 2014; Rodomsky and Calavan 2017). In total, 46 surveys were undeliverable and 18 possible respondents were either deceased or retired and each group was removed from the sample when calculating response rates (Table 3.1; Table 3.2). Fishers from the groundfish fishery responded at the highest rates, however, salmon fishers comprised the majority of survey respondents. Each designated port group received survey responses, including some respondents who landed consistently outside of Oregon (excluded from analyses).

Table 3.1. Survey Response by mailing round, non-response, and permit representation.

\begin{tabular}{|cc|}
\hline Response & $\mathrm{N}$ \\
\hline Total Surveys Mailed to Unique Addresses & 1086 \\
Total Permits Represented in Surveys Mailed to Unique Addresses & 1371 \\
$1^{\text {ST }}$ Round Returned Surveys & 115 \\
$2^{\text {nd }}$ Round Returned Surveys & 90 \\
Total Returned Surveys & 205 \\
Total Permits Represented in Returned Surveys & 270 \\
Undeliverable & 46 \\
Retired/Deceased/Does not use Permit & ${ }^{*}$ \\
Non-Response Surveys & 18 \\
\end{tabular}


Table 3.2. Respondent distribution by fishery affiliation and by port group.

\begin{tabular}{|ccccc|}
\hline County (Port Group*) & Dungeness crab & Groundfish & Salmon & Total \\
\hline Clatsop (Port A) & 22 & 3 & 18 & 43 \\
Tillamook (Port B) & 10 & 7 & 19 & 36 \\
Lincoln (Port C) & 20 & 8 & 23 & 51 \\
Coos (Port D) & 9 & 5 & 22 & 36 \\
Curry (Port E) & 9 & 13 & 3 & 25 \\
Brookings (Port F) & 8 & 5 & 7 & 20 \\
Not in Oregon (Port H) & 16 & 1 & 21 & 38 \\
No Port & 4 & 2 & 15 & 21 \\
Total Permits Represented in study & 98 & 44 & 128 & 270 \\
Total \# Permits Contacted & 378 & 101 & 892 & 1371 \\
Fishery Response Rate & $26 \%$ & $44 \%$ & $14 \%$ & $20 \%$ \\
\% Survey Respondents & $36 \%$ & $16 \%$ & $47 \%$ & $100 \%$ \\
\hline
\end{tabular}

*Port Group Codes: $\mathrm{A}=$ Astoria, Warrenton, and Hammond, $\mathrm{B}=$ Garibaldi and Pacific City, $\mathrm{C}=$ Newport, Depoe Bay, and Florence, $\mathrm{D}=$ Coos Bay, Bandon, Charleston and, Winchester Bay, $\mathrm{E}=$ Port Orford and Gold Beach, $\mathrm{F}=$ Brookings and $\mathrm{H}=$ Port not in Oregon).

Dungeness crab fishers fished the most hours per day (23 hours), and displayed the highest economic dependence on that fishery $(60 \%)$ compared to the other fisheries, which appear to have more diverse economic profiles. Dungeness crab fishers also exerted the most total effort and had the highest CPUE measurements while salmon fishers had the lowest CPUE measurements (Table 3.3).

Table 3.3. Fishing effort logistics, separated by fishery affiliation: Dungeness crab $(\mathrm{N}=65)$, groundfish $(\mathrm{N}=28)$, and salmon $(\mathrm{N}=56)$. Summary of mean, standard deviation and \pm standard error of mean for untransformed data.

\begin{tabular}{|c|c|c|c|c|c|c|c|c|c|}
\hline \multirow[b]{2}{*}{ Effort Logistic } & \multicolumn{3}{|c|}{ Dungeness crab } & \multicolumn{3}{|c|}{ Groundfish } & \multicolumn{3}{|c|}{ Salmon } \\
\hline & Mean & SD & $\mathrm{SE}$ & Mean & $\mathrm{SD}$ & $\mathrm{SE}$ & Mean & SD & SE \\
\hline $\begin{array}{c}\text { \%Financial } \\
\text { Dependence }\end{array}$ & 60 & 23.8 & 1.71 & 28 & 29.1 & 3.17 & 36 & 32.3 & 2.48 \\
\hline Days Fished/Year* & 67 & 48.8 & 3.50 & 43 & 44.8 & 4.90 & 58 & 59.9 & 4.60 \\
\hline Hours Fished/ Day* & 23 & 3.10 & 0.22 & 8 & 5.10 & 0.56 & 10 & 4.60 & 0.36 \\
\hline Total Effort ${ }^{*}$ & 1289 & 686 & 99 & 361 & 339 & 101 & 638 & 515 & 71 \\
\hline $\begin{array}{l}\text { Catch Per Unit } \\
\text { Effort }^{*}\end{array}$ & 40 & 52 & 7.7 & 36.2 & 56 & 2.9 & 10 & 21 & 11 \\
\hline
\end{tabular}

* Data were standardized when used in analyses 
Fishing vessels were the largest among Dungeness crab fishers and smallest among groundfish fishers ( 43 feet, 28 feet, respectively). For each fishery, the median number of vessels owned was one (Table 3.4). The Clatsop and Lincoln County port groups had the largest average vessels ( 44 feet, 42 feet, respectively), while Tillamook and Curry County vessels were the smallest (24 feet, 27 feet respectively). For each port group the median number of vessels owned was one (Table 3.5).

Table 3.4. Fishing vessel feature aggregated $(\mathrm{N}=168)$ and separated by fishery affiliation; Dungeness crab $(\mathrm{N}=66)$, salmon $(\mathrm{N}=71)$ and groundfish $(\mathrm{N}=31)$. Summary of mean, median (med), standard deviation and \pm standard error of mean for untransformed data.

\begin{tabular}{|cccccccccccccc|}
\hline & \multicolumn{3}{c}{ Aggregated } & \multicolumn{3}{c}{ Dungeness crab } & \multicolumn{3}{c|}{ Salmon } & \multicolumn{3}{c|}{ Groundfish } \\
\cline { 2 - 13 } $\begin{array}{c}\text { Vessel } \\
\text { Feature }\end{array}$ & Mean & SD & SE & Mean & SD & SE & Mean & SD & SE & Mean & SD & SE \\
\hline Length* & 36 & 13 & 1.0 & 43 & 15 & 1.8 & 33 & 9.5 & 1.0 & 28 & 9.8 & 1.8 \\
\hline & Med & SD & SE & Med & SD & SE & Med & SD & SE & Med & SD & SE \\
\hline $\begin{array}{c}\# \\
\text { Owned }\end{array}$ & 1 & 0.34 & 0.02 & 1 & 0.39 & 0.05 & 1 & 0.3 & 0.03 & 1 & 0.4 & 0.07 \\
\hline
\end{tabular}

* Data were standardized when used in analyses

Table. 3.5. Fishing vessel feature aggregated $(\mathrm{N}=168)$ and separated by port group; Clatsop ( $\mathrm{N}=32)$, Tillamook $(\mathrm{N}=21)$, Lincoln $(\mathrm{N}=46)$, Coos $(\mathrm{N}=27)$, Curry $(\mathrm{N}=24)$ and Brookings $(\mathrm{N}=18)$. Summary of mean, median (med), standard deviation and \pm standard error of mean for untransformed data.

\begin{tabular}{|cccccccccc|}
\hline Port & \multicolumn{3}{c}{ Clatsop } & \multicolumn{3}{c}{ Tillamook } & \multicolumn{3}{c|}{ Lincoln } \\
\hline Vessel Feature & Mean & SD & SE & Mean & SD & SE & Mean & SD & SE \\
Length* & 44.1 & 16.1 & 2.85 & 23.9 & 3.56 & 0.78 & 41.9 & 12.1 & 1.78 \\
& Median & SD & SE & Median & SD & SE & Median & SD & SE \\
\# Owned & 1 & 0.4 & 0.07 & 1 & 0 & 0 & 1 & 0.35 & 0.051 \\
\hline Port & & Coos & & & Curry & & \multicolumn{3}{c|}{ Brookings } \\
\hline & Mean & SD & SE & Mean & SD & SE & Mean & SD & SE \\
Length* & 35.0 & 10.3 & 1.97 & 27.2 & 5.89 & 1.20 & 35.3 & 12.2 & 2.88 \\
& Median & SD & SE & Median & SD & SE & Median & SD & SE \\
\# Owned & 1 & 0.3 & 0.051 & 1 & 0.46 & 0.095 & 1 & 0 & 0 \\
\hline
\end{tabular}

* Data were standardized when used in analyses 


\subsubsection{SOCIOECONOMIC DRIVERS OF FAMILIAL SUCCESSION}

The reduced binomial logistic regression and backward-stepwise AIC indicated that vessel length and the number of vessels owned by each respondent were important variables in the prediction of familial succession (Table 3.6). Backward-stepwise AIC selection eliminated fisher generation, average CPUE, and financial dependence on a fishery from the final regression model. When considering vessel length, for each unit (1 foot) that a fisher's vessel increases, the odds of familial succession increase by a factor of 1.61. If a fisher owns two fishing vessels, the odds of familial succession increase by a factor of 2.77 (Figure 3.3).

The final model was significantly different when compared to the null model and ANOVA revealed no significant differences between the full and final models $\left(\right.$ McFadden $\mathrm{R}^{2}=0.062$, Nagelkerke $\left.\mathrm{R}^{2}=0.101, \mathrm{Chi}^{2} \mathrm{p}=0.17\right)$.

Table 3.6. Variables influencing familial succession probability (indicated in bold) based on regression. $\mathrm{N}=126,(92$ no succession or unsure, 34 succession). $\beta=$ Estimate, $\mathrm{SE}= \pm$ standard error of the mean, $2.5 \%$ and $97.5 \%=$ confidence intervals. McFadden $\mathrm{R}^{2}=0.062$, Nagelkerke $\mathrm{R}^{2}=0.101$, $\mathrm{Chi}^{2} \mathrm{p}=0.17$. P-value indicates that slope differs from zero.

\begin{tabular}{|ccccccc|}
\hline Variable & $\boldsymbol{\beta}$ & SE & P & Odds & $\mathbf{2 . 5 0 \%}$ & $\mathbf{9 7 . 5 0 \%}$ \\
\hline Intercept & -1.20 & 0.25 & 0.0003 & 0.30 & 0.18 & 0.48 \\
Vessel Length & $\mathbf{0 . 4 8}$ & $\mathbf{0 . 2 2}$ & $\mathbf{0 . 0 3 1}$ & $\mathbf{1 . 6 1}$ & $\mathbf{1 . 0 5}$ & $\mathbf{2 . 5 5}$ \\
2 Vessels Owned & $\mathbf{1 . 0 2}$ & $\mathbf{0 . 6 1}$ & $\mathbf{0 . 0 9 7}$ & $\mathbf{2 . 7 7}$ & $\mathbf{0 . 8 0 5}$ & $\mathbf{9 . 2 9}$ \\
Generation & 0.055 & 0.274 & 0.840 & - & - & - \\
CPUE & -0.17 & 0.30 & 0.568 & - & - & - \\
Financial & -0.148 & 0.287 & 0.607 & - & - & - \\
Dependence & & & & & & - \\
\hline
\end{tabular}




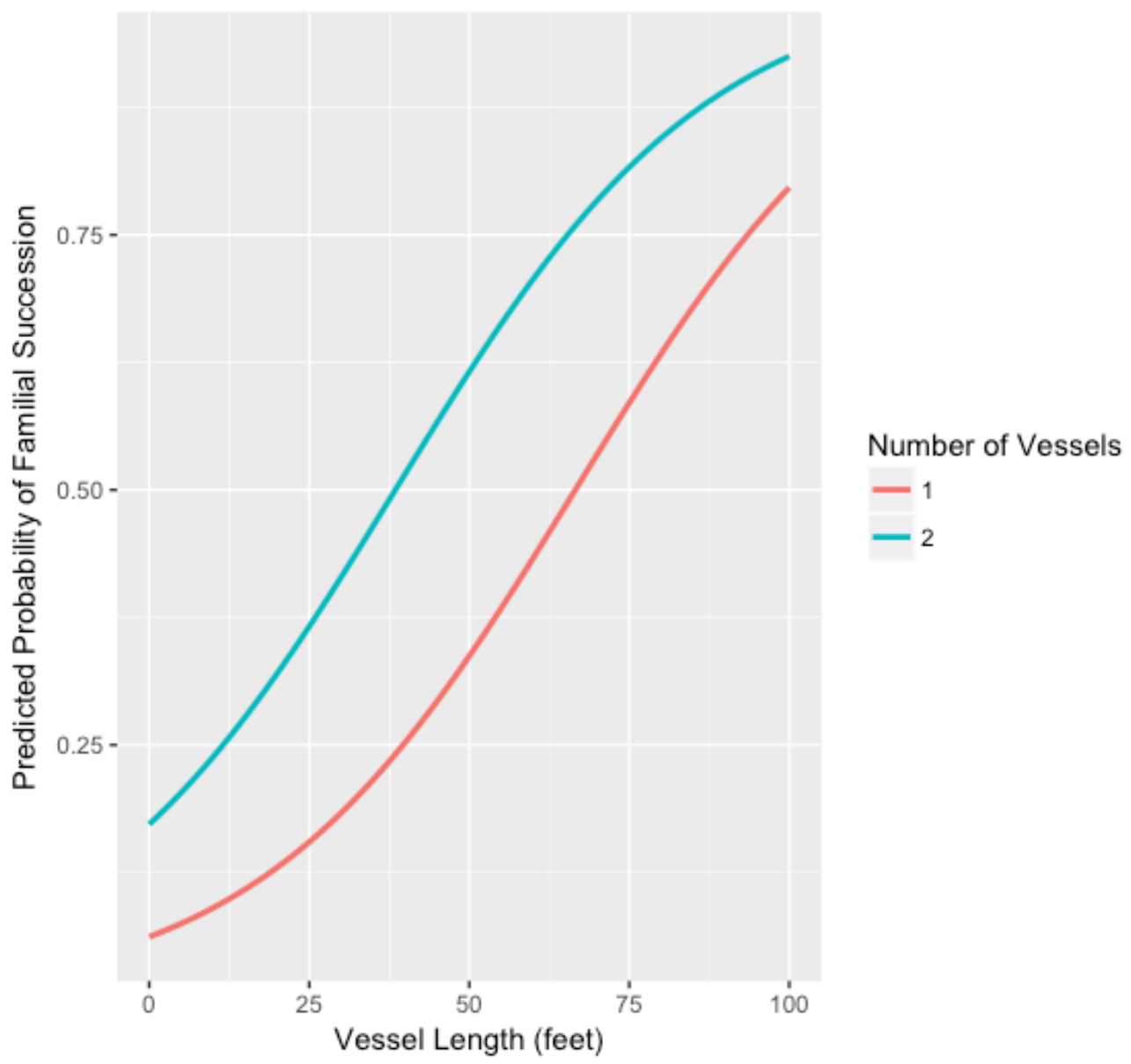

Figure 3.3. Vessel length and number of vessels owned significantly increase probability of familial succession within the commercial fishing industry (binomial logistic regression; $\mathrm{N}=126,92$ no succession or unsure, 34 succession).

\subsubsection{ACTUAL AND EXPECTED GENERATION CLASSES}

When separated by fishery, the Chi-Squared goodness of fit tests indicated that actual and expected generational proportions were significantly different for the Dungeness crab $(\mathrm{p}=0.0004)$ and salmon fisheries $(\mathrm{p}=0.0003)$ and not significantly different for the groundfish fishery $(\mathrm{p}=0.100$; Table 3.7). For Dungeness crab and salmon fisheries, the actual proportion of fourth or greater generation fishers was higher than expected while second and third-generation class proportions were lower than expected. There did not appear to be any related trends for the groundfish fishery (Figure 3.4). 
Table 3.7. Differences between actual and expected proportions of generational classes by fishery (Chi-Squared goodness of fit test; significant differences in bold); Dungeness crab $(\mathrm{N}=93)$, salmon $(\mathrm{N}=112)$ and groundfish $(\mathrm{N}=43)$.

\begin{tabular}{|c|c|c|c|}
\hline Fishery & $\chi^{2}$ & df & P \\
\hline Dungeness Crab & $\mathbf{1 7 . 9 8}$ & $\mathbf{3}$ & $\mathbf{0 . 0 0 0 4}$ \\
Salmon & $\mathbf{1 9 . 1 1}$ & $\mathbf{3}$ & $\mathbf{0 . 0 0 0 3}$ \\
Groundfish & 4.61 & 3 & 0.100 \\
\hline
\end{tabular}
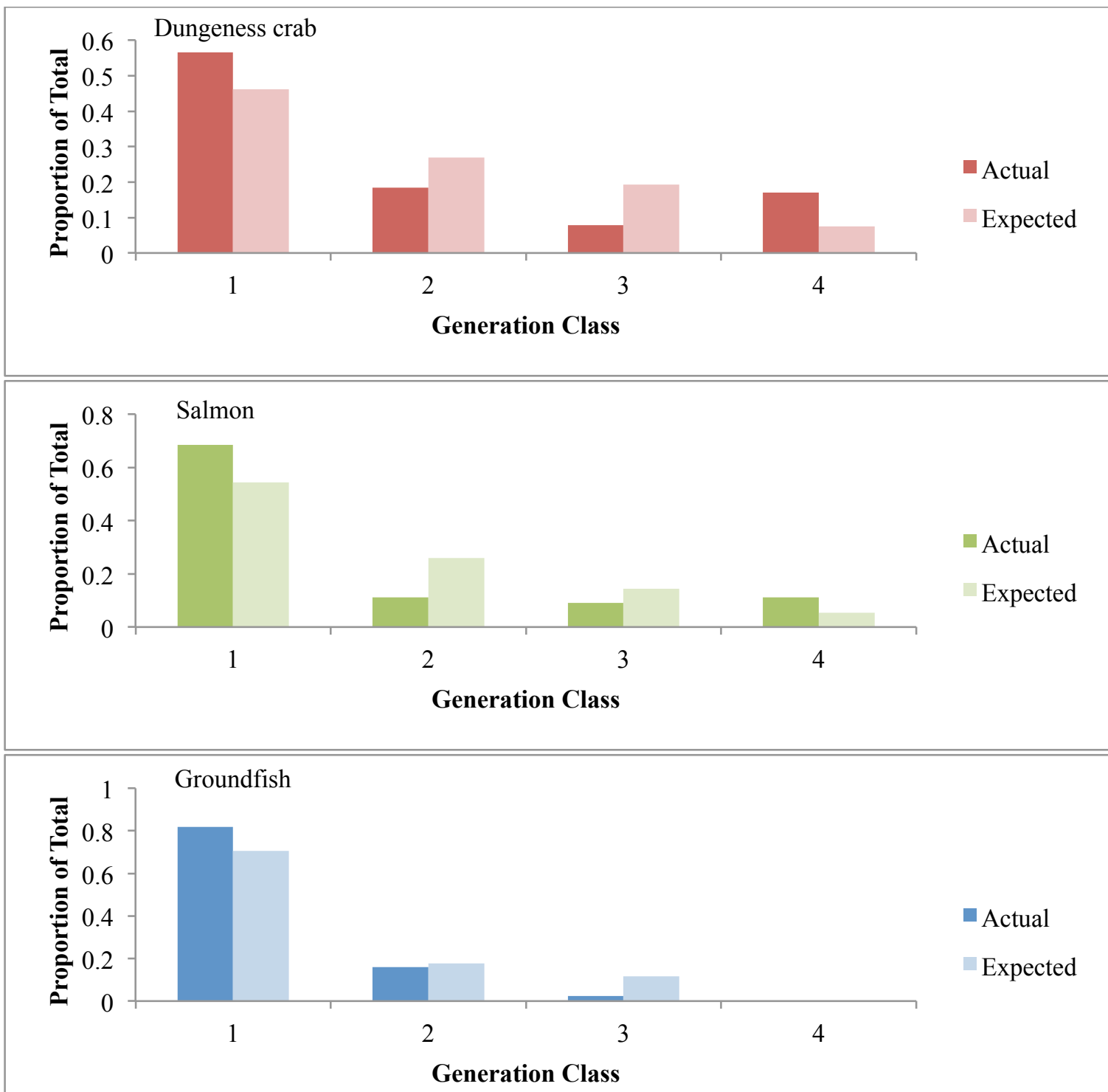

Figure 3.4. Proportional differences between actual and expected generational classes by fishery; Top: Dungeness crab ( $\mathrm{N}=93)$, middle: salmon $(\mathrm{N}=112)$ and bottom: groundfish $(\mathrm{N}=43)$. 
When separated by port group, Chi-Squared goodness of fit tests indicated that differences in actual and expected proportions of generational classes were significant only for Tillamook $(p=0.002)$ and Lincoln $(p=0.002$; Table 3.8) County groups. In Tillamook County, actual second and third-generation class proportions were lower than expected, while in Lincoln County actual second and forth or greater generation proportions were higher than expected (Figure 3.5).

Table 3.8. Differences between actual and expected proportions of generational classes by port group (Chi-Squared goodness of fit test; significant differences in bold): Clatsop $(\mathrm{N}=45), \mathrm{B})$, Tillamook $(\mathrm{N}=38)$, Lincoln $(\mathrm{N}=63)$, Coos $(\mathrm{N}=39)$, Curry $(\mathrm{N}=26)$, and Brookings $(\mathrm{N}=20)$. Significant differences in proportions indicated in bold. Marginally significant differences in proportions indicated in italics.

\begin{tabular}{|c|c|c|c|}
\hline Port Group & $\boldsymbol{\chi}^{\mathbf{2}}$ & Df & P \\
\hline Clatsop & 4.72 & 3 & 0.193 \\
Tillamook & $\mathbf{1 2 . 8 6}$ & $\mathbf{3}$ & $\mathbf{0 . 0 0 2}$ \\
Lincoln & $\mathbf{1 4 . 3 3}$ & $\mathbf{3}$ & $\mathbf{0 . 0 0 2}$ \\
Coos & 13.62 & 3 & 0.100 \\
Curry & 1.125 & 3 & 0.290 \\
Brookings & 5.44 & 3 & 0.066 \\
\hline
\end{tabular}




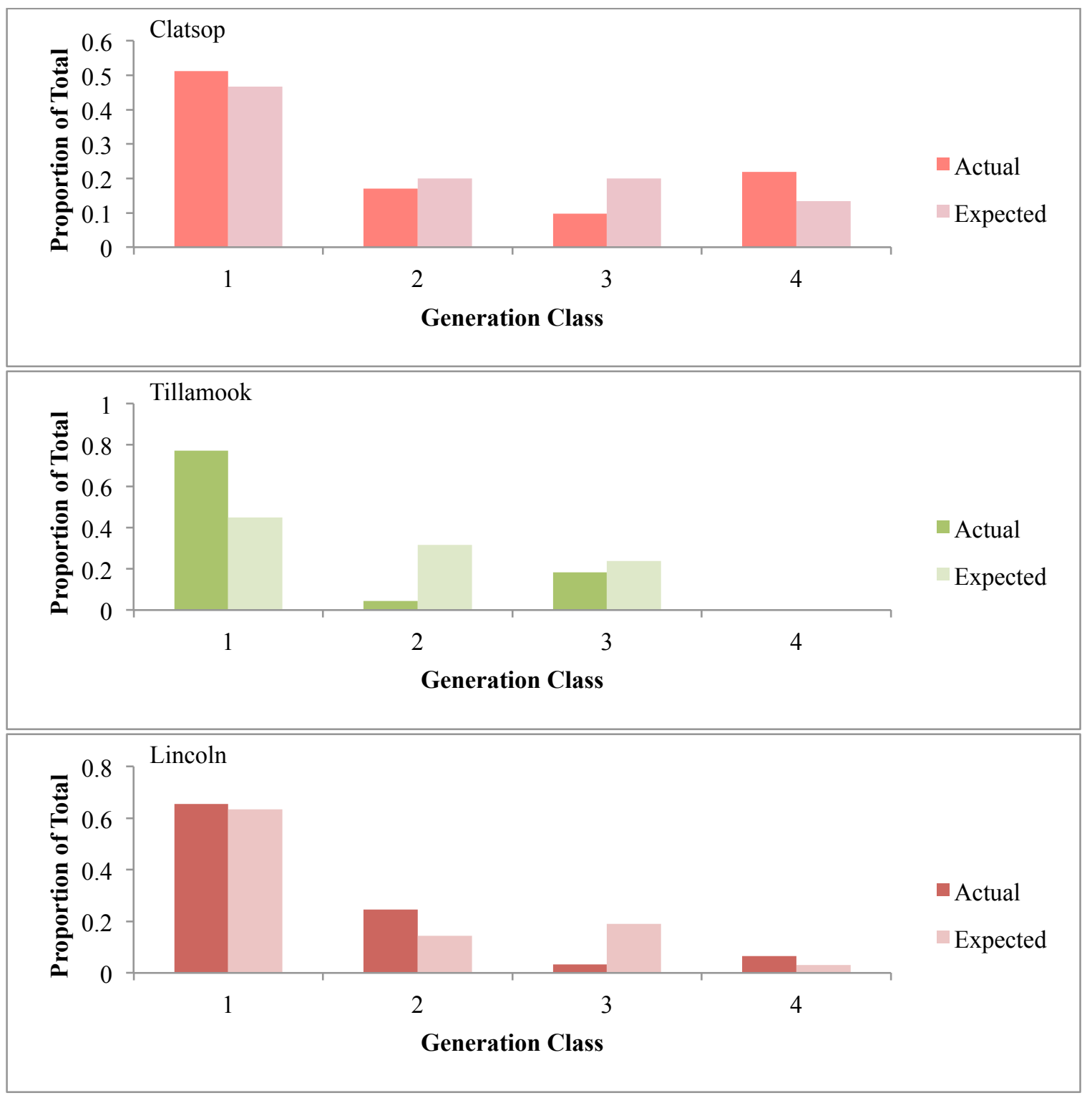




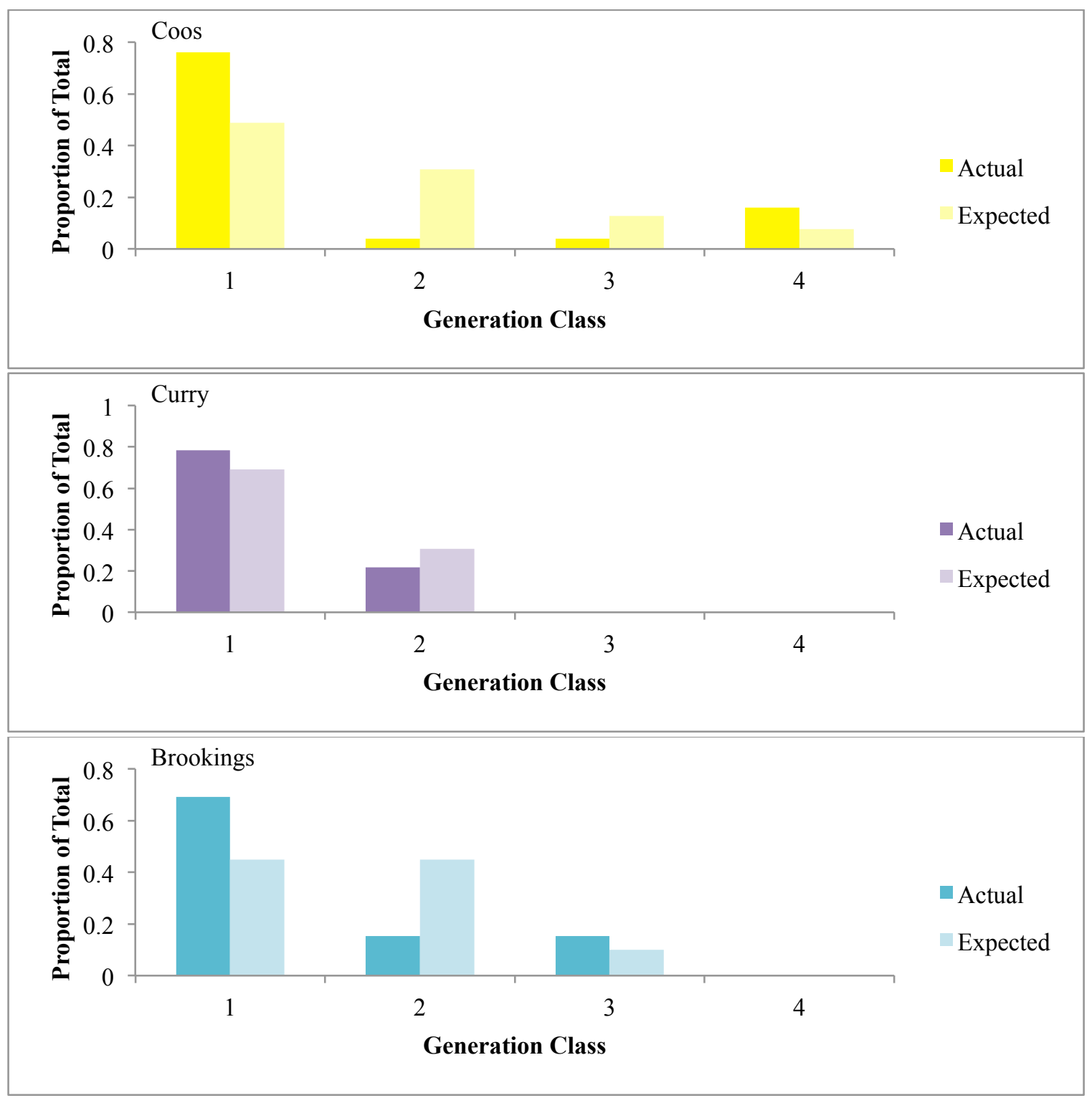

Figure 3.5. Proportional differences between actual and expected generational classes by port group. From top to bottom: Clatsop $(\mathrm{N}=45)$, Tillamook $(\mathrm{N}=38)$, Lincoln $(\mathrm{N}=63)$, Coos $(\mathrm{N}=39)$, Curry $(\mathrm{N}=26)$, and Brookings $(\mathrm{N}=20)$.

\subsection{DISCUSSION}

Findings from this study indicate that the scale of fishing operations ultimately drives familial succession. Fishers with larger and more vessels, had higher probabilities of participating in familial succession compared to fishers with smaller, fewer vessels. Projections of increasing proportions of fourth or greater generation fishers at a fishery 
level further reflected this trend. Geographic location also appeared to play some role in determining familial succession, however, patterns in succession differed by port groups.

The scale of fishing operation appeared to be the largest driver in familial succession within the industry. The social impacts of barriers to entry are apparent in that the more economically invested a fisher; the more likely a fisher's children are to continue in the fishing industry. Like many other skilled labor industries, large-scale productions typically generate the highest amounts of revenue and dominate the market (Kusel and Fortmann 1991; MacCannell 1988; Swanson 1988). One fisher reflected on the barriers regarding vessel size in the fishing industry:

"The state give[s] large vessels a competitive edge on smaller boats. It is becoming very difficult for boats under 50 feet to compete." Furthermore, diversified businesses are less vulnerable to negative impacts that often accompany homogenous natural resource income sources (Rumelt 1982). When a business model is diversified, the economic risk is more evenly distributed across multiple fisheries and a fisher with more than one fishing vessel is more spatially flexible and more resilient to fishery and weather volatility. Investment from multiple generations is likely to result in a more diversified, scaled, and lucrative operation that is equipped to support future generations of fishers. This may explain why the Dungeness crab and salmon fisheries experienced higher than expected participation in fourth generation or greater fishers. One fisher reflected on the benefits of diversified investment and fishery flexibility:

"I have three boats and multiple permits in multiple fisheries. Any opportunity a fisherman has is vital to financial survival. Whether used or not they are 
important due to fishery fluctuation. [Other permits] could be needed when other fisheries are in a down cycle."

In addition, catch share programs, as seen in Oregon's nearshore groundfish fishery, pose economic issues around high upfront costs necessary to enter the industry as well as maintaining catch shares in order to ensure profitability (Carothers 2011; Carothers and Chambers 2012). The groundfish fishery, however, was the only fishery where actual and expected generational proportions were not significantly different. It is reasonable to conclude that this catch share program may not pose a financial barrier for fishing families. In the last decade, landings have been relatively consistent and total landing values have steadily increased (Rodomsky and Calavan 2017). For this reason, familial retention may be higher for this fishery than in other observed fisheries. However, individual take quota accessibility may act as a barrier to entry for new participants to the fishery. For families already established in Oregon's fishing industry, inheritance of tangible items, such as large and multiple vessels, appear to be the biggest drivers of familial succession, opposed to barriers associated with catch quotas or permit costs.

While economic establishment appears to be important in determining familial succession, some facets of familial succession are still unexplained. One fisher reflected: "There are less young people involved in actual fishing and more involved in management and research."

This gives support to a hypothesis that some type of rural to urban labor migration is occurring out of the commercial fishing industry (Donkersloot 2011). While it may not be a physical movement between geographic locations, younger generations of fishing 
families appear to be participating in labor migration. These career changes may signal the transition from physical, skilled labor careers, such as fishing, to white-collar professions such as fisheries management, research, or something tangentially related to the fishing industry. Participation in white-collar professions is typically indicative of post-secondary education and is commonly accompanied by perceptions of more expansive career opportunities (Rutkowski 1996). Other studies that have explored generational succession found that younger generations do not recognize the commercial fishing industry as an economically viable career path and perceive fishing jobs as low quality of work (Power et al. 2014).

Local economies also appeared to play a role in determining familial succession. In the Tillamook County port group, reduced succession correlated well with the industry shift from the commercial to recreational fishing sector (Package and Conway 2010a). Furthermore, dory fishers, who utilize small, wooden vessels that launch from the beach, historically characterized the Pacific City fleet (Hall and Murphy 2012). Small vessel size and the low functionality of the harbor (beach launches) may reduce economic viability, resulting in a decline in youth participation in commercial fishing. In New Zealand, small-scale fishers are the primary group exiting commercial fisheries (Stewart et al. 2006). This trend partially resulted from the difficulty of extracting profitable catch due to vessel size constraints. This may be the opposite trend for large, heavily commercialized port towns that consistently prove lucrative, such as the Lincoln County group, which encompasses the largest fleet on the Oregon coast. Perhaps the ability to establish a fishing operation in a large, competitive geographic location means that a business is already scaled-up to a size that is profitable and resilient (Package and 
Conway 2010b). Increasing revenue per vessel and decreasing number of vessels within Oregon's fishing fleets indicate that resource consolidation has likely sifted many small fishing operations out of the industry leaving primarily large-scale operations to dominate the market (The Research Group 2013b).

Socioeconomics aside, natural volatility and increasing climatic variability have had detrimental impacts on commercial fish stocks. When reflecting on his own personal familial succession, one fisher commented:

"The fishing industry is failing. Why would I allow my children to invest and participate in a failing industry?"

Over the last century, salmon populations in the Northwestern United States and Canada have experienced declines, mainly linked to habitat loss and climatic variability (Lawson 1993). Decadal scale oceanic fluctuations, such as the Pacific Decadal and El Nino Southern Oscillations, characterized by wide variability in sea surface temperatures, have been cited as major influences on these population declines (Drake and Naiman 2007; Mantua et al. 1997). Since 2006, low stock assessments have resulted in five spatial closures for Oregon's commercial salmon troll fishery that have led to millions of dollars in lost revenue (Richardson et al. 2018). The most recent spatial closure (the first since 2010) occurred south of the city of Florence during the 2017-fishing season. The Dungeness crab fishery has also been largely impacted by oceanic variability. Domoic acid-producing algal blooms have led to delays in the 2016 and 2017 crabbing seasons (McCabe et al. 2016; McKibben et al. 2017). Historically, overcapitalization and poor stock management of the commercial groundfish fishery gave rise to numerous Rockfish Conservation Areas in 2002 (Pacific Fishery Management Council 2016). There are 
currently four Oregon Black Rockfish Management Areas that have established gear, catch, and trip restrictions on commercial vessels in an attempt to enhance sustainable fishing. Recently, however, groundfish stocks are stable and relatively profitable (Rodomsky and Calavan 2017). This may explain why familial retention in the groundfish fishery appears to be stable. Fish populations and oceanic conditions are variable by nature and are important to consider when discussing the overall health of specific fishing fleets.

There are several study limitations. The questionnaire was limiting due to the framing of questions surrounding familial succession. Fishers were asked if their "children" planned to continue on in the fishery rather than another next-generation family member, such as a niece or nephew. Furthermore, this question omits the fact that the ultimate decision regarding succession lies with the next generation of potential fishers. Results from this study are based on anticipated expectations of the current fishing fleet. A comparative analysis revealed that annual landings and revenue values for survey respondents were representative of the entire sample (The Research Group 2018). Further analysis of opinions of non-respondents, though beyond the scope of this study, would strengthen the conclusions.

Study findings indicate that increased scale of fishing operations partially determine the probability of familial succession. Successional patterns in this study are consistent with trends of mass consolidation of resources in the commercial fishing industry in Europe, New Zealand, and across Oregon (Caracciolo 2017; Donkersloot 2011; Stewart et al. 2006; The Research Group 2013b), as well as timber communities in the Pacific Northwestern US (Christensen and Donoghue 2001; Kusel and Fortmann 
1991), and agriculture across the US (MacCannell1988; Swanson 1988). These findings indicate that financial barriers to entry are pervasive within Oregon's fishing fleets. Patterns in familial retention across fisheries appeared to mirror trends in fish stock health and shifts within local economies. Similar to commercial fishing, other natural resource industries have experienced reduced employment opportunities as well economic instability has pushed many participants to abandon the trade and communities that have historically supported them (Christensen and Donoghue 2001; Murray 2009). While natural resource extraction provides economic opportunities for many rural communities, when industries exceed what is socially sustainable, small, local operations lose the ability to compete and are unable to maintain profitability (Kusel and Fortmann 1991; MacCannell 1988; Swanson 1988).

\subsection{CONCLUSION}

As consolidation of resources continues to occur in Oregon's fishing industry, economic winners and losers will ultimately emerge. In the future, large-scale, crossgenerational fishing operations will likely dominate commercial industry presence and shift stakeholder engagement techniques and conservation needs. Smaller fishing operations will be pushed to scale-up, shift to new markets, or exit the industry. For that reason, understanding where this consolidation is occurring can aid fisheries managers in engaging and managing specific stakeholder groups. While economic investments and variability are relatively measureable quantitative factors, other factors inevitably play a role in the ways that humans use and interact with natural resources. As climatic and oceanic variability are projected to intensify, the ultimate viability of some fisheries is unknown. The trends observed in this research are not unique to Oregon's commercial 
fishing sector and can be applied to commercial fisheries in other locations as well as a suite of other rural industries, including West Coast timber harvest and US agriculture (Christensen and Donoghue 2001; Kusel and Fortmann 1991; MacCannell 1988; Murray 2009; Swanson 1988). It is important to understand the aggregate impacts of economic, climatic, ecological, and societal variability on the financial viability and sustainability of natural resource industries in order to identify vulnerable populations and evaluate emerging stakeholder and market characteristics. 


\section{CHAPTER 4: CONCLUSIONS}

Using a collaborative mail questionnaire, this study aimed to (1) identify and assess which internal and external factors, including marine reserve designation, explain variability observed in fishing effort and success in Oregon's nearshore fisheries, and (2) evaluate familial succession patterns within different fishing communities. The findings for this study were as follows:

\section{Climatic and oceanic variability impacts fishery dynamics.}

Marine reserve designation in Oregon has not reduced or eliminated fishing effort. Instead, observed shifts in fishing effort correlated well with periods of low fish stock health and high oceanic variability that often resulted in fishery closures as well as market price fluctuations. Reduced projected youth participation was also present in fisheries that have been directly impacted by closures, while fisheries that appeared more resilient were projected to experience less variability in familial retention. For this reason, climatic fluctuations must be considered when evaluating natural resource industry dynamics.

\section{Larger fishing operations are more resilient to oceanic, regulatory, economic, and} market variability.

Large vessel size and increased travel capacity were indicative of high catch per unit effort. These fishers generate more revenue per trip and are less vulnerable to changing ocean and weather conditions. 


\section{Salmon fishers that have diversified business operations can thrive.}

Due to the volatile nature of salmon populations, business operations geared towards mobility (to locate and fish salmon) and flexibility (to shift effort) have higher catch per unit effort. Neither salmon nor groundfish fishers rely heavily on their respective fishery; due to the relative profitability of the fishery, shifts between the two fisheries may be occurring. Patterns within the groundfish fishery are difficult to identify due to the lack of statistically significant study results. The current strength of groundfish stocks and high CPUE may enhance familial retention within the fleet.

\section{In the future, commercial fleets will be dominated by large, intergenerational}

\section{fishing operations.}

Fishers with smaller, non-intergenerational fishing operations, and increased activity in the nearshore are particularly vulnerable to climatic, economic, regulatory, and ecological variability and are less likely to participate in familial succession. Barriers to maintain profitability in an industry dominated by conglomerate-like operations will ultimately drive smaller operations to scale-up, shift to new markets or exit the commercial fishing industry.

\section{Local economies drive familial succession and catch per unit effort.}

Patterns in familial succession and CPUE often mirror shifts in local industry as well as location-specific fleet characteristics. For this reason, fishery dynamics should continue to be studied with consideration of microeconomics and site-specificity. 
In order to holistically quantify and assess changing fishery dynamics, social, ecological, climatic, and economic factors need to be considered and incorporated into models that aim to explain human behavior. 


\section{REFERENCES}

Anticamara, J. A., Watson, R., Gelchu, A., \& Pauly, D. (2011). Global fishing effort (19502010): Trends, gaps, and implications. Fisheries Research, 107(1), 131-136. doi:https://doi.org/10.1016/j.fishres.2010.10.016.

Bastardie, F., Nielsen, J. R., Eigaard, O. R., Fock, H. O., Jonsson, P., \& Bartolino, V. (2014). Competition for marine space: modeling the Baltic Sea fisheries and effort displacement under spatial restrictions. ICES Journal of Marine Science, 72(3), 824-840.

Bellman, M. A., Heppell, S. A., \& Goldfinger, C. (2005). Evaluation of a US west coast groundfish habitat conservation regulation via analysis of spatial and temporal patterns of trawl fishing effort. Canadian Journal of Fisheries and Aquatic Sciences, 62(12), 28862900 .

Bindoff, N. L., Willebrand, J., Artale, V., Cazenave, A., Gregory, J., Gulev, S., ... \& Shum, C. K. (2007). Observations: oceanic climate change and sea level. Climate Change 2007: The Physical Science Basis. Contribution of Working Group I to the Fourth Assessment Report of the Intergovernmental Panel on Climate Change Cambridge University Press, Cambridge, United Kingdom and New York, NY, USA. Cambridge University Press, Cambridge, UK and New York, NY.

Branch, T. A., Hilborn, R., Haynie, A. C., Fay, G., Flynn, L., Griffiths, J., ... \& Young, M. (2006). Fleet dynamics and fishermen behavior: lessons for fisheries managers. Canadian Journal of Fisheries and Aquatic Sciences, 63(7), 1647-1668.

Caracciolo, D. (2017). Youth Recruitment and an Aging Workforce: A Pilot Study of Intergenerational Family Business in Oregon's Commercial Fishing Industry. Oregon State University.

Carothers, C. (2011). Equity and access to fishing rights: exploring the community quota program in the Gulf of Alaska. Human Organization, 70(3), 213-223.

Carothers, C., \& Chambers, C. (2012). Fisheries privatization and the remaking of fishery systems. Environment and Society, 3(1), 39-59.

Christensen, H. H., Donoghue, E. M. (2001). A research framework for natural resource-based communities in the Pacific Northwest. Gen. Tech. Rep. PNWGTR-515. Portland, OR: U.S. Department of Agriculture, Forest Service, Pacific Northwest Research Station. 21 p.

Cramer, L. \& Conway, F. (2016). The Old(er) Men of the Sea: Graying of the fishing industry and its impact on local community resiliency. Oregon State University. Retrieved from http://seagrant.oregonstate.edu/. 
Comet, S. M. (2017). Informing Oregon's Marine Protected Area (MPA) Baseline Past and Present tribal Uses of Marine Resources (Master's Thesis). Retrieved at http://seagrant.oregonstate.edu/sgpubs.

Cross, J. E. (2001). What is Sense of Place? Paper presented at the Headwaters Conference, Western State Colorado University, CO.

Dalton, T. M. (2004). An approach for integrating economic impact analysis into the evaluation of potential marine protected area sites. Journal of Environmental Management, 70(4), 333-349. doi:https://doi.org/10.1016/j.jenvman.2003.12.012.

Davis, S., Sylvia, G., Yochum, N., \& Cusack, C. (2017). Oregon Dungeness crab Fishery Bioeconomic Model: A Fishery Interactive Simulator Learning Tool Final Report. Corvallis, Oregon: OSU Coastal Oregon Marine Experiment Station and The Research Group, LLC. Retrieved from http://oregonmarinereserves.com.

Demsetz, H. (1982). Barriers to Entry. The American Economic Review, 72(1), 47-57.

Del Valle, I., Astorkiza, I., \& Astorkiza, K. (2003). Fishing effort validation and substitution possibilities among components: the case study of the VIII division European anchovy fishery. Applied Economics, 35(1), 63-77.

Dillman, D. A. (2011). Mail and Internet surveys: The tailored design method--2007 Update with new Internet, visual, and mixed-mode guide. John Wiley \& Sons.

Drake, D., \& Naiman, R. J. (2007). Reconstruction of Pacific Salmon Abundance from TreeRing Growth. Ecological Applications, 17(5), 1523-1542.

Donkersloot, R. (2011). What keeps me here: gendered and generational perspectives on rural life and leaving in an Irish fishing locale. University of British Columbia.

Eardley, C., \& Murphy, M. (2013). Long Form Recreational Fishing Community Profile: Cascade Head and the Coastal Salmon River Area, Oregon. Oregon Department of Fish and Wildlife. Retrieved from http://oregonmarinereserves.com/.

Epperly, H., Swearingen, T., \& Polis, H. (2017). 2010, 2011, 2014, and 2015 Business Surveys: Redfish Rocks, Cape Perpetua, Otter Rock, Cascade Head and Cape Falcon Marine Reserves. Oregon Department of Fish and Wildlife. Retrieved from http://oregonmarinereserves.com/.

Executive Order 08-07. (2008). Directing State Agencies To Protect Coast Communities In Siting Marine Reserve and Wave Energy Projects, 08-07 C.F.R.

FAO. (2016). The State of World Fisheries and Aquaculture 2016. Contributing to food security and nutrition for all. Retrieved from http://www.fao.org. 
Flint, C. G., \& Luloff, A. E. (2005). Natural resource-based communities, risk, and disaster: An intersection of theories. Society and Natural Resources, 18(5), 399412.

Flora, J. L., and C. Flora. (1991). Local economic development projects: Key factors. In Rural community economic development, edited by N. Walzer, 141-56. New York: Praeger

Fox, J. and Weisberg, S. (2011). An $\{R\}$ Companion to Applied Regression, Second Edition. Thousand Oaks CA: Sage.

http://socserv.socsci.mcmaster.ca/jfox/Books/Companion

Gabriel, O., Lange, K., Dahm, E., \& Wendt, T. (2008). Fish catching methods of the world: John Wiley \& Sons.

Gale, H. F. (2003). Age-Specific Patterns of Exit and Entry in U.S. Farming, 1978-1997. Review of Agricultural Economics, 25(1), 168-186.

Gell, F. R., \& Roberts, C. M. (2003). Benefits beyond boundaries: the fishery effects of marine reserves. Trends in Ecology \& Evolution, 18(9), 448-455. doi:10.1016/S01695347(03)00189-7

Gibson, C. C., Ostrom, E., \& Ahn, T. K. (2000). The concept of scale and the human dimensions of global change: a survey. Ecological Economics, 32(2), 217-239. doi:https://doi.org/10.1016/S0921-8009(99)00092-0

Glaser, M., Krause, G., Ratter, B., \& Welp, M. (2008). Human/Nature Interaction in the Anthropocene Potential of Social-Ecological Systems Analysis. GAIA - Ecological Perspectives for Science and Society, 17(1), 77-80. doi:10.14512/gaia.17.1.18

Grafton, R. Q., Arnason, R., Bjørndal, T., Campbell, D., Campbell, H. F., Clark, C. W., .. . Hilborn, R. (2006). Incentive-based approaches to sustainable fisheries. Canadian Journal of Fisheries and Aquatic Sciences, 63(3), 699-710.

Graham, J., \& Martin, K. S. (1990). Resources and restructuring in the international solid wood products industry. Geoforum, 21(3), 289-302.

Hall, E., \& Murphy, M. (2012). Long Form Fishing Community Profile: Pacific City, Oregon. Oregon Department of Fish and Wildlife. Retrieved from http://oregonmarinereserves.com/.

Halpern, B. S. (2003). The Impact of Marine Reserves: Do Reserves Work and Does Reserve Size Matter? Ecological Applications, 3(1), 21. 
Heberle, R. (1938). The causes of rural-urban migration a survey of German theories. American Journal of Sociology, 43(6), 932-950.

Himes-Cornell, A., \& Kent, K. (2014). Involving fishing communities in data collection: a summary and description of the Alaska Community Survey, 2011. U.S. Dep. Commerce. NOAA Tech. Memo. NMFSAFSC-284, $171 \mathrm{pp}$. Retrieved at https//:www.afsc.noaa.gov.

House Bill 3013, Oregon House 3 (2009).

Intergovernmental Panel on Climate Change. (2014). Mitigation of Climate Change.

Contribution of Working Group III to the Fifth Assessment Report of the Intergovernmental Panel on Climate Change. Cambridge University Press, Cambridge, UK and New York, NY.

Kirkley, J. E., Färe, R., Grosskopf, S., McConnell, K., Squires, D. E., \& Strand, I. (2001). Assessing capacity and capacity utilization in fisheries when data are limited. North American Journal of Fisheries Management, 21(3), 482-497.

Klein, C., Chan, A., Kircher, L., Cundiff, A., Gardner, N., Hrovat, Y., . . A Airame, S. (2008a). Striking a balance between biodiversity conservation and socioeconomic viability in the design of marine protected areas. Conservation Biology, 22(3), 691-700.

Klein, C. J., Steinback, C., Scholz, A. J., \& Possingham, H. P. (2008b). Effectiveness of marine reserve networks in representing biodiversity and minimizing impact to fishermen: a comparison of two approaches used in California. Conservation letters, 1(1), 44-51.

Kusel, J., and L. Fortmann. 1991. Well-being in forest-dependent communities. Vol. I. Sacramento: California Department of Forestry, Forest and Rangeland Assessment Program.

Kroodsma, D. A., Mayorga, J., Hochberg, T., Miller, N. A., Boerder, K., Ferretti, F., ... Worm, B. (2018). Tracking the global footprint of fisheries. Science, 359(6378), 904-908. doi:10.1126/science.aao5646

Lawrence, M.A (2016). ez: Easy Analysis and Visualization of Factorial Experiments. $\mathrm{R}$ package version 4.4-0. Retrieved from https://CRAN.R-project.org/package=ez

Lawson, P. W. (1993). Cycles in Ocean Productivity, Trends in Habitat Quality, and the Restoration of Salmon Runs in Oregon. Fisheries, 18(8), 6-10. doi:10.1577/15488446(1993)018<0006:CIOPTI $>2.0 . \mathrm{CO} ; 2$

Le Pape, O., \& Vigneau, J. (2001). The influence of vessel size and fishing strategy on the fishing effort for multispecies fisheries in northwestern France. ICES Journal of Marine Science, 58(6), 1232-1242. 
Low, S. M. (1992). Symbolic Ties That Bind. In I. Altman \& S. M. Low (Eds.), Place Attachment (pp. 165-185). Boston, MA: Springer US.

Mabogunje, A. L. (1970). Systems approach to a theory of rural-urban migration. Geographical analysis, 2(1), 1-18.

MacCannell, D. 1988. Industrial agriculture and rural community degradation. In Agriculture and community change in the U.S., edited by L. E. Swanson, 15-75. Boulder, CO: Westview Press.

Mantua, N. J., Hare, S. R., Zhang, Y., Wallace, J. M., \& Francis, R. C. (1997). A Pacific interdecadal climate oscillation with impacts on salmon production. Bulletin of the American Meteorological Society, 78(6), 1069-1079.

Marine Reserves Program. (n.d.) Retrieved from http://oregonmarinereserves.com/.

Marino, E. (2015). Cape Falcon Marine Reserve: A Pilot Study of Impacts, Outcome and Effort Shifts of Commercial and Charter Fishers. Oregon State University-Cascades. Retrieved from http://oregonmarinereserves.com/.

McCabe, R. M., Hickey, B. M., Kudela, R. M., Lefebvre, K. A., Adams, N. G., Bill, B. D., . . . Trainer, V. L. (2016). An unprecedented coastwide toxic algal bloom linked to anomalous ocean conditions. Geophysical research letters, 43(19).

McCarthy, J. J. (2001). Climate change 2001: impacts, adaptation, and vulnerability: contribution of Working Group II to the third assessment report of the Intergovernmental Panel on Climate Change: Cambridge University Press.

McClanahan, T. R., \& Mangi, S. (2000). Spillover of Exploitable Fishers from a Marine Park and its Effect on the Adjacent Fishery. Ecological Applications, 10(6), 1792-1805. doi:doi:10.1890/1051-0761(2000)010[1792:SOEFFA]2.0.CO;2

McClintock, N. (2010). Why farm the city? Theorizing urban agriculture through a lens of metabolic rift. Cambridge Journal of Regions, Economy and Society, 3(2), 191-207. doi:10.1093/cjres/rsq005

McCluskey, S. M., \& Lewison, R. L. (2008). Quantifying fishing effort: a synthesis of current methods and their applications. Fish and fisheries, 9(2), 188-200.

McKibben, S. M., Peterson, W., Wood, A. M., Trainer, V. L., Hunter, M., \& White, A. E. (2017). Climatic regulation of the neurotoxin domoic acid. Proceedings of the National Academy of Sciences, 114(2), 239-244.

Monaco, M. E., Friedlander, A. M., Caldow, C., Christensen, J. D., Rogers, C., Beets, J., ... \& Boulon, R. (2007). Characterizing reef fish populations and habitats within and outside 
the US Virgin Islands Coral Reef National Monument: a lesson in marine protected area design. Fisheries Management and Ecology, 14(1), 33-40.

Murphy, M., \& Hall, E. (2013). Long Form Fishing Community Profile: Depoe Bay, Oregon. Oregon Department of Fish and Wildlife. Retrieved from http://oregonmarinereserves.com/

Murray L. T. (2009). Exit from agriculture: a step forward or a step backward for the rural poor?. The Journal of Peasant Studies, 36(3), 629-636.

Mészáros, I. (1970). Marx's Theory of Alienation.

National Agricultural Statistics Service. (2013). Demographics Fact Sheet: Farmers by Age. Accessed July 5, 2013. Retrieved from:

http://www.agcensus.usda.gov/Publications/2007/Online_Highlights/Fact_Sheets/Demog raphics/ farmer_age.pdf

Needham, M. D., Cramer, L. A., \& Johnston, J. R. (2016). Resident perceptions of the Oregon marine reserve system. Oregon Department of Fish and Wildlife. Retrieved from http://oregonmarinereserves.com/

Oregon Department of Fish and Wildlife. (2016). Pounds and Values of Commercially Caught Fish and Shellfish Landed In Oregon: Years 2007-2016. [Data Set]

Oregon Department of Fish and Wildlife. (2017a). Marine Reserves: Human Dimensions Monitoring Plan. Retrieved from http://oregonmarinereserves.com/

Oregon Department of Fish and Wildlife (2017b). ODFW fisheries permit files for 2015-2017. [Data Set].

Oregon Department of Fish and Wildlife. (2018). Synopsis of Oregon Commercial Fishing Regulations. Oregon Department of Fish and Wildlife. Retrieved from http://www.dfw.state.or.us.

Ocean Policy Advisory Committee. (1994). State of Oregon territorial sea plan. Oregon Ocean Policy Advisory Council, Portland, OR.

Ocean Policy Advisory Committee. (2008). Oregon Marine Reserve Policy Recommendations. Department of Land Development and Conservation. Retrieved from www.oregon.gov/LDC

Pacific Fisheries Information Network. (2017). Annual vessel summary data, April 2009, March 2010, July 2011, April 2013, March 2014, April 2015, November 2016, and March 2017 extractions. [Data Set]. 
Package, C., \& Conway, F. (2010a). Long Form Fishing Community Profile: Garibaldi, Oregon. Oregon Department of Fish and Wildlife. Retrieved from http://oregonmarinereserves.com/

Package, C., \& Conway, F. (2010b). Long Form Fishing Community Profile: Newport, Oregon. Oregon Department of Fish and Wildlife. Retrieved from http://oregonmarinereserves.com/

Package, C., \& Conway, F. (2010c). Long Form Fishing Community Profile: Port Orford, Oregon. Oregon Department of Fish and Wildlife. Retrieved from http://oregonmarinereserves.com/

Pascoe, S., \& Robinson, C. (1996). Measuring changes in technical efficiency over time using catch and stock information. Fisheries Research, 28(3), 305-319.

Pauly, D., Watson, R., \& Alder, J. (2005). Global trends in world fisheries: impacts on marine ecosystems and food security. Philosophical Transactions of the Royal Society B: Biological Sciences, 360(1453), 5-12.

Pinheiro J, Bates D, DebRoy S, Sarkar D and R Core Team (2016)._nlme: Linear and Nonlinear Mixed Effects Models_. R package version 3.1-128. Retrieved from http://CRAN.R-project.org/package=nlme>.

Pollnac, R., Christie, P., Cinner, J. E., Dalton, T., Daw, T. M., Forrester, G. E., ... McClanahan, T. R. (2010). Marine reserves as linked social-ecological systems. Proceedings of the National Academy of Sciences, 107(43), 18262-18265.

Power, N. G., Norman, M. E., \& Dupré, K. (2014). “The fishery went away” : The impacts of long-term fishery closures on young people's experience and perception of fisheries employment in Newfoundland coastal communities. Ecology and Society, 19(3). doi:10.5751/ES-06693-190306

R Core Team (2016). R: A language and environment for statistical computing. $R$ Foundation for Statistical Computing, Vienna, Austria. Retrieved from https://www.R-project.org/

Richardson, K., Leonard, J., \& Holland, D. S. (2018). Predicting the economic impacts of the 2017 West Coast salmon troll ocean fishery closure. Marine Policy. doi:https://doi.org/10.1016/j.marpol.2018.03.005

Rijnsdorp, A. D., Dol, W., Hoyer, M., \& Pastoors, M. A. (2000). Effects of fishing power and competitive interactions among vessels on the effort allocation on the trip level of the Dutch beam trawl fleet. ICES Journal of Marine Science, 57(4), 927-937.

Roberts, C. M., Bohnsack, J. A., Gell, F., Hawkins, J. P., \& Goodridge, R. (2001). Effects of 
Marine Reserves on Adjacent Fisheries. Science, 294, 1920-1923.

Rodomsky, B. T. \& Calavan T.R. (2015). The Oregon Commercial Nearshore Fishery Summary: 2014. Oregon Department of Fish and Wildlife Marine Resources Program. 43 pp. Retrieved from http://www.dfw.state.or.us/MRP.

Rodomsky, B. T., Calavan, T. R., \& Carpenter, A. L. (2016). The Oregon Commercial Nearshore Fishery Summary. Oregon Department of Fish and Wildlife Marine Resources Program. 51pp. Retrieved from http://www.dfw.state.or.us/MRP.

Rodomsky, B. T. \& Calavan, T. R. (2017). The Oregon Commercial Nearshore Fishery Summary: 2016. Oregon Department of Fish and Wildlife Marine Resources Program. 63 pp. Retrieved from http://www.dfw.state.or.us/MRP.

Rumelt, R. P. (1982). Diversification strategy and profitability. Strategic management journal, 3(4), 359-369.

Rutkowski, J. (1996). High skills pay off: the changing wage structure during economic transition in Poland. Economics of Transition, 4(1), 89-112.

Ruttan, L. M. (2003). Finding fish: grouping and catch-per-unit-effort in the Pacific hake (Merluccius productus) fishery. Canadian Journal of Fisheries and Aquatic Sciences, 60(9), 1068-1077.

Sade, R. M. (2012). The graying of America: challenges and controversies. In: SAGE Publications Sage CA: Los Angeles, CA.

Sala, E., Mayorga, J., Costello, C., Kroodsma, D., Palomares, M. L., Pauly, D., ... \& Zeller, D. (2018). The economics of fishing the high seas. Science advances, 4(6), eaat2504.

Salas, S., \& Gaertner, D. (2004). The behavioral dynamics of fishers: management implications. Fish and fisheries, 5(2), 153-167.

Saputra, I. T. T., Tjandrawibawa, P., \& Christina, C. (2016). Generation Gap at PT Dharma Samudera Fishing Industries Tbk.

Schindler, D. E., Augerot, X., Fleishman, E., Mantua, N. J., Riddell, B., Ruckelshaus, M., . . Webster, M. (2008). Climate change, ecosystem impacts, and management for Pacific salmon. Fisheries, 33(10), 502-506.

Selznick, P. (1987). The idea of a communitarian morality. California Law Review, 75(1), 445463.

Senate Bill 1510, Oregon Senate 2 (2012).

Smith, M. D., Lynham, J., Sanchirico, J. N., \& Wilson, J. A. (2010). Political economy of marine 
reserves: Understanding the role of opportunity costs. Proceedings of the National Academy of Sciences, 107(43), 18300-18305.

Stewart, J., Walshe, K., \& Moodie, B. (2006). The demise of the small fisher? A profile of exiters from the New Zealand fishery. Marine Policy, 30(4), 328-340.

Swanson, L. (1988). Agriculture and community change in the U.S. Boulder, CO: Westview Press.

Swearingen, T., \& Epperly, H. (2016). 2015 Visitor Intercept Survey: Cape Falcon Marine Reserve. Oregon Department of Fish and Wildlife. Retrieved from http://oregonmarinereserves.com/

Swearingen, T., Epperly, H., \& Kazloff, L. (2016). 2014 Visitor Intercept Survey: Cape Perpetua, Otter Rock, and Cascade Head Marine. Oregon Department of Fish and Wildlife. Retrieved from http://oregonmarinereserves.com/

Teske, R. H., Hazlett, M. H., \& Parker, M. L. (1983). Texas Crime Poll: 1982 Survey. Survey Research Program, Texas Criminal Justice Center, Sam Houston State University.

The Research Group, LLC. (2013a). Economic Impact of Marine Recreational Fishing: Oregon Pilot Survey. Oregon Department of Fish and Wildlife. Retrieved from http://oregonmarinereserves.com/

The Research Group, LLC. (2015). Oregon's Commercial Fishing Industry, Year 2013 and 2014 Review. Oregon Department of Fish and Wildlife. Retrieved from http://oregonmarinereserves.com/

The Research Group, LLC. (2018). Oregon Nearshore Fisheries Effort Shift Survey Commercial Fishing Representativeness Report, Version 3.1. Oregon Department of Fish and Wildlife.

The Research Group, LLC. (2013b). Oregon's Commercial Fishing Industry, Year 2011 and 2012 Review. Oregon Department of Fish and Wildlife. Retrieved from http://oregonmarinereserves.com/

The Research Group, LLC. \& Consulting, G. M. (2012). Using Spatial Analysis of Fisheries and Habitat Data to Evaluate Economic Effects of Oregon Marine Reserve Sites. Oregon Department of Fish and Wildlife. Retrieved from http://oregonmarinereserves.com/

Venables, W. N. \& Ripley, B. D. (2002) Modern Applied Statistics with S. Fourth Edition. Springer, New York. ISBN 0-387-95457-0

Wani, M. H., Yousuf, S., Baba, S. H., \& Wani, S. A. (2011). Agricultural Labour Migration: Causes and Implications. Agricultural Economics Research Review, 24(conf), 563-563. 
Wilkinson, K. P. (1991). The community in rural America (No. 95). Greenwood Publishing Group.

World Bank. (2009). The Sunken Billions: The Economic Justification for Fisheries Reform. Washington DC: The International Bank for Reconstruction and Development/The World Bank.

World Conservation Congress (2008) Marine Protected Areas: Good for Fish! Good for People? Summary. Proceedings from Alliance Workshop, October 2008. 
APPENDIX A: Survey Instrument

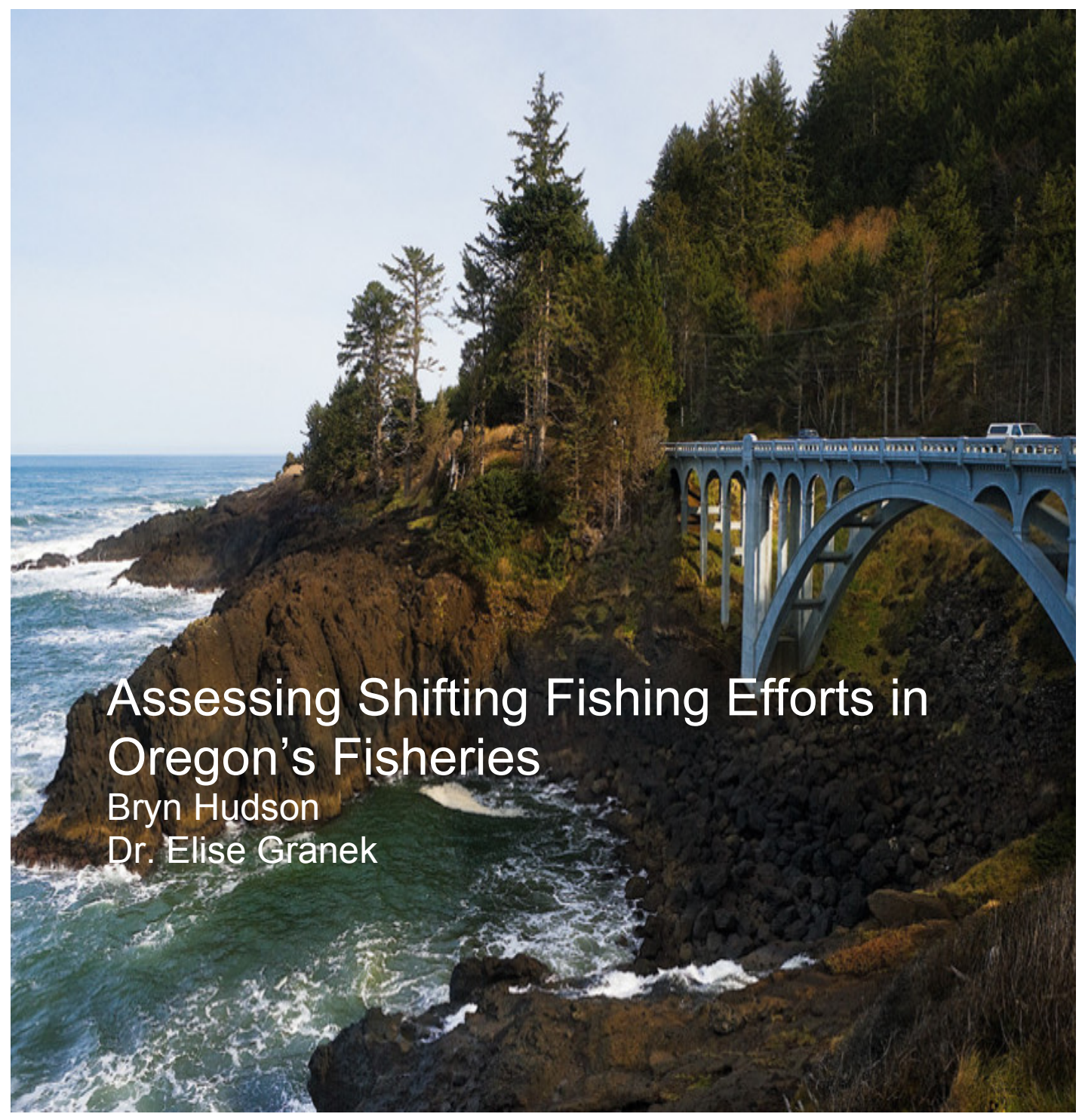

Portland State University

Department of Environmental Science and Management

POB Bx 751, Portland, OR 97207-9981 
Oregon Fishery Effort Survey

Department of Environmental Science \& Management

Portland State University

Post Office Box 751

Portland, Oregon 97207-0751

www.pdx.edu/esm

Hello! We are contacting you to ask for your help in a study on changes in Oregon fisheries over time. We are conducting this study as part of my graduate research at Portland State University with Drs. Elise Granek and Max Nielsen-Pincus, and in partnership with the Oregon Department of Fish and Wildlife.

As part of this study, we request that you complete the enclosed questionnaire about your experiences with Oregon fisheries. We will be evaluating shifting conditions in Oregon's nearshore commercial ground fish, Dungeness crab, nearshore salmon troll, urchin, charter and nearshore trawl fisheries. Participation in this study is an opportunity for you to voice your perspective and experience in Oregon's fisheries, which will contribute to a growing body of work regarding marine resource policy and management. Your responses will help develop more effective communication between management agencies and fishers.

Participation in this study will take 20-40 minutes and there is no more than minimal risk associated in your participation. Your personal information will only be used to mail and return your survey. Your responses are completely confidential, and your name will never be connected to your answers or included in any reporting. A final report will be published by Portland State University; a copy will be provided to the Oregon Department of Fish and Wildlife. If requested, we will send you a copy as well.

There is a separate postcard enclosed in this packet. On that postcard, you can enter into a raffle to win one of five $\$ 50$ gift cards and you may also opt to sign up for an in-depth interview for a related study. This interview is an opportunity to speak with another researcher about any additional information you feel is critical in understanding changes in fisheries or fisheries management over time. You will be compensated with a $\$ 25$ gift card if you choose to participate in the interview. Please include the postcard with your return mailing.

Your decision to participate in this study is completely voluntary, you may skip any questions you do not want to answer, and you have the right to end your participation at any time. When you complete and return the attached questionnaire, it means that you have read and understood this information, you agree to take part in this study, and you are over 18 years old. Thank you very much for your time and support of this study.

Sincerely,

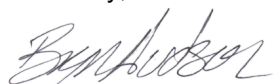

Bryn Hudson (Graduate Student)

503-686-5407

bryn@pdx.edu

PS. The Portland State University Institutional Review Board overseeing human research has reviewed and approved this study. If you have any questions before or after the survey, you can contact me, or my advisor Elise Granek at graneke@pdx.edu. If you have questions regarding your rights as a research participant, you may call the Portland State University Office for Research Integrity at (503) 725-2227 or 1(877) 480-4400. The Office for Research Integrity is the office that supports the PSU Institutional Review Board. For more information, you may also access the Institutional Review Board website at https://sites.google.com/a/pdx.edu/research/integrity 


\section{P Portland $\underset{\text { UnIVERSITY }}{\text { State }} 2$}

\section{Oregon Fishing Effort Survey}

Please answer the following questions to the best of your ability. Feel free to write your thoughts and comments anywhere on the survey.

1. Currently, what is your primary operating port? (Circle one or write one in)
a. Astoria, Warrenton, Hammond area
b. Garibaldi, Pacific City area
c. Newport, Depoe Bay, Florence area
d. Coos Bay, Bandon, Charleston, Winchester Bay area

e. Port Orford, Gold Beach area

f. Brookings

g. Other port in Oregon:

h. Port not in the State of Oregon:

2. For each commercial fishery in Oregon that you participated in since at least 2011 , fill in the table below.

\begin{tabular}{|l|l|l|l|}
\hline \multicolumn{1}{|c|}{$\begin{array}{c}\text { Fishery } \\
\text { (Circle all that apply) }\end{array}$} & $\begin{array}{c}\text { Years Fished } \\
\text { (From-to) }\end{array}$ & $\begin{array}{c}\text { Fulltime fishery } \\
\text { participant } \\
\text { (Write in yes or no) }\end{array}$ & $\begin{array}{c}\text { Percentage of household } \\
\text { income derived from } \\
\text { fishery } \\
\text { (Column must add to 100\% } \\
\text { fishing income) }\end{array}$ \\
\hline Nearshore ground fish & & & \\
\hline Dungeness crab & & & \\
\hline Salmon troll & & & \\
\hline Sea Urchin & & & \\
\hline Charter & & & \\
\hline Nearshore trawl \\
(Beach dragging)
\end{tabular}

If you have discontinued your activity in any of the above fisheries since 2011, please state the name of the fishery(ies) and the reason for your discontinuation in the box below. 
3. How many generations has your family participated in Oregon's fisheries? (Circle one)
a. 1 ( $\mathrm{am}$ a first generation fisher)
b. 2
c. 3
d. 4 or more

4. Do you anticipate that your children will participate in your family's fishing operation? (Circle one)
Yes
No
Maybe
I Don't Have Children

5. To what degree do you agree/disagree with each statement below? (Check one box for each statement)

\begin{tabular}{|l|cccc|}
\hline \multicolumn{1}{|c|}{ Statement } & $\begin{array}{l}\text { Strongly } \\
\text { disagree }\end{array}$ & $\begin{array}{c}\text { Moderately } \\
\text { disagree }\end{array}$ & Neutral $\quad \begin{array}{c}\text { Moderately } \\
\text { agree }\end{array}$ & $\begin{array}{c}\text { Strongly } \\
\text { agree }\end{array}$ \\
\hline $\begin{array}{l}\text { Public agencies have done a good } \\
\text { job advocating for my personal } \\
\text { interests }\end{array}$ & $\square$ & $\square$ & $\square$ \\
\hline $\begin{array}{l}\text { Public agencies have done a good } \\
\text { job advocating for the interests of } \\
\text { the fisheries in which I participate }\end{array}$ & $\square$ & $\square$ & $\square$ \\
\hline $\begin{array}{l}\text { Public agencies adequately } \\
\text { communicate issues regarding } \\
\text { Oregon fishery management to my } \\
\text { local fishing community }\end{array}$ & $\square$ & $\square$ & $\square$ \\
\hline $\begin{array}{l}\text { I am satisfied with the amount of } \\
\text { contact I have with agency } \\
\text { representatives }\end{array}$ & $\square$ & $\square$ & $\square$ \\
\hline $\begin{array}{l}\text { I feel comfortable voicing my } \\
\text { opinions about Oregon ocean } \\
\text { management and policy to public } \\
\text { agencies }\end{array}$ & $\square$ & $\square$ & $\square$ \\
\hline $\begin{array}{l}\text { I know where to obtain information } \\
\text { about policy changes regarding } \\
\text { Oregon ocean issues }\end{array}$ & $\square$ & $\square$ & $\square$ \\
\hline $\begin{array}{l}\text { I know where to obtain information } \\
\text { about scientific research regarding } \\
\text { Oregon ocean issues }\end{array}$ & $\square$ & $\square$ & $\square$ \\
\hline
\end{tabular}


For questions 6-14, please write in each fishery that you participate in. If you participate in more than two, pick the two fisheries that contribute most to your net household income. If you are a participant in the Charter fishery, please select the two most lucrative species for which you fish: example= Charter: Dungeness crab, Charter: Salmon.

6. Since 2011 , which best describes the extent to which your catch rates have been generally increasing or decreasing? (Check one box for each statement)

\begin{tabular}{|c|cccccc|}
\hline Fishery & $\begin{array}{c}\text { Large } \\
\text { decreases }\end{array}$ & $\begin{array}{c}\text { Moderate } \\
\text { decreases }\end{array}$ & $\begin{array}{c}\text { Some } \\
\text { increases and } \\
\text { decreases }\end{array}$ & $\begin{array}{c}\text { Moderate } \\
\text { increases }\end{array}$ & $\begin{array}{c}\text { Large } \\
\text { increases }\end{array}$ & $\begin{array}{c}\text { No clear } \\
\text { trend }\end{array}$ \\
\hline & $\square$ & $\square$ & $\square$ & $\square$ & $\square$ & $\square$ \\
\hline & $\square$ & $\square$ & $\square$ & $\square$ & $\square$ & $\square$ \\
\hline
\end{tabular}

7. What do you see to be the main factors influencing the trends in your catch rates? (Circle up to $\mathbf{3}$ factors that influence catch rates and rank them 1-3, with 1 being the largest influence)

Fishery:

\section{RANK}

a.

b.

c.

d.

d.

f.

f.

g. __ Regulations (specify):

h. Regulations (specify):

i.

_ Other:
Fishery:

\section{RANK}

a. __ Operating expenses

b. Catch limits

c. Catch per unit efforts

d. Ocean conditions

e. Weather conditions

f. __ Market prices

g. __ Regulations (specify):

h. Regulations (specify):

Other:

8. Since 2011, which best describes the extent to which your fishery related profits have been generally increasing or decreasing? (Check one box for each statement)

\begin{tabular}{|c|c|c|c|c|c|c|}
\hline Fishery & $\begin{array}{c}\text { Large } \\
\text { decreases }\end{array}$ & $\begin{array}{l}\text { Moderate } \\
\text { decreases }\end{array}$ & $\begin{array}{c}\text { Some } \\
\text { increases and } \\
\text { decreases }\end{array}$ & $\begin{array}{l}\text { Moderate } \\
\text { increases }\end{array}$ & $\begin{array}{c}\text { Large } \\
\text { increases }\end{array}$ & $\begin{array}{l}\text { No clear } \\
\text { trend }\end{array}$ \\
\hline & $\square$ & $\square$ & $\square$ & $\square$ & $\square$ & $\square$ \\
\hline & $\square$ & $\square$ & $\square$ & $\square$ & $\square$ & $\square$ \\
\hline
\end{tabular}


9. What do you see as the main factors influencing the trends of your fishery related profits? (Circle up to 3 factors that influence profits and rank them 1-3, with 1 being the largest influence)

Fishery:

\section{RANK}
a. __ Operating expenses
b. __ Catch limits
c. Catch per unit efforts
d. Ocean conditions
e. Weather conditions
f. __ Market prices
g. Regulations (specify):
h. __ Regulations (specify):
i. Other

Fishery:

\section{RANK}
a. Operating expenses
b. Catch limits
c. Catch per unit efforts
d. Ocean conditions
e. Weather conditions
f. __ Market prices
g. Regulations (specify):
h. Regulations (specify):
i. Other:

10. Since 2011, what are the main factors that explain the variability in your fishing effort? (Circle up to 3 factors that influence fishing effort and rank them 1-3, with 1 being the largest influence)

Fishery:

\section{RANK}
a. __ Operating expenses
b. Catch limits
c. __ Catch per unit efforts
d. Ocean conditions
e. W_ Weather conditions
f. __ Market prices
g. __ Regulations (specify):
h. Regulations (specify):
i. Other:

Fishery:

\section{RANK}

a. __ Operating expenses

b. Catch limits

c. __ Catch per unit efforts

d. Ocean conditions

e. Weather conditions

f. __ Market prices

g. __ Regulations (specify):

h. Regulations (specify):

i. Other:

11. Please fill the table in below explaining how the percentage of each cost has contributed to your total operating costs in the years 2011, 2014 and 2017. (Ensure each box adds to $100 \%$ for each year)

\begin{tabular}{|c|c|c|c|}
\hline Fishery & 2011 & 2014 & 2017 \\
\hline & $\begin{array}{l}\% \text { fuel } \\
\% \text { crew } \\
\% \text { other }\end{array}$ & $\begin{array}{c}\% \text { fuel } \\
\% \text { \% crew } \\
\% \text { other }\end{array}$ & $\begin{array}{c}\% \text { fuel } \\
\% \text { crew } \\
\% \text { other }\end{array}$ \\
\hline & $\begin{array}{l}\% \text { fuel } \\
\% \text { crew } \\
\% \text { other }\end{array}$ & $\begin{array}{c}\% \text { fuel } \\
\% \text { crew } \\
\% \text { other }\end{array}$ & $\begin{array}{c}\% \text { fuel } \\
\% \text { crew } \\
\% \text { other }\end{array}$ \\
\hline
\end{tabular}


12. To the best of your memory, fill in the table below that describes your fishing effort of each fishery in which you participate over the last seven years (2011-2017). We acknowledge that the 2017 season is not over for some fisheries, answer for that year to the best of your ability. Please note that 3 nautical miles falls within state territorial waters and is typically less than 40 fathoms deep.

\begin{tabular}{|c|c|c|c|c|}
\hline Fishery: & Year & 2011 & 2014 & 2017 \\
\hline \multicolumn{2}{|c|}{ Define your fishing season (Circle the months fished) } & $\begin{array}{l}\text { Jan. Feb. Mar. } \\
\text { Apr. May June } \\
\text { July Aug. Sept. } \\
\text { Oct. Nov. Dec. }\end{array}$ & $\begin{array}{l}\text { Jan. Feb. Mar. } \\
\text { Apr. May June } \\
\text { July Aug. Sept. } \\
\text { Oct. Nov. Dec. }\end{array}$ & $\begin{array}{l}\text { Jan. Feb. Mar. } \\
\text { Apr. May June } \\
\text { July Aug. Sept. } \\
\text { Oct. Nov. Dec. }\end{array}$ \\
\hline \multicolumn{5}{|c|}{$\begin{array}{l}\text { What percentage of your net household income was } \\
\text { derived from this fishery? }(0-100 \%)\end{array}$} \\
\hline \multicolumn{5}{|c|}{$\begin{array}{l}\text { About how many days did you fish during the season, } \\
\text { total? }(0-365)\end{array}$} \\
\hline \multicolumn{5}{|c|}{$\begin{array}{l}\text { About how many days did you fish during the season, } \\
\text { within } 3 \text { nautical miles? }(0-365)\end{array}$} \\
\hline \multicolumn{5}{|c|}{$\begin{array}{l}\text { About how many hours was your fishing gear deployed } \\
\text { each day during the season? }(0-24)\end{array}$} \\
\hline \multicolumn{5}{|c|}{$\begin{array}{l}\text { About how many hours was your fishing gear deployed } \\
\text { each day during the season, within } 3 \text { nautical miles? } \\
(0-24)\end{array}$} \\
\hline \multicolumn{5}{|c|}{$\begin{array}{l}\text { About how many miles did you travel before deploying } \\
\text { fishing gear? }\end{array}$} \\
\hline \multicolumn{5}{|c|}{$\begin{array}{l}\text { About how many days did you fish within what is now } \\
\text { marine reserve limits? }(0-365)\end{array}$} \\
\hline \multicolumn{5}{|c|}{$\begin{array}{l}\text { What percentage of your annual revenue was caught } \\
\text { within what is now marine reserve limits? }(0-100 \%)\end{array}$} \\
\hline Fishery: & Year & 2011 & 2014 & 2017 \\
\hline \multicolumn{2}{|c|}{ Define your fishing season (Circle the months fished) } & $\begin{array}{l}\text { Jan. Feb. Mar. } \\
\text { Apr. May June } \\
\text { July Aug. Sept. } \\
\text { Oct. Nov. Dec. }\end{array}$ & $\begin{array}{l}\text { Jan. Feb. Mar. } \\
\text { Apr. May June } \\
\text { July Aug. Sept. } \\
\text { Oct. Nov. Dec. }\end{array}$ & $\begin{array}{l}\text { Jan. Feb. Mar. } \\
\text { Apr. May June } \\
\text { July Aug. Sept. } \\
\text { Oct. Nov. Dec. }\end{array}$ \\
\hline \multicolumn{5}{|c|}{$\begin{array}{l}\text { What percentage of your net household income was } \\
\text { derived from this fishery? }(0-100 \%)\end{array}$} \\
\hline \multicolumn{5}{|c|}{$\begin{array}{l}\text { About how many days did you fish during the season, } \\
\text { total? }(0-365)\end{array}$} \\
\hline \multicolumn{5}{|c|}{$\begin{array}{l}\text { About how many days did you fish during the season, } \\
\text { within } 3 \text { nautical miles? }(0-365)\end{array}$} \\
\hline \multicolumn{5}{|c|}{$\begin{array}{l}\text { About how many hours was your fishing gear deployed } \\
\text { each day during the season? }(0-24)\end{array}$} \\
\hline \multicolumn{5}{|c|}{$\begin{array}{l}\text { About how many hours was your fishing gear deployed } \\
\text { each day during the season, within } 3 \text { nautical miles? } \\
(0-24)\end{array}$} \\
\hline \multicolumn{5}{|c|}{$\begin{array}{l}\text { About how many miles did you travel before launching } \\
\text { fishing gear? }\end{array}$} \\
\hline \multicolumn{5}{|c|}{$\begin{array}{l}\text { About how many days did you fish within what is now } \\
\text { marine reserve limits? }(0-365)\end{array}$} \\
\hline $\begin{array}{l}\text { What percentage of your a } \\
\text { within what is now marine } r\end{array}$ & $\begin{array}{l}\text { nue was caught } \\
\text { s? }(0-100 \%)\end{array}$ & & & \\
\hline
\end{tabular}


13. Which best describes the type of impact that the establishment of no-take marine reserves has had on your ability to partake in at least one Oregon fishery in which you participate? If reserves have had NO CLEAR IMPACT on your fishing efforts, skip to the end of the survey. (Check one box for each statement)

\begin{tabular}{|c|c|c|c|c|c|}
\hline Fishery & $\begin{array}{c}\text { Largely } \\
\text { negative }\end{array}$ & $\begin{array}{c}\text { Moderately } \\
\text { negative }\end{array}$ & No clear impact & $\begin{array}{c}\text { Moderately } \\
\text { positive }\end{array}$ & $\begin{array}{l}\text { Largely } \\
\text { positive }\end{array}$ \\
\hline & $\square$ & $\square$ & $\square$ & $\square$ & $\square$ \\
\hline & 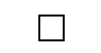 & $\square$ & $\square$ & $\square$ & 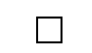 \\
\hline
\end{tabular}

14. How has marine reserve establishment impacted your ability to partake in any of the Oregon fisheries in which you participate? (Circle up to 3 outcomes and rank them 1-3, with 1 being the greatest impact)

Fishery:

\section{RANK}

a. ___ Fishing ground displacement

b. ___ Increased spatial competition

c. Longer travel distances

d. Other:

e. Other:

f. Other:
Fishery:

\section{RANK}

a. ___ Fishing ground displacement

b. Increased spatial competition

c. Longer travel distances

d. Other:

e. Other:

f. Other:

15. Identify which marine reserve (if any) has had the greatest impact on your fishing operations. (Circle one)

\section{GREATEST IMPACT}

a. Marine reserve implementation has not impacted my fishing operation

b. Cape Falcon

c. Cascade Head

d. Otter Rock

e. Cape Perpetua

f. Redfish Rocks

\section{SECOND GREATEST IMPACT}

a. Marine reserve implementation has not impacted my fishing operation

b. Cape Falcon

c. Cascade Head

d. Otter Rock

e. Cape Perpetua

f. Redfish Rocks

-This is the end of the survey-

Thank you for your time. We greatly value your answers and opinions. Please return your survey and the raffle ticket in the self-addressed stamped envelop within two weeks.

Please remove and keep the cover letter for your records. If you have any questions or concerns, please contact the number given on the cover letter. If you would like to be entered in a raffle to win one of five $\$ 50$ gift cards, please fill out and send back the enclosed postcard in your return envelope.

Feel free to write any other thoughts you have about Oregon Fisheries in the space below or on the next page: 
APPENDIX B: Summary Report 


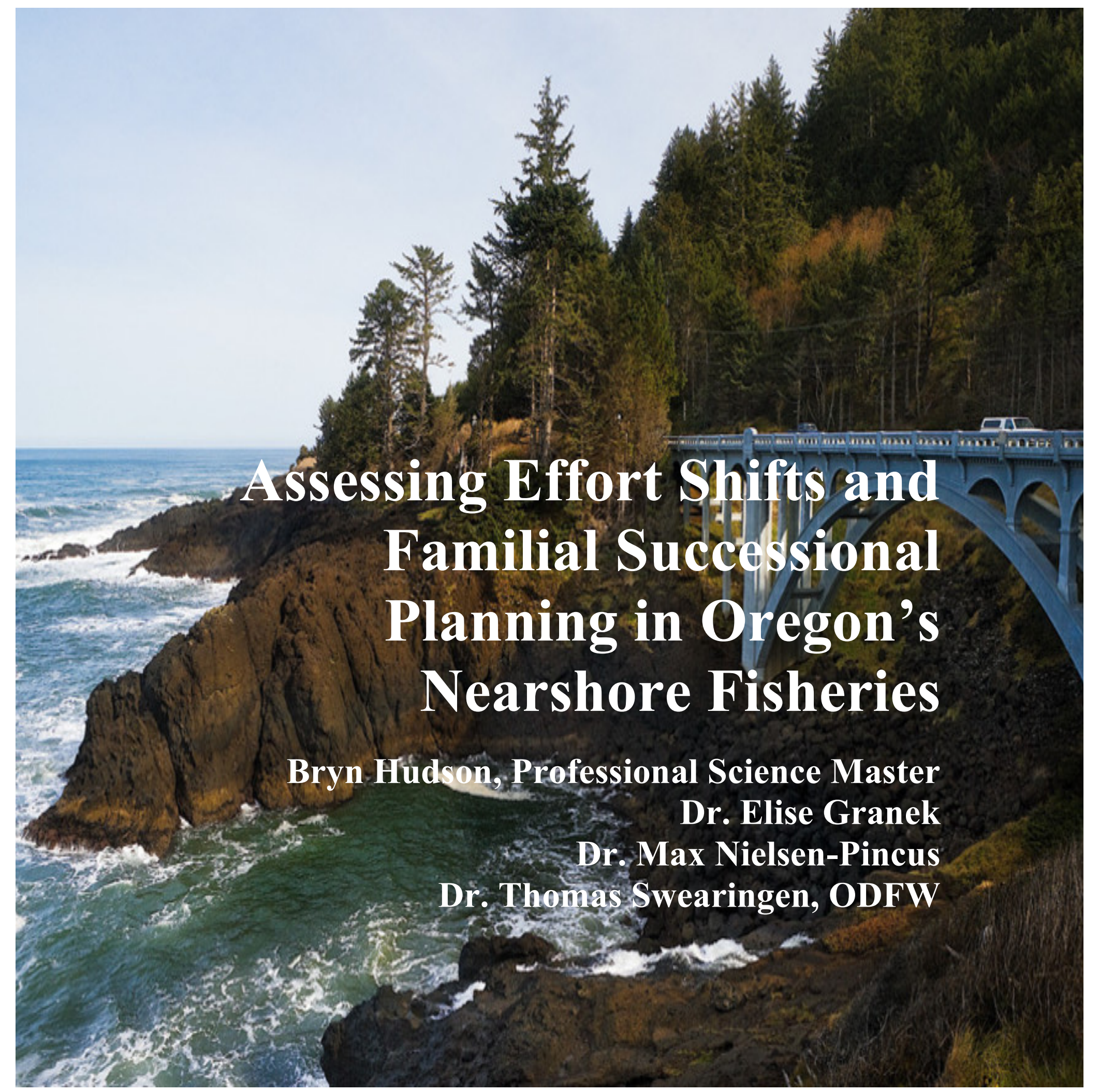

Portland State University

Conducted for and in cooperation with the Oregon Department of Fish and Wildife 


\section{ACKNOWLEDGEMENTS}

I would first like to thank Dr. Elise Granek, Dr. Max Nielsen-Pincus, and Dr. Thomas Swearingen of Oregon Department of Fish and Wildlife for serving on my committee and providing guidance and patience through this entire process. The mentorship, advice and inspiration that you three have provided me with is absolutely priceless. I would also like to thank Dr. Yangdong Pan for offering his invaluable knowledge regarding statistical analysis and patience. I would like to recognize Shannon Davis and The Research Group LLC for obtaining vital fisheries data and performing extensive representative analyses for this study.

This research would not have been possible without the constant support and efficient envelope stuffing from Casey Lewis, Amy Ehrhart, Britta Baechler, Dorothy Horn, Kaegan ScullyEngelmeyer, Amy Hemingway, Anna Bolm and Sabra Comet in the Applied Coastal Ecology Lab at PSU along with Emma Huston, Mom, Luke and Justin.

Thank you to the Fishermen Involved in Natural Energy (FINE), Fishermen Advisory Committee for Tillamook County (FACT), Port Orford Ocean Resource Team (POORT), the ODFW Shellfish Program, the Dungeness the Crab Commission, the Salmon Troll Commission, and the Association of Trawlers for their extensive collaboration to create and advertise the survey and overall study objectives. Further thanks to all of the fishers who took the time to complete the survey for this.

Finally, this study would not have been possible without the generous funding opportunities provided by the Oregon Department of Fish and Wildlife, the Ed and Olive Bushby Foundation and The Institute for Sustainable Solutions. 


\section{EXECUTIVE SUMMARY}

\section{Overview and Objectives}

In 2008, Governor Theodore Kulongoski signed Executive Order 08-07 declaring that marine reserve designations in Oregon's Territorial Sea (0-3 nautical miles from shore) have the potential to provide coastal communities and ocean users with opportunities for continued economic growth and prosperity. Shortly after Executive Order 08-07, the Ocean Policy Advisory Council released the decided upon objectives, principles and guidelines for reserve implementation. The overall goal of the reserve system was to "conserve marine habitats and biodiversity; provide a framework for scientific research and effectiveness monitoring; and avoid significant adverse social and economic impacts on ocean users and coastal communities" (OPAC 2008). From 2012-2016, five marine reserves have been implemented within Oregon's Territorial Sea: Otter Rock and Redfish Rocks were established in 2012, Cascade Head and Cape Perpetua in 2014, and Cape Falcon in 2016. While marine reserves and protected areas have been shown to be beneficial for aquatic systems, long-term, social controversies surrounding these policies have partially limited widespread implementation (Klein et al. 2008a, 2008b; Pollnac et al. 2010).

Eliminating fishing grounds has the potential for short-term negative economic and social implications. Economic variability and societal perceptions of reserves are at the forefront of the Oregon Department of Fish and Wildlife Marine Reserves Program's research agenda. Coastal resident, visitor, local business, and recreational/commercial fisher studies have been conducted in order to understand opinions surrounding marine conservation but there are currently few quantitative studies regarding how coastal communities have responded to variability within their system. The ultimate goal of this research is to understand how social, economic, behavioral, and familial dynamics are shifting over time in Oregon's commercial nearshore fishing communities. The research objectives are as follows:

(1) Provide baseline summary statistics regarding fishing behavior, opinions of management and community engagement, and general demographics in Oregon's nearshore fleets,

(2) Identify and assess which internal and external factors explain the variability observed in fishing effort and success in Oregon's nearshore fisheries, and

(3) Evaluate shifting familial succession patterns in fishery and operating port groups.

\section{Methods}

A paper mail survey was dispersed to current permit holders in Oregon's commercial Dungeness crab, salmon and groundfish fisheries and charter fishers (survey $\mathrm{N}=1161$, unique permit $\mathrm{N}=1446$ ) and asked participants to provide information regarding spatial and temporal shifts in fishing behavior, operating expenditures as well as demographic information (Appendix A). After allowing seven months for respondents to return their survey, 230 surveys, representing 300 permits were received. A $21 \%$ response rate was achieved for this study. Summary statistics, including mean, standard deviation and standard error were calculated for all continuous, numeric variables. Survey responses and summary statistics were separated by fishery. Any data transformations or standardizations are indicated in tables/figures. An external comparative 
analysis revealed that survey respondents were representative of the entire sampling frame (The Research Group LLC 2018; Appendix D). The review for representativeness was primarily based on landed value distribution. Other measures reviewed for representativeness were vessel size, operating port, and permit owner residency. The analysis concluded that respondents for this study closely adhered to known survey frame characteristics suggesting that calibration schemes to improve representation were not needed; however, an analysis of non-respondents, though beyond the scope of the study, would strengthen the conclusions.

Total fishing effort was calculated by multiplying the total days fished in a year by the average number of hours that fishing gear was deployed per day to give the total hours that fishing gear was deployed per year for 2011, 2014 and 2017. Repeated measures two-way ANOVAs were calculated in order to analyze for differences in fishing effort. Fishery, operating port group, and sampling year were factors with respondent identification number included as an error term to account for the non-independence between temporal samples. CPUE was calculated by dividing a fisher's total annual landings (in pounds) by their reported total annual effort (hours fished). The repeated measures ANOVA revealed no significant variability in CPUE over time between 2011, 2014, and 2017 (with the exception of one year in the salmon fishery, which was excluded from analyses). CPUE measurements from 2011, 2014, and 2017 were averaged to create a single CPUE value for each survey respondent. Linear mixed effects models were generated to analyze which socioeconomic drivers contributed to variability in CPUE. Due to the differences in fishing methods between each fishery, data were separated by fishery in order to generate three unique models. Familial succession was evaluated using a success-failure binomial probability, with 1 indicating succession of offspring in the fishing business and 0 indicating no succession of offspring. A binomial logistic regression model evaluated the impacts of fishery dynamics and scale of business models on the probability of familial continuation in the commercial fishing industry. A series of Chi-Squared goodness of fit tests (separated by fishery affiliation and operating port groups) were conducted on in order to identify differences between current and future generational proportions.

\section{Results}

- Respondents did not feel that public agencies have effectively advocated for individual and fishery interests. Respondents held neutral opinions regarding the quantity and quality of communication with public agency representatives and their general accessibility to scientific research. Respondents felt comfortable voicing their opinions regarding management and policy to public agencies and that information regarding policy changes was accessible. General opinions regarding management and policy did not differ between fishery affiliations, however fishers operating in a port not in Oregon help more neutral opinions.

- Charter fishers reported moderate declines in fishery related profits within the past 7 years (2011-2017). Both catch rates and profits were driven by regulations, ocean conditions, and catch limits.

- Dungeness crab fishers reported both increases and decreases in personal catch rates and fishery related profits within the past 7 years (2011-2017). Weather conditions, ocean conditions, and market prices were the top drivers of catch rates and profits were driven by ocean conditions, market prices, and operating expenses. 
- Groundfish fishers reported both increases and decreases in personal catch rates and fishery related profits within the past 7 years (2011-2017). Catch limits, ocean conditions, and operating expenses were the top drivers of catch rates and profits.

- Salmon troll fishers reported large declines in personal catch rates and fishery related profits within the past 7 years (2011-2017). Regulations, ocean conditions, and catch limits were the top drivers of catch rates, and profits were driven by regulations, operating expenses, and catch limits.

- A majority of fishers (61\%) reported that marine reserves have had no clear impact on fishing participation. Responses indicating displacement of fishing, increased spatial competition, and increases travel distances to fish were evenly distributed among aggregated responses as well as fishery dependent responses. Respondents from the Dungeness crab fishery reported the highest percentage of negative impacts (48\%) resulting from marine reserves.

- Costs associated with crew appeared to be the lowest operating expenditure across all fisheries (Average $=16 \%$ ), with the exception of Dungeness crab, where associated fuel costs were the lowest (16\%). Other operating expenses, such as insurance, loan payments or permits, made up the largest percentage of expenses for every fishery. Relative operating expenditures did not appear to significantly fluctuate between the years 2011, 2014, and 2017.

- Respondents within the Dungeness crab fishery displayed the highest economic dependence on that single fishery (60\%), compared to the other fisheries, which appear to have more diverse economic profiles. Salmon fishers spent the largest proportion of time fishing offshore (64\%), while the other fisheries spent a majority days fishing nearshore. Dungeness crab fishers traveled the farthest distances in order to fish (15 miles) and fished the most in areas that are now marine reserves (20\%).

- Total effort (measured in hours fished per year) was the highest among Dungeness crab respondents (1289 hours/year). Effort marginally declined in the Dungeness crab and groundfish fisheries and significantly in the salmon fishery between the years 2014 and 2017.

- Dungeness crab fishers reported marginal declines in effort from 2014 to 2017 in all port groups, the largest from the Tillamook port group, likely corresponding with 2016 and 2017 season delays due to high levels of domoic acid. Weather conditions, ocean conditions, and market prices were reported as the top external factors driving overall fishing effort. Vessel length was positively correlated with high CPUE while nearshore effort, revenue from marine reserves, fuel expenditure were negatively correlated with high CPUE.

- Salmon fishers reported significant declines in effort from 2014 to 2017, with marginal declines occurring in all central and southern located port groups, corresponding with the fishery closures south of Florence for the 2016-2017 season due to low stock returns. Regulations, ocean conditions, and operating expenses were reported as the top external factors driving overall fishing effort. The number of owned fishing vessels and increased travelling capacity were positively correlated with high CPUE.

- Groundfish fishers reported marginal effort increases in the Coos and Brookings port groups and marginal decreases in the Lincoln and Curry port groups for the three-year sampling period (2011, 2014, and 2017). Catch limits, ocean conditions, and weather 
conditions were reported as the top external factors driving overall fishing effort. None of the observed socioeconomic demographics were selected as predictors of CPUE.

- The most common expectation among first, second and third-generation fishers was that their children would not continue to participate in their family fishing operation. In the Dungeness crab and salmon fisheries, the fourth or greater generation fishers were more likely to expect their family members would continue fishing. In the charter fishery, second-generation fishers were more likely to expect their family members would continue fishing. In the Tillamook port group, it appears that in general, all fishers expected that their family members would not continue fishing, while in the Lincoln port group second-generation and forth or greater generation fishers were more likely to expect their family members would continue fishing.

- Probability of expectations for continuation of familial involvement increases by a factor 1.64 for each unit ( 1 foot) that a fisher's vessel length increases, and increases by a factor of 2.77 if a fisher owns two fishing vessels.

\section{Management Implications}

- Climatic and oceanic variability impacts fishery dynamics. Observed shifts in fishing effort correlated with periods of low fish stock health and high oceanic variability that often resulted in fishery closures as well as market price fluctuations. Large-scale warming events have resulted in domoic acid-producing algal blooms that have led to delays in 2016 and 2017 Dungeness crab fishing season and the most recent closure in the salmon fishery, during the 2017-fishing season. Reduced expectations around familial continuation in fishing was also present in fisheries that have been directly impacted by closures, while fisheries that appeared more resilient were projected to experience less variability in familial retention. For this reason, climatic fluctuations must be considered when evaluating natural resource industry dynamics.

- Larger fishing operations are more resilient to oceanic, regulatory, economic, and market variability. Large vessel size and increased travel capacity were indicative of high catch per unit effort. Larger fishing operations allow for more gear storage than smaller vessels and are typically able fish for longer periods of time in highly variable weather conditions, due to increased fuel capacity and general size. These fishers generate more revenue per trip and are less vulnerable to changing ocean and weather conditions.

- Salmon fishers that have diversified business operations can effectively cope with variability. Due to the volatile nature of salmon populations, business operations geared towards mobility (to locate and fish salmon) and flexibility (to shift effort) have higher catch per unit effort.

- In the future, commercial fleets will be dominated by large, intergenerational fishing operations. Fishers with smaller, non-intergenerational fishing operations, and increased activity in the nearshore are particularly vulnerable to climatic, economic, regulatory, and ecological variability and are less likely to participate in familial succession. Barriers to maintain profitability in an industry dominated by large-scale 
diversified fishing operations may drive smaller operations to scale-up, shift to new markets or exit the commercial fishing industry.

- Local economies drive familial succession and catch per unit effort. Patterns in familial succession and CPUE mirrored shifts in local industry as well as locationspecific fleet characteristics. In the Tillamook County port group, reduced succession correlated with the industry shift from the commercial to recreational fishing sector and dory fishing characteristics. The opposite was observed in the Lincoln County group, which encompasses the largest fleet on the Oregon coast. Perhaps the ability to establish a fishing operation in a large, competitive geographic location means that a business is already scaled-up to a size that is profitable. For this reason, fishery dynamics should continue to be studied with consideration of microeconomics and site-specificity.

- Trends in the charter fleet are difficult to predict. Due to the nature of the business (primarily day trips with tourists), climatic and ecological variability makes this fleet particularly susceptible to volatility. Rough weather, ocean conditions, and area closures may disproportionately impact this specific fishery. This volatility, however, is homogenous across all fisheries and may lead to shifts from commercial fishing to recreational fishing, as seen in Tillamook County. This may occur because charter fleets are more dependent on tourism, rather than profitable landings. However, because the charter fleet displays vastly different business operations and behaviors, responses from that fishery did not receive advanced statistical analyses. For that reason, drawing conclusions about fishing effort is difficult.

- Fishers may shift between fisheries. Interactions with other fisheries must be taken into account when internal patterns are not apparent. Increases and decreases in effort may be indicative of fishers shifting from one fishery to another due to internal volatility or stability. Because neither groundfish nor salmon fisheries appear to provide a sufficient amount of income, fishers may participate in both and switch between the two based on fishery health. High anticipation of familial succession among second-generation charter fishers may also signal a shift from commercial to recreational fishing.

- There is no support that marine reserve designation has displaced or reduced fishing effort. The overall economic implications of marine reserve implementation are still relatively unknown. What is known is that nearshore variability, whether climatic, economic or regulatory, is likely to disproportionately impacts small-scale fishing operations. While economic losses may appear marginal, as climate variability increases, preservation and sustainable exploitation of productive fishing grounds are more becoming more important than ever. 


\section{TABLE OF CONTENTS}

Acknowledgements..........................................................................

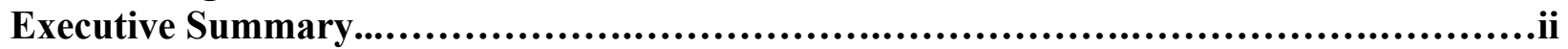

Table of Contents.........................................................................vii

Introduction.................................................................................1

Marine Reserves in Oregon................................................................1

Socioeconomic Drivers of Variability.................................................1

Human Dimensions Research.............................................................3

Project Goals and Objectives..........................................................4

Methods............................................................................................4

Survey Design............................................................................4

Sampling and Survey Implementation................................................

Data Analysis.........................................................................7

Results...............................................................................................9

Section 1. Respondent Summaries.....................................................9

Section 2. Fisher Perceptions of Management and Communication...................11

Key Findings: Section 2....................................................13

Section 3. Observed Variability in Ecological, Economic and Regulatory Fishery

Dynamics..............................................................................13

Observed Variability and Drivers of Catch Rates and Profits.................13

Observed Impacts of Marine Reserves..........................................19

Key Findings: Section 3....................................................22

Section 4. Fishery Socioeconomics and Fishing Effort...............................23

Operating Expenditures........................................................23

Observed Variability in Fishing Effort.........................................24

Perceived Drivers of Fishing Effort..........................................30

Socioeconomic Drivers of Fishing Effort......................................33

Key Findings: Section 4.....................................................37

Section 5. Familial Succession and Generation Class Projections.....................37

Industry Generation Profiles and Projected Familial Succession..............37

Socioeconomic Drivers of Familial Succession...............................43

Key Findings: Section 5....................................................44

Management Implications..............................................................45

References....................................................................................48

Appendix A: Survey Instrument.........................................................54

Appendix B: Respondent Perceptions of Management...................................62

Appendix C: Fishery Socioeconomics and Fishing Effort................................68

Appendix D: Representative Analysis Summary Report...................................72 


\section{INTRODUCTION}

\section{MARINE RESERVES IN OREGON}

In 2008, Governor Theodore Kulongoski signed Executive Order 08-07 declaring that marine reserve designations in Oregon's Territorial Sea (0-3 nautical miles from shore) have the potential to provide coastal communities and ocean users with opportunities for continued economic growth and prosperity. Soon after, the Ocean Policy Advisory Council (OPAC) comprised of representatives from state agencies, non-governmental organizations, fishers and local coastal groups began the planning process for marine reserve designations.

Shortly after Executive Order 08-07, OPAC released the decided upon objectives, principles and guidelines. The overall goal of the reserve system was to "conserve marine habitats and biodiversity; provide a framework for scientific research and effectiveness monitoring; and avoid significant adverse social and economic impacts on ocean users and coastal communities" (OPAC 2008). Key recommendations highlighted collaborative methods, utilizing local knowledge by heavily engaging with communities of interest. During the planning process, priority was given to proposals submitted by groups that worked collaboratively with coastal community members, ocean users, and other interested parties. This collaboration further reinforced the theme of bottom-up management in the state of Oregon. Following OPAC recommendations, House Bill 3013 in 2009 and Senate Bill 1510 in 2012, put forth procedures for adopting rules to establish, study, monitor, evaluate and enforce marine reserves at Otter Rock, Redfish Rocks, Cape Falcon, Cascade Head, and Cape Perpetua.

From 2012 to 2016, five marine reserves were established within Oregon's Territorial Sea: Otter Rock and Redfish Rocks were established in 2012, Cascade Head and Cape Perpetua in 2014, and Cape Falcon in 2016. These marine reserves were proposed and selected as ideal reserve sites based on ecological data and relative community/cultural importance. Each marine reserve is unique in its geomorphic and ecological composition as well as its diverse array of ocean users in which each supports. While research around marine reserves and protected areas has shown to be beneficial long term for aquatic systems, social controversies surrounding these policies have partially limited widespread implementation (Klein et al. 2008a, 2008b; Pollnac et al. 2010). Coastal resident, visitor, local business, and recreational/commercial fisher studies have been conducted in order to understand opinions surrounding marine conservation but there are currently few quantitative studies regarding how coastal communities have responded to variability within their system. The ultimate goal of this research is to understand how social, economic, behavioral, and familial dynamics are shifting over time in Oregon's commercial nearshore fishing communities.

\section{SOCIOECONOMIC DRIVERS OF VARIABILITY}

Due to Oregon's commitment to bottom up natural resource management, it is imperative to understand how the behaviors and perceptions of individuals within each stakeholder group are changing over time and potentially impacted by marine reserves. Factors such as climatic variability, market dynamics, conservation policy, and generational structures have potential to alter the ways in which ocean users interact with and rely on resource extraction. An 
investigation into shifting behaviors and community dynamics will provide local policy makers information regarding relevant stakeholders, the best ways to engage with them, and the ways in which future policy may impact them.

Fishing effort is a measurement of the resources required for fishing, such as time, capital, labor, or gear (Pascoe and Robinson 1996; Del Valle et al. 2003; Ruttan 2003). Catch per unit effort, typically measured by weight of catch per a certain time period or specific type of gear is an effective measurement used to quantify effort. This measurement is an important tool that aids fishery managers in accurately evaluating fish stocks and managing participants by estimating areas that are most heavily fished and how fisher behaviors respond to market, ecological, and climatic variability (McCluskey and Lewison 2008; Branch et al. 2006). If the total effort of a fleet increases and landings remain constant, fish stocks may be declining and profitable extraction may be more difficult. Since the turn of the century, several of Oregon's fisheries have experienced lower health and yield. Fishers' geographic locations and a variety of other socioeconomic variables, such as industry investment and scale of business have been shown to drive overall effort as well as fishing success.

"Sense of place" is a common factor that helps shape a person's perceptions of the socioeconomic impacts of marine reserves (Dalton 2004). Sense of place is often defined as a symbolic relationship to a specific place, derived from shared cultural, behavioral or emotional experiences of a group of people (Low 1992; Cross 2001). Coastal community profiles, visitor intercept surveys and commercial fishery evaluations in Oregon have revealed that sense of place shapes patterns of ocean usage and opinions on conservation and marine reserves (Package and Conway 2010a, 2010b, 2010c; Hall and Murphy 2012; Eardley and Murphy 2013; Murphy and Hall 2013). Differing opinions exist ranging from perceiving that fishing effort will be directly displaced by reserves to resenting the idea of government interference in the commercial fishing industry (Marino 2015). Furthermore, the general proximity to a reserve has the potential to disproportionately impact fishers based on their geographic location along the coast. Because of the spectrum of perceptions surrounding reserves, port of operation was a variable of observation.

Fishing capacity and scale of business operation are frequently cited factors that heavily impact a fisher's ability to participate in the fishing industry (Smith et al. 2010; Davis et al. 2017; Kirkley et al. 2001). Larger fishing vessels are typically indicative of scaled-up businesses because fishers are able to increase fishing capacity and maintain resiliency to oceanic variability. These larger business operations, however, are also often associated with higher operating costs in terms of fuel, crew, and insurance expenditures (Davis et al. 2017). In order to effectively manage fishery participants, it is imperative to understand differing business operations and fishing success dynamics when evaluating the effort and fishing pressure that each fishery supports.

Age structure and youth recruitment are two very important demographics to consider that allow managers to evaluate how workforce structure is changing and predict workforce dynamics. The United States baby boom era (1946-1964) resulted in large population increases that have resulted in uneven age class distributions. Studies project that by the year $2030,20 \%$ of the national population will be over the age of 65 (Sade 2012). "Graying" is a commonly used term 
to describe the shift within the workforce in which the average age of participants increases in tandem with the decrease of youth recruitment. Rural industries, such as timber, agriculture, and commercial fishing have experienced this graying effect (Gale 2003; Cramer and Conway 2016). Urban migration and socioeconomic barriers of entry into these industries, have largely contributed to the decline in participation of younger generations (Mabogunje 1970; Heberle 1938). Commercial fishing industries are observing a steady global decrease in recruitment and participation among younger age classes; this issue is particularly pervasive in many of Oregon's commercial fleets (Donkersloot 2011; Saputra 2016; Caracciolo 2017; Cramer \& Conway 2016).

Human migration is defined as groups of people moving from one place to another and typically occurs in four different ways; rural-rural, rural-urban, urban-rural, and urban-urban. The reasons why people choose to migrate from one community to another are defined as "push-pull" factors (Heberle 1938). Urban areas are typically associated with higher wages, standards of living, and enhanced social connectivity. In conjunction with the technological revolution, urban areas have increased mid-level career opportunities that have typically been eliminated in rural economies, such as industrial or agricultural markets (Mabogunje 1970; Heberle 1938). This type of rural to urban migration has had a direct impact on the commercial fishing industry and has ultimately contributed to decreases in fisheries participation over time (Donkersloot 2011; Caracciolo 2017).

Another commonly cited reason for decreased participation in rural, labor intensive industries are large barriers to entry. Barriers to entry are typically defined as high financial start-up costs that prevent feasible entrance of newer competitors (Demsetz 1982). Industries, such as fishing or agriculture, require large sums of upfront capital or resource investment; i.e., large swaths of land or a fishing vessel. If not inherited, the burden falls upon the new competitor to acquire sufficient capital needed to enter the market. In the fishing industry, the implementation of many catch share programs (purchased rights to take a finite number of fish) has increased values of individual take quotas, posing a massive up-front financial burden and access issue for many new fishers (Carothers 2011; Carothers and Chambers 2012; Caracciolo 2017). An increase in operating expenses and risk associated with fishing may limit new or continuous investments (Davis et al. 2017). While overall vessel revenue has been increasing since the $1960 \mathrm{~s}$, the number of fishing vessels has drastically decreased, indicating an accumulation of wealth of those who have been able to afford to participate and scale business operations (The Research Group 2013b). For younger generations, fishing as a profession is perceived to be incapable of supporting families in the modern economy due to low yields and lack of quality and quantity of jobs (Power et al. 2014). Due to these massive barriers of entry and infeasibility as a reliable career path, the commercial fishing industry on the West Coast is likely to experience decreases in youth recruitment and retention.

\section{OREGON'S MARINE RESERVES HUMAN DIMENSIONS PROGRAM}

The primary goal of the ODFW Marine Reserves Program is to evaluate how ecological and socioeconomic systems are responding to marine reserve implementation (ODFW 2017a). ODFW's human dimensions research continuously seeks to understand how different groups of ocean users depend on and interact with the ocean and its economy in Oregon. While reserves have been shown to enhance localized biodiversity and adjacent fishery production (Gell and 
Roberts 2003; Halpern 2003), eliminating fishing grounds has the potential for short-term negative socioeconomic impacts (Klein et al. 2008a, 2008b; Pollnac et al. 2010).

Economic variability and societal perceptions of reserves are at the forefront of ODFW's Human Dimensions research agenda. Spatial analyses and stakeholder perception surveys before and during reserve implementation have found a suite of positive and negative beliefs about marine reserves. Fishers predicted decreases in revenue from commercial fishing and recreational fishing, while revenue from tourism was predicted to increase (The Research Group LLC and Golden Marine Consulting 2012; The Research Group LLC 2013a). Coastal business and resident surveys found that a majority of coastal communities did not feel that the reserves would have an economic impact on the local economy (Needham et al. 2016; Epperly et al. 2017). Visitor intercept surveys have revealed overall positive perceptions of the marine reserve system by ocean users not from the Oregon coast (Swearingen et al. 2016; Swearingen and Epperly 2016). There have also been extensive research efforts to develop community profiles of several relevant fishing port towns in order to understand demographics and cultural attributes (Package and Conway 2010a, 2010b, 2010 c; Hall and Murphy 2012; Eardley and Murphy 2013; Murphy and Hall 2013). The actual economic and social impacts of marine reserves, however, are still largely unknown. Data gaps remain in understanding how commercial fishing behaviors and dynamics have shifted in response to marine reserve designation. Furthermore, research regarding familial succession within Oregon's fisheries is also sparse.

\section{PROJECT GOALS AND OBJECTIVES}

The ultimate goal of the research was to evaluate and assess the ways in which opinions, behaviors, and familial dynamics within Oregon's nearshore fishing fleets are shifting. Data were collected from permit holders within the commercial Dungeness crab, salmon troll and groundfish fisheries as well as the charter fleet. These groups operate more frequently in the nearshore and are most likely to react to variability within those areas. The overarching research objectives of this project are:

(1) Provide baseline summary statistics regarding fishing behavior, opinions of management and community engagement, and general demographics in Oregon's nearshore fleets,

(2) Identify and assess which internal and external factors explain the variability observed in fishing effort and success in Oregon's nearshore fisheries, and

(3) Evaluate shifting familial succession expectations across fishery affiliation and port group.

\section{METHODS}

\section{SURVEY DESIGN}

A mail questionnaire was used to conduct a survey for this study. Mail surveys are often used over other commonly used survey methods, such as telephone and face-to-face interviews, due to low associated costs and simplicity (Dillman 2011). In order to ensure consistent language and tone palatable for Oregon fishers, survey questions were developed in collaboration with 
members of the commercial fishing community. The Dungeness crab and salmon commissions, as well as the Oregon Trawlers Association, and volunteers within the fishing community provided feedback regarding survey structure and content. Furthermore, meetings with Fishermen Involved in Natural Energy (FINE), Fishermen's Advisory Committee for Tillamook County (FACT), Port Orford Ocean Resource Team (POORT), ODFW fishery managers and several other fishers along the coast helped streamline questions to collect relevant information that would effectively quantify fishing effort.

The survey contained 15 questions and addressed the following subject matter: fisher demographics (fishery, port, familial information), perceptions of management, drivers of profit, landing and effort variability, operating expense breakdown, fishing effort logistics, and perceptions of marine reserves (Appendix A). The survey used 5-point-Likert scale, multiple choice, ranking, and open-ended response options. In order to reduce respondent burden, fishers that held permits in more than two fisheries were instructed to select the two that contributed the most to their household income and complete the survey with respect to those two fisheries. It was assumed that two fisheries captured the most of fishery related household income. This assumption may have created modest limitations to the collected data. Fishers were also instructed to choose their primary port of operation from seven fishing port groups. Grouping fishers by operating port group is a commonly used aggregation method when collecting fisheries data. The groupings used in this study are based on ODFW groups (Figure 1; Rodomsky \& Calavan 2015; Rodomsky et al. 2016; Rodomsky and Calavan 2017). 


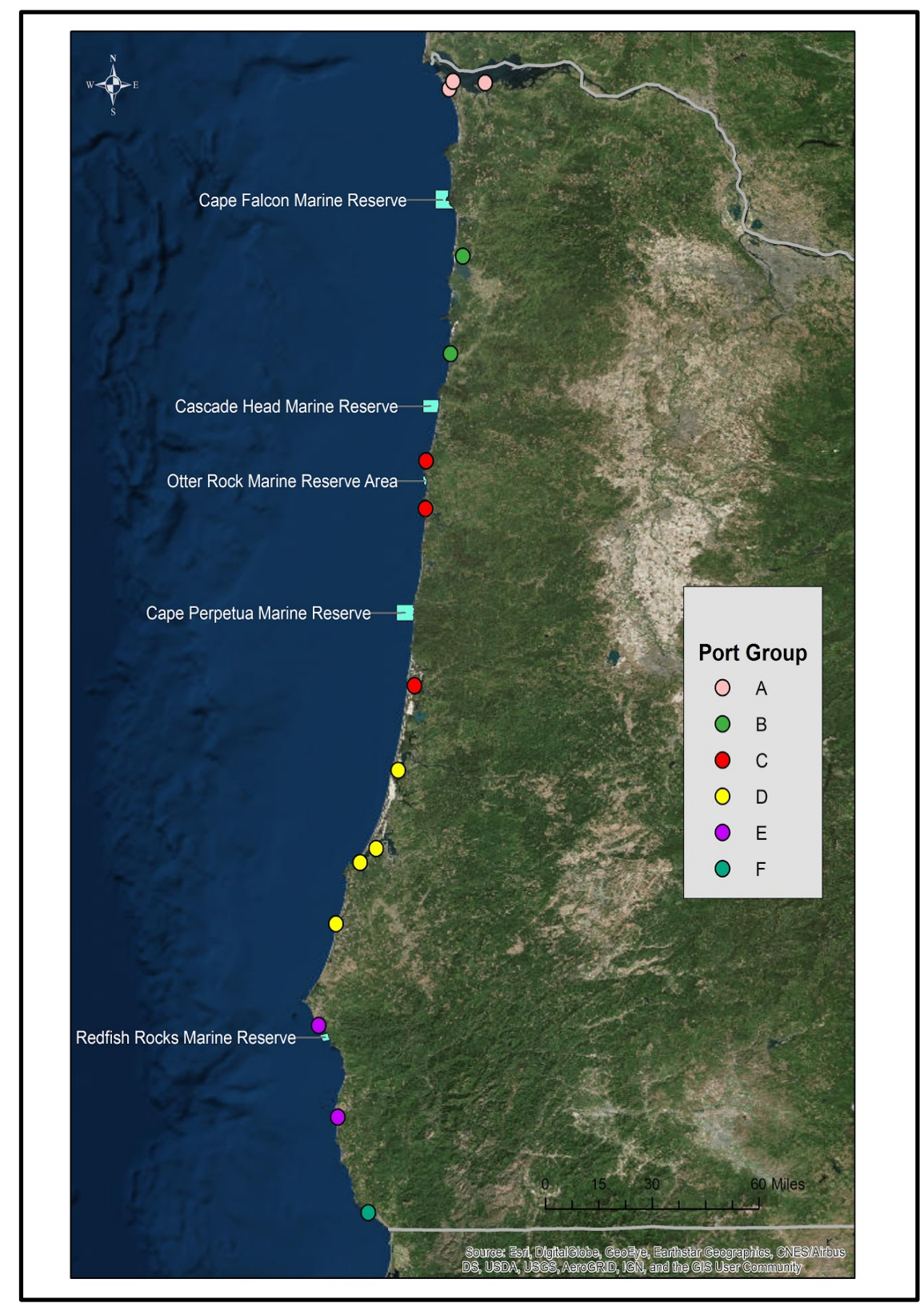

A= Clatsop County: Astoria, Warrenton, and Hammond,

$\mathrm{B}=$ Tillamook County: Garibaldi and Pacific City,

$\mathrm{C}=$ Lincoln County: Newport, Depoe Bay, and Florence,

$\mathrm{D}=$ Coos County: Coos Bay, Bandon, Charleston and, Winchester Bay,

$\mathrm{E}=$ Curry County: Port Orford and Gold Beach,

$\mathrm{F}=$ Brookings

Figure 1. Primary operating port group distribution and proximity to marine reserves. 
An operating expenditure profile was constructed by asking fishers to report the approximate percentage of operating expenses for fuel, crew, and other expenses for the years 2011, 2014, and 2017. Fishing effort was assessed for 2011, 2014, and 2017 in terms of:

- \% Household income derived from commercial fishing

- Total days fished

- Days fished in the nearshore (0-3 miles from shore)

- Total hours gear was deployed/day

- Total hours gear was deployed in the nearshore/day (0-3 miles from shore)
- Total miles traveled before deploying fishing gear/day

- Days fished in areas that are now marine reserves

- \% Fishery related income supported by catch from areas that are now marine reserves

To facilitate additional analyses, secondary landing, revenue, and vessel feature data were obtained from ODFW (2017b) and the Pacific Fisheries Information Network (2017) for each survey respondent.

\section{SAMPLING FRAME AND SURVEY IMPLEMENTATION}

Using current permit lists provided by the Oregon Department of Fish and Wildlife, mail questionnaires were sent to current permit holders in the commercial Dungeness crab, salmon and groundfish fisheries, and charter fisheries (Total $\mathrm{N}=1,097$ ). Permit holders received five items via mail during the two-month sampling period. Permit holders received an announcement post card two weeks prior, then a reminder postcard two weeks after receiving the first survey. Non-respondents were mailed a replacement survey, with a financial incentive (\$2.00 USD bill) enclosed, four weeks after receiving the initial survey. A reminder postcard was sent six weeks after receiving the initial survey.

A total of 230 surveys were returned, representing 300 individual permits. Respondents that did not complete the entire questionnaire mainly skipped questions regarding operating expenditures, fishing effort logistics or marine reserve perceptions.

\section{DATA ANALYSIS}

Summary statistics, including mean, standard deviation, and standard error were calculated for all continuous, numeric variables. Survey responses and summary statistics were separated by fishery or port group when appropriate. Kruskal-Wallis Tests were used to evaluate differences in mean responses to opinions regarding management between fishery affiliations and operating port groups. Any data transformations or standardizations are indicated in table or graph.

To assess potential nonresponse bias, an external comparative analysis revealed that survey respondents were representative of the entire sampling frame (The Research Group LLC 2018; Appendix D). The review for representativeness was primarily based on landed value distribution. Other measures reviewed for representativeness were vessel size, operating port, and permit owner residency. Permit identification numbers and associated characteristics were cross-referenced with survey respondents and compared to the characteristics of the sampling 
frame. The analysis concluded that respondents for this study closely adhered to known survey frame characteristics suggesting that calibration schemes to improve representation were not needed. Although beyond the scope of the study, a comparative analysis of nonrespondents' opinions on critical questions would strengthen validity of the conclusions herein.

Total fishing effort was calculated by multiplying the total days fished in a year by the average number of hours that fishing gear was deployed per day to give the total hours that fishing gear was deployed per year for 2011, 2014, and 2017. Repeated measures two-way ANOVAs were calculated in order analyze differences in fishing effort. Fishery, operating port group, and sampling year were factors with respondent identification number included as an error term to account for the non-independence between temporal samples. The assumption of sphericity, equal variance between all possible pairs of within-subject conditions, was tested for each parameter using the Mauchly test and adjusted using Greenhouse-Geisser corrections. Because several parameters did not meet the assumption of sphericity and were adjusted using Greenhouse-Geisser corrections, Bonferroni-Holm correction pair-wise comparisons between fisheries, operating ports, and sampling year were preformed where significant differences in effort were observed. Normality and equal variance assumptions of repeated measures ANOVA were assessed via inspection of model residuals and total fishing effort values were square rooted in order to meet assumptions.

CPUE was calculated by dividing a fisher's total annual landings (in pounds) by their reported total annual effort (hours fished). The repeated measures ANOVA revealed no significant variability in CPUE over time between 2011, 2014, and $2017^{1}$. As a result, CPUE measurements from each year were averaged to create a single CPUE value for each survey respondent. Linear mixed effects models were generated to analyze which socioeconomic drivers contributed to variability in CPUE. Due to the differences in fishing methods between each fishery, data were separated by fishery in order to generate three unique models. Vessel length, number of vessels owned, average nearshore effort (measured in total annual hours fished in the nearshore), average fuel expenditure ratio, average number of days fished in what is now a marine reserve, average percentage of income derived from marine reserves, seasonal delays/closures, and an average financial dependence on fishing were used as fixed effects while operating port and respondent identification number were used as random effects. Averages were obtained using measurements collected from the years 2011, 2014, and 2017. In order to incorporate seasonal delays and closures, each delay in the years 2011 to 2017 was given a value of 0.5 and each closure was given a value of 1 . If the seasonal delay or closure was not spatially distributed evenly, only port groups directly adjacent to closures received those values. All closures/delays for each fishery from 2011 to 2017 were added and applied as one value.

Backwards-stepwise Akaike Information Criterion (AIC) model selection was used in order to eliminate fixed effects that did not contribute to variability in average CPUE and a variance inflation factor (VIF) analysis evaluated predictor variables for multicollinearity. CPUE values were log-transformed in order to obtain normal distribution. All independent variables were standardized to make regression coefficients more easily comparable.

\footnotetext{
${ }^{1}$ Fishing effort in 2017 for the salmon fishery was significantly less than 2011 and 2014 and was excluded from linear mixed effects models in order to eliminate outliers
} 
Familial succession expectations were evaluated using a success-failure binomial probability, with 1 indicating succession of offspring in the fishing business and 0 indicating no succession of offspring. A binomial logistic regression model evaluated the impacts of fishery dynamics and scale of business operations on the expectations of familial continuation in the commercial fishing industry. Fishery affiliation, primary operating port group, average annual catch per unit effort (landings per total hours fished for years 2011, 2014 and 2017), respondent's generational standing within the fishery, financial dependence on fishery income (percentage of household income), vessel length, and number of vessels owned were used as predictor variables for succession expectations. Backwards-stepwise Akaike information criterion (AIC) model selection was used to in order to eliminate variables that did not contribute to familial succession and a variance inflation factor (VIF) analysis evaluated predictor variables for multicollinearity.

Model fit was assessed using a Chi Squared p-value of the deviance of the residuals where a pvalue $<0.05$ indicated that the model fit the data well. The McFadden and Nagelkerke $\mathrm{R}^{2}$ values were calculated to further evaluate model fit compared to a null model. An analysis of variance (ANOVA) was used to compare the full logistic model to the final logistic model. Continuous predictor variables were standardized to make coefficients more comparable. In order to keep familial succession responses binomial, respondents that indicated "Maybe" for familial succession were combined with respondents that indicated "No". Respondents who did not have children were excluded from the analysis, as they do not take part in familial successional planning.

A series of Chi-Squared tests compared fisher expectations of familial succession disaggregated by fishery affiliation and by port groups were conducted in order to identify differences between current and expected generational proportions. Current generation class proportions were based on the current generational standing indicated by the survey respondent. Expected generation class proportions were based on fisher responses to the fate of their offspring within the industry. For example, a current first-generation fisher that indicated his/her offspring would continue in the fishing industry would correlate to an expected second-generation fisher. These tests aimed to evaluate if and how generational class proportions are changing in different communities. There were no projected data for first-generation fishers and for that reason it was assumed that the number of first generation fishers remained the same for current and expected proportions. The combination scheme for "Maybe", "No" and "No Children" responses that was used for the binomial logistic regression was used in these analyses as well.

\section{RESULTS}

Section 1. Respondent Summaries. In total, 1161 surveys, representing 1446 unique permit holders (some fishers owned more than one permit in multiple fisheries). After allowing seven months for respondents to return their survey, 230 surveys, representing 300 permits were received. A $21 \%$ response rate was achieved for this study, which is comparable to other survey studies conducted with commercial fishing communities (Himes-Cornell and Kent 2014; Rodomsky and Calavan 2017). In total, 46 surveys were undeliverable and 18 possible respondents were either deceased or retired and were removed from the sample when calculating response rates (Table 1.1; Table 1.2). Fishers from the groundfish fishery responded at the highest rates, however, salmon fishers comprised the largest majority of survey respondents 
(Figure 1.2). Survey responses were received from all port groups. A few respondents who primarily landed in ports outside for Oregon were excluded from the analyses.

Table 1.1. Survey Response by mailing round, non-response and permit representation.

\begin{tabular}{|cc|}
\hline Response & $\mathrm{N}$ \\
\hline Total Surveys Mailed to Unique Addresses & 1161 \\
Total Permits Represented in Surveys Mailed to Unique Addresses & 1446 \\
$1^{\text {ST }}$ Round Returned Surveys & 122 \\
$2^{\text {nd }}$ Round Returned Surveys & 108 \\
Total Returned Surveys & 230 \\
Total Permits Represented in Returned Surveys & 300 \\
Undeliverable & 46 \\
Retired/Deceased/Does not use Permit & 18 \\
Non-Response Surveys & 867 \\
\hline
\end{tabular}

*Removed from potential respondents

Table 1.2. Respondent distribution by fishery affiliation aggregated by port group*.

\begin{tabular}{|ccccccccccc|c|c|}
\hline Fishery & $\begin{array}{c}\text { Total \# } \\
\text { Permits }\end{array}$ & CL & TL & LC & CS & CR & BR & N & $\begin{array}{c}\text { No } \\
\text { Port }\end{array}$ & $\begin{array}{c}\text { Total } \\
\text { Permits } \\
\text { Returned }\end{array}$ & $\begin{array}{c}\text { Fishery } \\
\text { Response } \\
\text { Rate }\end{array}$ & $\begin{array}{c}\% \text { Survey } \\
\text { Respondents }\end{array}$ \\
\hline $\begin{array}{c}\text { Charter } \\
\text { Dungeness }\end{array}$ & 75 & 2 & 5 & 12 & 3 & 4 & 0 & 2 & 2 & 30 & $37 \%$ & $10 \%$ \\
crab & 378 & 22 & 10 & 20 & 9 & 9 & 8 & 16 & 4 & 98 & $25 \%$ & $33 \%$ \\
Groundfish & 101 & 3 & 7 & 8 & 5 & 13 & 5 & 1 & 2 & 44 & $42 \%$ & $15 \%$ \\
Salmon & 892 & 18 & 19 & 23 & 22 & 3 & 7 & 21 & 15 & 128 & $13 \%$ & $42 \%$ \\
Total & $\mathbf{1 4 4 6}$ & $\mathbf{4 5}$ & $\mathbf{4 1}$ & $\mathbf{6 3}$ & $\mathbf{3 9}$ & $\mathbf{2 9}$ & $\mathbf{2 0}$ & $\mathbf{4 0}$ & $\mathbf{2 3}$ & $\mathbf{3 0 0}$ & $\mathbf{2 1 \%}$ & $\mathbf{1 0 0 \%}$ \\
\hline
\end{tabular}

*Port Group Codes: $\mathrm{CL}=$ Clatsop, $\mathrm{TL}=$ Tillamook, $\mathrm{LC}=$ Lincoln $, \mathrm{CS}=\mathrm{Coos}, \mathrm{CR}=\mathrm{Curry}, \mathrm{BR}=\mathrm{Brookings}$ and, $\mathrm{N}=$ Port not in Oregon. 


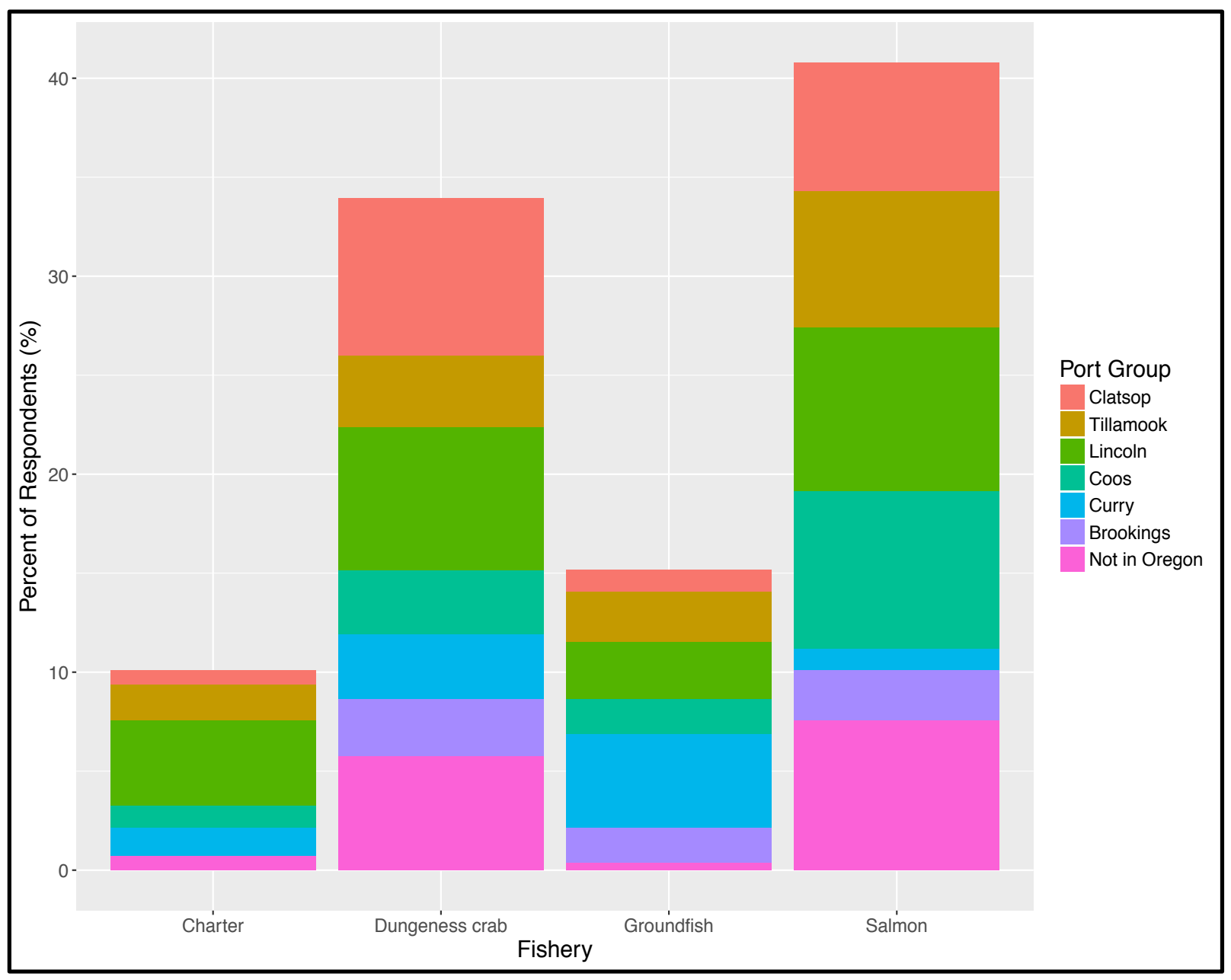

$\mathrm{N}=300$; Charter $(\mathrm{N}=28)$, Dungeness crab $(\mathrm{N}=94)$, groundfish $(\mathrm{N}=42)$ and salmon $(\mathrm{N}=113)$

\section{Figure 1.1. Respondent fishery by port.}

Section 2. Fisher Perceptions of Management and Communication. Respondents were asked to indicate their degree of agreement with a series of questions regarding perceptions of management based on a five-point scale: $-2=$ Strongly Disagree, $-1=$ Disagree, $0=$ Neutral, $+1=$ Agree, $+2=$ Strongly Agree. Chi-squared tests compared actual response proportions to randomly distributed response proportions. Results indicated that responses were not normally distributed and that there were patterns in responses (Table 2.1). When prompted about advocacy, a general consensus among fishers was that public agencies have performed moderately poor in terms of advocating for personal and fishery specific interests (Median=-1). Fishers exhibited neutral opinions regarding the frequency and quality of agency to stakeholder communication and of accessibility to scientific research occurring on the Oregon coast (Median=0). Fishers held moderately positive opinions concerning comfort in voicing concerns and relative accessibility to information regarding policy/regulatory changes on the Oregon coast (Median=+1; Table 2.2). Kruskal-Wallis Tests were used to evaluate differences in mean responses to opinions regarding management between fishery affiliations and operating port groups. When separated by port group, responses regarding personal interest, fishery interest, agency communication, and 
research accessibility were typically more neutral for fishers that do not operate in Oregon. Fishers operating out of the Brookings port group displayed more negative views regarding agency advocacy for personal interests (Table 2.3; Appendix B, Table B.1, Table B.2). Responses did not differ by fishery affiliation (Appendix B, Table B.3).

Table 2.1. Aggregated frequencies of participant responses to perceptions of management.

\begin{tabular}{|c|c|c|c|c|c|c|c|}
\hline \multirow{2}{*}{ Statement } & \multicolumn{5}{|c|}{ Degree of Agreement } & \multirow[b]{2}{*}{$\chi^{2}$} & \multirow[b]{2}{*}{$\mathrm{P}$} \\
\hline & $\mathrm{SD}$ & $\mathrm{D}$ & $\mathrm{N}$ & A & $\mathrm{SA}$ & & \\
\hline $\begin{array}{l}\text { Public agencies have done a good job advocating for my } \\
\text { personal interests }\end{array}$ & 83 & 94 & 61 & 34 & 3 & 98 & $1 \mathrm{E}-20$ \\
\hline $\begin{array}{l}\text { Public agencies have done a good job advocating for the } \\
\text { interests of the fisheries in which I participate }\end{array}$ & 69 & 91 & 53 & 53 & 9 & 66 & $2 \mathrm{E}-13$ \\
\hline $\begin{array}{l}\text { Public agencies adequately communicated issues regarding } \\
\text { Oregon fishery management to my local community }\end{array}$ & 44 & 53 & 77 & 83 & 18 & 50 & $3 \mathrm{E}-10$ \\
\hline $\begin{array}{l}\text { I am satisfied with the amount of contact I have with } \\
\text { agency representatives }\end{array}$ & 28 & 34 & 110 & 78 & 25 & 102 & $3 \mathrm{E}-21$ \\
\hline $\begin{array}{l}\text { I feel comfortable voicing my opinions about Oregon ocean } \\
\text { management and policy to public agencies }\end{array}$ & 17 & 26 & 82 & 84 & 66 & 72 & $7 \mathrm{E}-15$ \\
\hline $\begin{array}{c}\text { I know where to obtain information about policy changes } \\
\text { regarding Oregon ocean issues }\end{array}$ & 26 & 31 & 49 & 115 & 54 & 92 & $5 \mathrm{E}-19$ \\
\hline $\begin{array}{l}\text { I know where to obtain information about scientific } \\
\text { research regarding Oregon ocean issues }\end{array}$ & 42 & 58 & 69 & 69 & 37 & 16 & 0.003 \\
\hline
\end{tabular}

$\mathrm{N}=275$

Table 2.2. Respondent perceptions of management.

\begin{tabular}{|c|c|c|c|c|}
\hline Statement & Mean* & Median* & SD & SE \\
\hline $\begin{array}{l}\text { Public agencies have done a good job advocating for my } \\
\text { personal interests }\end{array}$ & -0.80 & -1 & 1.04 & 0.06 \\
\hline $\begin{array}{l}\text { Public agencies have done a good job advocating for the } \\
\text { interests of the fisheries in which I participate }\end{array}$ & -0.68 & -1 & 1.15 & 0.07 \\
\hline $\begin{array}{l}\text { Public agencies adequately communicate issues regarding } \\
\text { Oregon fishery management to my local fishing community }\end{array}$ & -0.18 & 0 & 1.18 & 0.07 \\
\hline $\begin{array}{l}\text { I am satisfied with the amount of contact I have with } \\
\text { agency representatives }\end{array}$ & 0.14 & 0 & 1.08 & 0.07 \\
\hline $\begin{array}{l}\text { I feel comfortable voicing my opinions about Oregon ocean } \\
\text { management and policy to public agencies }\end{array}$ & 0.57 & +1 & 1.13 & 0.07 \\
\hline $\begin{array}{c}\text { I know where to obtain information about policy changes } \\
\text { regarding Oregon ocean issues }\end{array}$ & 0.51 & +1 & 1.20 & 0.07 \\
\hline $\begin{array}{l}\text { I know where to obtain information about scientific } \\
\text { research regarding Oregon ocean issues }\end{array}$ & 0.00 & 0 & 1.27 & 0.08 \\
\hline
\end{tabular}

Likert Scale ranged from Strongly Disagree (-2) to Strongly Agree (2) $\mathrm{N}=275$ 
Table 2.3. Response to perceptions of management, grouped by statistically significant differences between operating port groups.

\begin{tabular}{|c|c|c|c|c|c|}
\hline Statement & \multicolumn{5}{|c|}{ Response Percentages } \\
\hline Public agencies have done a good job advocating for my personal interests & $\mathrm{SD}$ & $\mathrm{D}$ & $\mathrm{N}$ & A & SA \\
\hline Aggregated ports* $(\mathrm{N}=215)$ & $30 \%$ & $37 \%$ & $19 \%$ & $13 \%$ & $1 \%$ \\
\hline Brookings port $(\mathrm{N}=20)$ & $60 \%$ & $30 \%$ & $10 \%$ & $0 \%$ & $0 \%$ \\
\hline Port not in Oregon $(\mathrm{N}=40)$ & $18 \%$ & $20 \%$ & $53 \%$ & $10 \%$ & $0 \%$ \\
\hline $\begin{array}{l}\text { Public agencies have done a good job advocating for the interests of the } \\
\text { fisheries in which I participate }\end{array}$ & $\mathrm{SD}$ & $\mathrm{D}$ & $\mathrm{N}$ & A & SA \\
\hline Aggregated ports $\wedge(\mathrm{N}=235)$ & $28 \%$ & $34 \%$ & $17 \%$ & $18 \%$ & $3 \%$ \\
\hline Port not in Oregon $(\mathrm{N}=40)$ & $10 \%$ & $28 \%$ & $33 \%$ & $25 \%$ & $5 \%$ \\
\hline $\begin{array}{l}\text { Public agencies adequately communicate issues regarding Oregon fishery } \\
\text { management to my local fishing community }\end{array}$ & $\mathrm{SD}$ & $\mathrm{D}$ & $\mathrm{N}$ & A & $\mathrm{SA}$ \\
\hline Aggregated ports $^{\wedge}(\mathrm{N}=235)$ & $18 \%$ & $22 \%$ & $25 \%$ & $29 \%$ & $6 \%$ \\
\hline Port not in Oregon $(\mathrm{N}=40)$ & $3 \%$ & $5 \%$ & $48 \%$ & $38 \%$ & $8 \%$ \\
\hline $\begin{array}{l}\text { I know where to obtain information about scientific research regarding } \\
\text { Oregon ocean issues }\end{array}$ & SD & $\mathrm{D}$ & $\mathrm{N}$ & A & SA \\
\hline Aggregated ports $^{\wedge}(\mathrm{N}=235)$ & $17 \%$ & $23 \%$ & $23 \%$ & $25 \%$ & $13 \%$ \\
\hline Port not in Oregon $(\mathrm{N}=40)$ & $5 \%$ & $10 \%$ & $40 \%$ & $28 \%$ & $18 \%$ \\
\hline
\end{tabular}

*Aggregated port groups=Clatsop, Tillamook, Lincoln, Coos and Curry

$\wedge$ Aggregated port groups $=$ Clatsop, Tillamook, Lincoln, Coos, Curry and Brookings $\mathrm{N}=275$

Key Findings: Section 2.

- Respondents did not feel that public agencies have effectively advocated for individual and fishery interests.

- Respondents held neutral opinions regarding the quantity and quality of communication with public agency representatives and their general accessibility to scientific research.

- Respondents felt comfortable voicing their opinions regarding management and policy to public agencies and that information regarding policy changes was accessible.

- General opinions regarding management and policy did not differ between fishery affiliations.

- Fishers that do not operate in a port group in Oregon typically held more neutral opinions regarding management.

\section{Section 3. Observed Variability in Ecological, Economic and Regulatory Fishery Dynamics}

Observed Variability and Drivers of Catch Rates and Profits. Respondents were asks to indicate observed patterns in personal catch rates and fishery related profits on a five-point scale: $-2=$ Large Decreases, $-1=$ Moderate Decreases, $0=$ Decreases and Increases, $+1=$ Moderately Increases, $+2=$ Large Increases. Chi-squared tests compared actual response proportions to randomly distributed response proportions. Chi-squared goodness of fit tests indicated that responses were not evenly distributed and that there were patterns in responses, with the 
exception of responses for catch rates for the charter fishery (Table 3.1). When separated based on fishery affiliation, catch rates and profits for the Dungeness crab and the groundfish fisheries displayed no discernable pattern in observed catch rates or profits, with most fishes indicating that they have experience both increases and decreases in catch rates and profits (Table 3.2). The salmon fishery, however, reported moderate and large decreases in catch rates and profits, and the charter fisher reported reductions in profits (Table 3.2). Results from analyses of fishers' top three drivers of variability revealed that in general, the same drivers determined catch rates and profits. When aggregated, regulations and ocean conditions were identified as the largest drivers of catch rate variability $(20 \%, 17 \%$, respectively; Table 3.3; Figure 3.1$)$. Regulations, operating expenses, and ocean conditions were identified as the largest drivers of profit $(17 \%, 17 \%, 16 \%$, respectively; Table 3.3; Figure 3.2).

Table 3.1. Perceived temporal variability of personal catch rates and profits.

\begin{tabular}{|ccccccccc|}
\hline Fishery & Variable & LD & MD & N & MI & LI & $\chi^{2}$ & P \\
\hline Aggregated & Catch Rate & 97 & 43 & 92 & 33 & 6 & 111 & $3 \mathrm{E}-23$ \\
$(\mathrm{~N}=291)$ & Profit & 87 & 43 & 108 & 36 & 3 & 127 & $2 \mathrm{E}-16$ \\
\hline Charter & Catch Rate & 7 & 10 & 7 & 5 & 1 & 7.33 & 0.11 \\
$(\mathrm{~N}=30)$ & Profit & 12 & 5 & 6 & 7 & 0 & 12.3 & 0.01 \\
\hline Dungeness crab & Catch Rate & 4 & 10 & 54 & 16 & 3 & 102 & $3 \mathrm{E}-21$ \\
$(\mathrm{~N}=97)$ & Profit & 2 & 8 & 62 & 19 & 1 & 140 & $2 \mathrm{E}-29$ \\
\hline Groundfish & Catch Rate & 9 & 4 & 15 & 10 & 1 & 15.3 & 0.004 \\
$(\mathrm{~N}=40)$ & Profit & 5 & 8 & 17 & 7 & 1 & 18.3 & 0.001 \\
\hline Salmon & Catch Rate & 77 & 19 & 16 & 2 & 1 & 169 & $1 \mathrm{E}-35$ \\
$(\mathrm{~N}=124)$ & Profit & 68 & 22 & 23 & 3 & 1 & 124 & $6 \mathrm{E}-26$ \\
\hline
\end{tabular}

Table 3.2. Perceived temporal variability of catch rates and profits by fishery affiliation.

\begin{tabular}{|cccccc|}
\hline Fishery & Variable & Mean & Median & SD & SE \\
\hline Aggregated & Catch Rate & -0.5 & 0 & 1.44 & 0.08 \\
$(\mathrm{~N}=291)$ & Profit & -0.5 & 0 & 1.31 & 0.08 \\
\hline Charter & Catch Rate & -0.60 & -1 & 1.14 & 0.21 \\
$(\mathrm{~N}=30)$ & Profit & -0.30 & -1 & 1.23 & 0.22 \\
\hline Dungeness crab & Catch Rate & 0.40 & 0 & 1.17 & 0.12 \\
$(\mathrm{~N}=97)$ & Profit & 0.40 & 0 & 0.90 & 0.09 \\
\hline Groundfish & Catch Rate & -0.20 & 0 & 1.26 & 0.2 \\
$(\mathrm{~N}=40)$ & Profit & -0.10 & 0 & 1.21 & 0.19 \\
\hline Salmon & Catch Rate & -1.20 & -2 & 1.43 & 0.13 \\
$(\mathrm{~N}=124)$ & Profit & -1.10 & -2 & 1.35 & 0.12 \\
\hline
\end{tabular}

Likert scale ranges from Large Decreases, $(-2)$ to Large Increases (+2) 
Table 3.3. Perceived top three drivers of personal catch rates and profits.

\begin{tabular}{|ccccc|}
\hline & \multicolumn{2}{c}{ Catch Rate $(\mathrm{N}=774)$} & \multicolumn{2}{c|}{ Profit $(\mathrm{N}=664)$} \\
\cline { 2 - 5 } Driver of Variability & Frequency & Percent $(\%)$ & Frequency & Percent $(\%)$ \\
\hline Regulations & 156 & 20 & 115 & 17 \\
Ocean Conditions & 134 & 17 & 104 & 16 \\
Weather Conditions & 103 & 13 & 84 & 13 \\
Catch Limits & 101 & 13 & 75 & 11 \\
Operating Expenses & 102 & 13 & 111 & 17 \\
Market Prices & 81 & 10 & 92 & 14 \\
Catch Per Unit Effort & 61 & 8 & 55 & 8 \\
Other & 36 & 5 & 28 & 4 \\
\hline
\end{tabular}

Each respondent was directed to select up to three drivers

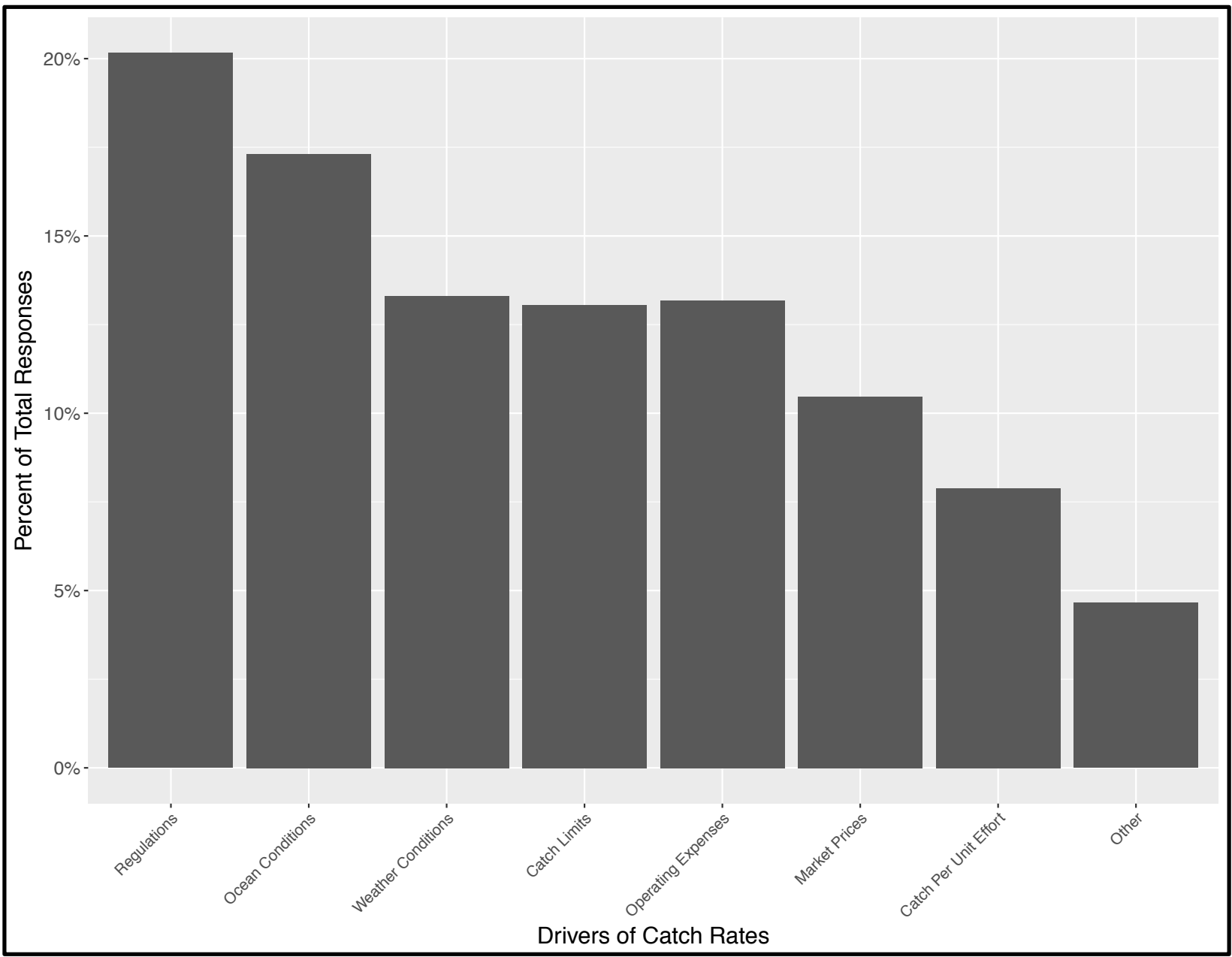

Each participant was directed to select up to three drivers. $(\mathrm{N}=774)$

Figure 3.1. Perceived top three drivers of personal catch rates. 


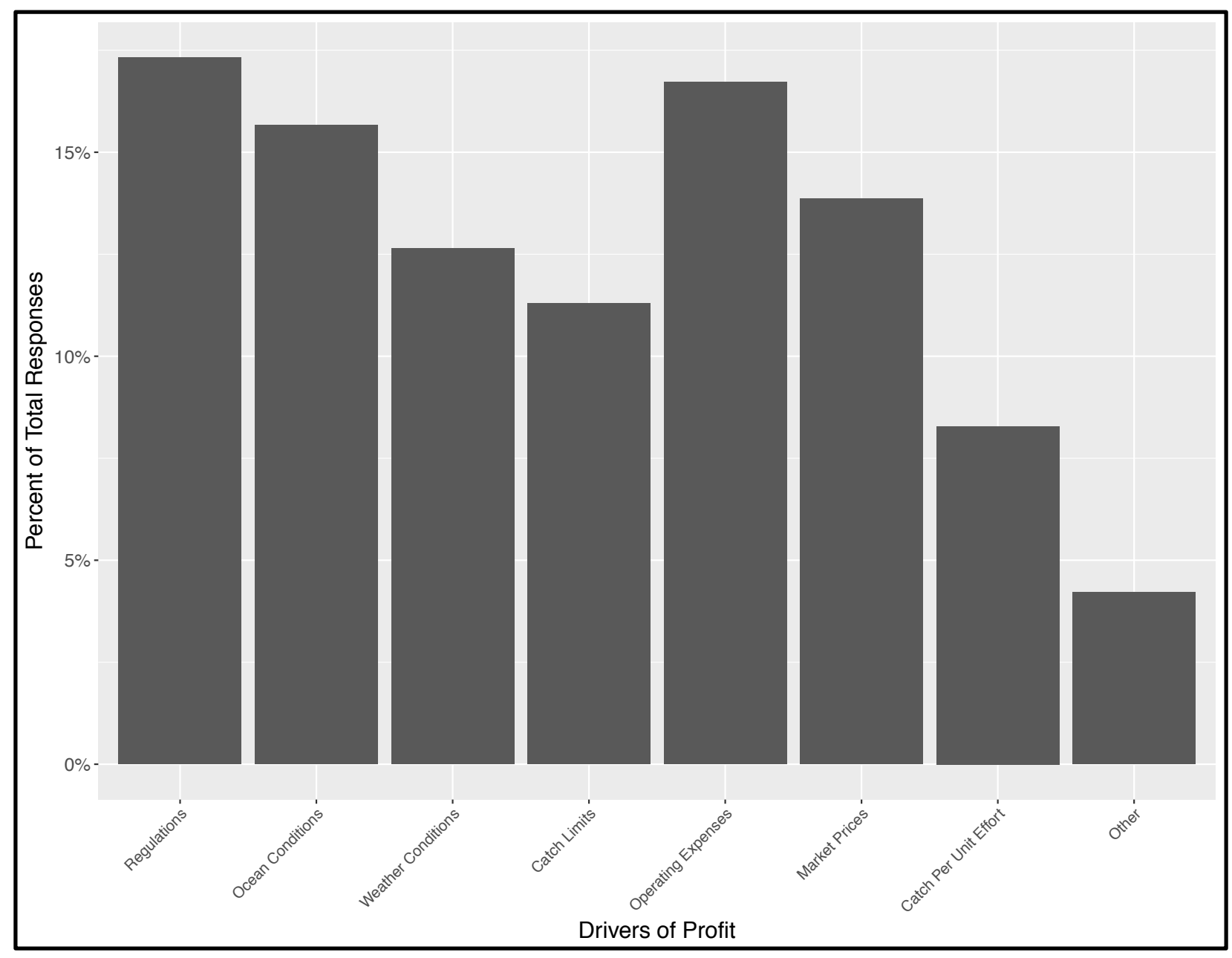

Each participant was directed to select up to three drivers $(\mathrm{N}=664)$

\section{Figure 3.2. Perceived top three drivers of personal profits.}

When compared across the fisheries, the drivers of variability were fishery specific. Charter fishers and salmon fishers both indicated that regulations $(30 \%, 27 \%)$, ocean conditions $(19 \%$, $15 \%)$, and catch limits $(19 \%, 16 \%)$ were the main drivers of catch rates, respectively. Dungeness crab fishers indicated that weather conditions, ocean conditions, and market prices were the main drivers of catch rates $(19 \%, 18 \%, 18 \%$, respectively). Groundfish fishers indicated that catch limits, ocean conditions, and operating expenses were the main drivers of catch rates $(21 \%, 20 \%$, $14 \%$, respectively; Table 3.4; Figure 3.3). Profits in the charter fishery appeared to be driven by regulations, ocean conditions, and weather conditions/catch limits $(32 \%, 17 \%, 15 \%$, respectively). Market prices, operating expenses, and ocean conditions were the main drivers of profit in the Dungeness crab fishery $(22 \%, 19 \%, 17 \%$, respectively). Groundfish fishers indicated that catch limits, operating expenses, and ocean conditions/market prices were the main drivers of profit $(22 \%, 18 \%, 18 \%$, respectively). While, catch limits and operating expenses were still important, regulations appeared to be the largest drivers of profits within the salmon fishery $(15 \%, 18 \%, 22 \%$, respectively; Table 3.4; Figure 3.4). 
Table 3.4. Participant selections of top three drivers of personal catch rates and profits.

\begin{tabular}{|ccccccccc|}
\hline & \multicolumn{2}{c}{$\begin{array}{c}\text { Charter }^{\#} \\
(\mathrm{~N}=73, \mathrm{~N}=65)\end{array}$} & $\begin{array}{c}\text { Dungeness } \mathrm{crab}^{\#} \\
(\mathrm{~N}=262, \mathrm{~N}=231)\end{array}$ & $\begin{array}{c}\text { Groundfish } \\
(\mathrm{N}=104, \mathrm{~N}=95)\end{array}$ & \multicolumn{2}{c|}{$\begin{array}{c}\text { Salmon\# } \\
(\mathrm{N}=335, \mathrm{~N}=273)\end{array}$} \\
\cline { 2 - 9 } Driver of Variability & $\mathrm{N}^{\#}$ & $\begin{array}{c}\text { Response }^{\#} \\
(\%)\end{array}$ & $\mathrm{N}^{\#}$ & $\begin{array}{c}\text { Response }^{\#} \\
(\%)\end{array}$ & $\mathrm{N}^{\#}$ & $\begin{array}{c}\text { Response }^{\#} \\
(\%)\end{array}$ & $\mathrm{N}^{\#}$ & $\begin{array}{c}\text { Response }^{\#} \\
(\%)\end{array}$ \\
\hline Regulations & 22,21 & 30,32 & 31,23 & 12,10 & 13,11 & 13,12 & 90,60 & 27,22 \\
Ocean Conditions & 14,39 & 19,17 & 48,39 & 18,17 & 21,15 & 20,16 & 51,39 & 15,14 \\
Weather Conditions & 9,10 & 12,15 & 50,37 & 19,16 & 14,11 & 13,12 & 30,26 & 9,10 \\
Catch Limits & 14,10 & 19,15 & 10,3 & 4,1 & 22,21 & 21,22 & 55,41 & 16,15 \\
Operating Expenses & 8,7 & 11,11 & 38,43 & 10,19 & 10,13 & 14,18 & 46,48 & 14,18 \\
Market Prices & 0,0 & 0,0 & 48,51 & 18,22 & 11,15 & 11,16 & 22,26 & 7,10 \\
Catch Per Unit Effort & 3,4 & 4,6 & 23,22 & 9,10 & 9,6 & 9,6 & 26,23 & 8,8 \\
Other & 3,2 & 4,3 & 14,13 & 5,6 & 4,3 & 4,3 & 15,10 & 4,4 \\
\hline
\end{tabular}

Each participant was directed to select up to three drivers

${ }^{\#}$ First number=Catch rate variability responses, second number=Fishery related profit variability responses 


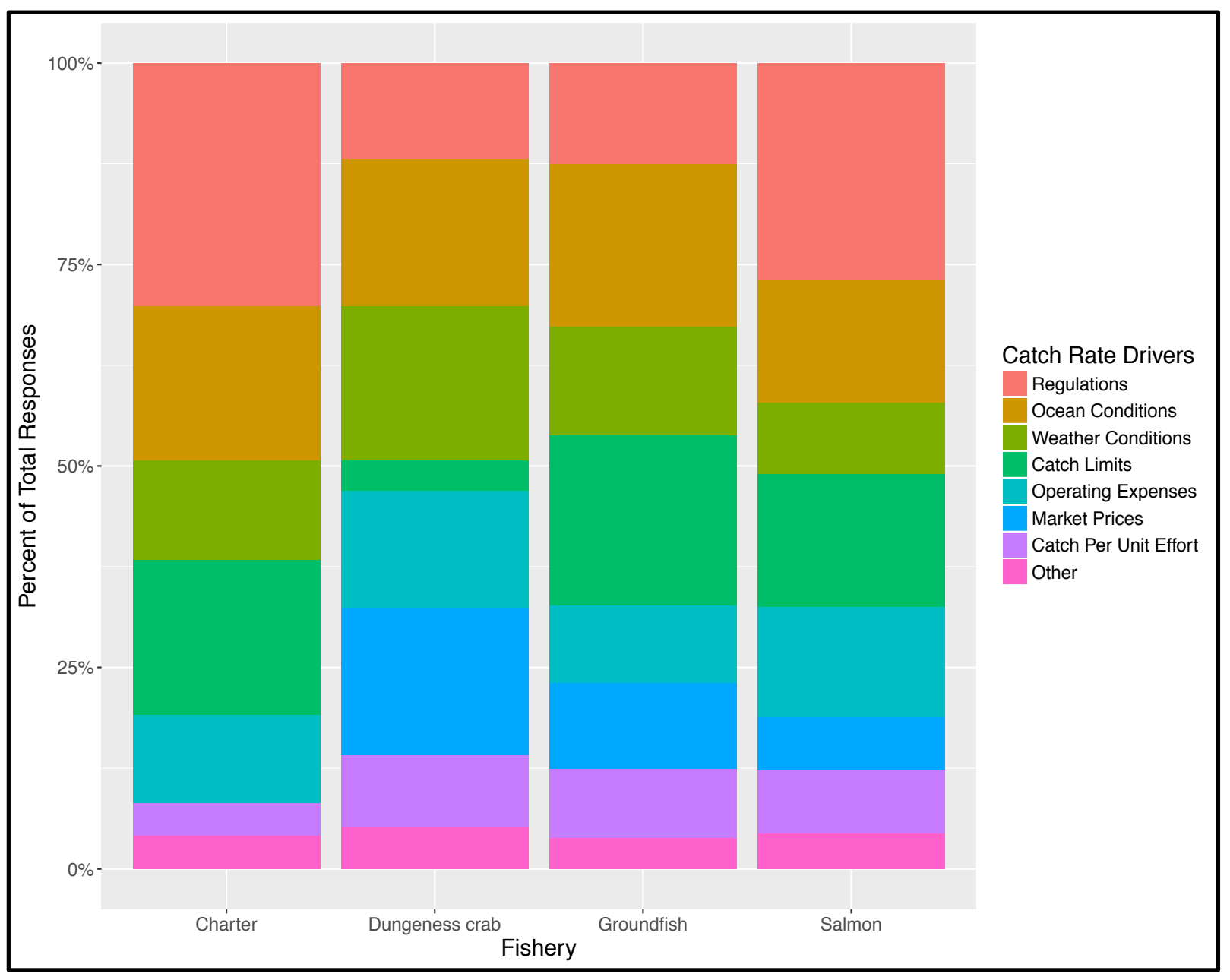

$(\mathrm{N}=774)$; Charter $(\mathrm{N}=73)$, Dungeness crab $(\mathrm{N}=262)$, groundfish $(\mathrm{N}=104)$ and salmon $(\mathrm{N}=335)$ Each participant was directed to select up to three drivers.

\section{Figure 3.3. Participant selections of top three drivers of personal catch rates}




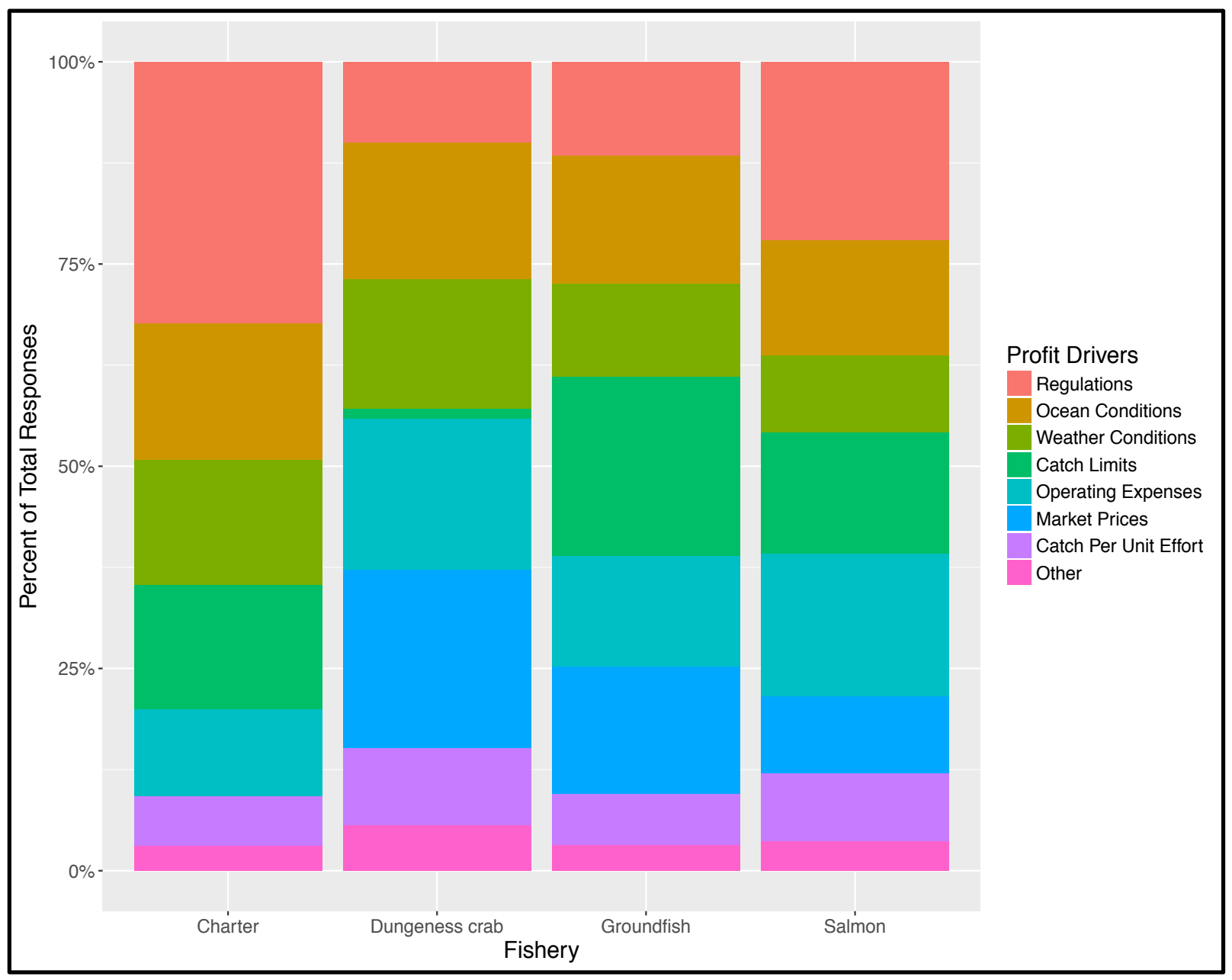

$\mathrm{N}=664$; Charter $(\mathrm{N}=65)$, Dungeness crab $(\mathrm{N}=231)$, groundfish $(\mathrm{N}=95)$ and salmon $(\mathrm{N}=273)$ Each participant was directed to select up to three drivers

\section{Figure 3.4. Participant selections of top three drivers of personal profits.}

Perceived Impacts of Marine Reserves. Respondents were asked to indicate the degree of impact that marine reserve implementation has had on their ability to participate in their fishery on a five-point scale: $-2=$ Largely Negative, $-1=$ Moderately Negative, $0=$ No Clear Impacts, $+1=$ Moderately Positive, $+2=$ Largely Positive. When prompted to indicate whether or not marine reserves have had any impact, positive or negative, on fishery participation, the general consensus was that marine reserve implementation has had no clear impact (Table 3.5).

When compared by fishery affiliation, fisher's still indicated that reserves have had no clear impact on fishery participation, with very small leanings towards negative impacts (Table 3.6). This was further reinforced when fishers were asked to select the top impacts experienced by marine reserve implementation and the overwhelming response was no impacts $(61 \%$; Table 3.7). Indications of displacement of fishing, increased spatial competition, and increases travel distances to fish were evenly distributed among aggregated responses as well as fishery dependent responses (Figure 3.5; Figure 3.6). While a majority of Dungeness crab fishers 
indicated that there have not been any impacts of marine reserve implementation, (52\%; Table 3.8), there appeared to be a broader range of responses.

Table 3.5. Perceived impacts of marine reserve implementation.

\begin{tabular}{|cccccccc|}
\hline Fishery & LN & MN & NCI & MP & LP & $\chi^{2}$ & P \\
\hline Aggregated (N=239) & 24 & 32 & 106 & 4 & 1 & 217 & $5 \mathrm{E}-46$ \\
Charter $(\mathrm{N}=20)$ & 6 & 3 & 11 & 0 & 0 & 21.5 & 0.0003 \\
Dungeness crab $(\mathrm{N}=78)$ & 10 & 25 & 38 & 4 & 1 & 62 & $1 \mathrm{E}-12$ \\
Groundfish $(\mathrm{N}=35)$ & 9 & 10 & 13 & 2 & 1 & 15.7 & 0.003 \\
Salmon $(\mathrm{N}=106)$ & 16 & 19 & 61 & 1 & 9 & 102 & $3 \mathrm{E}-21$ \\
\hline
\end{tabular}

Likert scale ranges from Largely Negative (-2) to Largely Positive (+2)

Table 3.6. Perceived impacts marine reserve implementation, by fishery affiliation.

\begin{tabular}{|ccccc|}
\hline Fishery & Mean* & Median* & SD & SE \\
\hline Aggregated $(\mathrm{N}=239)$ & -0.5 & 0 & 0.78 & 0.06 \\
Charter $(\mathrm{N}=20)$ & -0.6 & 0 & 0.91 & 0.24 \\
Dungeness crab $(\mathrm{N}=78)$ & -0.4 & 0 & 0.81 & 0.11 \\
Groundfish $(\mathrm{N}=35)$ & -0.5 & 0 & 0.94 & 0.2 \\
Salmon $(\mathrm{N}=106)$ & -0.5 & 0 & 0.72 & 0.08 \\
\hline
\end{tabular}

Likert scale ranges from Largely Negative (-2) to Largely Positive (+2)

Table 3.7. Aggregated participant selections of top impacts of marine reserves.

\begin{tabular}{|ccc|}
\hline Impact & Frequency & Percent (\%) \\
\hline Displacement of Fishing & 69 & 14 \\
Increased Spatial Competition & 62 & 13 \\
Increased Travel Distances to Fish & 59 & 12 \\
No Impacts & 297 & 61 \\
\hline
\end{tabular}

Each participant was directed to select up to three impacts $\mathrm{N}=497$ 


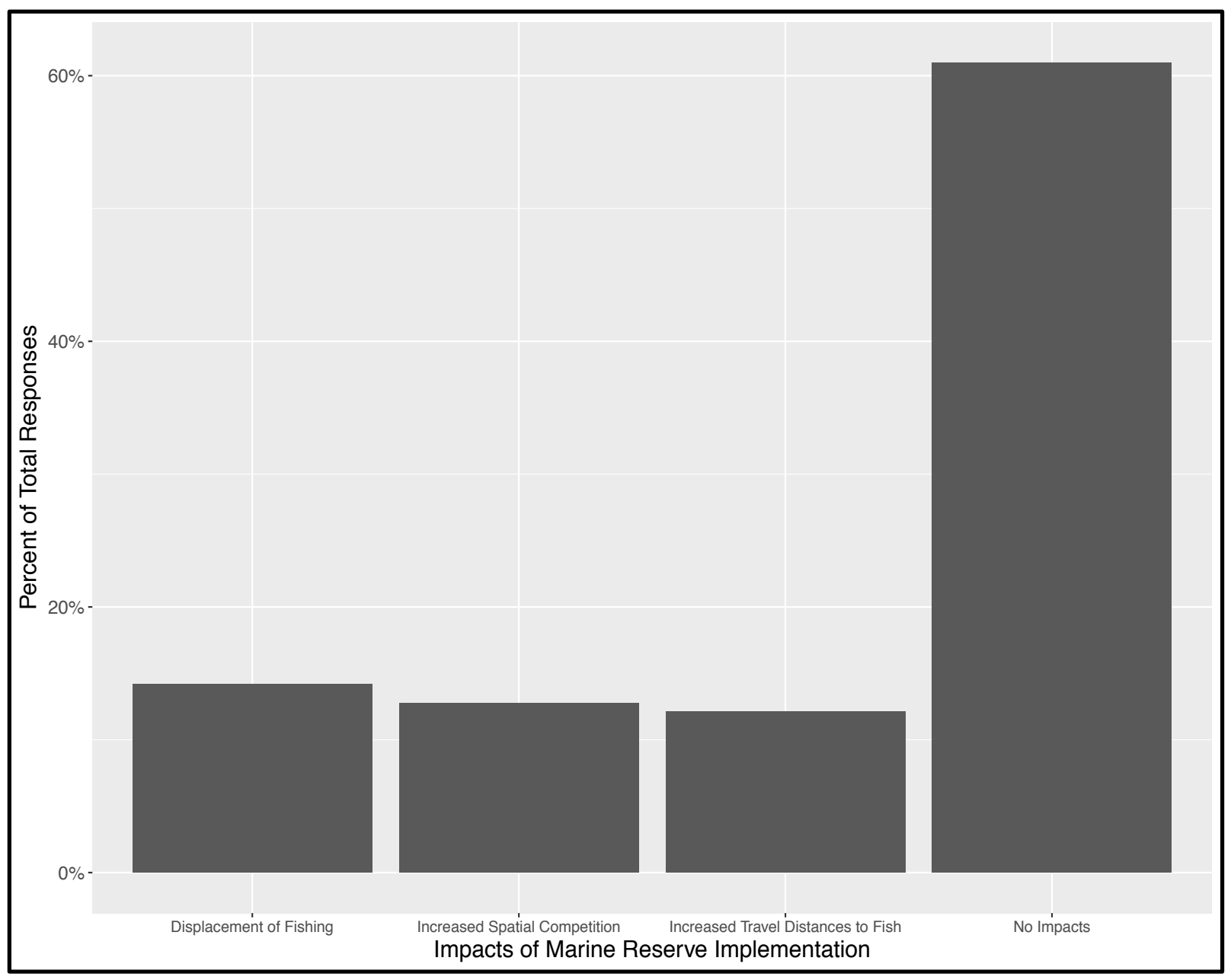

Each participant was directed to select up to three drivers $\mathrm{N}=487$

Figure 3.5. Perceived impacts of marine reserve implementation.

Table 3.8. Perceived impacts of marine reserve implementation, by fishery affiliation.

\begin{tabular}{|c|c|c|c|c|c|c|c|c|}
\hline \multirow[b]{2}{*}{ Impact } & \multicolumn{2}{|c|}{$\begin{array}{l}\text { Charter } \\
(\mathrm{N}=42)\end{array}$} & \multicolumn{2}{|c|}{$\begin{array}{l}\text { Dungeness crab } \\
\qquad(\mathrm{N}=155)\end{array}$} & \multicolumn{2}{|c|}{$\begin{array}{l}\text { Groundfish } \\
(\mathrm{N}=65)\end{array}$} & \multicolumn{2}{|c|}{$\begin{array}{l}\text { Salmon } \\
(\mathrm{N}=225)\end{array}$} \\
\hline & Freq. & $\begin{array}{c}\text { Percent } \\
(\%)\end{array}$ & Freq. & $\begin{array}{c}\text { Percent } \\
(\%)\end{array}$ & Freq. & $\begin{array}{c}\text { Percent } \\
(\%)\end{array}$ & Freq. & $\begin{array}{c}\text { Percent } \\
(\%)\end{array}$ \\
\hline Displacement of Fishing & 4 & $10 \%$ & 28 & $18 \%$ & 9 & $14 \%$ & 28 & $12 \%$ \\
\hline Increased Spatial Competition & 2 & $5 \%$ & 26 & $17 \%$ & 8 & $12 \%$ & 26 & $12 \%$ \\
\hline Increased Travel Distances to Fish & 3 & $7 \%$ & 21 & $14 \%$ & 8 & $12 \%$ & 27 & $12 \%$ \\
\hline No Impacts & 33 & $79 \%$ & 80 & $52 \%$ & 40 & $62 \%$ & 144 & $64 \%$ \\
\hline
\end{tabular}

Each participant was directed to select up to three impacts $\mathrm{N}=487$ 


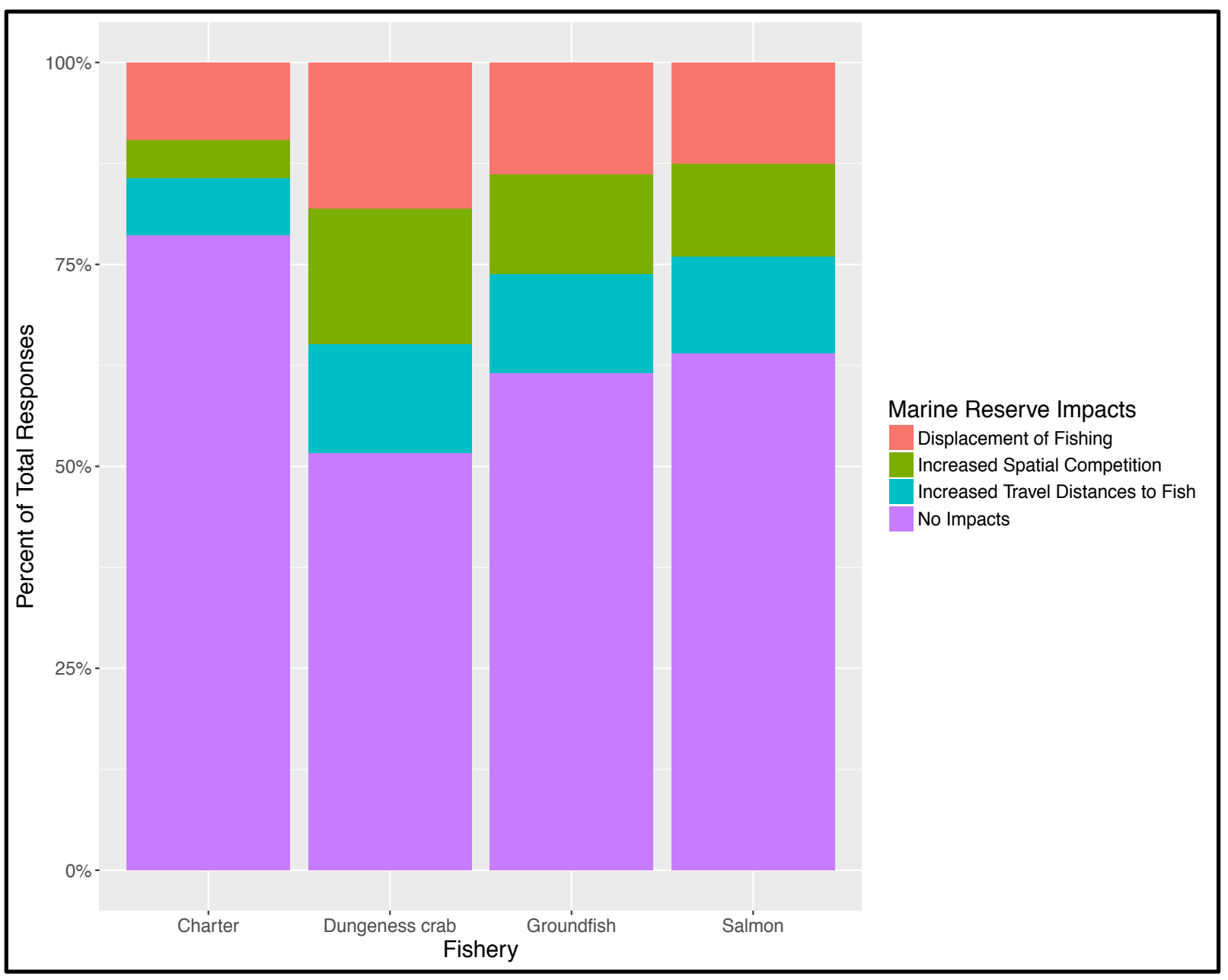

Each participant was directed to select up to three drivers $\mathrm{N}=487$; Charter $(\mathrm{N}=42)$, Dungeness crab $(\mathrm{N}=155)$, groundfish $(\mathrm{N}=65)$ and salmon $(\mathrm{N}=225)$

\section{Figure 3.6. Perceived impacts of marine reserve implementation.}

\section{Key Findings: Section 3.}

- Charter fishers reported moderate declines in fishery related profits within the past 7 years (2011-2017). Both catch rates and profits appeared to be driven by regulations, ocean conditions, and catch limits.

- Dungeness crab fishers reported both increases and decreases in personal catch rates and fishery related profits within the past 7 years (2011-2017). Weather conditions, ocean conditions, and market prices were the top drivers of catch rates and profits were driven by ocean conditions, market prices, and operating expenses.

- Groundfish fishers reported both increases and decreases in personal catch rates and fishery related profits within the past 7 years (2011-2017). Catch limits, ocean conditions, and operating expenses were the top drivers of catch rates and profits.

- Salmon troll fishers reported large declines in personal catch rates and fishery related profits within the past 7 years (2011-2017). Regulations, ocean conditions, and catch 
limits were the top drivers of catch rates, and profits appeared to be driven by regulations, operating expenses, and catch limits.

- A majority of fishers reported that marine reserves had no clear impact on fishing participation. Responses indicating displacement of fishing, increased spatial competition, and increased travel distances to fish were evenly distributed among aggregate responses as well as fishery dependent responses. Respondents from the Dungeness crab fishery had the highest percentage of negative impacts resulting from marine reserves, comparatively.

\section{Section 4. Fishery Socioeconomics and Fishing Effort}

Operating Expenditures. Costs associated with crew appeared to be the lowest operating expenditure across all fisheries, with the exception of Dungeness crab, where associated fuel costs were the lowest. "Other" operating expenses made up the largest percentage of expenses for every fishery. The Dungeness crab fishery reported the lowest relative fuel expenditure while the salmon fishery reported the highest crew expenditure $(16 \%, 33 \%$, respectively; Table 4.1 ; Figure 4.1). Relative fuel expenditure was roughly equal for the charter, groundfish and salmon fisheries $(26 \%, 25 \%, 26 \%$, respectively; Figure 4.1). Relative operating expenditures did not significantly fluctuate between the years 2011, 2014, and 2017 (Appendix C, Table C.1).

Table 4.1. Operating expenditure percentages, separated by fishery affiliation.

\begin{tabular}{|c|cccc|}
\hline Fishery & Operating Expense & Mean & SD & SE \\
\hline \multirow{2}{*}{ Charter } & Fuel & $26 \%$ & 13.4 & 2.3 \\
$(\mathrm{~N}=19)$ & Crew & $14 \%$ & 14.2 & 2.39 \\
& Other & $49 \%$ & 19.2 & 2.71 \\
\hline \multirow{2}{*}{ Dungeness crab } & Fuel $^{*}$ & $16 \%$ & 10.2 & 1.05 \\
$(\mathrm{~N}=60)$ & Crew & $33 \%$ & 14.1 & 1.3 \\
& Other & $39 \%$ & 22.7 & 2.09 \\
\hline \multirow{2}{*}{ Groundfish } & Fuel $^{*}$ & $25 \%$ & 21.6 & 3.51 \\
$(\mathrm{~N}=22)$ & Crew & $20 \%$ & 16.5 & 2.54 \\
& Other & $40 \%$ & 26 & 4 \\
\hline \multirow{2}{*}{ Salmon } & Fuel & $26 \%$ & 26.4 & 2.64 \\
$(\mathrm{~N}=57)$ & Crew & $13 \%$ & 13.4 & 1.35 \\
& Other & $48 \%$ & 31.3 & 2.85 \\
\hline
\end{tabular}

Data were standardized when used in analyses

Note that total expenses do not equal $100 \%$

Operating expenditure percentages is the relative amount of money allocated to each category of operating expense $\mathrm{N}=158$ 


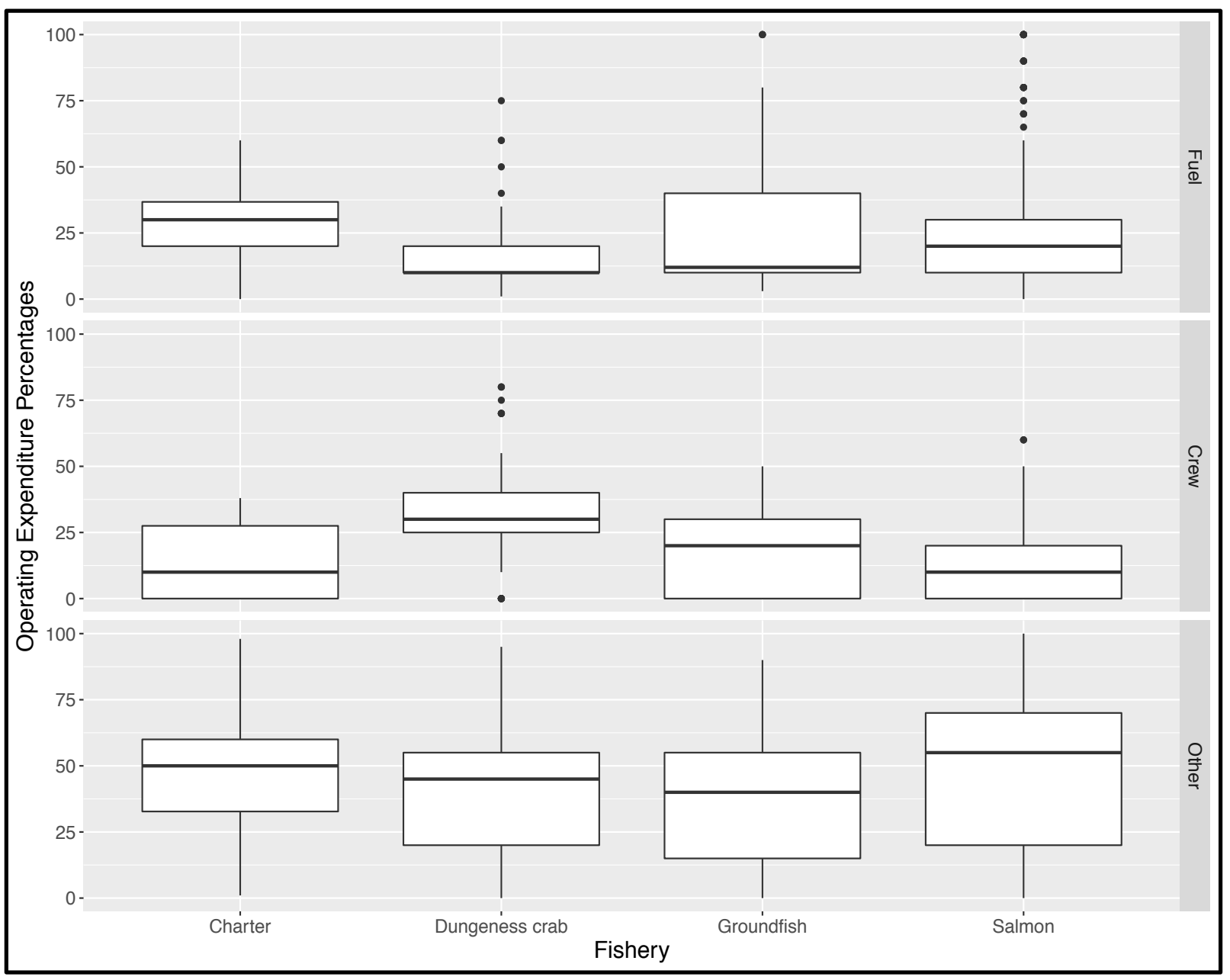

Data were standardized when used in analyses

Operating expenditure percentages is the relative amount of money allocated to each category of operating expense $\mathrm{N}=158$; Charter $=19$, Dungeness $\mathrm{crab}=60$, groundfish $=22$, and salmon $=57$

Figure 4.1. Operating expenditure percentages, separated by fishery affiliation.

Observed Variability in Fishing Effort. Dungeness crab fishers displayed the highest financial dependence up on that fishery $(60 \%)$ compared to the other fishers, who appear to have more diverse economic profiles. Charter fishers fished the most days annually while the Dungeness crab fishers fished the most hours per day ( 78 days, 23 hours, respectively). Salmon fishers spent the most days fishing offshore (63\% outside three miles), while participants in other fisheries spent a majority days fishing nearshore (inside three miles). Dungeness crab fishers traveled the farthest distances in order to fish and fished the most days in areas that are now marine reserves (15 miles, 15 days, respectively; Table 4.2). Fishing effort logistics did not differ between sampling years (Appendix C, Table C.2). 
Table 4.2. Fishing effort logistics, separated by fishery affiliation.

\begin{tabular}{|c|c|c|c|c|c|c|c|c|c|c|c|c|}
\hline \multirow[b]{2}{*}{ Effort Logistic } & \multicolumn{3}{|c|}{$\begin{array}{l}\text { Charter } \\
(\mathrm{N}=19)\end{array}$} & \multicolumn{3}{|c|}{$\begin{array}{c}\text { Dungeness crab } \\
(\mathrm{N}=65)\end{array}$} & \multicolumn{3}{|c|}{$\begin{array}{l}\text { Groundfish } \\
(\mathrm{N}=28)\end{array}$} & \multicolumn{3}{|c|}{$\begin{array}{l}\text { Salmon } \\
(\mathrm{N}=56)\end{array}$} \\
\hline & Mean & $\mathrm{SD}$ & SE & Mean & SD & $\mathrm{SE}$ & Mean & $\mathrm{SD}$ & SE & Mean & SD & $\mathrm{SE}$ \\
\hline $\begin{array}{c}\text { Financial } \\
\text { Dependence }\end{array}$ & 40 & 32.4 & 4.29 & $60^{*}$ & 23.8 & 1.71 & $28^{*}$ & 29.1 & 3.17 & $36^{*}$ & 32.3 & 2.48 \\
\hline Annual Days Fished & 78 & 55.1 & 7.3 & $67^{+}$ & 48.8 & 3.50 & $43^{+}$ & 44.8 & 4.90 & $58^{+}$ & 59.9 & 4.60 \\
\hline $\begin{array}{c}\text { Annual Days Fished } \\
\text { (inside } 3 \text { miles) }\end{array}$ & 72 & 53.0 & 7.02 & $52^{*}$ & 38.6 & 2.77 & $43^{*}$ & 47.4 & 5.17 & $21^{*}$ & 32.8 & 2.52 \\
\hline $\begin{array}{c}\text { Hours Fished Per } \\
\text { Day }\end{array}$ & 6 & 2.2 & 0.3 & $23^{+}$ & 3.1 & 0.22 & $8^{+}$ & 5.1 & 0.56 & $10^{+}$ & 4.6 & 0.36 \\
\hline $\begin{array}{c}\text { Hours Fished Per } \\
\text { Day (inside } 3 \text { miles) }\end{array}$ & 5 & 2.7 & 0.36 & $21^{*}$ & 6.9 & 0.49 & $6^{*}$ & 3.4 & 0.37 & $6^{*}$ & 6.2 & 0.48 \\
\hline $\begin{array}{l}\text { Miles Traveled to } \\
\text { Fish } \\
\end{array}$ & 4 & 4.3 & 0.57 & $15^{*}$ & 17.1 & 1.23 & $7^{*}$ & 5.8 & 0.63 & $14^{*}$ & 25.8 & 1.98 \\
\hline $\begin{array}{c}\text { Annual Days Fished } \\
\text { (reserve limits) }\end{array}$ & 2 & 7.6 & 1 & $13^{*}$ & 28.0 & 2.01 & $3^{*}$ & 10.0 & 1.10 & $2^{*}$ & 8.3 & 0.64 \\
\hline $\begin{array}{c}\text { Financial } \\
\text { Dependence } \\
\text { (reserve catch) }\end{array}$ & 1 & 3.3 & 0.44 & $5^{*}$ & 10.7 & 0.76 & $4^{*}$ & 10.5 & 1.15 & $4^{*}$ & 15.7 & 1.20 \\
\hline Total Effort & 518 & 430 & 90 & $1289^{+}$ & 686 & 99 & $361^{+}$ & 339 & 101 & $638^{+}$ & 515 & 71 \\
\hline $\begin{array}{c}\text { Catch Per Unit } \\
\text { Effort }\end{array}$ & - & - & - & $40^{\#}$ & 52 & 7.7 & $36.2^{\#}$ & 56 & 2.9 & $10^{\#}$ & 21 & 11 \\
\hline
\end{tabular}

* Data were standardized when used in analyses

+ Data were square rooted when used in analyses

${ }^{\#}$ Data were log-transformed when used in analyses

Fishing vessels were the largest among Dungeness crab fishers and smallest among groundfish fishers (43 feet, 28 feet, respectively). For each fishery, the median number of vessels owned was one (Table 4.3). The Clatsop and Lincoln County port groups had the largest average vessels (44 feet, 42 feet, respectively), while Tillamook and Curry County vessels were the smallest (24 feet, 27 feet respectively). For each port group the median number of vessels owned was one (Table 4.4).

Table 4.3. Fishing vessel features aggregated and separated by fishery affiliation.

\begin{tabular}{|c|c|c|c|c|c|c|c|c|c|c|c|c|}
\hline \multirow[b]{2}{*}{$\begin{array}{l}\text { Vessel } \\
\text { Feature }\end{array}$} & \multicolumn{3}{|c|}{$\begin{array}{c}\text { Aggregated } \\
(\mathrm{N}=168)\end{array}$} & \multicolumn{3}{|c|}{$\begin{array}{c}\text { Dungeness crab } \\
(\mathrm{N}=66)\end{array}$} & \multicolumn{3}{|c|}{$\begin{array}{c}\text { Salmon } \\
(\mathrm{N}=71)\end{array}$} & \multicolumn{3}{|c|}{$\begin{array}{l}\text { Groundfish } \\
(\mathbf{N}=\mathbf{3 1})\end{array}$} \\
\hline & Mean & SD & SE & Mean & SD & SE & Mean & SD & SE & Mean & SD & SE \\
\hline Length* & 36 & 13 & 1.0 & 43 & 15 & 1.8 & 33 & 9.5 & 1.0 & 28 & 9.8 & 1.8 \\
\hline Owned & 1 & 0.34 & 0.02 & 1 & 0.4 & 0.05 & 1 & 0.3 & 0.03 & 1 & 0.40 & 0.07 \\
\hline
\end{tabular}

*Data were standardized when used in analyses; mean length in feet 
Table 4.4. Fishing vessel features aggregated and separated by port group.

\begin{tabular}{|ccccccccccc|}
\hline Port & \multicolumn{3}{c}{ Clatsop (N=32) } & \multicolumn{3}{c|}{ Tillamook (N=21) } & \multicolumn{3}{c|}{ Lincoln (N=46) } \\
\hline Vessel Feature & Mean & SD & SE & Mean & SD & SE & Mean & SD & SE \\
Length* & 44.1 & 16.1 & 2.85 & 23.9 & 3.56 & 0.78 & 41.9 & 12.1 & 1.78 \\
Owned & 1 & 0.4 & 0.07 & 1 & 0 & 0 & 1 & 0.35 & 0.051 \\
\hline Port & \multicolumn{3}{c}{ Coos (N=27) } & \multicolumn{3}{c}{ Curry (N=24) } & \multicolumn{3}{c|}{ Brookings (N=18) } \\
\hline & Mean & SD & SE & Mean & SD & SE & Mean & SD & SE \\
Length* & 35.0 & 10.3 & 1.97 & 27.2 & 5.89 & 1.20 & 35.3 & 12.2 & 2.88 \\
Owned & 1 & 0.3 & 0.051 & 1 & 0.46 & 0.095 & 1 & 0 & 0 \\
\hline
\end{tabular}

*Data were standardized when used in analyses; mean length in feet

Total fishing effort was calculated by multiplying the total days fished in a year by the average number of hours that fishing gear was deployed per day to give the total hours that fishing gear was deployed per year, for years 2011, 2014, and 2017. Total days and hours fished were selected to represent total effort based on results from a Principle Component Analysis that indicated those two variables explained the overall patterns of effort (Appendix C, Figure C.1). Repeated measure analyses of variance were performed in order to identify how fishing effort varied over time between different subsections of fishers. Statistical significance was determined by a p-value $<0.05$ for each fishery examined. Sampling year, fishery affiliation, and the interaction between sampling years within fisheries were factors that exhibited significant differences in fishing effort (Table 4.5). Dungeness crab fishers exhibited the most overall effort for each of the years sampled, followed by the salmon and then groundfish fishers, with the exception of the year 2017, when groundfish fishers exerted more effort than salmon fishers. Overall effort within the all of the fisheries appeared to decrease in 2017 (Figure 4.2). Because fishery affiliation was indicated as a significant factor, data were separated by fishery and analyzed, with repeated measures ANOVA, for differences between sampling year and operating port. Due to the vast differences in business operations and lack of catch per unit effort and vessel feature data, the charter fishery was excluded from this analysis.

Data were separated by fishery and analyzed for patterns between sampling year and operating port group. ANOVA results indicated that effort between years and operating ports did not significantly vary, with the exception of the sampling year in the salmon fishery, $\mathrm{F}=14.9$, $\mathrm{p}=0.006$ (Table 4.5). A Bonferroni-Holm pairwise test indicated that there was significantly higher fishing effort in the years 2011 and 2014 than in the year 2017 (Table 4.6, Figure 4.3). While not statistically significant, patterns in fishing effort between operating ports and sampling years were observed in each fishery. In 2011 and 2014, the salmon fishers in the Clatsop and Tillamook port groups (farthest north) exhibited less effort compared to other port groups. In 2017, however, the overall effort exerted by the Lincoln and Coos port groups fell, thereby mirroring the most northern port groups (Figure 4.3). The sample size for the Curry and Brookings port groups were too small to draw conclusions from. In the Dungeness crab fishery, the Coos port group exerted low overall effort, regardless of year, while the Tillamook and Curry port groups' exerted slightly higher effort in 2011 and 2014 and then decreased effort in 2017 when compared to other port groups (Figure 4.3). In the groundfish fishery, effort gradually increased over time for the Coos and Brookings port groups and decreased for the Lincoln and 
Curry port groups. The sample size for the Clatsop port group was too small to draw conclusions from (Figure 4.3).

Table 4.5. Repeated measures analysis of variance results for average fishing effort within individual survey respondents ${ }^{\#}$.

\begin{tabular}{|cccccc|}
\hline Factor & SS & MS & df & F & P \\
\hline Fishery & $\mathbf{1 5 8 0 5}$ & $\mathbf{7 9 0 3}$ & $\mathbf{2}$ & $\mathbf{1 8 . 7}$ & $\mathbf{2 . 8 3 E - 0 7}$ \\
Port & 965 & 193 & 5 & 0.544 & 0.741 \\
^Year & $\mathbf{5 9 1}$ & $\mathbf{2 9 6}$ & $\mathbf{2}$ & $\mathbf{1 0 . 1 6}$ & $\mathbf{0 . 0 0 0 7}$ \\
Fishery*Port & 4681 & 468 & 10 & 1.74 & 0.087 \\
^Fishery*Year $^{\wedge}$ & $\mathbf{3 8 3}$ & $\mathbf{9 6}$ & $\mathbf{4}$ & $\mathbf{3 . 8}$ & $\mathbf{0 . 0 1 6}$ \\
^Port*Year & 224 & 22 & 10 & 0.7 & 0.663 \\
^Fishery*Port*Year & 760 & 38 & 20 & 1.58 & 0.104 \\
Error between participants & 29765 & 431 & 69 & - & - \\
Error within participants & 3615 & 26 & 138 & - & - \\
\hline
\end{tabular}

${ }^{\#}$ Significant factors indicated in bold, marginally significant factors indicated in italics

$\wedge=$ Greenhouse-Geisser corrected $\mathrm{P}$ value

*= Interaction (Factor column)

$\mathrm{SS}=$ sum of squares, $\mathrm{MS}=$ multiple squares, $\mathrm{df}=$ degrees of freedom, $\mathrm{F}=$ test statistic $\mathrm{N}=91$ 


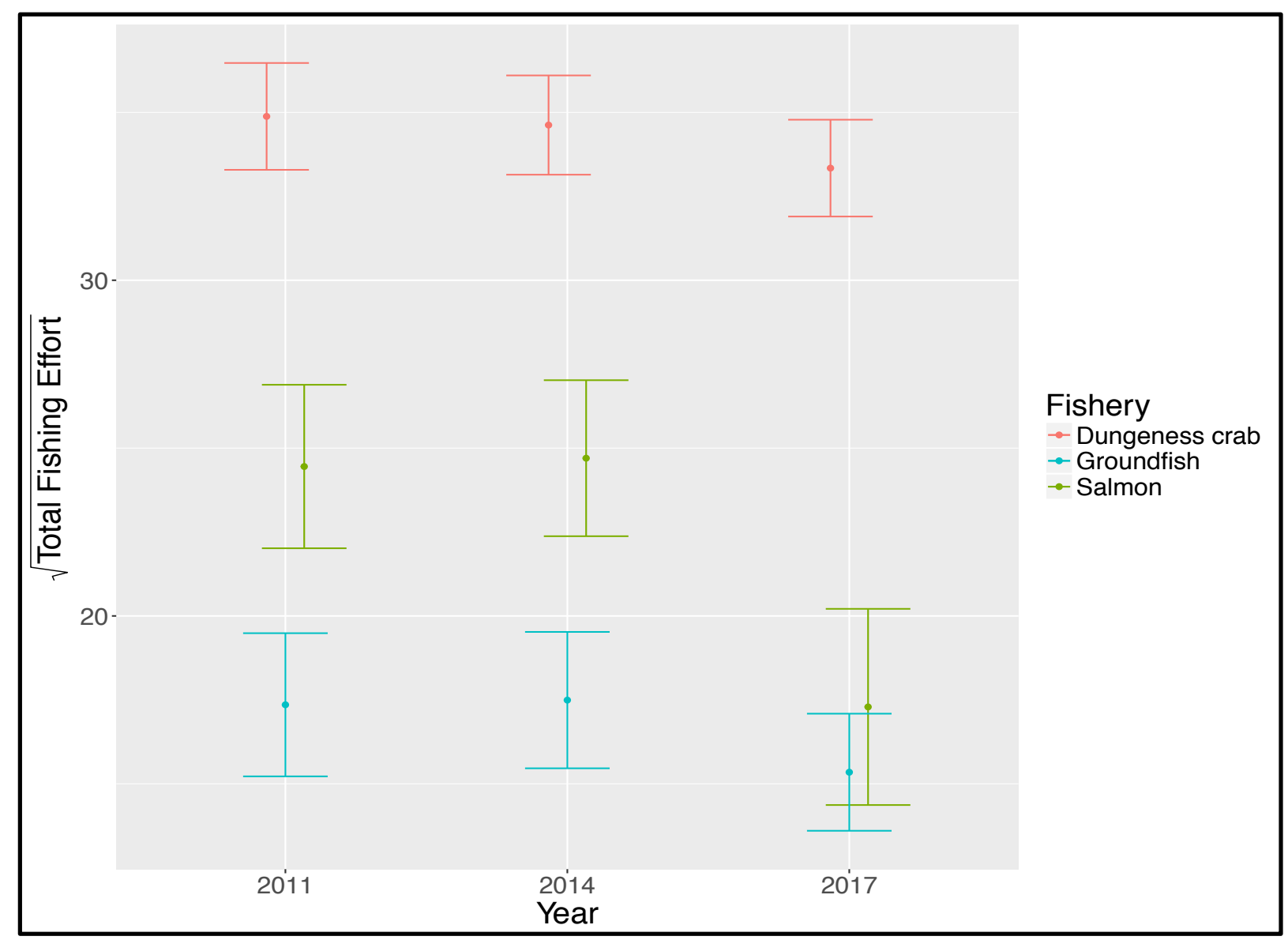

$\mathrm{N}=96$; Dungeness crab=49; Salmon=24; Groundfish=23

Error bars represent \pm standard error of the mean.

Figure 4.2. Average total fishing effort, by fishery, 2011, 2014, and 2017. 
Table 4.6. Repeated measures analysis of variance results for average fishing effort within each fishery.

\begin{tabular}{|c|c|c|c|c|c|c|}
\hline Fishery & Factor & SS & MS & df & $\mathbf{F}$ & $\mathbf{P}$ \\
\hline \multirow{5}{*}{$\begin{array}{l}\text { Dungeness } \\
\text { crab }(N=45)\end{array}$} & Port & 2239 & 448 & 5 & 1.72 & 0.152 \\
\hline & ${ }^{\wedge}$ Year & 61 & 31 & 2 & 2.14 & 0.132 \\
\hline & ${ }^{\wedge}$ Year*Port & 182 & 18 & 10 & 1.57 & 0.146 \\
\hline & Error between participants & 10128 & 260 & 39 & - & - \\
\hline & Error within participants & 906 & 12 & 78 & - & - \\
\hline \multirow{5}{*}{$\begin{array}{l}\text { Salmon } \\
(\mathbf{N}=\mathbf{2 4})\end{array}$} & Port & 2636 & 527 & 5 & 1.5 & 0.237 \\
\hline & ${ }^{\wedge}$ Year & 849 & 425 & 2 & 7.35 & 0.01 \\
\hline & ${ }^{\wedge}$ Year*Port & 454 & 45 & 10 & 1.04 & 0.426 \\
\hline & Error between participants & 6303 & 350 & 18 & - & - \\
\hline & Error within participants & 1571 & 44 & 36 & - & - \\
\hline \multirow{5}{*}{$\begin{array}{l}\text { Groundfish } \\
\qquad(\mathbf{N}=\mathbf{2 2})\end{array}$} & Port & 771 & 154 & 5 & 0.76 & 0.592 \\
\hline & $\wedge$ Year & 63 & 32 & 2 & 0.759 & 0.540 \\
\hline & ${ }^{\wedge}$ Year*Port & 349 & 35 & 10 & 0.426 & 0.412 \\
\hline & Error between participants & 3249 & 203 & 16 & - & - \\
\hline & Error within participants & 1042 & 33 & 32 & - & - \\
\hline
\end{tabular}

"Significant factors indicated in bold, marginally significant factors indicated in italics

$\wedge=$ Greenhouse-Geisser corrected P value

*= Interaction (Factor column)

$\mathrm{SS}=$ sum of squares, $\mathrm{MS}=$ multiple squares, $\mathrm{df}=$ degrees of freedom, $\mathrm{F}=$ test statistic

Table 4.7. Bonferroni-Holm pairwise comparison tests between sampling years in overall fishing effort for the salmon fishery $(\mathrm{N}=\mathbf{2 4})$. $^{\#}$

\begin{tabular}{|c|cc|}
\hline \multicolumn{2}{|c|}{ Pairwise Comparisons } & $\mathbf{2 0 1 4}$ \\
\hline Sampling Year & $\mathbf{2 0 1 1}$ & - \\
$\mathbf{2 0 1 4}$ & 0.762 & $\mathbf{0 . 0 0 8}$ \\
\hline
\end{tabular}

${ }^{\#}$ Significant factors indicated in bold 


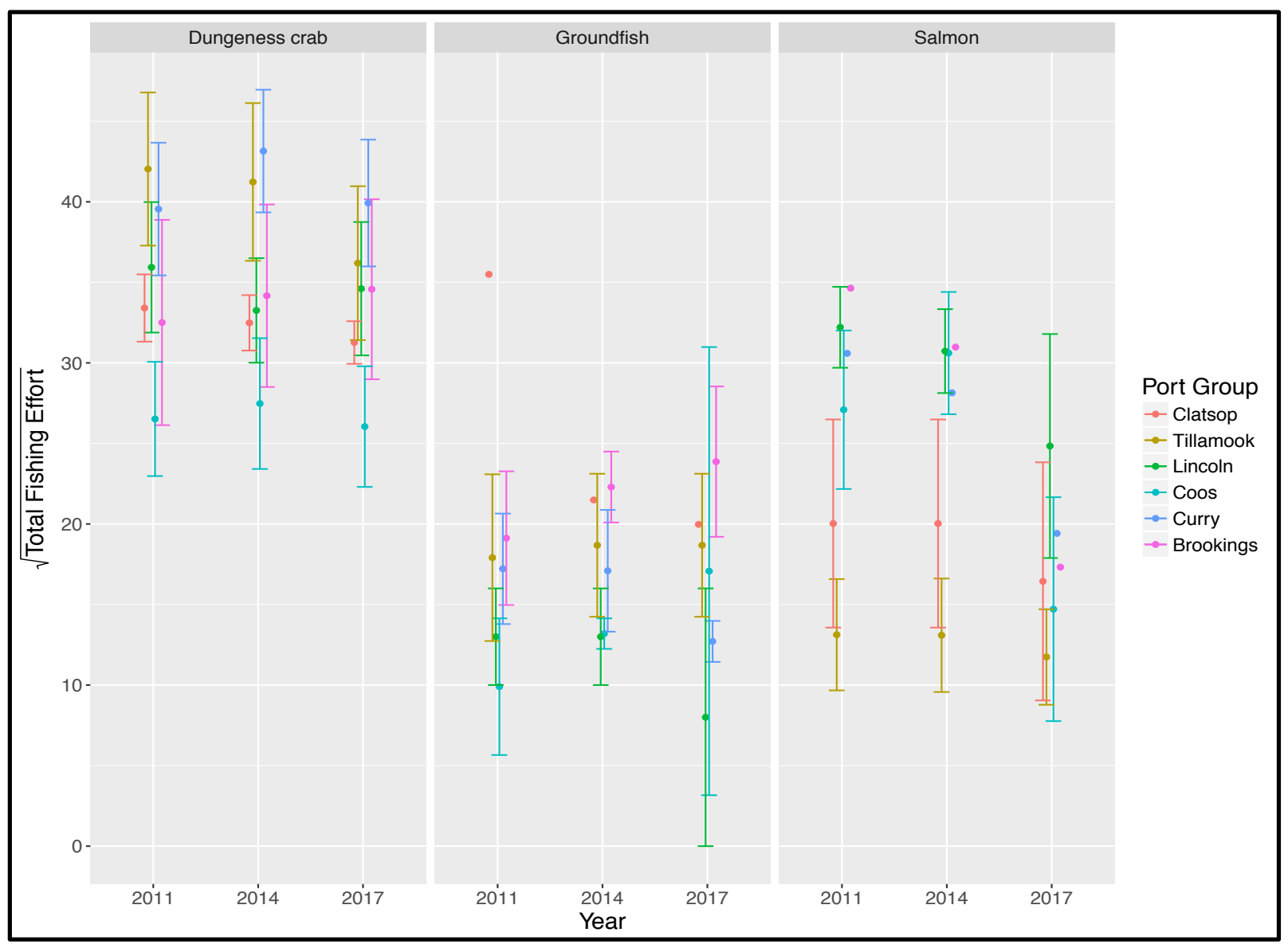

Dungeness $\mathrm{crab}=45$; Groundfish $=22$; Salmon $=24$

Error bars represent \pm standard error of the mean

Figure 4.3. Average total fishing effort for 2011, 2014 and 2017 by port group.

Perceived Drivers of Fishing Effort. When aggregated, weather conditions, regulations, and ocean conditions, were selected as the top three drivers of fishing effort among fishers (18\%, $17 \%, 17 \%$ respectively; Table 4.8; Figure 4.4). When separated by fishery, it was revealed that the previously mentioned drivers were also the top three drivers of effort within the charter fishery $(26 \%, 23 \%, 19 \%$, respectively). Weather conditions, market prices, and ocean conditions were the top drivers of effort within the Dungeness crab fishery $(21 \%, 20 \%, 17 \%$, respectively). Groundfish fishers indicated that catch limits, ocean conditions, and weather conditions primarily drove their effort $(22 \%, 17 \%, 14 \%$, respectively). Regulations, ocean conditions, and operating expenses were the largest drivers of effort among salmon fishers $(24 \%, 17 \%, 16 \%$ respectively; Table 4.9; Figure 4.5). 
Table 4.8. Perceived top three drivers of personal fishing effort.

\begin{tabular}{|ccc|}
\hline Driver & Frequency & Percent (\%) \\
\hline Regulations & 103 & 17 \\
Ocean Conditions & 105 & 17 \\
Weather Conditions & 107 & 18 \\
Catch Limits & 59 & 10 \\
Operating Expenses & 88 & 15 \\
Market Prices & 69 & 11 \\
Catch Per Unit Effort & 50 & 8 \\
Other & 24 & 4 \\
\hline
\end{tabular}

Each participant was directed to select up to three drivers $\mathrm{N}=605$

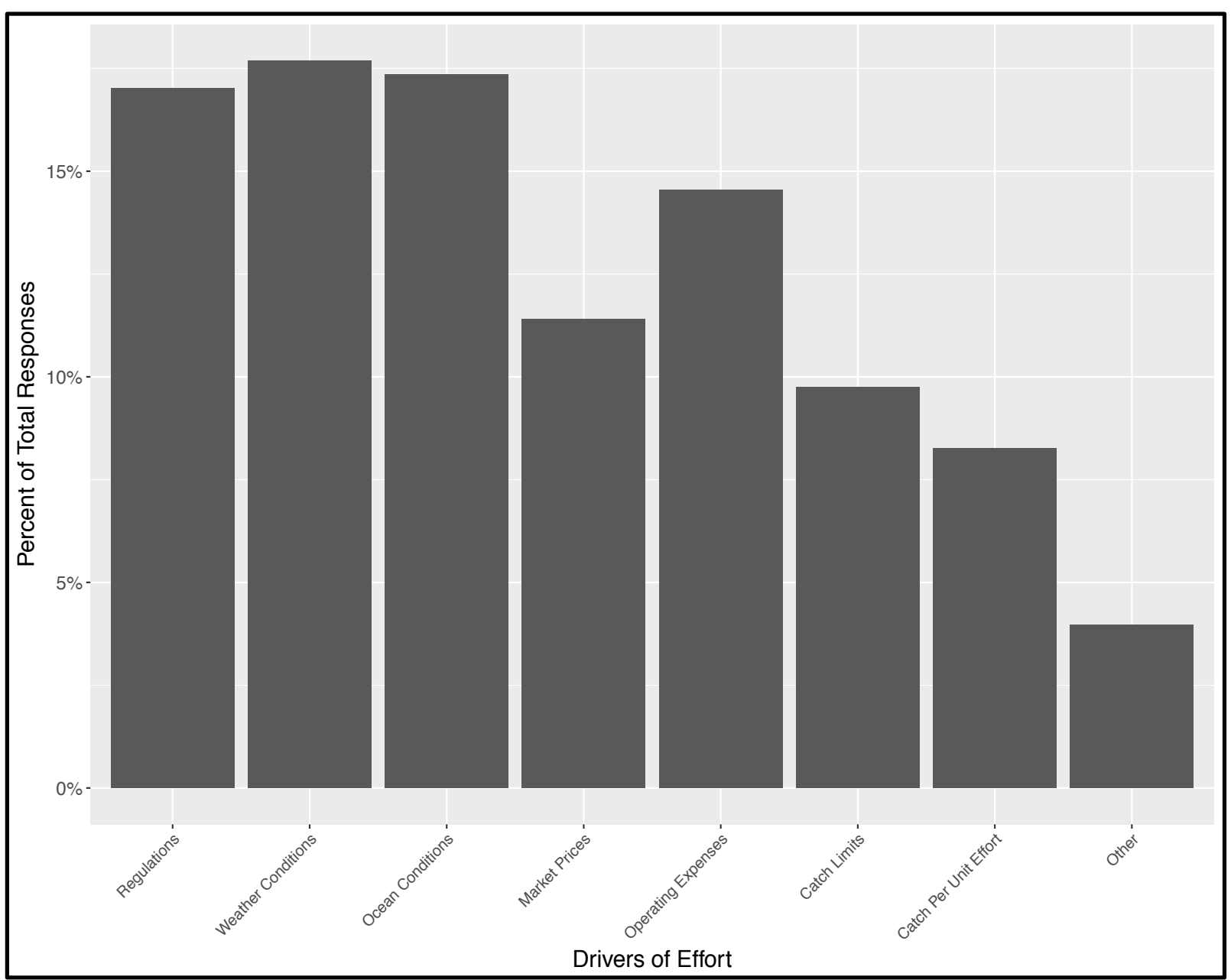

Each participant was directed to select up to three drivers $\mathrm{N}=605$

Figure 4.4. Perceived top three drivers of personal fishing effort. 
Table 4.9. Perceived top three drivers of personal fishing effort by fishery affiliation.

\begin{tabular}{|c|c|c|c|c|c|c|c|c|}
\hline \multirow[b]{2}{*}{$\begin{array}{c}\text { Driver of } \\
\text { Variability }\end{array}$} & \multicolumn{2}{|c|}{$\begin{array}{c}\text { Charter } \\
(\mathrm{N}=57)\end{array}$} & \multicolumn{2}{|c|}{$\begin{array}{c}\text { Dungeness crab } \\
(\mathrm{N}=\mathbf{2 2 0})\end{array}$} & \multicolumn{2}{|c|}{$\begin{array}{c}\text { Groundfish } \\
(\mathbf{N}=90)\end{array}$} & \multicolumn{2}{|c|}{$\begin{array}{l}\text { Salmon } \\
(\mathrm{N}=\mathbf{2 3 8})\end{array}$} \\
\hline & Freq. & Percent $(\%)$ & Freq. & Percent $(\%)$ & Freq. & Percent $(\%)$ & Freq. & Percent (\%) \\
\hline Regulations & 13 & 23 & 23 & 10 & 10 & 11 & 57 & 24 \\
\hline Ocean Conditions & 11 & 19 & 38 & 17 & 15 & 17 & 41 & 17 \\
\hline Weather Conditions & 15 & 26 & 46 & 21 & 13 & 14 & 33 & 14 \\
\hline Catch Limits & 7 & 12 & 5 & 2 & 20 & 22 & 27 & 11 \\
\hline Operating Expenses & 3 & 5 & 36 & 16 & 11 & 12 & 38 & 16 \\
\hline Market Prices & 0 & 0 & 44 & 20 & 10 & 11 & 15 & 6 \\
\hline $\begin{array}{c}\text { Catch Per Unit } \\
\text { Effort }\end{array}$ & 4 & 7 & 19 & 9 & 7 & 8 & 20 & 8 \\
\hline Other & 4 & 7 & 9 & 4 & 4 & 4 & 7 & 3 \\
\hline
\end{tabular}

Each participant was directed to select up to three drivers

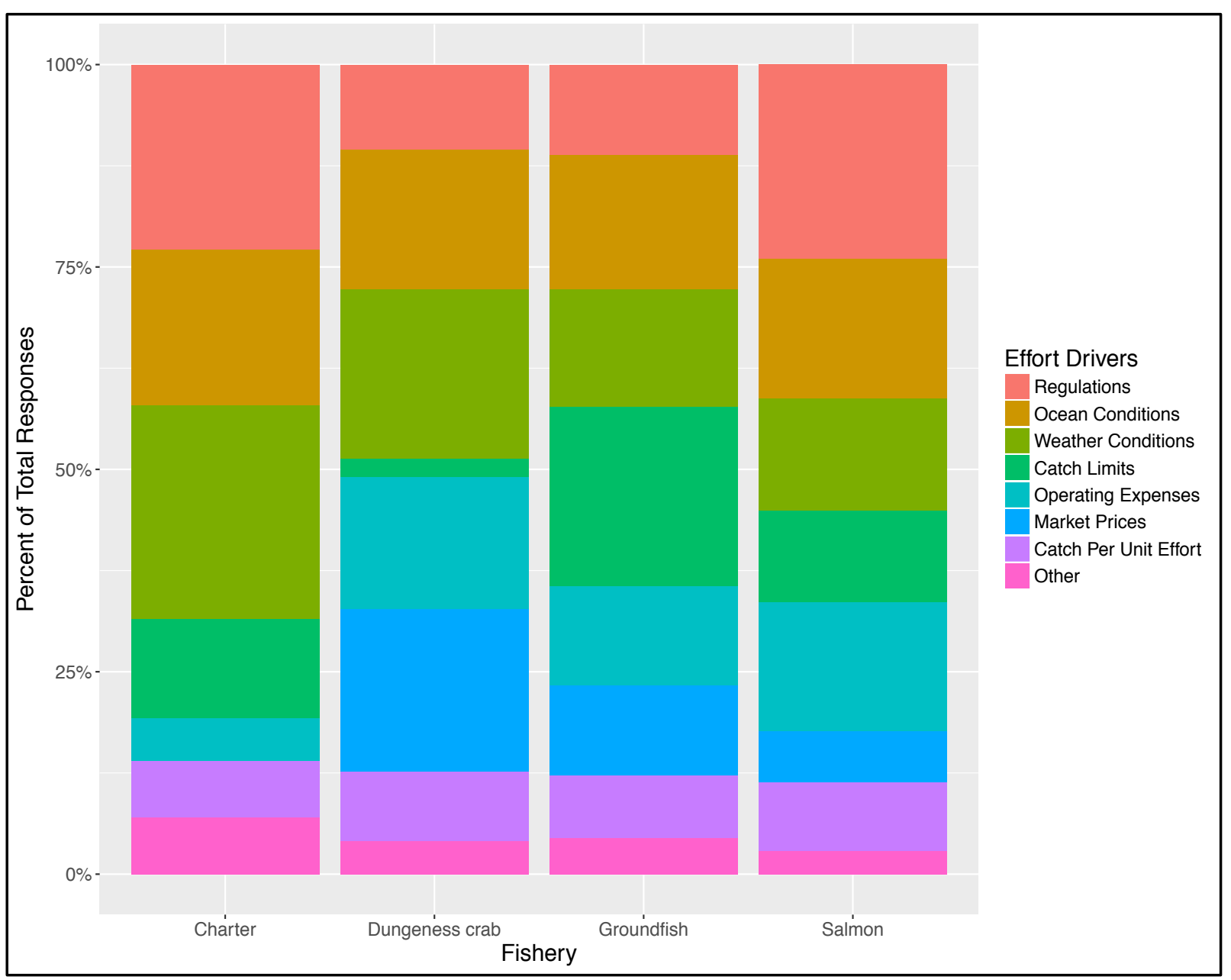

$\mathrm{N}=605$; Charter $=57$; Dungeness $\mathrm{crab}=220$; Groundfish=90; Salmon $=238$

Each participant was directed to select up to three drivers.

Figure 4.5. Perceived top three drivers of personal fishing effort by fishery affiliation. 
Socioeconomic Drivers of Fishing Effort. CPUE was calculated by dividing a fisher's total annual landings (in pounds) by their reported total annual effort (hours fished). CPUE measurements from 2011, 2014, and 2017 were averaged to create a single CPUE value for each survey respondent. A linear mixed effects model was produced for each fishery. A linear mixed effects model was produced for each fishery. The Dungeness crab fishery had the largest coefficient (2.92), indicating the highest CPUE, followed by the groundfish (2.41) and then the salmon fishery (0.414). In the Dungeness crab fishery, backwards-stepwise AIC model selection indicated vessel length (in feet) acted as a positive predictor of CPUE, while nearshore fishing effort, marine reserve revenue, and fuel expenditure ratios were selected as negative predictors. Backward-stepwise AIC selection eliminated number of vessels owned, miles traveled to fish, marine reserve effort, financial dependence, and seasonal delays from the final regression model. Because the Dungeness crab season was partially delayed in 2016 and 2017 for all fishers, the seasonal delay variable did not have any variability (1 for all fishers) and did not have a final intercept or $\mathrm{p}$-value. The final regression model, including only fixed effects, resulted in an Adjusted $\mathrm{R}^{2}$ value $=0.409$. The addition of survey respondent port group as a random effect (in order to account for variability explained by unquantifiable differences between individual respondents) resulted in an intra-class correlation coefficient (ICC) $=0.990$ (Table 4.10). The ICC value enhances the explanatory power of the model and indicates that other variables contribute to variability in fishing success. The Clatsop County port group had the highest CPUE measurement (74 lbs/hour; Figure 4.6). All other port groups were within 0.2 units of each other (2.82-3.06). The final model explaining variability in CPUE for Dungeness crab fishers is as follows:

\section{$\mathrm{Y}(C P U E)=2.92+0.323$ (Vessel Length) -0.368 (Nearshore Effort $)-0.693$ (Reserve Revenue $)$ -0.641(Fuel Expenditure)+Error(Port Group)}

In the salmon fishery, number of vessels owned by the fisher and miles traveled before launching fishing gear were selected as fixed effects that acted as positive predictors of CPUE, while fuel expenditure ratios were selected as negative predictor. A fisher owning one vessel, rather than two vessels, was predicted to exhibit higher CPUE. Fishers than spent a larger percentage of operating expenditures on fuel, were predicted to have lower CPUE. Backward-stepwise AIC selection eliminated vessel length, financial dependence, nearshore and marine reserve effort, marine reserve revenue, and seasonal delays from the final regression model. The final regression model, including only fixed effects, resulted in an Adjusted $\mathrm{R}^{2}$ value $=0.319$ and the addition of survey respondent port group as a random effect resulted in an ICC value $=0.990$ (Table 4.10). Lincoln and Clatsop County port groups had the highest CPUE measurements (17 lbs/hour and $16.5 \mathrm{lbs}$ /hour) while the Coos County group had the lowest (5 lbs/hour; Figure 4.6). Random intercepts were distributed within 0.3 units of each other (1.78-2.08). The final model explaining variability in CPUE for salmon fishers is as follows:

$$
\begin{gathered}
\mathrm{Y}(C P U E)=1.58+4.58\left(2^{\text {nd }} \text { Vessel Owned }\right)+0.618(\text { Miles Traveled }) \\
-0.232(\text { Fuel Expenditure })+\operatorname{Error}(\text { Port Group })
\end{gathered}
$$

In the groundfish fishery backwards-stepwise AIC selection eliminated number of vessels owned, vessel length, miles traveled to fish, financial dependence, nearshore and marine reserve effort, reserve revenue, fuel expenditure ratios, and seasonal delays from the final regression 
model. Because there were no unexpected seasonal delays or closures in the groundfish fishery, the seasonal delay variable did not have any variability and did not have a final intercept or pvalue. All variables were eliminated during the model selection process and for that reason no Adjusted $\mathrm{R}^{2}$ value was produced. The addition of survey respondent port group as a random effect resulted in an ICC value $=0.681$ (Table 4.10). Clatsop and Curry County port groups had the highest CPUE measurements (149 lbs/hour and $52 \mathrm{lbs} /$ hour) while Lincoln and Coos counties had the lowest measurements (5 lbs/hour and $8 \mathrm{lbs} /$ hour; Figure 4.6). ANOVA revealed that all final models were significantly different when compared to null models and that there were no significant differences between the full and reduced models. 
Table 4.10. Predictors for catch per unit effort based on fishery affiliation.

\begin{tabular}{|c|c|c|c|c|c|}
\hline Fishery & Fixed Effects & Estimate* & SE & $\mathbf{P}^{\wedge}$ & Random Effects (ICC) \\
\hline \multirow{11}{*}{$\begin{array}{l}\text { Dungeness } \\
\text { crab }(\mathrm{N}=44)\end{array}$} & Intercept & 2.92 & 0.260 & $1.22 \mathrm{E}-14$ & \multirow{11}{*}{$\begin{array}{l}\text { Port Group } \\
\text { ICC }=0.990\end{array}$} \\
\hline & 2 Vessels Owned & 0.579 & 0.537 & 0.288 & \\
\hline & Vessel length & 0.323 & 0.145 & 0.031 & \\
\hline & Financial Dependence & 0.111 & 0.224 & 0.622 & \\
\hline & Nearshore Effort & -0.368 & 0.14 & 0.013 & \\
\hline & Miles Traveled & -0.129 & 0.122 & 0.298 & \\
\hline & Reserve Effort & 0.487 & 0.445 & 0.282 & \\
\hline & Reserve Revenue & -0.693 & 0.24 & 0.007 & \\
\hline & Fuel Expenditure & -0.641 & 0.32 & 0.052 & \\
\hline & Seasonal Delay & - & - & - & \\
\hline & \multicolumn{4}{|c|}{ Adjusted $\mathrm{R}^{2}=0.409$} & \\
\hline \multirow{11}{*}{$\begin{array}{l}\text { Salmon } \\
(\mathrm{N}=47)\end{array}$} & Intercept & 0.41 & 0.131 & $1.40 \mathrm{E}-15$ & \multirow{11}{*}{$\begin{array}{l}\text { Port Group } \\
\text { ICC }=0.990\end{array}$} \\
\hline & 2 Vessels Owned & 1.84 & 0.375 & 0.0004 & \\
\hline & Vessel Length & 0.193 & 0.234 & 0.414 & \\
\hline & Financial Dependence & -0.033 & 0.155 & 0.833 & \\
\hline & Nearshore Effort & 0.152 & 0.706 & 0.830 & \\
\hline & Miles Traveled & 0.400 & 0.196 & 0.04 & \\
\hline & Reserve Effort & 0.264 & 0.261 & 0.318 & \\
\hline & Reserve Revenue & -0.133 & 0.171 & 0.443 & \\
\hline & Fuel Expenditure & -0.232 & 0.112 & 0.045 & \\
\hline & Seasonal Delays & -0.350 & 0.27 & 0.205 & \\
\hline & \multicolumn{4}{|c|}{ Adjusted $\mathrm{R}^{2}=0.319$} & \\
\hline \multirow{10}{*}{$\begin{array}{l}\text { Groundfish } \\
(\mathrm{N}=26)\end{array}$} & Intercept & 2.41 & 1.07 & 0.039 & \multirow{10}{*}{$\begin{array}{l}\text { Port Group } \\
\text { ICC }=0.681\end{array}$} \\
\hline & 2 Vessels Owned & -0.854 & 1.20 & 0.486 & \\
\hline & Vessel Length & -0.146 & 0.663 & 0.828 & \\
\hline & Financial Dependence & 0.722 & 0.683 & 0.305 & \\
\hline & Nearshore Effort & -2.03 & 1.45 & 0.180 & \\
\hline & Miles Traveled & -0.136 & 1.54 & 0.931 & \\
\hline & Reserve Effort & 2.39 & 1.65 & 0.164 & \\
\hline & Reserve Revenue & -1.87 & 2.02 & 0.367 & \\
\hline & Fuel Expenditure & -0.172 & 0.33 & 0.613 & \\
\hline & Seasonal Delays & - & - & - & \\
\hline
\end{tabular}

Fixed effects contributing to observed variability in CPUE are indicated in bold

*Coefficients are standardized

${ }^{\wedge} \mathrm{P}$-value indicates that slope of line differs from zero 


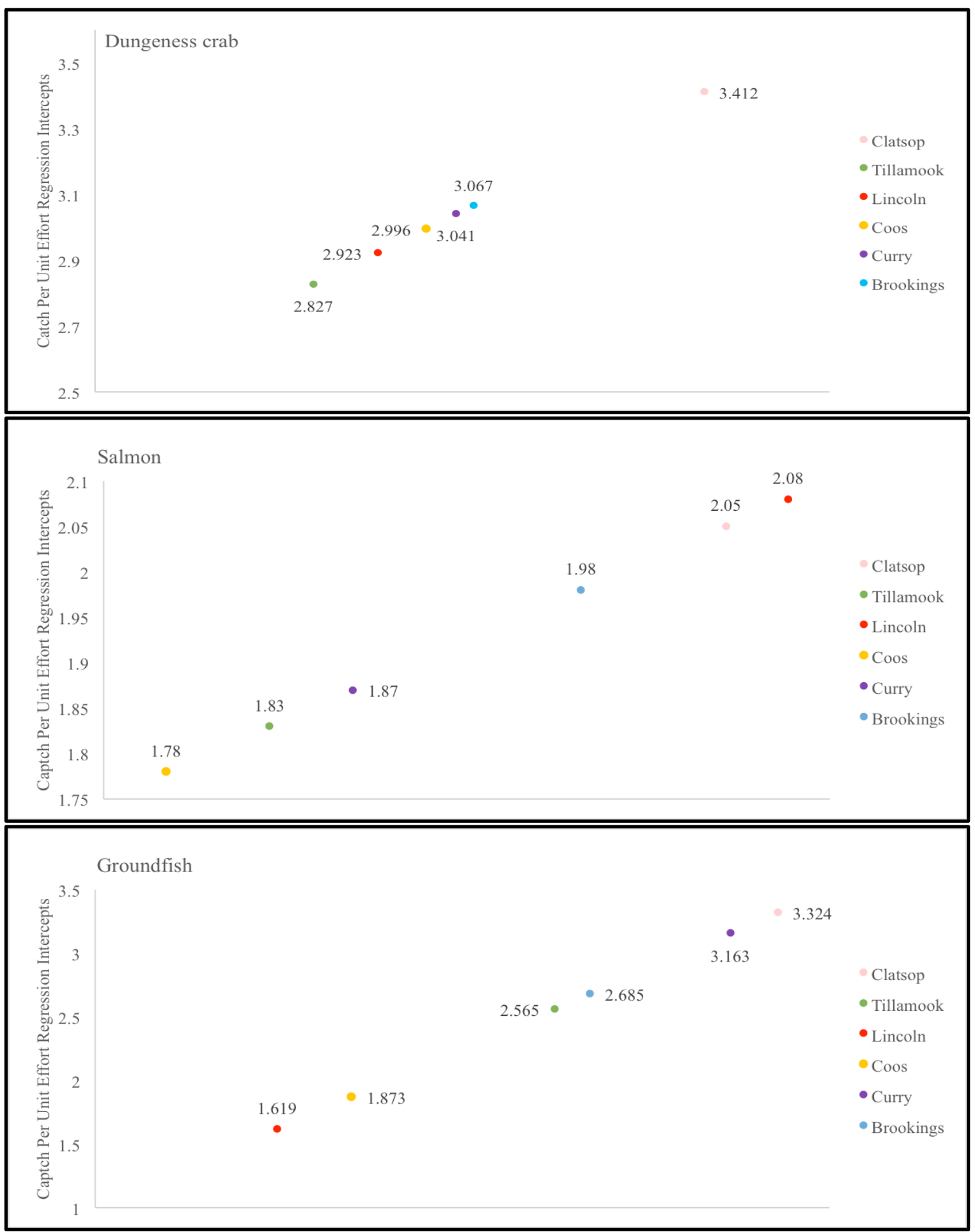

Intercept coefficients are log-transformed

Higher intercept values indicate higher CPUE measurements for a given port group.

Figure 4.6. Catch per unit effort regression intercepts display CPUE measurements for each port group by fishery. 


\section{Key Findings: Section 4.}

- Costs associated with crew appeared to be the lowest operating expenditure across all fisheries, with the exception of Dungeness crab, where associated fuel costs were the lowest. Other operating expenses, such as insurance, loan payments or permits, made up the largest percentage of expenses for every fishery. Relative operating expenditures did not appear to significantly fluctuate between the years 2011, 2014, and 2017.

- Respondents within the Dungeness crab displayed the highest economic dependence on that single fishery, compared to the other fisheries, which appear to have more diverse economic profiles. Salmon fishers spent the largest proportion of time fishing offshore, while the other fisheries spent a majority days fishing nearshore. Dungeness crab fishers traveled the farthest distances in order to fish and fished the most days in areas that are now marine reserves.

- Total effort (measured in hours fished per year) was the highest among Dungeness crab respondents. Effort marginally declined in the Dungeness crab and groundfish fisheries and significantly in the salmon fishery between the years 2014 and 2017.

- Dungeness crab fishers reported marginal declines in effort from 2014 to 2017 in all port groups, the largest from the Tillamook port group, likely corresponding with 2016 and 2017 season delays due to high levels of domoic acid. Weather conditions, ocean conditions, and market prices were reported as the top external factors driving overall fishing effort. Vessel length was positively correlated with high CPUE while nearshore effort, revenue from marine reserves, and fuel expenditure ratios were negatively correlated with high CPUE.

- Salmon fishers reported marginal declines from 2014 to 2017 in all central and southern located port groups, corresponding with the fishery closures south of Florence for the 2016-2017 season due to low stock returns. Regulations, ocean conditions, and operating expenses were reported as the top external factors driving overall fishing effort. The number of owned fishing vessels and increased travelling capacity were positively correlated with high CPUE and fuel expenditure ratios were negatively correlated with high CPUE.

- Groundfish fishers reported marginal increases in effort were observed for the Coos and Brookings port groups and marginal decreases were observed for the Lincoln and Curry port groups for the three-year sampling period (2011, 2014, and 2017). Catch limits, ocean conditions, and weather conditions were reported as the top external factors driving overall fishing effort. None of the observed socioeconomic demographics were selected as predictors of CPUE.

\section{Section 5. Familial Succession and Generation Class Projections}

Industry Generational Profiles and Expected Familial Succession. The general consensus among fishers suggests that a many do not anticipate that their children will continue on within Oregon's commercial fishing industry (i.e., No familial succession would occur; Table 5.1). Furthermore, it appeared that no familial succession was most common among first, second and third generation fishers, while succession appeared more likely for fourth or greater generation fishers (Figure 5.1). 
Table 5.1. Anticipated familial succession in fishing by generational involvement in fishing.

\begin{tabular}{|cccccc|}
\hline & \multicolumn{5}{c|}{ Generation Class Frequencies } \\
\cline { 2 - 6 } Familial Succession & $\mathbf{1}$ & $\mathbf{2}$ & $\mathbf{3}$ & $\mathbf{4}$ & Total \\
\hline Yes & 38 & 18 & 15 & 10 & $\mathbf{8 1}$ \\
Maybe & 25 & 18 & 9 & 0 & $\mathbf{5 2}$ \\
No & 79 & 27 & 24 & 7 & $\mathbf{1 3 7}$ \\
No Children & 13 & 8 & 3 & 0 & $\mathbf{2 4}$ \\
Total & $\mathbf{1 5 5}$ & $\mathbf{7 1}$ & $\mathbf{5 1}$ & $\mathbf{1 7}$ & $\mathbf{2 9 4}$ \\
\hline
\end{tabular}

$\mathrm{N}=294$

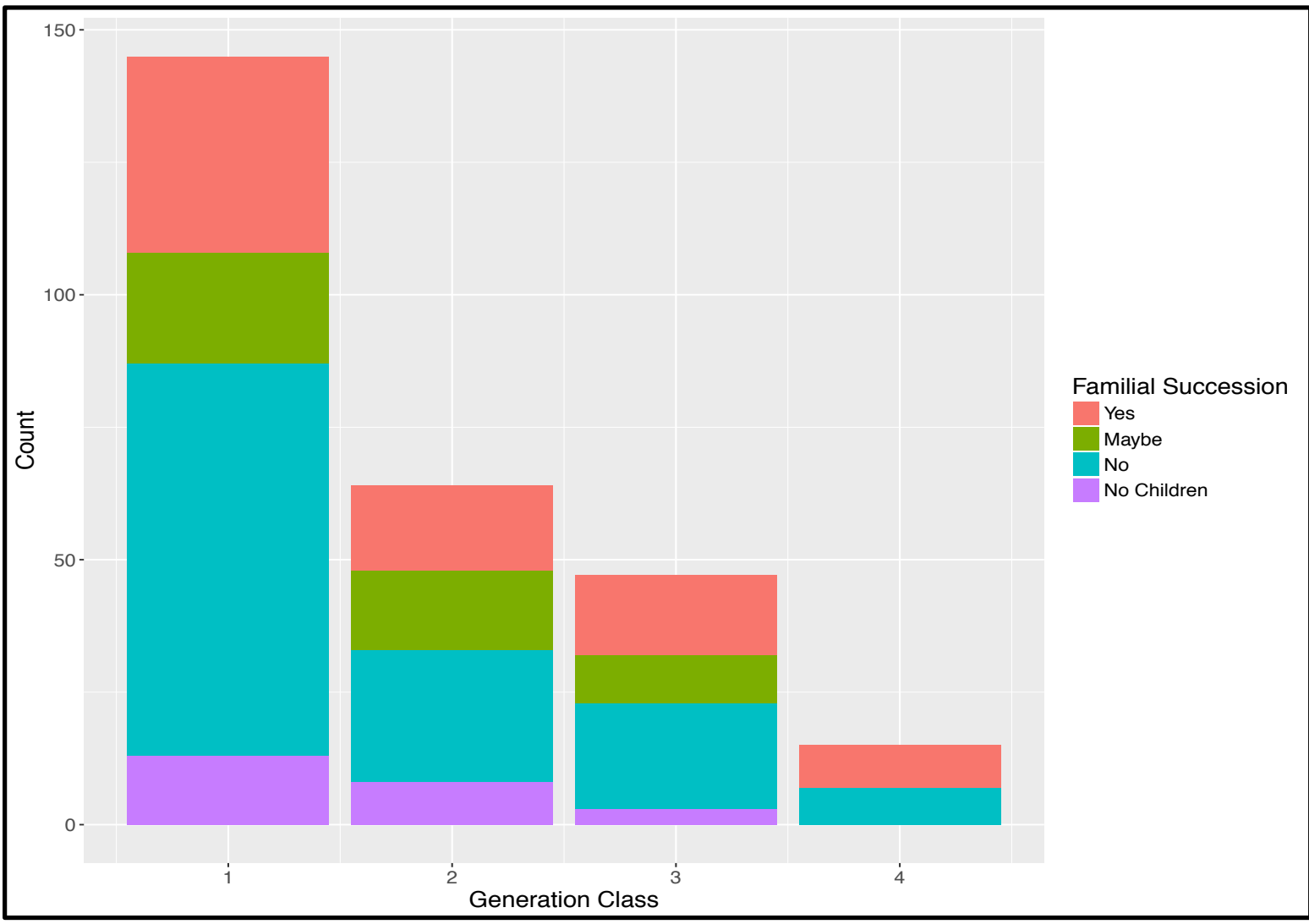

$\mathrm{N}=249$

Figure 5.1. Anticipated familial succession in fishing by generational involvement in fishing

When disaggregated by fishery, the Chi-Squared tests indicated that current and expected generational proportions were significantly different for respondents from the Dungeness crab $(p=0.0004)$, salmon $(p=0.0003)$ and charter $(p=4.8 E-07)$ fisheries and not significantly different for respondents from the groundfish fishery $(\mathrm{p}=0.100$; Table 5.2). For Dungeness crab and salmon fisheries, the expected proportion of fourth or greater generation fishers is higher than current while second and expected third-generational class proportions are lower than current. In the charter fishery, the expected proportion of second-generation fishers is greater than current 
proportions and the expected proportion of third-generation fishers is lower than current proportions. There do not appear to be any related trends for the groundfish fishery (Figure 5.2).

Table 5.2. Chi-Squared goodness of fit testing differences between actual and expected proportions of generational classes by fishery."

\begin{tabular}{|c|c|c|c|}
\hline Fishery & $\chi^{2}$ & df & P \\
\hline Dungeness Crab (N=93) & $\mathbf{1 7 . 9 8}$ & $\mathbf{3}$ & $\mathbf{0 . 0 0 0 4}$ \\
Salmon $(\mathbf{N}=\mathbf{1 1 2})$ & $\mathbf{1 9 . 1 1}$ & $\mathbf{3}$ & $\mathbf{0 . 0 0 0 3}$ \\
Groundfish $(\mathrm{N}=51)$ & 4.61 & 3 & 0.100 \\
Charter $(\mathbf{N}=\mathbf{2 5})$ & $\mathbf{3 2 . 1 4}$ & $\mathbf{3}$ & $\mathbf{4 . 9 E - 0 7}$ \\
\hline
\end{tabular}

\# Significantly different expected and actual proportions indicated in bold 

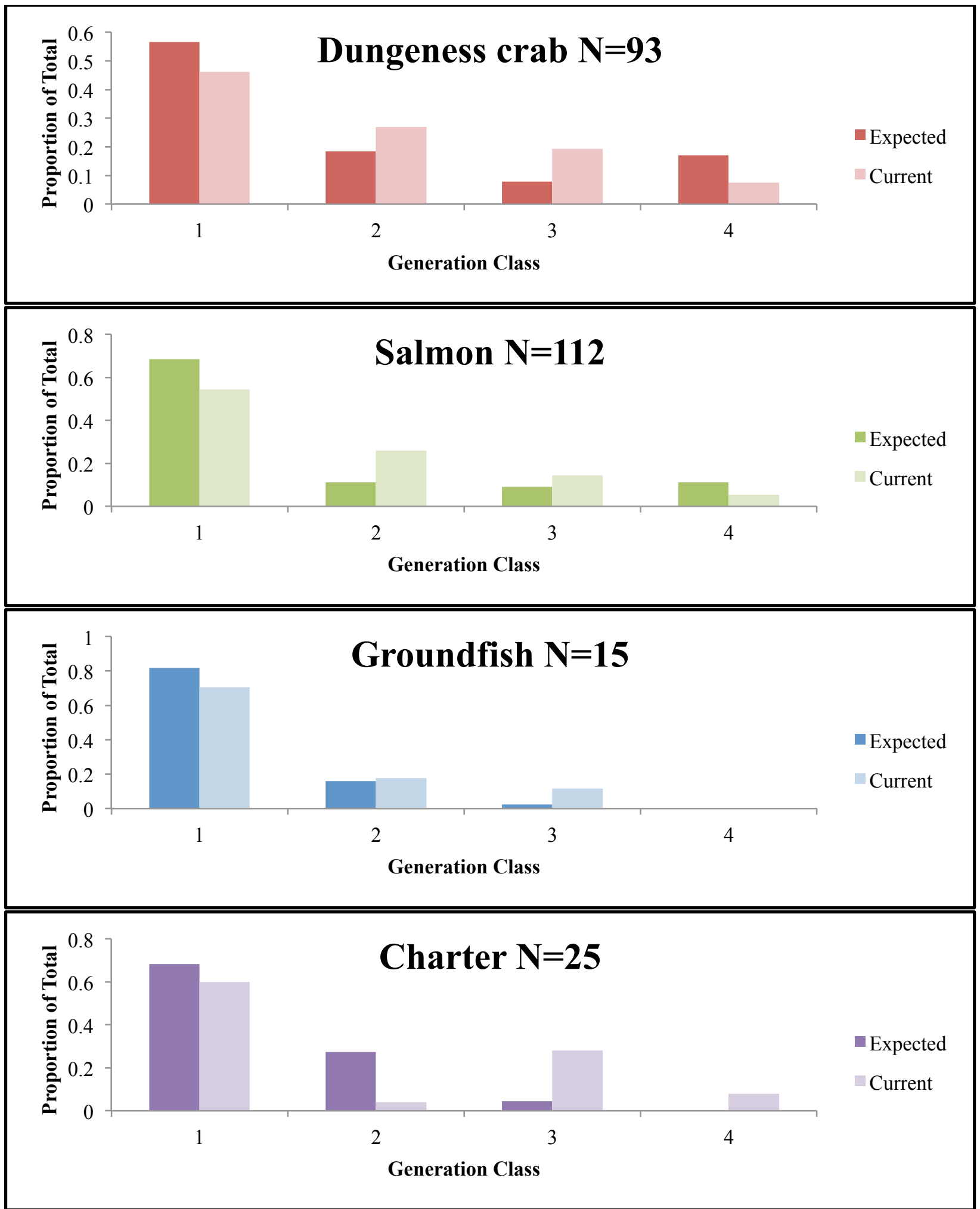

Figure 5.2. Differences between expected and current generational class proportions by fishery. 
When disaggregated by port group, Chi-Squared tests indicated that differences in expected and current proportions of generational classes are significant only for Tillamook $(p=0.002)$ and Lincoln County groups ( $p=0.002$; Table 5.3). In Tillamook County expected second and thirdgeneration class proportions are lower than current proportions, while in Lincoln County expected second and forth or greater generation proportions are higher than current proportions (Figure 5.3).

Table 5.3. Differences between expected and current generational class proportions by port group."

\begin{tabular}{|c|c|c|c|}
\hline Port Group & $\chi^{\mathbf{2}}$ & df & P \\
\hline Clatsop $(\mathrm{N}=45)$ & 4.72 & 3 & 0.193 \\
Tillamook (N=38) & $\mathbf{1 2 . 8 6}$ & $\mathbf{3}$ & $\mathbf{0 . 0 0 2}$ \\
Lincoln $(\mathbf{N}=\mathbf{6 3})$ & $\mathbf{1 4 . 3 3}$ & $\mathbf{3}$ & $\mathbf{0 . 0 0 2}$ \\
Coos $(\mathrm{N}=39)$ & 13.62 & 3 & 0.100 \\
Curry $(\mathrm{N}=26)$ & 1.125 & 3 & 0.290 \\
Brookings $(\mathrm{N}=20)$ & 5.44 & 3 & 0.066 \\
\hline
\end{tabular}

\# Significant differences in proportions indicated in bold
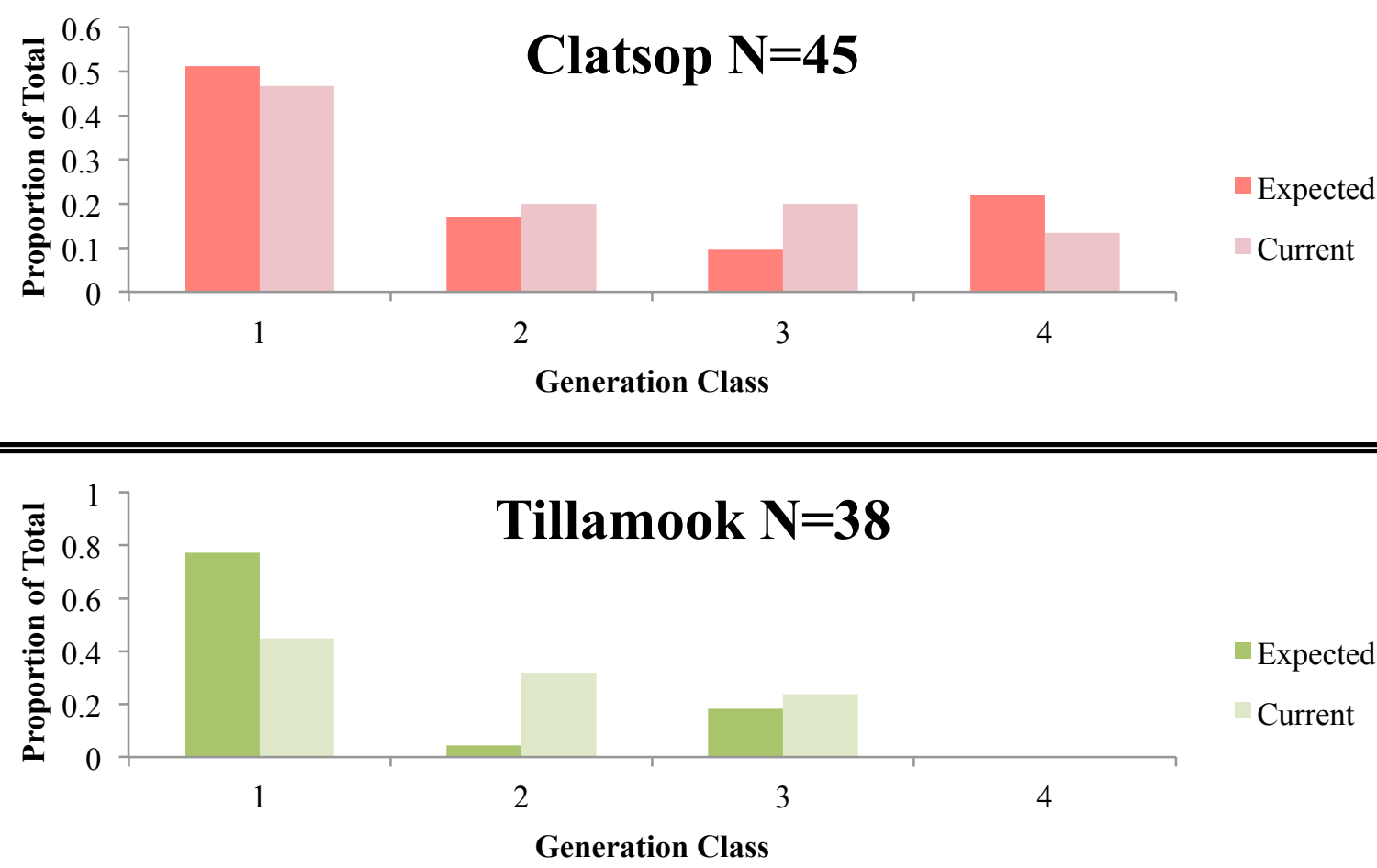


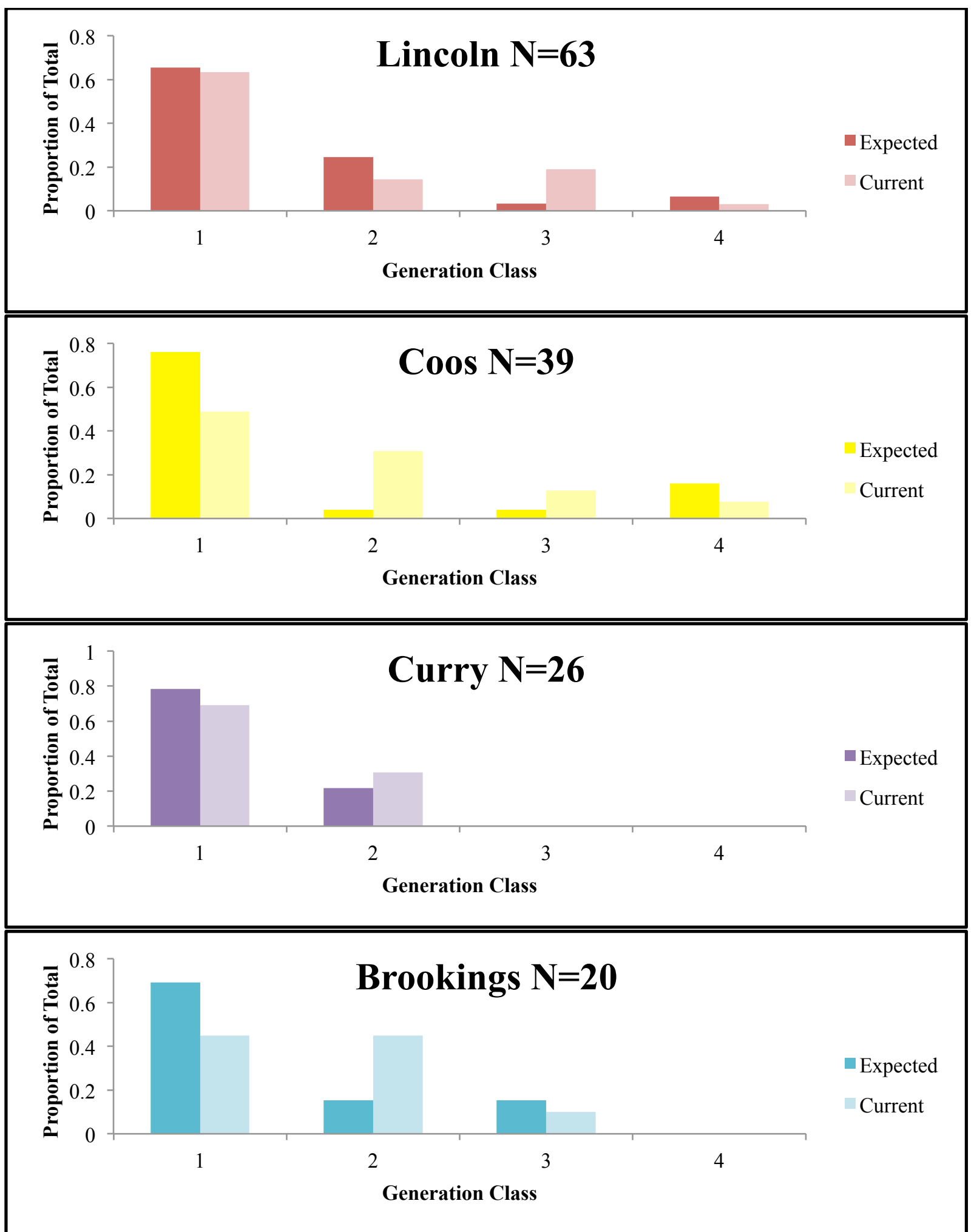

Figure 5.3. Differences between expected and current generational class proportions by port group. 
Socioeconomic Drivers of Familial Succession. When prompted about fisher expectations of familial continuation in fishing, a fisher's vessel length and number of vessels owned were the main determinates of expectations. When considering vessel length, for each unit ( 1 foot) that a fisher's vessel increases, the odds of familial succession increases by a factor 1.61. If a fisher owns two fishing vessels, the odds of familial succession increase by a factor of 2.77 (Figure 5.4).

The final model was significantly different when compared to the null model and ANOVA revealed no significant differences between the full and final models $\left(\right.$ McFadden $\mathrm{R}^{2}=0.062$, Nagelkerke $\mathrm{R}^{2}=0.101, \mathrm{Chi}^{2} \mathrm{p}=0.17$ ).

Table 5.4. Regression output for variables influencing familial succession probability on a $\mathbf{9 5 \%}$ confidence interval. Variables influencing probability of familial succession indicated in bold ( $\mathrm{N}=126,92$ no succession or unsure, 34 succession).

\begin{tabular}{|ccccccc|}
\hline Variable & $\boldsymbol{\beta}$ & SE & $\mathbf{P}$ & Odds & $\mathbf{2 . 5 0 \%}$ & $\mathbf{9 7 . 5 0 \%}$ \\
\hline Intercept & -1.20 & 0.25 & 0.0003 & 0.30 & 0.18 & 0.48 \\
Vessel Length & $\mathbf{0 . 4 8}$ & $\mathbf{0 . 2 2}$ & $\mathbf{0 . 0 3 1}$ & $\mathbf{1 . 6 1}$ & $\mathbf{1 . 0 5}$ & $\mathbf{2 . 5 5}$ \\
2 Vessels Owned & $\mathbf{1 . 0 2}$ & $\mathbf{0 . 6 1}$ & $\mathbf{0 . 0 9 7}$ & $\mathbf{2 . 7 7}$ & $\mathbf{0 . 8 0 5}$ & $\mathbf{9 . 2 9}$ \\
Generation & 0.055 & 0.274 & 0.840 & - & - & - \\
CPUE & -0.17 & 0.30 & 0.568 & - & - & - \\
Financial Dependence & -0.148 & 0.287 & 0.607 & - & - & - \\
\hline
\end{tabular}

$\beta=$ Estimate, $\mathrm{SE}= \pm$ standard error of the mean, $2.5 \%$ and $97.5 \%=$ confidence intervals McFadden $\mathrm{R}^{2}=0.062$, Nagelkerke $\mathrm{R}^{2}=0.101, \mathrm{Chi}^{2} \mathrm{p}=0.17$

The related regression curves are plotted in Figure 5.4. The curves illustrate that vessel length and number of vessels owned significantly increase probability of familial succession within the commercial fishing industry (binomial logistic; $\mathrm{N}=126,92$ no succession or unsure, 34 succession). 


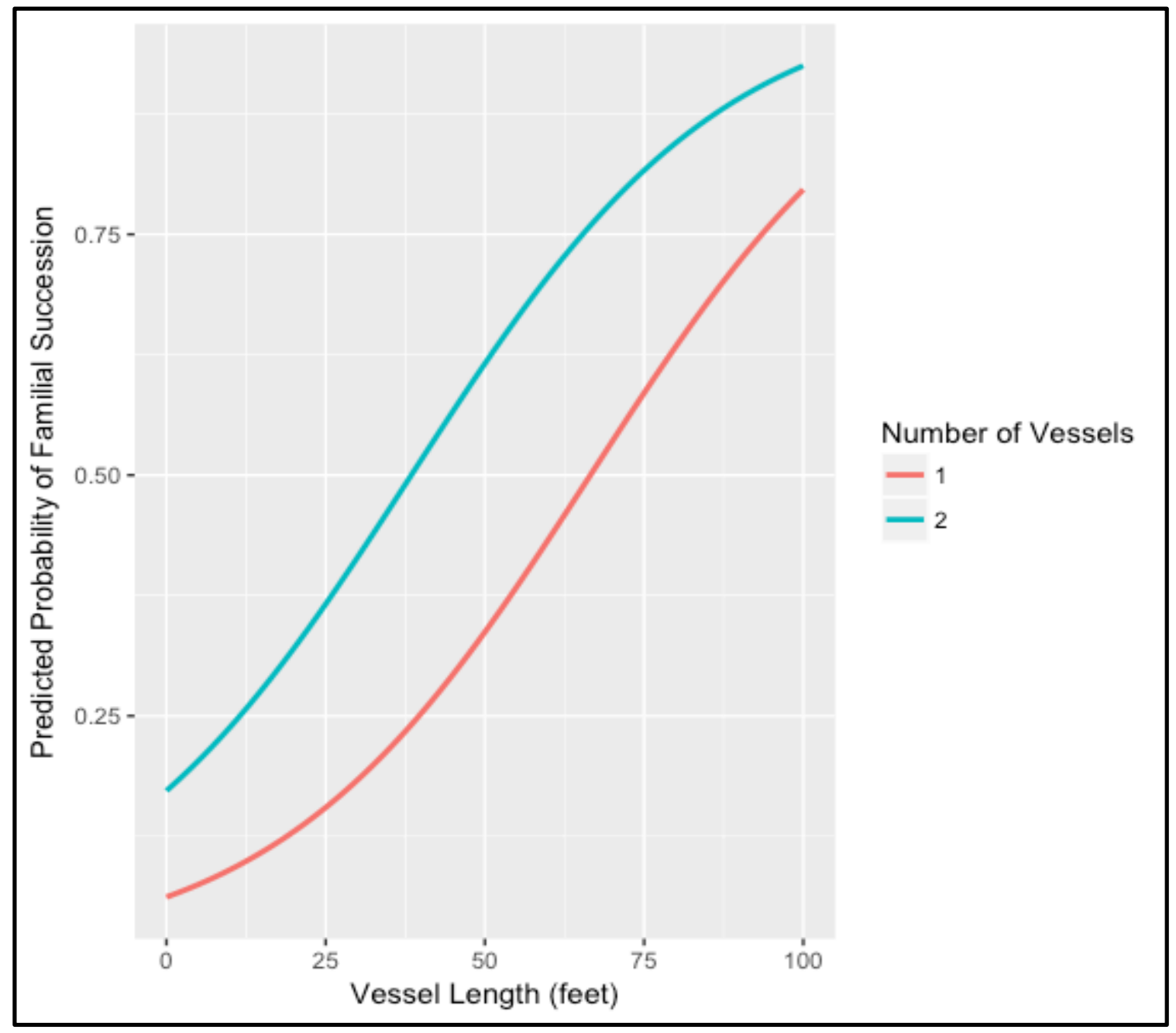

Figure 5.4. Regression curves relating vessel length and number of vessels owned to familial successional expectations.

Key Findings: Section 5.

- The most common expectation among first, second and third-generation fishers was that their children would not continue to participate in their family fishing operation. In the Dungeness crab and salmon fisheries, the fourth or greater generation fishers were more likely to expect their family members would continue fishing. In the charter fishery, second-generation fishers were more likely to expect their family members would continue fishing. In the Tillamook port group, it appears that in general, all fishers expected that their family members would not continue fishing, while in the Lincoln port group second-generation and forth or greater generation fishers were more likely to expect their family members would continue fishing.

- Probability of expectations for continuation of familial involvement increases by a factor 1.64 for each unit ( 1 foot) that a fisher's vessel length increases, and increases by a factor of 2.77 if a fisher owns two fishing vessels. 


\section{MANAGEMENT IMPLICATIONS}

\section{Climatic and oceanic variability impacts fishery dynamics.}

Observed shifts in fishing effort correlated with periods of low fish stock health and high oceanic variability that often resulted in fishery closures as well as market price fluctuations. Large-scale warming events have resulted in domoic acid-producing algal blooms that have led to delays in 2016 and 2017 Dungeness crab fishing season and the most recent closure in the salmon fishery, during the 2017-fishing season (McCabe et al., 2016; McKibben et al, 2017). In the words of one fisher:

"My effort has been impacted greatly by changing ocean conditions. Climate change has led to warmer oceans that produce more algal blooms that ultimately cause seasonal delays."

Furthermore, over the last century, salmon populations in the Northwestern United States and Canada have experienced declines, mainly linked to habitat loss and climatic variability (Gavin et al. 2017; Lawson 1993). Decadal scale oceanic fluctuations, such as the Pacific Decadal and El Nino Southern Oscillations, characterized by wide variability in sea surface temperatures, have been cited as major influences on these population declines (Mantua et al. 1997; Drake and Naiman 2007). Since 2006, low stock assessments have resulted in five spatial closures for Oregon's commercial salmon troll fishery that have led to millions of dollars in lost revenue (Richardson et al. 2018). The most recent spatial closure (the first since 2010) occurred south of the city of Florence during the 2017-fishing season, which corresponded to the decrease in effort observed between 2014 and 2017.

Reduced expectations around familial continuation in fishing was also present in fisheries that have been directly impacted by closures, while fisheries that appeared more resilient were projected to experience less variability in familial retention. For this reason, climatic fluctuations must be considered when evaluating natural resource industry dynamics.

\section{Larger fishing operations are more resilient to oceanic, regulatory, economic, and market variability. \\ Large vessel size and increased travel capacity (measured in miles traveled to fish) were indicative of high catch per unit effort. Larger fishing operations allow for more gear storage than smaller vessels and are typically able fish for longer periods of time in highly variable weather conditions, due to increased fuel capacity and durability (Le Pape and Vigneau 2001; Smith et al. 2010; Davis et al. 2017). These fishers generate more revenue per trip and are less vulnerable to changing ocean and weather conditions. One surveyed fisher reflected on the difficulties of reduced fishing capacity:}

"I have a smaller boat (36 feet) that made it hard to travel and fish successfully. For that reason, I lost interest and sold my salmon permit." 


\section{Salmon fishers that have diversified business operations can effectively cope with variability.}

Due to the volatile nature of salmon populations, fishing operations that are able travel farther to fish have higher catch per unit effort. One fisher reflected on the importance of business diversification:

"I have three boats and multiple permit and multiple fisheries. Any opportunity a fisherman has is vital to financial survival. Whether used or not they are important due to fishery fluctuation. [Other permits] could be needed when other fisheries are in a down cycle."

\section{In the future, commercial fleets will be dominated by large, intergenerational fishing operations.}

Fishers with smaller, non-intergenerational fishing operations, and increased activity in the nearshore are particularly vulnerable to climatic, economic, regulatory, and ecological variability and are less likely to participate in familial succession. Barriers to maintain profitability in an industry dominated by conglomerate-like operations will ultimately drive smaller operations to scale-up, shift to new markets or exit the commercial fishing industry.

\section{Local economies drive familial succession and catch per unit effort.}

Patterns in familial succession and CPUE often mirror shifts in local industry as well as locationspecific fleet characteristics. In the Tillamook County port group, reduced succession correlated with the industry shift from the commercial to recreational fishing sector (Package and Conway 2010a). Furthermore, dory fishers, who utilize small, wooden vessels that launch from the beach, historically characterized the Pacific City fleet (Hall and Murphy 2012). Small vessel size may reduce economic viability, resulting in a decline in youth participation in commercial fishing. This may be the opposite trend for large, heavily commercialized port towns that consistently prove lucrative, such as the Lincoln County group, which encompasses the largest fleet on the Oregon coast. Perhaps the ability to establish a fishing operation in a large, competitive geographic location means that a business is already scaled-up to a size that is profitable and resilient (Package and Conway 2010b). For this reason, fishery dynamics should continue to be studied with consideration of microeconomics and site-specificity.

\section{Trends in the charter fleet are difficult to predict.}

Due to the nature of the business (primarily day trips with tourists), climatic and ecological variability makes this fleet particularly susceptible to volatility. Rough weather, ocean conditions, and area closures may disproportionately impact this specific fishery. This volatility, however, is homogenous across all fisheries and may lead to shifts from commercial fishing to recreational fishing, as seen in Tillamook County. This may occur because charter fleets are more dependent on tourism, rather than profitable landings. However, because the charter fleet displays vastly different business operations and behaviors, responses from that fishery did not receive advanced statistical analyses. For that reason, drawing conclusions about fishing effort is difficult.

Fishers may be shifting between fisheries.

Interactions with other fisheries must be taken into account when internal patterns are not apparent. Increases and decreases in effort may be indicative of fishers shifting from one fishery 
to another due to internal volatility or stability. Because neither groundfish nor salmon fisheries appear to provide a sufficient amount of income, fishers may participate in both and switch between the two based on fishery health. Furthermore, high CPUE measurements may indicate strength and stability in fish stocks, which may explain why anticipated familial succession appears to be constant within the groundfish fisheries. High anticipation of familial succession among second-generation charter fishers may also signal a shift from commercial to recreational fishing.

There is no support that marine reserve designation has displaced or reduced fishing effort. Data from this study do not reveal any trends in perceptions surrounding marine reserves and overall, fishers appeared to hold relatively neutral opinions. Nearshore variability, whether climatic, economic or regulatory, is likely to disproportionately impacts small-scale fishing operations. While economic losses may appear marginal, as climate variability increases, preservation and sustainable exploitation of productive fishing grounds are more becoming more important than ever:

"The 3\% of profit from marine reserves would come on days too windy to participate elsewhere. Redfish Rocks marine reserve is in a protected bay. The wind is unpredictable in some seasons and my family still needs food and shoes. My point, it's an incredibly important 3\%, don't undervalue it."

Together, socio-ecological and economic patterns paint a picture of social resiliency; however, natural ecosystems shift and respond to environmental pressures that inevitably drive and limit the ways in which humans interact with them. In order to holistically quantify and assess fishing effort shifts, social, ecological, climatic and economic factors need to be considered and incorporated into models that aim to explain human behavior. 


\section{REFERENCES}

Branch, T. A., Hilborn, R., Haynie, A. C., Fay, G., Flynn, L., Griffiths, J., ... \& Young, M. (2006). Fleet dynamics and fishermen behavior: lessons for fisheries managers. Canadian Journal of Fisheries and Aquatic Sciences, 63(7), 1647-1668.

Caracciolo, D. (2017). Youth Recruitment and an Aging Workforce: A Pilot Study of Intergenerational Family Business in Oregon's Commercial Fishing Industry.

Carothers, C. (2011). Equity and access to fishing rights: exploring the community quota program in the Gulf of Alaska. Human Organization, 70(3), 213-223.

Carothers, C., \& Chambers, C. (2012). Fisheries privatization and the remaking of fishery systems. Environment and Society, 3(1), 39-59.

Cross, J. E. (2001). What is Sense of Place? Paper presented at the Headwaters Conference, Western State Colorado University, CO.

Dalton, T. M. (2004). An approach for integrating economic impact analysis into the evaluation of potential marine protected area sites. Journal of Environmental Management, 70(4), 333-349. doi:https://doi.org/10.1016/j.jenvman.2003.12.012.

Davis, S., Sylvia, G., Yochum, N., \& Cusack, C. (2017). Oregon Dungeness Crab Fishery Bioeconomic Model: A Fishery Interactive Simulator Learning Tool Final Report. Corvallis, Oregon: OSU Coastal Oregon Marine Experiment Station and The Research Group, LLC. Retrieved from http://oregonmarinereserves.com.

Demsetz, H. (1982). Barriers to Entry. The American Economic Review, 72(1), 47-57.

Del Valle, I., Astorkiza, I., \& Astorkiza, K. (2003). Fishing effort validation and substitution possibilities among components: the case study of the VIII division European anchovy fishery. Applied Economics, 35(1), 63-77.

Dillman, D. A. (1978). Mail and telephone surveys: The total design method (Vol. 19): Wiley New York.

Donkersloot, R. (2011). What keeps me here: gendered and generational perspectives on rural life and leaving in an Irish fishing locale. University of British Columbia.

Duncan, W. J. (1979). Mail questionnaires in survey research: A review of response inducement techniques. Journal of Management, 5(1), 39-55.

Eardley, C., \& Murphy, M. (2013). Long Form Recreational Fishing Community Profile: Cascade Head and the Coastal Salmon River Area, Oregon. Prepared for Oregon Department of Fish and Wildlife. Retrieved from http://oregonmarinereserves.com/. 
Epperly, H., Swearingen, T., \& Polis, H. (2017). 2010, 2011, 2014, and 2015 Business Surveys: Redfish Rocks, Cape Perpetua, Otter Rock, Cascade Head and Cape Falcon Marine Reserves. Oregon Department of Fish and Wildlife. Retrieved from http://oregonmarinereserves.com/.

Executive Order 08-07. (2008). Directing State Agencies To Protect Coast Communities In Siting Marine Reserve and Wave Energy Projects, 08-07 C.F.R.

Fox, R. J., Crask, M. R., \& Kim, J. (1988). Mail survey response rate: A meta-analysis of selected techniques for inducing response. Public Opinion Quarterly, 52(4), 467-491.

Gale, H. F. (2003). Age-Specific Patterns of Exit and Entry in U.S. Farming, 1978-1997. Review of Agricultural Economics, 25(1), 168-186.

Gell, F. R., \& Roberts, C. M. (2003). Benefits beyond boundaries: the fishery effects of marine reserves. Trends in Ecology \& Evolution, 18(9), 448-455. doi:10.1016/S0169-5347(03)00189-7

Goyder, J. C. (1982). Further evidence on factors affecting response rates to mailed questionnaires. American Sociological Review, 550-553.

Halpern, B. S. (2003). The Impact of Marine Reserves: Do Reserves Work and Does Reserve Size Matter? Ecological Applications, 3(1), 21.

Heberle, R. (1938). The causes of rural-urban migration a survey of German theories. American Journal of Sociology, 43(6), 932-950.

Heberlein, T. A., \& Baumgartner, R. (1978). Factors affecting response rates to mailed questionnaires: A quantitative analysis of the published literature. American sociological review, 447-462.

Himes-Cornell, A., \& Kent, K. (2014). Involving fishing communities in data collection: a summary and description of the Alaska Community Survey, 2011. U.S. Dep. Commerce. NOAA Tech. Memo. NMFSAFSC-284, 171 pp. Retrieved at https//:www.afsc.noaa.gov.

House Bill 3013, Oregon House 3 (2009).

Kirkley, J. E., Färe, R., Grosskopf, S., McConnell, K., Squires, D. E., \& Strand, I. (2001). Assessing capacity and capacity utilization in fisheries when data are limited. North American Journal of Fisheries Management, 21(3), 482-497.

Kanuk, L., \& Berenson, C. (1975). Mail surveys and response rates: A literature review. Journal of Marketing Research, 440-453.

Klein, C., Chan, A., Kircher, L., Cundiff, A., Gardner, N., Hrovat, Y., . . Airame, S. (2008a). Striking a balance between biodiversity conservation and socioeconomic viability in the design of marine protected areas. Conservation Biology, 22(3), 691-700.

Klein, C. J., Steinback, C., Scholz, A. J., \& Possingham, H. P. (2008b). Effectiveness of marine reserve 
networks in representing biodiversity and minimizing impact to fishermen: a comparison of two approaches used in California. Conservation letters, 1(1), 44-51.

Lawson, P. W. (1993). Cycles in Ocean Productivity, Trends in Habitat Quality, and the Restoration of Salmon Runs in Oregon. Fisheries, 18(8), 6-10. doi:10.1577/15488446(1993)018<0006:CIOPTI $>2.0 . \mathrm{CO} ; 2$

Le Pape, O., \& Vigneau, J. (2001). The influence of vessel size and fishing strategy on the fishing effort for multispecies fisheries in northwestern France. ICES Journal of Marine Science, 58(6), 1232-1242.

Linsky, A. S. (1975). Stimulating responses to mailed questionnaires: A review. Public Opinion Quarterly, 39(1), 82-101.

Low, S. M. (1992). Symbolic Ties That Bind. In I. Altman \& S. M. Low (Eds.), Place Attachment (pp. 165-185). Boston, MA: Springer US.

Mabogunje, A. L. (1970). Systems approach to a theory of rural-urban migration. Geographical analysis, 2(1), 1-18.

Marino, E. (2015). Cape Falcon Marine Reserve: A Pilot Study of Impacts, Outcome and Effort Shifts of Commercial and Charter Fishers. Oregon State University-Cascades. Retrieved from http://oregonmarinereserves.com/.

McCabe, R. M., Hickey, B. M., Kudela, R. M., Lefebvre, K. A., Adams, N. G., Bill, B. D., . . Trainer, V. L. (2016). An unprecedented coastwide toxic algal bloom linked to anomalous ocean conditions. Geophysical research letters, 43(19).

McCluskey, S. M., \& Lewison, R. L. (2008). Quantifying fishing effort: a synthesis of current methods and their applications. Fish and fisheries, 9(2), 188-200.

McKibben, S. M., Peterson, W., Wood, A. M., Trainer, V. L., Hunter, M., \& White, A. E. (2017). Climatic regulation of the neurotoxin domoic acid. Proceedings of the National Academy of Sciences, 114(2), 239-244.

Murphy, M., \& Hall, E. (2013). Long Form Fishing Community Profile: Depoe Bay, Oregon. Prepared for Oregon Department of Fish and Wildlife. Retrieved from http://oregonmarinereserves.com/

Nederhof, A. J. (1988). Effects of a final telephone reminder and questionnaire cover design in mail surveys. Social Science Research, 17(4), 353-361.

Needham, M. D., Cramer, L. A., \& Johnston, J. R. (2016). Resident perceptions of the Oregon marine reserve system. Prepared for Oregon Department of Fish and Wildlife. Retrieved from http://oregonmarinereserves.com/

Oregon Department of Fish and Wildlife. (2016). Pounds and Values of Commercially Caught Fish and 
Shellfish Landed In Oregon: Years 2007-2016. [Data Set]

Oregon Department of Fish and Wildlife. (2017a). Marine Reserves: Human Dimensions Monitoring Plan. Retrieved from http://oregonmarinereserves.com/

Oregon Department of Fish and Wildlife (2017b). ODFW fisheries permit files for 2015-2017. [Data Set].

Ocean Policy Advisory Committee. (2008). Oregon Marine Reserve Policy Recommendations. Department of Land Development and Conservation. Retrieved from www.oregon.gov/LDC

Pacific Fisheries Information Network. (2017). Annual vessel summary data, April 2009, March 2010, July 2011, April 2013, March 2014, April 2015, November 2016, and March 2017 extractions. [Data Set].

Package, C., \& Conway, F. (2010a). Long Form Fishing Community Profile: Garibaldi, Oregon. Oregon Department of Fish and Wildlife. Retrieved from http://oregonmarinereserves.com/

Package, C., \& Conway, F. (2010b). Long Form Fishing Community Profile: Newport, Oregon. Oregon Department of Fish and Wildlife. Retrieved from http://oregonmarinereserves.com/

Package, C., \& Conway, F. (2010c). Long Form Fishing Community Profile: Port Orford, Oregon. Oregon Department of Fish and Wildlife. Retrieved from http://oregonmarinereserves.com/

Pascoe, S., \& Robinson, C. (1996). Measuring changes in technical efficiency over time using catch and stock information. Fisheries Research, 28(3), 305-319.

Pollnac, R., Christie, P., Cinner, J. E., Dalton, T., Daw, T. M., Forrester, G. E., ... McClanahan, T. R. (2010). Marine reserves as linked social-ecological systems. Proceedings of the National Academy of Sciences, 107(43), 18262-18265.

Power, N. G., Norman, M. E., \& Dupré, K. (2014).“The fishery went away": The impacts of long-term fishery closures on young people's experience and perception of fisheries employment in Newfoundland coastal communities. Ecology and Society, 19(3). doi:10.5751/ES-06693-190306

Rodomsky, B. T. \& Calavan T.R. (2015). The Oregon Commercial Nearshore Fishery Summary: 2014. Oregon Department of Fish and Wildlife Marine Resources Program. 43 pp. Retrieved from http://www.dfw.state.or.us/MRP.

Rodomsky, B. T., Calavan, T. R., \& Carpenter, A. L. (2016). The Oregon Commercial Nearshore Fishery Summary. Oregon Department of Fish and Wildlife Marine Resources Program. 51pp. Retrieved from http://www.dfw.state.or.us/MRP.

Rodomsky, B. T. \& Calavan, T. R. (2017). The Oregon Commercial Nearshore Fishery Summary: 2016. Oregon Department of Fish and Wildlife Marine Resources Program. 63 pp. Retrieved from 
http://www.dfw.state.or.us/MRP.

Richerson, K., Leonard, J., \& Holland, D. S. (2018). Predicting the economic impacts of the 2017 West Coast salmon troll ocean fishery closure. Marine Policy.

doi:https://doi.org/10.1016/j.marpol.2018.03.005

Rumelt, R. P. (1982). Diversification strategy and profitability. Strategic management journal, 3(4), 359369.

Ruttan, L. M. (2003). Finding fish: grouping and catch-per-unit-effort in the Pacific hake (Merluccius productus) fishery. Canadian Journal of Fisheries and Aquatic Sciences, 60(9), 1068-1077.

Sade, R. M. (2012). The graying of America: challenges and controversies. In: SAGE Publications Sage CA: Los Angeles, CA.

Scott, C. (1961). Research on mail surveys. Journal of the Royal Statistical Society. Series A (General), 143-205.

Senate Bill 1510, Oregon Senate 2 (2012).

Smith, M. D., Lynham, J., Sanchirico, J. N., \& Wilson, J. A. (2010). Political economy of marine reserves: Understanding the role of opportunity costs. Proceedings of the National Academy of Sciences, 107(43), 18300-18305.

Swearingen, T., \& Epperly, H. (2016). 2015 Visitor Intercept Survey: Cape Falcon Marine Reserve. Oregon Department of Fish and Wildlife. Retrieved from http://oregonmarinereserves.com/

Swearingen, T., Epperly, H., \& Kazloff, L. (2016). 2014 Visitor Intercept Survey: Cape Perpetua, Otter Rock, and Cascade Head Marine. Oregon Department of Fish and Wildlife. Retrieved from http://oregonmarinereserves.com/

Teske, R. H., Hazlett, M. H., \& Parker, M. L. (1983). Texas Crime Poll: 1982 Survey. Survey Research Program, Texas Criminal Justice Center, Sam Houston State University.

The Research Group, LLC. \& Golden Marine Consulting. (2012). Using Spatial Analysis of Fisheries and Habitat Data to Evaluate Economic Effects of Oregon Marine Reserve Sites. Prepared for Oregon Department of Fish and Wildlife. Retrieved from http://oregonmarinereserves.com/

The Research Group, LLC. (2013a). Oregon's Commercial Fishing Industry, Year 2011 and 2012 Review. Prepared for Oregon Department of Fish and Wildlife. Retrieved from http://oregonmarinereserves.com/

The Research Group, LLC. (2013b). Economic Impact of Marine Recreational Fishing: Oregon Pilot Survey. Prepared for Oregon Department of Fish and Wildlife. Retrieved from http://oregonmarinereserves.com/ 
The Research Group, LLC. (2018). Oregon Nearshore Fisheries Effort Shift Survey Commercial Fishing Representativeness Report. Prepared for Marine Resources Program, Oregon Department of Fish and Wildlife. 
APPENDIX A. Survey Instrument

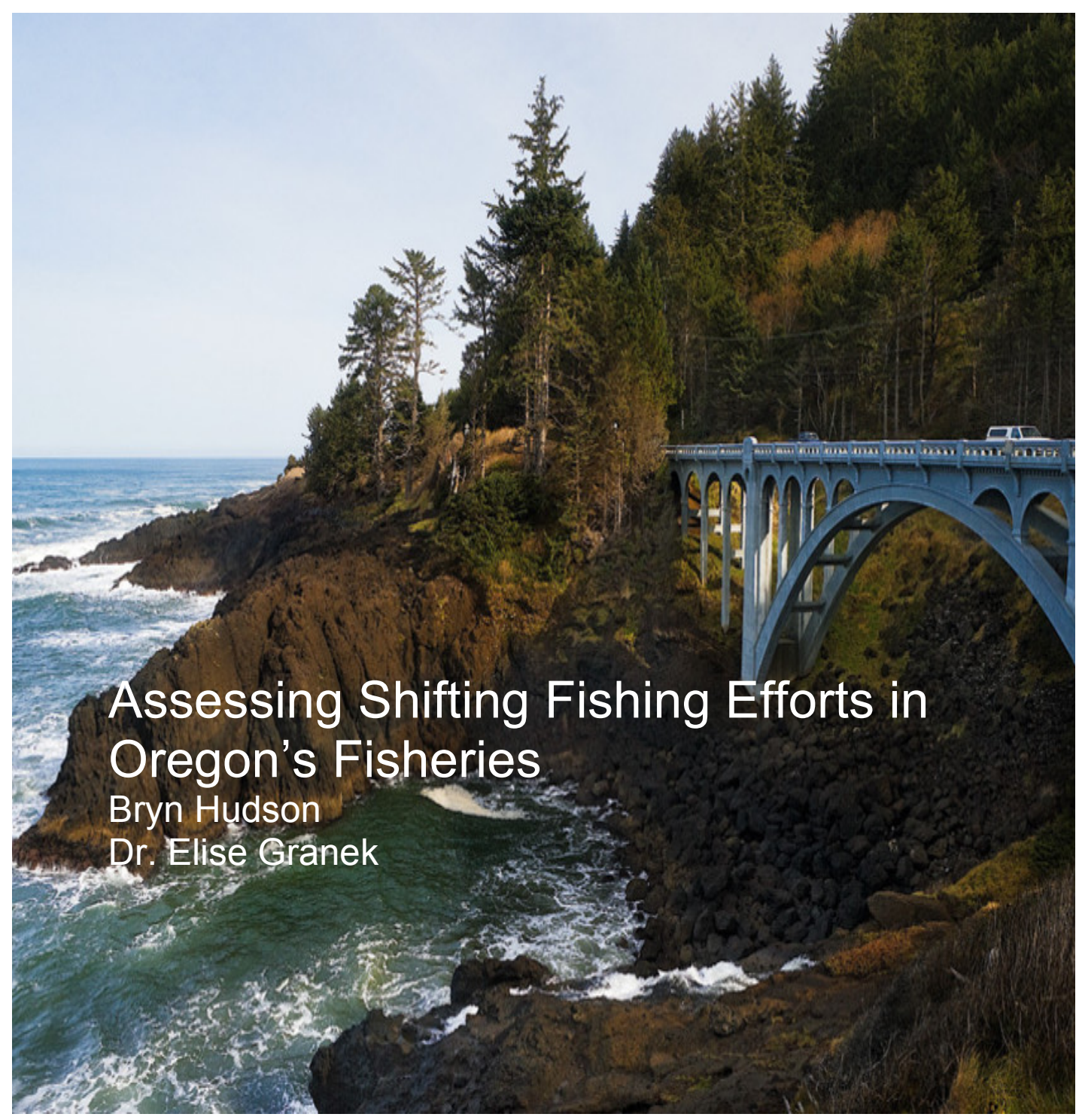

Portland State University

Department of Environmental Science and Management

POBox 751, Portland, OR 97207-9981 
Oregon Fishery Effort Survey

Department of Environmental Science \& Management

Portland State University

Post Office Box 751

Portland, Oregon 97207-0751

www.pdx.edu/esm

Hello! We are contacting you to ask for your help in a study on changes in Oregon fisheries over time. We are conducting this study as part of my graduate research at Portland State University with Drs. Elise Granek and Max Nielsen-Pincus, and in partnership with the Oregon Department of Fish and Wildlife.

As part of this study, we request that you complete the enclosed questionnaire about your experiences with Oregon fisheries. We will be evaluating shifting conditions in Oregon's nearshore commercial ground fish, Dungeness crab, nearshore salmon troll, urchin, charter and nearshore trawl fisheries. Participation in this study is an opportunity for you to voice your perspective and experience in Oregon's fisheries, which will contribute to a growing body of work regarding marine resource policy and management. Your responses will help develop more effective communication between management agencies and fishers.

Participation in this study will take 20-40 minutes and there is no more than minimal risk associated in your participation. Your personal information will only be used to mail and return your survey. Your responses are completely confidential, and your name will never be connected to your answers or included in any reporting. A final report will be published by Portland State University; a copy will be provided to the Oregon Department of Fish and Wildlife. If requested, we will send you a copy as well.

There is a separate postcard enclosed in this packet. On that postcard, you can enter into a raffle to win one of five $\$ 50$ gift cards and you may also opt to sign up for an in-depth interview for a related study. This interview is an opportunity to speak with another researcher about any additional information you feel is critical in understanding changes in fisheries or fisheries management over time. You will be compensated with a $\$ 25$ gift card if you choose to participate in the interview. Please include the postcard with your return mailing.

Your decision to participate in this study is completely voluntary, you may skip any questions you do not want to answer, and you have the right to end your participation at any time. When you complete and return the attached questionnaire, it means that you have read and understood this information, you agree to take part in this study, and you are over 18 years old. Thank you very much for your time and support of this study.

Sincerely,

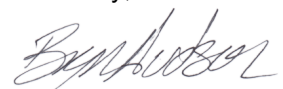

Bryn Hudson (Graduate Student)

503-686-5407

bryn@pdx.edu

PS. The Portland State University Institutional Review Board overseeing human research has reviewed and approved this study. If you have any questions before or after the survey, you can contact me, or my advisor Elise Granek at graneke@pdx.edu. If you have questions regarding your rights as a research participant, you may call the Portland State University Office for Research Integrity at (503) 725-2227 or 1(877) 480-4400. The Office for Research Integrity is the office that supports the PSU Institutional Review Board. For more information, you may also access the Institutional Review Board website at https://sites.google.com/a/pdx.edu/research/integrity 


\section{舟 Portland State 2}

\section{Oregon Fishing Effort Survey}

Please answer the following questions to the best of your ability. Feel free to write your thoughts and comments anywhere on the survey.

1. Currently, what is your primary operating port? (Circle one or write one in)
a. Astoria, Warrenton, Hammond area
e. Port Orford, Gold Beach area
b. Garibaldi, Pacific City area
f. Brookings
c. Newport, Depoe Bay, Florence area
g. Other port in Oregon:
d. Coos Bay, Bandon, Charleston,
h. Port not in the State of Oregon: Winchester Bay area

2. For each commercial fishery in Oregon that you participated in since at least 2011 , fill in the table below.

\begin{tabular}{|l|l|l|l|}
\hline \multicolumn{1}{|c|}{$\begin{array}{c}\text { Fishery } \\
\text { (Circle all that apply) }\end{array}$} & $\begin{array}{c}\text { Years Fished } \\
\text { (From-to) }\end{array}$ & $\begin{array}{c}\text { Fulltime fishery } \\
\text { participant } \\
\text { (Write in yes or no) }\end{array}$ & $\begin{array}{c}\text { Percentage of household } \\
\text { income derived from } \\
\text { fishery } \\
\text { (Column must add to 100\% } \\
\text { fishing income) }\end{array}$ \\
\hline Nearshore ground fish & & & \\
\hline Dungeness crab & & & \\
\hline Salmon troll & & & \\
\hline Sea Urchin & & & \\
\hline Charter & & & \\
\hline $\begin{array}{l}\text { Nearshore trawl } \\
\text { (Beach dragging) }\end{array}$ & & & \\
\hline Other: & & & \\
\hline
\end{tabular}

If you have discontinued your activity in any of the above fisheries since 2011, please state the name of the fishery(ies) and the reason for your discontinuation in the box below. 
3. How many generations has your family participated in Oregon's fisheries? (Circle one)
a. 1 (I am a first generation fisher)
b. 2
c. 3
d. 4 or more

4. Do you anticipate that your children will participate in your family's fishing operation? (Circle one)
Yes
No
Maybe
I Don't Have Children

5. To what degree do you agree/disagree with each statement below? (Check one box for each statement)

\begin{tabular}{|l|lllll|}
\hline \multicolumn{1}{|c|}{ Statement } & $\begin{array}{l}\text { Strongly } \\
\text { disagree }\end{array}$ & $\begin{array}{c}\text { Moderately } \\
\text { disagree }\end{array}$ & Neutral $\quad \begin{array}{c}\text { Moderately } \\
\text { agree }\end{array}$ & $\begin{array}{c}\text { Strongly } \\
\text { agree }\end{array}$ \\
\hline $\begin{array}{l}\text { Public agencies have done a good } \\
\text { job advocating for my personal } \\
\text { interests }\end{array}$ & $\square$ & $\square$ & $\square$ & $\square$ \\
\hline $\begin{array}{l}\text { Public agencies have done a good } \\
\text { job advocating for the interests of } \\
\text { the fisheries in which I participate }\end{array}$ & $\square$ & $\square$ & $\square$ & $\square$ \\
\hline $\begin{array}{l}\text { Public agencies adequately } \\
\text { communicate issues regarding } \\
\text { Oregon fishery management to my } \\
\text { local fishing community }\end{array}$ & $\square$ & $\square$ & $\square$ & $\square$ \\
\hline $\begin{array}{l}\text { I am satisfied with the amount of } \\
\text { contact I have with agency } \\
\text { representatives }\end{array}$ & $\square$ & $\square$ & $\square$ & $\square$ \\
\hline $\begin{array}{l}\text { I feel comfortable voicing my } \\
\text { opinions about Oregon ocean } \\
\text { management and policy to public } \\
\text { agencies }\end{array}$ & $\square$ & $\square$ & $\square$ & $\square$ \\
\hline $\begin{array}{l}\text { I know where to obtain information } \\
\text { about policy changes regarding } \\
\text { Oregon ocean issues }\end{array}$ & $\square$ & $\square$ & $\square$ & $\square$ \\
\hline $\begin{array}{l}\text { I know where to obtain information } \\
\text { about scientific research regarding } \\
\text { Oregon ocean issues }\end{array}$ & $\square$ & $\square$ & $\square$ \\
\hline
\end{tabular}


For questions 6-14, please write in each fishery that you participate in. If you participate in more than two, pick the two fisheries that contribute most to your net household income. If you are a participant in the Charter fishery, please select the two most lucrative species for which you fish: example= Charter: Dungeness crab, Charter: Salmon.

6. Since 2011, which best describes the extent to which your catch rates have been generally increasing or decreasing? (Check one box for each statement)

\begin{tabular}{|c|cccccc|}
\hline Fishery & $\begin{array}{c}\text { Large } \\
\text { decreases }\end{array}$ & $\begin{array}{c}\text { Moderate } \\
\text { decreases }\end{array}$ & $\begin{array}{c}\text { Some } \\
\text { increases and } \\
\text { decreases }\end{array}$ & $\begin{array}{c}\text { Moderate } \\
\text { increases }\end{array}$ & $\begin{array}{c}\text { Large } \\
\text { increases }\end{array}$ & $\begin{array}{c}\text { No clear } \\
\text { trend }\end{array}$ \\
\hline & $\square$ & $\square$ & $\square$ & $\square$ & $\square$ & $\square$ \\
\hline & $\square$ & $\square$ & $\square$ & $\square$ & $\square$ & $\square$ \\
\hline
\end{tabular}

7. What do you see to be the main factors influencing the trends in your catch rates? (Circle up to $\mathbf{3}$ factors that influence catch rates and rank them 1-3, with 1 being the largest influence)

Fishery:

\section{RANK}

a. __ Operating expenses

b. Catch limits

c. Catch per unit efforts

d. Ocean conditions

e. Weather conditions

f. _ Market prices

g. __ Regulations (specify):

h. Regulations (specify):

i. _ Other:
Fishery:

\section{RANK}

a. __ Operating expenses

b. Catch limits

c. Catch per unit efforts

d. Ocean conditions

e. Weather conditions

f. _ Market prices

g. Regulations (specify):

h. Regulations (specify):

i. Other:

8. Since 2011, which best describes the extent to which your fishery related profits have been generally increasing or decreasing? (Check one box for each statement)

\begin{tabular}{|c|cccccc|}
\hline Fishery & $\begin{array}{c}\text { Large } \\
\text { decreases }\end{array}$ & $\begin{array}{c}\text { Moderate } \\
\text { decreases }\end{array}$ & $\begin{array}{c}\text { Some } \\
\text { increases and } \\
\text { decreases }\end{array}$ & $\begin{array}{c}\text { Moderate } \\
\text { increases }\end{array}$ & $\begin{array}{c}\text { Large } \\
\text { increases }\end{array}$ & $\begin{array}{c}\text { No clear } \\
\text { trend }\end{array}$ \\
\hline & $\square$ & $\square$ & $\square$ & $\square$ & $\square$ & $\square$ \\
\hline & $\square$ & $\square$ & $\square$ & $\square$ & $\square$ & $\square$ \\
\hline
\end{tabular}


9. What do you see as the main factors influencing the trends of your fishery related profits? (Circle up to 3 factors that influence profits and rank them 1-3, with 1 being the largest influence)

Fishery:

\section{RANK}
a. Operating expenses
b. Catch limits
c. Catch per unit efforts
d. Ocean conditions
e. Weather conditions
f. — Market prices
g. __ Regulations (specify):
h. Regulations (specify):
i. Other:

Fishery:

\section{RANK}
a. Operating expenses
b. Catch limits
c. _ Catch per unit efforts
d. Ocean conditions
e. Weather conditions
f. _ Market prices
g. Regulations (specify):
h. Regulations (specify):

10. Since 2011, what are the main factors that explain the variability in your fishing effort? (Circle up to 3 factors that influence fishing effort and rank them 1-3, with 1 being the largest influence)

Fishery:

\section{RANK}

a.

b.

c.

Catch per unit efforts

d. Ocean conditions

e. W_ Weather conditions

f. __ Market prices

g. __ Regulations (specify):

h. Regulations (specify):

i. Other:
Fishery:

\section{RANK}

a. __ Operating expenses

b. Catch limits

c. Catch per unit efforts

d. Ocean conditions

e. W__ Weather conditions

f. Market prices

g. ___ Regulations (specify):

h. Regulations (specify): Other:

11. Please fill the table in below explaining how the percentage of each cost has contributed to your total operating costs in the years 2011,2014 and 2017 . (Ensure each box adds to $100 \%$ for each year)

\begin{tabular}{|c|c|c|c|}
\hline Fishery & 2011 & 2014 & 2017 \\
\hline & $\begin{array}{c}\% \text { fuel } \\
\% \text { crew } \\
\% \text { other }\end{array}$ & $\begin{array}{c}\% \text { fuel } \\
\% \text { crew } \\
\% \text { other }\end{array}$ & $\begin{array}{l}\% \text { fuel } \\
\% \text { crew } \\
\% \text { other }\end{array}$ \\
\hline & $\begin{array}{c}\% \text { fuel } \\
\% \text { crew } \\
\% \text { other }\end{array}$ & $\begin{array}{c}\text { \% fuel } \\
\% \text { crew } \\
\% \text { other }\end{array}$ & $\begin{array}{c}\text { \% } \% \text { fuel } \\
\% \text { crew } \\
\% \text { other }\end{array}$ \\
\hline
\end{tabular}


12. To the best of your memory, fill in the table below that describes your fishing effort of each fishery in which you participate over the last seven years (2011-2017). We acknowledge that the 2017 season is not over for some fisheries, answer for that year to the best of your ability. Please note that 3 nautical miles falls within state territorial waters and is typically less than 40 fathoms deep.

\begin{tabular}{|c|c|c|c|c|}
\hline Fishery: & Year & 2011 & 2014 & 2017 \\
\hline \multicolumn{2}{|c|}{ Define your fishing season (Circle the months fished) } & $\begin{array}{l}\text { Jan. Feb. Mar. } \\
\text { Apr. May June } \\
\text { July Aug. Sept. } \\
\text { Oct. Nov. Dec. }\end{array}$ & $\begin{array}{l}\text { Jan. Feb. Mar. } \\
\text { Apr. May June } \\
\text { July Aug. Sept. } \\
\text { Oct. Nov. Dec. }\end{array}$ & $\begin{array}{l}\text { Jan. Feb. Mar. } \\
\text { Apr. May June } \\
\text { July Aug. Sept. } \\
\text { Oct. Nov. Dec. }\end{array}$ \\
\hline \multicolumn{5}{|c|}{$\begin{array}{l}\text { What percentage of your net household income was } \\
\text { derived from this fishery? }(0-100 \%)\end{array}$} \\
\hline \multicolumn{5}{|c|}{$\begin{array}{l}\text { About how many days did you fish during the season, } \\
\text { total? }(0-365)\end{array}$} \\
\hline \multicolumn{5}{|c|}{$\begin{array}{l}\text { About how many days did you fish during the season, } \\
\text { within } 3 \text { nautical miles? }(0-365)\end{array}$} \\
\hline \multicolumn{5}{|c|}{$\begin{array}{l}\text { About how many hours was your fishing gear deployed } \\
\text { each day during the season? }(0-24)\end{array}$} \\
\hline \multicolumn{5}{|c|}{$\begin{array}{l}\text { About how many hours was your fishing gear deployed } \\
\text { each day during the season, within } 3 \text { nautical miles? } \\
(0-24)\end{array}$} \\
\hline \multicolumn{5}{|c|}{$\begin{array}{l}\text { About how many miles did you travel before deploying } \\
\text { fishing gear? }\end{array}$} \\
\hline \multicolumn{5}{|c|}{$\begin{array}{l}\text { About how many days did you fish within what is now } \\
\text { marine reserve limits? }(0-365)\end{array}$} \\
\hline \multicolumn{5}{|c|}{$\begin{array}{l}\text { What percentage of your annual revenue was caught } \\
\text { within what is now marine reserve limits? }(0-100 \%)\end{array}$} \\
\hline Fishery: & Year & 2011 & 2014 & 2017 \\
\hline \multicolumn{2}{|c|}{ Define your fishing season (Circle the months fished) } & $\begin{array}{l}\text { Jan. Feb. Mar. } \\
\text { Apr. May June } \\
\text { July Aug. Sept. } \\
\text { Oct. Nov. Dec. }\end{array}$ & $\begin{array}{l}\text { Jan. Feb. Mar. } \\
\text { Apr. May June } \\
\text { July Aug. Sept. } \\
\text { Oct. Nov. Dec. }\end{array}$ & $\begin{array}{l}\text { Jan. Feb. Mar. } \\
\text { Apr. May June } \\
\text { July Aug. Sept. } \\
\text { Oct. Nov. Dec. }\end{array}$ \\
\hline \multicolumn{5}{|c|}{$\begin{array}{l}\text { What percentage of your net household income was } \\
\text { derived from this fishery? }(0-100 \%)\end{array}$} \\
\hline \multicolumn{5}{|c|}{$\begin{array}{l}\text { About how many days did you fish during the season, } \\
\text { total? }(0-365)\end{array}$} \\
\hline \multicolumn{5}{|c|}{$\begin{array}{l}\text { About how many days did you fish during the season, } \\
\text { within } 3 \text { nautical miles? }(0-365)\end{array}$} \\
\hline \multicolumn{5}{|c|}{$\begin{array}{l}\text { About how many hours was your fishing gear deployed } \\
\text { each day during the season? }(0-24)\end{array}$} \\
\hline \multicolumn{5}{|c|}{$\begin{array}{l}\text { About how many hours was your fishing gear deployed } \\
\text { each day during the season, within } 3 \text { nautical miles? } \\
(0-24)\end{array}$} \\
\hline \multicolumn{5}{|c|}{$\begin{array}{l}\text { About how many miles did you travel before launching } \\
\text { fishing gear? }\end{array}$} \\
\hline \multicolumn{5}{|c|}{$\begin{array}{l}\text { About how many days did you fish within what is now } \\
\text { marine reserve limits? }(0-365)\end{array}$} \\
\hline $\begin{array}{l}\text { What percentage of your } \\
\text { within what is now marine }\end{array}$ & $\begin{array}{l}\text { nue was caught } \\
\text { ts? }(0-100 \%)\end{array}$ & & & \\
\hline
\end{tabular}


13. Which best describes the type of impact that the establishment of no-take marine reserves has had on your ability to partake in at least one Oregon fishery in which you participate? If reserves have had NO CLEAR IMPACT on your fishing efforts, skip to the end of the survey. (Check one box for each statement)

\begin{tabular}{|c|c|c|c|c|c|}
\hline Fishery & $\begin{array}{l}\text { Largely } \\
\text { negative }\end{array}$ & $\begin{array}{l}\text { Moderately } \\
\text { negative }\end{array}$ & No clear impact & $\begin{array}{c}\text { Moderately } \\
\text { positive }\end{array}$ & $\begin{array}{l}\text { Largely } \\
\text { positive }\end{array}$ \\
\hline & $\square$ & $\square$ & $\square$ & $\square$ & $\square$ \\
\hline & 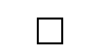 & $\square$ & $\square$ & $\square$ & $\square$ \\
\hline
\end{tabular}

14. How has marine reserve establishment impacted your ability to partake in any of the Oregon fisheries in which you participate? (Circle up to 3 outcomes and rank them 1-3, with 1 being the greatest impact)

Fishery:

RANK
a. ___ Fishing ground displacement
b. Increased spatial competition
c. Longer travel distances
d. Other:
e. Other:
f. _ Other:

Fishery:

\section{RANK}

a. ___ Fishing ground displacement

b. Increased spatial competition

c. Longer travel distances

d. Other:

e. Other:

f. Other:

15. Identify which marine reserve (if any) has had the greatest impact on your fishing operations. (Circle one)

\section{GREATEST IMPACT}

a. Marine reserve implementation has not impacted my fishing operation

b. Cape Falcon

c. Cascade Head

d. Otter Rock

e. Cape Perpetua

f. Redfish Rocks

\section{SECOND GREATEST IMPACT}

a. Marine reserve implementation has not impacted my fishing operation

b. Cape Falcon

c. Cascade Head

d. Otter Rock

e. Cape Perpetua

f. Redfish Rocks

-This is the end of the survey-

Thank you for your time. We greatly value your answers and opinions. Please return your survey and the raffle ticket in the self-addressed stamped envelop within two weeks.

Please remove and keep the cover letter for your records. If you have any questions or concerns, please contact the number given on the cover letter. If you would like to be entered in a raffle to win one of five $\$ 50$ gift cards, please fill out and send back the enclosed postcard in your return envelope.

Feel free to write any other thoughts you have about Oregon Fisheries in the space below or on the next page: 


\section{APPENDIX B. Respondent Perceptions of Management.}

Table B.1. Respondent perceptions of management aggregated by port group.

Statement \#1:Public agencies have done a good job advocating for my personal interests

A) Astoria, Warrenton, and Hammond $(\mathrm{N}=44)$

Median

$-1$

Mean

SD

0.87

0.13

C) Newport, Depoe Bay, and Florence $(\mathrm{N}=63)$

$\begin{array}{cccc}\text { Median } & \text { Mean } & \text { SD } & \text { SE } \\ -1 & +0.8 & 1.07 & 0.13\end{array}$

E) Port Orford and Gold Beach $(\mathrm{N}=28)$

Median Mean SD

$-1$

$-0.5$

1.07

0.2

H) Port not in Oregon $(\mathrm{N}=40)$

Median Mean SD

$\begin{array}{llll}0 & -0.4 & 0.90 & 0.14\end{array}$

Statement \#2: Public agencies have done a good job advocating for the interests of the fisheries in which I participate

A) Astoria, Warrenton, and Hammond ( $\mathrm{N}=44)$

B) Garibaldi and Pacific City $(\mathrm{N}=41)$

$\begin{array}{ccccccrr}\text { Median } & \text { Mean } & \text { SD } & \text { SE } & \text { Median } & \text { Mean } & \text { SD } & \text { SE } \\ -1 & -0.7 & 1.12 & 0.17 & -1 & -0.6 & 1.30 & 0.2\end{array}$

C) Newport, Depoe Bay, and Florence $(\mathrm{N}=63)$

D) Coos Bay, Bandon, Charleston and, Winchester Bay $(\mathrm{N}=39)$

$\begin{array}{cccccccc}\text { Median } & \text { Mean } & \text { SD } & \text { SE } & \text { Median } & \text { Mean } & \text { SD } & \text { SE } \\ -1 & -0.6 & 1.16 & 0.15 & -1 & -0.9 & 0.83 & 0.13\end{array}$

E) Port Orford and Gold Beach $(\mathrm{N}=28)$

F) Brookings $(\mathrm{N}=20)$

$\begin{array}{cccccccc}\text { Median } & \text { Mean } & \text { SD } & \text { SE } & \text { Median } & \text { Mean } & \text { SD } & \text { SE } \\ -1 & -0.3 & 1.28 & 0.24 & -2 & -1.1 & 1.17 & 0.26\end{array}$

$\mathrm{H})$ Port not in Oregon $(\mathrm{N}=40)$

Median Mean SD SE

$0 \quad-0$.

1.07

0.17

Statement \#3:Public agencies adequately communicate issues regarding Oregon fishery management to my local fishing community

A) Astoria, Warrenton, and Hammond ( $\mathrm{N}=44)$

B) Garibaldi and Pacific City $(\mathrm{N}=41)$

Median Mean SD SE

$\begin{array}{llll}0 & -0.3 & 1.09 & 0.17\end{array}$

C) Newport, Depoe Bay, and Florence $(\mathrm{N}=63)$

Median Mean SD SE

0

$\begin{array}{lll}+0.1 & 1.19 & 0.15\end{array}$

E) Port Orford and Gold Beach $(\mathrm{N}=28)$
Median Mean SD

$\begin{array}{lll}-0.3 & 1.08 & 0.17\end{array}$

D) Coos Bay, Bandon, Charleston and, Winchester Bay $(\mathrm{N}=39)$

$\begin{array}{cccc}\text { Median } & \text { Mean } & \text { SD } & \text { SE } \\ -1 & -0.6 & 1.29 & 0.21\end{array}$

F) Brookings $(\mathrm{N}=20)$ 


\begin{tabular}{|cccccccc} 
Median & Mean & SD & SE & Median & Mean & SD & SE \\
+0.5 & +0.1 & 1.40 & 0.26 & 0 & +0.1 & 1.19 & 0.27 \\
& H) Port not in Oregon (N=40) & & & & & \\
Median & Mean & SD & SE & & & \\
0 & +0.4 & 0.81 & 0.13 & & & & \\
\hline
\end{tabular}

Statement \#4: I am satisfied with the amount of contact I have with agency representatives

\begin{tabular}{cccccccc}
\hline \multicolumn{2}{|c}{ A) Astoria, Warrenton, and Hammond $(\mathrm{N}=44)$} & \multicolumn{3}{c}{ B) Garibaldi and Pacific City $(\mathrm{N}=41)$} \\
Median & Mean & SD & SE & Median & Mean & SD & SE \\
0 & 0.0 & 1.01 & 0.15 & 0 & +0.2 & 0.94 & 0.15
\end{tabular}

C) Newport, Depoe Bay, and Florence $(\mathrm{N}=63)$

D) Coos Bay, Bandon, Charleston and, Winchester Bay

Median Mean $\quad$ SD $\quad$ SE Median Mean

$\begin{array}{llllllll}0 & +0.2 & 1.06 & 0.13 & 0 & -0.4 & 1.27 & 0.2\end{array}$

$\begin{array}{ll}\text { E) Port Orford and Gold Beach }(\mathrm{N}=28) & \text { F) Brookings }(\mathrm{N}=20)\end{array}$

$\begin{array}{cccccccc}\text { Median } & \text { Mean } & \text { SD } & \text { SE } & \text { Median } & \text { Mean } & \text { SD } & \text { SE } \\ +0.5 & +0.4 & 1.23 & 0.23 & 0 & +0.4 & 1.09 & 0.24\end{array}$

H) Port not in Oregon $(\mathrm{N}=40)$

Median Mean SD SE

$\begin{array}{llll}0 & +0.4 & 0.81 & 0.13\end{array}$

Statement \#5: I feel comfortable voicing my opinions about Oregon ocean management and policy to public agencies

\begin{tabular}{|c|c|c|c|c|c|c|c|}
\hline \multicolumn{8}{|c|}{ agencies } \\
\hline \multicolumn{4}{|c|}{ A) Astoria, Warrenton, and Hammond $(\mathrm{N}=44)$} & \multicolumn{4}{|c|}{ B) Garibaldi and Pacific City $(\mathrm{N}=41)$} \\
\hline Median & Mean & $\mathrm{SD}$ & SE & Median & Mean & SD & SE \\
\hline 0 & +0.5 & 1.05 & 0.16 & +1 & +0.7 & 1.15 & 0.18 \\
\hline \multicolumn{4}{|c|}{ C) Newport, Depoe Bay, and Florence ( $N=63$ ) } & \multicolumn{4}{|c|}{$\begin{array}{l}\text { D) Coos Bay, Bandon, Charleston and, Winchester Bay } \\
\qquad(\mathrm{N}=39)\end{array}$} \\
\hline Median & Mean & $\mathrm{SD}$ & $\mathrm{SE}$ & Median & Mean & $\mathrm{SD}$ & SE \\
\hline+1 & +0.5 & 1.16 & 0.15 & +1 & +0.3 & 1.18 & 0.19 \\
\hline \multicolumn{4}{|c|}{ E) Port Orford and Gold Beach ( $\mathrm{N}=28)$} & \multicolumn{4}{|c|}{ F) Brookings $(\mathrm{N}=20)$} \\
\hline Median & Mean & $\mathrm{SD}$ & $\mathrm{SE}$ & Median & Mean & SD & SE \\
\hline+1 & +0.8 & 1.23 & 0.23 & +1.5 & +0.8 & 1.55 & 0.35 \\
\hline \multicolumn{4}{|c|}{ H) Port not in Oregon $(\mathrm{N}=40)$} & & & & \\
\hline Median & Mean & $\mathrm{SD}$ & SE & & & & \\
\hline+1 & +0.7 & 0.79 & 0.13 & & & & \\
\hline \multicolumn{8}{|c|}{ Statement \#6: I know where to obtain information about policy changes regarding Oregon ocean issues } \\
\hline \multicolumn{4}{|c|}{ A) Astoria, Warrenton, and Hammond $(\mathrm{N}=44)$} & \multicolumn{4}{|c|}{ B) Garibaldi and Pacific City $(\mathrm{N}=41)$} \\
\hline Median & Mean & $\mathrm{SD}$ & $\mathrm{SE}$ & Median & Mean & SD & SE \\
\hline+1 & +0.3 & 1.10 & 0.17 & +1 & +0.7 & 1.09 & 0.17 \\
\hline \multicolumn{4}{|c|}{ C) Newport, Depoe Bay, and Florence ( $N=63$ ) } & \multicolumn{4}{|c|}{$\begin{array}{l}\text { D) Coos Bay, Bandon, Charleston and, Winchester Bay } \\
\qquad(\mathrm{N}=39)\end{array}$} \\
\hline Median & Mean & $\mathrm{SD}$ & $\mathrm{SE}$ & Median & Mean & SD & SE \\
\hline
\end{tabular}


E) Port Orford and Gold Beach $(\mathrm{N}=28)$

F) Brookings $(\mathrm{N}=20)$

\begin{tabular}{|c|c|c|c|c|c|c|c|}
\hline Median & Mean & SD & $\mathrm{SE}$ & Median & Mean & $\mathrm{SD}$ & SE \\
\hline+1 & +0.7 & 1.49 & 0.28 & \multirow[t]{4}{*}{+1} & \multirow[t]{4}{*}{+0.3} & 1.17 & \multirow[t]{4}{*}{0.26} \\
\hline \multicolumn{4}{|c|}{ H) Port not in Oregon $(\mathrm{N}=40)$} & & & & \\
\hline Median & Mean & SD & SE & & & & \\
\hline+1 & +0.8 & 0.85 & 0.14 & & & & \\
\hline
\end{tabular}

Statement \# 7: I know where to obtain information about scientific research regarding Oregon ocean issues

\begin{tabular}{|c|c|c|c|c|c|c|c|}
\hline \multicolumn{4}{|c|}{ A) Astoria, Warrenton, and Hammond $(\mathrm{N}=44)$} & \multicolumn{4}{|c|}{ B) Garibaldi and Pacific City $(\mathrm{N}=41)$} \\
\hline Median & Mean & SD & $\mathrm{SE}$ & Median & Mean & SD & $\mathrm{SE}$ \\
\hline 0 & -0.3 & 1.18 & 0.18 & 0 & +0.4 & 1.30 & 0.2 \\
\hline \multicolumn{4}{|c|}{ C) Newport, Depoe Bay, and Florence (N=63) } & \multicolumn{4}{|c|}{$\begin{array}{l}\text { D) Coos Bay, Bandon, Charleston and, Winchester Bay } \\
\qquad(\mathrm{N}=39)\end{array}$} \\
\hline Median & Mean & SD & SE & Median & Mean & SD & SE \\
\hline-1 & -0.3 & 1.21 & 0.15 & +1 & 0.0 & 1.41 & 0.23 \\
\hline \multicolumn{4}{|c|}{ E) Port Orford and Gold Beach $(\mathrm{N}=28)$} & \multicolumn{4}{|c|}{ F) Brookings $(\mathrm{N}=20)$} \\
\hline Median & Mean & SD & SE & Median & Mean & SD & SE \\
\hline 0 & +0.1 & 1.30 & 0.25 & 0 & -0.1 & 1.37 & 0.31 \\
\hline \multicolumn{4}{|c|}{ H) Port not in Oregon $(\mathrm{N}=40)$} & & & & \\
\hline Median & Mean & SD & SE & & & & \\
\hline 0 & +0.4 & 1.06 & 0.17 & & & & \\
\hline
\end{tabular}

Response scale: $-2=$ Strongly Disagree, $-1=$ Moderately Disagree, $0=$ Neutral,$+1=$ Moderately Agree, $+2=$ Strongly Agree 
Table B.2. Pairwise Kruskal-Wallis test outputs for perceptions of management responses for groups that were significantly different.

\begin{tabular}{|c|c|c|c|c|c|c|}
\hline \multicolumn{7}{|c|}{ Statement \#1:Public agencies have done a good job advocating for my personal interests } \\
\hline Pairwise test & Clatsop & Tillamook & Lincoln & Coos & Curry & Brookings \\
\hline Tillamook & 0.22 & - & - & - & - & - \\
\hline Lincoln & 0.37 & 0.67 & - & - & - & - \\
\hline Coos & 0.67 & 0.38 & 0.60 & - & - & - \\
\hline Curry & 0.12 & 0.67 & 0.38 & 0.21 & - & - \\
\hline Brookings & 0.21 & 0.04 & 0.04 & 0.12 & 0.03 & - \\
\hline Not in Oregon & 0.02 & 0.38 & 0.12 & 0.05 & 0.67 & 0.008 \\
\hline \multicolumn{7}{|c|}{$\begin{array}{c}\text { Statement \#2: Public agencies have done a good job advocating for the interests of the fisheries in which I } \\
\text { participate }\end{array}$} \\
\hline Pairwise test & Clatsop & Tillamook & Lincoln & Coos & Curry & Brookings \\
\hline Tillamook & 0.95 & - & - & - & - & - \\
\hline Lincoln & 0.74 & 0.81 & - & - & - & - \\
\hline Coos & 0.71 & 0.64 & 0.46 & - & - & - \\
\hline Curry & 0.48 & 0.56 & 0.61 & 0.21 & - & - \\
\hline Brookings & 0.21 & 0.26 & 0.19 & 0.43 & 0.15 & - \\
\hline Not in Oregon & 0.13 & 0.19 & 0.19 & 0.03 & 0.64 & 0.029 \\
\hline \multicolumn{7}{|c|}{$\begin{array}{c}\text { Statement \#3:Public agencies adequately communicate issues regarding Oregon fishery management to my local } \\
\text { fishing community }\end{array}$} \\
\hline Pairwise test & Clatsop & Tillamook & Lincoln & Coos & Curry & Brookings \\
\hline Tillamook & 0.96 & - & - & - & - & - \\
\hline Lincoln & 0.22 & 0.22 & - & - & - & - \\
\hline Coos & 0.42 & 0.42 & 0.06 & - & - & - \\
\hline Curry & 0.30 & 0.31 & 0.90 & 0.21 & - & - \\
\hline Brookings & 0.41 & 0.42 & 0.90 & 0.22 & 0.90 & - \\
\hline Not in Oregon & 0.02 & 0.02 & 0.41 & 0.01 & 0.75 & 0.41 \\
\hline \multicolumn{7}{|c|}{ Statement \#7: I know where to obtain information about scientific research regarding Oregon ocean issues } \\
\hline Pairwise test & Clatsop & Tillamook & Lincoln & Coos & Curry & Brookings \\
\hline Tillamook & 0.07 & - & - & - & - & - \\
\hline Lincoln & 0.94 & 0.07 & - & - & - & - \\
\hline Coos & 0.49 & 0.50 & 0.53 & - & - & - \\
\hline Curry & 0.43 & 0.71 & 0.43 & 0.85 & - & - \\
\hline Brookings & 0.71 & 0.49 & 0.73 & 0.85 & 0.71 & - \\
\hline Not in Oregon & 0.05 & 0.94 & 0.05 & 0.50 & 0.64 & 0.43 \\
\hline
\end{tabular}


Table B.3. Respondent perceptions of management aggregated by fishery.

\begin{tabular}{|c|c|c|c|c|c|c|c|}
\hline \multicolumn{8}{|c|}{ Statement \#1:Public agencies have done a good job advocating for my personal interests } \\
\hline \multicolumn{4}{|c|}{ Dungeness Crab $(\mathrm{N}=94)$} & \multicolumn{4}{|c|}{ Salmon $(\mathrm{N}=112)$} \\
\hline Median & Mean & SD & SE & Median & Mean & SD & SE \\
\hline-1 & -0.7 & 1.06 & 0.11 & -1 & -0.9 & 1.01 & 0.10 \\
\hline \multicolumn{4}{|c|}{ Groundfish $(\mathrm{N}=41)$} & \multicolumn{4}{|c|}{ Charter $(\mathrm{N}=28)$} \\
\hline Median & Mean & $\mathrm{SD}$ & SE & Median & Mean & SD & SE \\
\hline-1 & -0.6 & 1.07 & 0.17 & -1 & -0.8 & 0.99 & 0.19 \\
\hline \multicolumn{8}{|c|}{$\begin{array}{c}\text { Statement \#2: Public agencies have done a good job advocating for the interests of the fisheries in which I } \\
\text { participate }\end{array}$} \\
\hline \multicolumn{4}{|c|}{ Dungeness Crab $(\mathrm{N}=94)$} & \multicolumn{4}{|c|}{ Salmon $(\mathrm{N}=112)$} \\
\hline Median & Mean & $\mathrm{SD}$ & SE & Median & Mean & SD & SE \\
\hline-0.5 & -0.4 & 1.18 & 0.12 & -1 & -0.7 & 1.10 & 0.10 \\
\hline \multicolumn{4}{|c|}{ Groundfish $(\mathrm{N}=41)$} & \multicolumn{4}{|c|}{ Charter $(\mathrm{N}=28)$} \\
\hline Median & Mean & $\mathrm{SD}$ & SE & Median & Mean & SD & SE \\
\hline-1 & -0.5 & 1.25 & 0.19 & -1 & -0.7 & 1.13 & 0.21 \\
\hline \multicolumn{8}{|c|}{$\begin{array}{c}\text { Statement \#3:Public agencies adequately communicate issues regarding Oregon fishery management to m. } \\
\text { local fishing community }\end{array}$} \\
\hline \multicolumn{4}{|c|}{ Dungeness Crab $(\mathrm{N}=94)$} & \multicolumn{4}{|c|}{ Salmon $(N=112)$} \\
\hline Median & Mean & $\mathrm{SD}$ & SE & Median & Mean & SD & SE \\
\hline 0 & 0.00 & 1.23 & 0.13 & 0 & -0.3 & 1.12 & 0.11 \\
\hline \multicolumn{4}{|c|}{ Groundfish $(\mathrm{N}=41)$} & \multicolumn{4}{|c|}{ Charter $(\mathrm{N}=28)$} \\
\hline Median & Mean & $\mathrm{SD}$ & SE & Median & Mean & SD & SE \\
\hline 0 & 0 & 1.25 & 0.20 & 0 & 0.00 & 1.07 & 0.20 \\
\hline \multicolumn{8}{|c|}{ Statement \#4: I am satisfied with the amount of contact I have with agency representatives } \\
\hline \multicolumn{4}{|c|}{ Dungeness Crab $(\mathrm{N}=94)$} & \multicolumn{4}{|c|}{ Salmon $(\mathrm{N}=112)$} \\
\hline Median & Mean & $\mathrm{SD}$ & $\mathrm{SE}$ & Median & Mean & SD & $\mathrm{SE}$ \\
\hline 0 & +0.2 & 1.02 & 0.11 & 0 & 0 & 1.12 & 0.11 \\
\hline \multicolumn{4}{|c|}{ Groundfish $(\mathrm{N}=41)$} & \multicolumn{4}{|c|}{ Charter $(\mathrm{N}=28)$} \\
\hline Median & Mean & $\mathrm{SD}$ & SE & Median & Mean & SD & SE \\
\hline 0 & +0.3 & 1.16 & 0.18 & 0 & +0.4 & 0.91 & 0.17 \\
\hline \multicolumn{8}{|c|}{$\begin{array}{c}\text { Statement \#5: I feel comfortable voicing my opinions about Oregon ocean management and policy to public } \\
\text { agencies }\end{array}$} \\
\hline \multicolumn{4}{|c|}{ Dungeness Crab $(\mathrm{N}=94)$} & \multicolumn{4}{|c|}{ Salmon $(N=112)$} \\
\hline Median & Mean & $\mathrm{SD}$ & SE & Median & Mean & SD & SE \\
\hline+1 & +0.6 & 1.22 & 0.13 & +0.5 & +0.5 & 1.03 & 0.10 \\
\hline \multicolumn{4}{|c|}{ Groundfish $(\mathrm{N}=41)$} & \multicolumn{4}{|c|}{ Charter $(\mathrm{N}=28)$} \\
\hline Median & Mean & $\mathrm{SD}$ & SE & Median & Mean & SD & SE \\
\hline+1 & +0.6 & 1.21 & 0.19 & +1 & +0.8 & 1.09 & 0.21 \\
\hline
\end{tabular}




\begin{tabular}{|c|c|c|c|c|c|c|c|}
\hline \multicolumn{4}{|c|}{ Dungeness Crab $(\mathrm{N}=94)$} & \multicolumn{4}{|c|}{ Salmon $(\mathrm{N}=112)$} \\
\hline Median & Mean & $\mathrm{SD}$ & SE & Median & Mean & $\mathrm{SD}$ & $\mathrm{SE}$ \\
\hline+1 & +0.5 & 1.19 & 0.12 & +1 & +0.4 & 1.17 & 0.11 \\
\hline \multicolumn{4}{|c|}{ Groundfish $(\mathrm{N}=41)$} & \multicolumn{4}{|c|}{ Charter $(\mathrm{N}=28)$} \\
\hline Median & Mean & $\mathrm{SD}$ & $\mathrm{SE}$ & Median & Mean & $\mathrm{SD}$ & SE \\
\hline+1 & +0.7 & 1.30 & 0.20 & +1 & +0.6 & 1.26 & 0.24 \\
\hline \multicolumn{8}{|c|}{ Statement \#7: I know where to obtain information about scientific research regarding Oregon ocean issues } \\
\hline \multicolumn{4}{|c|}{ Dungeness Crab $(\mathrm{N}=94)$} & \multicolumn{4}{|c|}{ Salmon $(\mathrm{N}=112)$} \\
\hline Median & Mean & $\mathrm{SD}$ & SE & Median & Mean & $\mathrm{SD}$ & SE \\
\hline 0 & 0.00 & 1.20 & 0.12 & 0 & 0.00 & 1.25 & 0.12 \\
\hline \multicolumn{4}{|c|}{ Groundfish $(\mathrm{N}=41)$} & \multicolumn{4}{|c|}{ Charter $(\mathrm{N}=28)$} \\
\hline Median & Mean & $\mathrm{SD}$ & $\mathrm{SE}$ & Median & Mean & $\mathrm{SD}$ & $\mathrm{SE}$ \\
\hline 0 & 0 & 1.35 & 0.21 & -0.5 & 0.00 & 1.50 & 0.28 \\
\hline
\end{tabular}

Response scale: $-2=$ Strongly Disagree, $-1=$ Moderately Disagree, $0=$ Neutral,$+1=$ Moderately Agree,$+2=$ Strongly Agree 


\section{APPENDIX C. Fishery Socioeconomics and Fishing Effort}

Table C.1. Operating expenditure percentages, separated by fishery affiliation and sampling year. Operating expenditure percentage is a measurement of the relative amount of money that went towards each operating expense (fuel, crew, other expenses).

\begin{tabular}{|c|c|c|c|c|c|c|c|c|c|c|c|c|c|}
\hline \multirow[b]{2}{*}{ Fishery } & \multirow[b]{2}{*}{$\begin{array}{l}\text { Operating } \\
\text { Expense }\end{array}$} & \multicolumn{4}{|c|}{2011} & \multicolumn{4}{|c|}{2014} & \multicolumn{4}{|c|}{2017} \\
\hline & & $\mathrm{N}^{\#}$ & Mean & SD & SE & $\mathrm{N}^{\#}$ & Mean & SD & SE & $\mathrm{N}^{\#}$ & Mean & $\mathrm{SD}$ & SE \\
\hline \multirow{3}{*}{ Charter } & Fuel & 21 & $27 \%$ & 12.8 & 3.29 & 24 & $28 \%$ & 13.8 & 3.28 & 20 & $23 \%$ & 13.7 & 3.2 \\
\hline & Crew & 18 & $15 \%$ & 14.5 & 3.63 & 21 & $13 \%$ & 14.2 & 3.24 & 18 & $13 \%$ & 14.7 & 3.68 \\
\hline & Other & 17 & $48 \%$ & 15.3 & 3.71 & 20 & $48 \%$ & 17.8 & 4 & 17 & $51 \%$ & 24.7 & 6 \\
\hline \multirow{3}{*}{$\begin{array}{l}\text { Dungeness } \\
\text { crab }\end{array}$} & Fuel $^{*}$ & 72 & $16 \%$ & 10.3 & 1.43 & 73 & $16 \%$ & 11.3 & 1.54 & 77 & $15 \%$ & 8.9 & 1.2 \\
\hline & Crew & 61 & $32 \%$ & 13.6 & 1.8 & 62 & $33 \%$ & 14.6 & 1.88 & 64 & $34 \%$ & 14.2 & 1.8 \\
\hline & Other & 59 & $39 \%$ & 23.6 & 3.07 & 61 & $39 \%$ & 22.5 & 2.88 & 63 & $40 \%$ & 22.4 & 2.82 \\
\hline \multirow{3}{*}{ Groundfish } & Fuel $^{*}$ & 26 & 245 & 21 & 4.96 & 29 & $27 \%$ & 21.2 & 5.08 & 31 & $24 \%$ & 23 & 5.5 \\
\hline & Crew & 22 & $20 \%$ & 16.3 & 3.65 & 22 & $20 \%$ & 17 & 3.62 & 22 & $19 \%$ & 17 & 3.63 \\
\hline & Other & 22 & $41 \%$ & 26 & 5.72 & 23 & $40 \%$ & 26.1 & 5.61 & 23 & $39 \%$ & 27.2 & 5.86 \\
\hline \multirow{3}{*}{ Salmon } & Fuel $^{*}$ & 68 & $28 \%$ & 27.9 & 3.88 & 73 & $27 \%$ & 25.1 & 3.39 & 67 & $26 \%$ & 27.2 & 3.82 \\
\hline & Crew & 58 & $15 \%$ & 14.4 & 1.9 & 61 & $14 \%$ & 14.1 & 1.77 & 56 & $10 \%$ & 11.6 & 1.59 \\
\hline & Other & 57 & $46 \%$ & 30.5 & 4.06 & 61 & $49 \%$ & 30.8 & 3.92 & 56 & $53 \%$ & 32 & 4.42 \\
\hline
\end{tabular}

* Data were standardized when used in analyses

${ }^{\#}$ Note that total expenses do not equal $100 \%$ 
Table C.2. Fishing effort logistics, separated by fishery affiliation and sampling year: Charter $(\mathrm{N}=19)$, Dungeness crab $(\mathrm{N}=65)$, groundfish $(\mathrm{N}=28)$, and salmon $(\mathrm{N}=56)$. Summary of mean, standard deviation and \pm standard error of mean for untransformed, raw data.

\begin{tabular}{|c|c|c|c|c|c|c|c|c|c|}
\hline \multirow[b]{4}{*}{ Effort Logistic } & \multicolumn{9}{|c|}{ Sampling Year } \\
\hline & \multicolumn{9}{|c|}{ Charter } \\
\hline & \multicolumn{3}{|c|}{$2011(\mathrm{~N}=19)$} & \multicolumn{3}{|c|}{$2014(\mathrm{~N}=20)$} & \multicolumn{3}{|c|}{$2017(\mathrm{~N}=18)$} \\
\hline & Mean & $\mathrm{SD}$ & SE & Mean & SD & SE & Mean & SD & $\mathrm{SE}$ \\
\hline Financial Dependence & 41 & 29.1 & 6.7 & 39 & 32.1 & 7.2 & 39 & 37.7 & 8.9 \\
\hline Annual Days Fished & 87 & 58.0 & 13.3 & 79 & 53.7 & 12 & 67 & 54.8 & 13 \\
\hline $\begin{array}{c}\text { Annual Days Fished (inside } 3 \\
\text { miles) }\end{array}$ & 77 & 52.9 & 12.1 & 76 & 54.2 & 12.1 & 62 & 53.5 & 12.6 \\
\hline Hours Fished Per Day & 6 & 2.0 & 0.47 & 6 & 1.8 & 0.39 & 5 & 2.8 & 0.66 \\
\hline $\begin{array}{l}\text { Hours Fished Per Day (inside } \\
\qquad 3 \text { miles) }\end{array}$ & 6 & 2.7 & 0.62 & 5 & 2.4 & 0.54 & 5 & 3.2 & 0.75 \\
\hline Miles Traveled to Fish & 5 & 5.0 & 1.2 & 5 & 4.6 & 1 & 3 & 2.8 & 0.65 \\
\hline $\begin{array}{l}\text { Annual Days Fished (in } \\
\text { marine reserve limits) }\end{array}$ & 5 & 11.8 & 2.7 & 1 & 4.5 & 1 & 0 & 0.0 & 0 \\
\hline \multirow[t]{3}{*}{$\begin{array}{l}\text { Financial Dependence on } \\
\text { Catch from Marine Reserve }\end{array}$} & 3 & 5.4 & 1.2 & 0 & 1.1 & 0.25 & 0 & 0.0 & 0 \\
\hline & \multicolumn{9}{|c|}{ Dungeness crab } \\
\hline & \multicolumn{3}{|c|}{$2011(\mathrm{~N}=64)$} & \multicolumn{3}{|c|}{$2014(\mathrm{~N}=63)$} & \multicolumn{3}{|c|}{$2017(\mathrm{~N}=67)$} \\
\hline Effort Logistic & Mean & $\mathrm{SD}$ & $\mathrm{SE}$ & Mean & $\mathrm{SD}$ & SE & Mean & $\mathrm{SD}$ & SE \\
\hline Financial Dependence ${ }^{*}$ & 60 & 22.8 & 2.8 & 60 & 22.7 & 2.8 & 60 & 26.1 & 3.19 \\
\hline Annual Days Fished ${ }^{+}$ & 68 & 49.3 & 6.2 & 67 & 48.7 & 6.1 & 66 & 49.2 & 6 \\
\hline $\begin{array}{l}\text { Annual Days Fished (inside } 3 \\
\text { miles) }{ }^{*}\end{array}$ & 54 & 41.6 & 5.2 & 53 & 38.2 & 4.8 & 50 & 36.5 & 4.5 \\
\hline Hours Fished Per Day ${ }^{+}$ & 23 & 2.6 & 0.33 & 23 & 2.6 & 0.33 & 23 & 3.8 & 0.46 \\
\hline $\begin{array}{l}\text { Hours Fished Per Day (inside } \\
\qquad 3 \text { miles) }\end{array}$ & 21 & 7.5 & 0.93 & 21 & 6.5 & 0.81 & 21 & 6.7 & 0.81 \\
\hline Miles Traveled to Fish ${ }^{*}$ & 15 & 17.3 & 2.2 & 13 & 13.1 & 1.6 & 16 & 20.2 & 2.5 \\
\hline $\begin{array}{l}\text { Annual Days Fished (in } \\
\text { marine reserve limits) }\end{array}$ & 14 & 28.2 & 3.5 & 13 & 27.8 & 3.5 & 11 & 28.4 & 3.5 \\
\hline $\begin{array}{l}\text { Financial Dependence on } \\
\text { Catch from Marine Reserve }\end{array}$ & 6 & 10.7 & 1.3 & 5 & 10.0 & 1.3 & 4 & 11.3 & 1.4 \\
\hline Effort $^{+}$ & 1340 & 791 & 114 & 1309 & 717 & 103 & 1221 & 648 & 93 \\
\hline \multirow[t]{3}{*}{ CPUE $^{\#}$} & 48 & 63 & 10.6 & 33 & 54 & 8.9 & 48 & 55 & 9 \\
\hline & \multicolumn{9}{|c|}{ Groundfish } \\
\hline & \multicolumn{3}{|c|}{$2011(\mathrm{~N}=25)$} & \multicolumn{3}{|c|}{$2014(\mathrm{~N}=29)$} & \multicolumn{3}{|c|}{$2017(\mathrm{~N}=30)$} \\
\hline Effort Logistic & Mean & $\mathrm{SD}$ & SE & Mean & SD & SE & Mean & SD & $\mathrm{SE}$ \\
\hline Financial Dependence ${ }^{*}$ & 29 & 29.3 & 5.9 & 25 & 27.1 & 5 & 30 & 31.6 & 5.8 \\
\hline Annual Days Fished ${ }^{+}$ & 46 & 47.8 & 9.6 & 43 & 49.8 & 9.2 & 39 & 38.0 & 6.9 \\
\hline $\begin{array}{l}\text { Annual Days Fished (inside } 3 \\
\text { miles) }{ }^{*}\end{array}$ & 45 & 50.7 & 10.1 & 44 & 52.2 & 9.7 & 40 & 40.6 & 7.4 \\
\hline Hours Fished Per Day ${ }^{+}$ & 9 & 5.6 & 1.1 & 8 & 5.2 & 0.97 & 8 & 4.6 & 0.84 \\
\hline $\begin{array}{l}\text { Hours Fished Per Day (inside } \\
\qquad 3 \text { miles) }\end{array}$ & 6 & 4.0 & 0.79 & 6 & 3.7 & 0.69 & 6 & 2.7 & 0.49 \\
\hline Miles Traveled to Fish ${ }^{*}$ & 7 & 6.1 & 1.2 & 7 & 5.7 & 1.1 & 6 & 5.7 & 1 \\
\hline Annual Days Fished (in & 7 & 17.0 & 3.4 & 1 & 3.8 & 0.7 & 1 & 3.7 & 0.68 \\
\hline
\end{tabular}




\begin{tabular}{|c|c|c|c|c|c|c|c|c|c|}
\hline \multicolumn{10}{|l|}{ marine reserve limits) ${ }^{*}$} \\
\hline $\begin{array}{l}\text { Financial Dependence on } \\
\text { Catch from Marine Reserve }\end{array}$ & 6 & 12.5 & 2.5 & 3 & 9.4 & 1.74 & 3 & 9.8 & 1.8 \\
\hline Effort $^{+}$ & 395 & 453 & 94 & 389 & 475 & 99 & 300 & 274 & 57 \\
\hline \multirow[t]{3}{*}{ CPUE $^{\#}$} & 41 & 62 & 1.5 & 34 & 68 & 1.9 & 49 & 47 & 8.3 \\
\hline & \multicolumn{9}{|c|}{ Salmon } \\
\hline & \multicolumn{3}{|c|}{$2011(\mathrm{~N}=56)$} & \multicolumn{3}{|c|}{$2014(\mathrm{~N}=63)$} & \multicolumn{3}{|c|}{$2017(\mathrm{~N}=50)$} \\
\hline Effort Logistic & Mean & SD & SE & Mean & SD & SE & Mean & $\mathrm{SD}$ & SE \\
\hline Financial Dependence ${ }^{*}$ & 38 & 31.0 & 4.1 & 39 & 32.0 & 4 & 32 & 34.3 & 4.8 \\
\hline Annual Days Fished $^{+}$ & 60 & 57.2 & 7.6 & 64 & 56.2 & 7.1 & 48 & 67.0 & 9.5 \\
\hline $\begin{array}{c}\text { Annual Days Fished (inside } 3 \\
\text { miles) }\end{array}$ & 22 & 32.9 & 4.4 & 21 & 31.1 & 3.9 & 19 & 35.1 & 5 \\
\hline Hours Fished Per Day ${ }^{+}$ & 10 & 4.3 & 0.57 & 11 & 4.0 & 0.5 & 9 & 5.5 & 0.78 \\
\hline $\begin{array}{l}\text { Hours Fished Per Day (inside } \\
\qquad 3 \text { miles) }\end{array}$ & 7 & 5.2 & 0.69 & 7 & 7.3 & 0.92 & 5 & 5.4 & 0.77 \\
\hline Miles Traveled to Fish ${ }^{*}$ & 15 & 29.6 & 4 & 14 & 27.6 & 3.5 & 13 & 18.1 & 2.6 \\
\hline $\begin{array}{l}\text { Annual Days Fished (in } \\
\text { marine reserve limits) }\end{array}$ & 3 & 9.9 & 1.3 & 2 & 9.3 & 1.2 & 1 & 4.0 & 0.56 \\
\hline $\begin{array}{l}\text { Financial Dependence on } \\
\text { Catch from Marine Reserve }\end{array}$ & 5 & 16.7 & 2.2 & 4 & 15.7 & 2 & 3 & 14.6 & 2.1 \\
\hline Effort $^{+}$ & 724 & 542 & 106 & 758 & 536 & 105 & 432 & 583 & 114 \\
\hline CPUE $^{\#}$ & 5 & 7.8 & 14.2 & 13 & 13 & 15 & 14 & 78 & 16 \\
\hline
\end{tabular}

* Data were standardized when used in analyses

+ Data were raised to the square rooted power when used in analyses

\#Data were log-transformed when used in analyses 


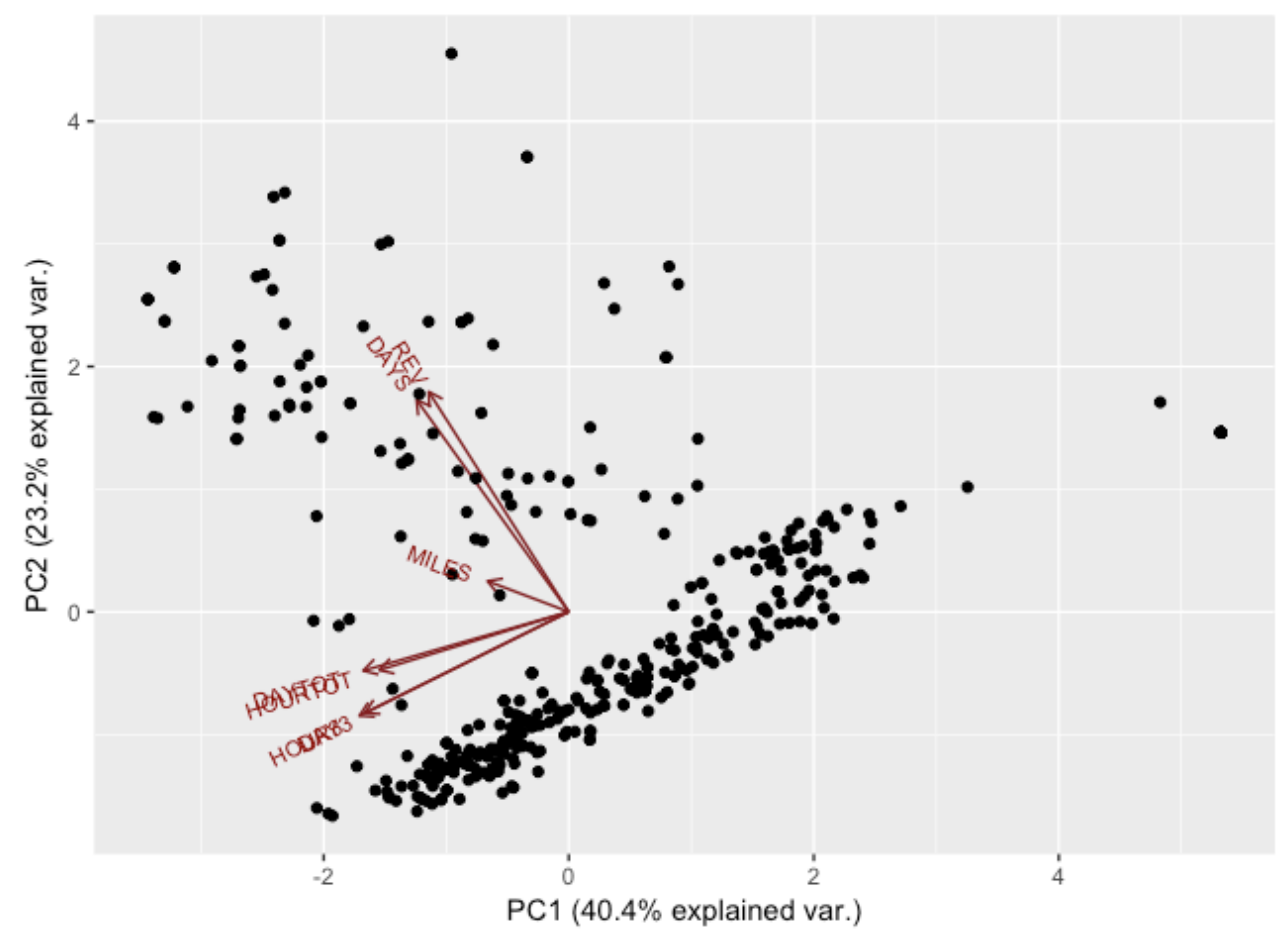

Figure C.1. Principle Component Analysis displaying observed variability in overall effort based on seven logistics of effort: DAYTOT= total days fished per year, HOUR TOT=hours fished per day, DAY3=total days fished per year, inside three miles, HOUR3=hours fished per day, inside three miles, MILES=miles traveled to fish, DAYS=total days fished inside area that is now marine reserve, $\mathrm{REV}=$ percent annual revenue from catch from areas that is now a marine reserve. 
Appendix D. Representative Analysis Summary Report 


\title{
DRAFT
}

\section{Oregon Nearshore Fisheries Effort Shift Survey Commercial Fishing Representativeness Report}

Version 3.1

\author{
prepared by \\ The Research Group, LLC \\ Corvallis, Oregon \\ prepared for \\ Marine Resources Program \\ Oregon Department of Fish and Wildlife
}

May 2018 


\section{$\underline{\text { Suggested Citation }}$}

The Research Group, LLC. Oregon Nearshore Fisheries Effort Shift Survey Commercial Fishing Representativeness Report. Prepared for Marine Resources Program, Oregon Department of Fish and Wildlife. May 2018. 


\section{Preface}

This analysis project was sponsored by the Oregon Department of Fish and Wildlife (ODFW) Marine Resources Program. The analysis was to find the degree of representativeness for respondents to a survey project being undertaken by the Department of Environmental Science and Management, Portland State University (PSU). This analysis project is one of many human dimension investigative studies being used to support ODFW's responsibilities to establish, monitor, and evaluate Oregon's marine reserve (MR) system. A more thorough description of each of the studies and data collection projects can be found in the Oregon Marine Reserves Internet portal.

This analysis project was completed by The Research Group, LLC Corvallis, Oregon. Shannon Davis was the lead author and was greatly assisted by Kari Olsen. Hans Radtke, Ph.D. needs to be recognized for his valuable input. Bryn Hudson, Master of Science Candidate, PSU has been outstanding for communicating about all matters dealing with the survey project. The authors thank ODFW staff Tommy Swearingen, Human Dimensions MR Project Leader and Cristen Don, MR Program Leader for their guidance.

Authorization is granted for this analysis project report's contents to be quoted either orally or in written form without prior consent of the authors. Customary reference to authorship is requested.

The analysis project authors and not the sponsors were responsible for generating project results. The authors do not make any warranties with respect to the project including fitness for any particular purpose. In no event shall the authors assume any liability for use of the program or derived information and shall not be responsible for any direct, indirect, or consequential damages that might arise from the application. 


\section{Table of Contents}

Preface

Table of Contents

Glossary
A. Introduction
B. Background
C. Survey Project Scope
1. Objective
2. Population
3. Sampling
4. Frame
5. Administration
D. Associating Vessels with Permit Owners
E. Respondents
F. Representativeness
G. Discussion
H. Bibliography

Maps, Tables and Figures

Map A: Marine Reserve Location and Relative Size Map

Table A: Survey Frame and Survey Respondents Vessel Counts With Matches to Vessels Having Oregon Onshore Landings in 2011-2016

Table B: Survey Frame and Survey Respondents With Matches to Oregon Onshore Landings in 2011-2016

Table C: Survey Frame and Survey Respondents With Matches to Oregon Onshore Landed Value by Major Fishery in 2011-2016

Table D: Survey Frame and Survey Respondents With Matches to Oregon Onshore Landing Vessels by Major Fishery in 2011-2016

Table E: Frequency Distribution of Oregon Onshore, Survey Frame, and Survey Respondent Average Annual Landed Value in 2016

Table F: $\quad$ Oregon Onshore Landed Value and Vessel Counts for Survey Fisheries in 2008-2017

Table G: Frequency Distribution of Oregon Onshore, Survey Frame, and Survey Respondent Delivering Vessel Average Annual Landed Value in 2016

Table H: Residency of Oregon Permitted, Survey Frame, and Survey Respondent Permit Owners in 2016

Table I: $\quad$ Vessels by Principal Oregon Delivery Port Area in 2016

Figure A: Delivering Vessel Counts in 2016

Figure B: Delivering Vessel Count Shares of Oregon Onshore and Survey Frame in 2016

Figure C: Delivering Vessel Landed Value in 2016 


\section{Table of Contents (cont.)}

Figure D: Delivering Vessel Landed Value Shares of Oregon Onshore and Survey Frame in 2016

Figure E: Delivering Vessel Trips in 2016

Figure F: Delivering Vessel Trips Shares of Oregon Onshore and Survey Frame in 2016

Figure G: Delivering Vessel Average Annual Landed Value in 2016

Figure H: Delivering Vessel Average Annual Landed Value Shares of Oregon Onshore and Survey Frame in 2016

Figure I: Histogram of Delivering Vessel Average Annual Landed Value in 2016

Figure J: Quartiles of Delivering Vessel Average Annual Landed Value in 2016

\section{Appendix}

Appendix A: Survey Instrument 


\section{Glossary}

\section{$\underline{\text { Acronyms }}$}

$\begin{array}{ll}\text { CASRO } & \text { Council of American Survey Research Organizations } \\ \text { GDP } & \text { Gross Domestic Product } \\ \text { MR's } & \text { Oregon marine reserve system sites } \\ \text { ODFW } & \text { Oregon Department of Fish and Wildlife } \\ \text { OPAC } & \text { Oregon Ocean Policy Advisory Council } \\ \text { PacFIN } & \text { Pacific Coast Fisheries Information Network } \\ \text { PSU } & \text { Portland State University } \\ \text { TRG } & \text { The Research Group, LLC } \\ \text { USPS } & \text { U.S. Postal Service }\end{array}$

$\underline{\text { Terms }}$

Dollar Where dollar values are noted to be real, the adjustment index was the adjustments GDP implicit price deflator developed by the U.S. Bureau of Economic Analysis.

Nearshore area The part of the continental shelf closest to shoreline and includes an intertidal zone. The intertidal zone extreme is the high tide splash zone and includes lower bay saline dominated estuarine waters. Some nearshore fisheries have management specifications using depth restrictions. Management depth closures can vary during the year.

Nearshore species Survey fisheries for commercial fishing are Dungeness crab, troll salmon, and nearshore groundfish. Nearshore groundfish species include selections of rockfish, roundfish, and flatfish. An estimate of the nearshore harvested portion of lingcod is included. The criteria used to select species that are nearshore groundfish is discussed in TRG (2014). The selection is inclusive of State managed nearshore species for which an Oregon Nearshore Fishery Permit is needed. There are other federal managed species in the selection that are typically caught in nearshore areas. The landings for lingcod were determined using species and gear filter queries to include open access landings with longline, other hook and line, or pot gear; and limited entry landings with longline, other hook and line, or selective FF trawl (small footrope) if it was on the same fish ticket with black or blue rockfish or certain other nearshore species. The nearshore species are listed by common name in an appendix. Some tables only show nearshore species harvests for vessels that have an Oregon Nearshore Fishery Permit. Other tables content is for all selected nearshore species determined without filtering on vessels associated with permits. 
Oregon The ocean that is three nautical miles seaward of shoreline. The seaward

Territorial Sea extent can be approximated to be the 30 fathom depth contour along the Oregon Coast.

Survey calibration Procedures to better pattern survey responses for being representative of known indicators of the survey population. Techniques include weighting response types whose numbers are deficient. Weights can be greater than one (under represented) and smaller than one (over-represented). Deville and Särndal (1992) explain the term and offer methods for survey calibration. Gelman and Little (1997) explain post-stratification procedures. Kolenikov (2014) discusses raking techniques.

Survey frame Commercial fishing permit and charter boat permit registration names. The fisheries permit types are Dungeness crab, salmon troll, and nearshore groundfish.

Survey population The intended commercial fishermen and recreational charter boat operators to receive a survey questionnaire are those likely to fish in nearshore waters sometime during a calendar year.

Commercial

Trips are approximated using fish tickets. A fish ticket represents the landing fishing trips of fish or shellfish product from one fishing trip. Ticket counts may not reflect fishing trips, because multiple tickets can be issued for a single trip when a vessel delivers to more than one dealer after returning to port, and vessels issue tickets when a sale is made directly to the public. Trip undercounts could occur in the occasion when tendering services are used because more than one vessel's harvest could be combined onto a single fish ticket. Delivery counts are not additive across fisheries because a fish ticket may include more than one species.

Recreational The mode can be charter boat, private boat, bank fishing, or diving. A charter fishing mode boat is owned by a private business which provides for-hire services on daily and fishing season schedules. The services are usually recreational fishing, but can for non-angling trips such as whale watching or just touring. The boat may make more than one trip per day depending on the distance to fishing grounds. Private boats do not provide for-hire services, although it is not uncommon that friends and relatives on the trip contribute to cost reimbursement. Bank fishing distinguishes an angling trip when the fishing opportunity will not rely on a boat. It can occur on piers and water shorelines. Dive trips can originate from a boat or shore. There are very few ocean bank or dive fishing trips in Oregon and they are not included in the analysis. 


\section{Oregon Nearshore Fisheries Effort Shift Survey Commercial Fishing Representativeness Report}

\section{A. Introduction}

An Oregon nearshore fisheries effort shift investigation was undertaken in 2017. The project used primary data collection to find related ocean commercial fishermen and recreational charter operators responses to management changes such as fishing grounds closures. The survey project contractor was Department of Environmental Science and Management, Portland State University (PSU). The survey project commenced in March 2017 and will conclude August 31, 2018. ${ }^{1}$

The survey project is to make progress on ODFW tasking to understand changes within coastal fishing communities affected by marine reserves implementation. The contractor in collaboration with the ODFW Marine Reserves Program staff sent a questionnaire via USPS mailing to nearshore fisheries permit and charter boat permit registrants as of early 2017 . There were three commercial fishing permit types and a charter boat permit type selected to cover nearshore fisheries' participants. The commercial fishing permit types are Dungeness crab, salmon troll, and nearshore groundfish. ${ }^{2}$

The survey project purpose was to solicit financial, operational, and social characteristic information as well as attitudinal information about fisheries management and other influences on fishing success. There were specific questions about fishing effort and whether the marine reserve program impacted fishing operations. Survey project questions were structured to be both objective and subjective with close-ended and open-ended wording. (An appendix to this report contains the final survey instrument.) The survey project design has a descriptive and an experimental context. The survey project contractor will use modeling to find predictive factors for fishing operation choices.

A representative analysis can be useful for developing calibration schemes for adjusting survey results to minimize any discovered non-coverage and non-response bias. Kruskal and Mosteller (1980) in a four-publication series present an extensive overview of representativeness analysis. Methods to overcome representative bias are explained by Särndal and Lundström (2005).

This report contains information about the representativeness of the survey frame and survey respondents. While the survey frame was commercial fishing nearshore fisheries permit registrants and recreational charter boat permit registrants, the representativeness analysis is only for the former. The primary measure to analyze representativeness is distribution of landed value. An inset on the next page in this report shows summaries of other indicator comparisons.

1. The project's lead author is Bryn Hudson, Master of Science Candidate. Ms. Hudson's master's degree committee members include Max Nielsen-Pincus, Ph.D. (chair), Elise Granek, Ph.D., and Thomas Swearingen, Ph.D.

2. The nearshore groundfish permit type was inclusive of permits for black/blue rockfish with and without nearshore groundfish endorsements. 


\begin{tabular}{|c|c|c|}
\hline \multicolumn{3}{|c|}{ Representative Measures } \\
\hline Measure & Survey Frame & Respondents \\
\hline $\begin{array}{l}\text { Survey size } \\
\text { including charter } \\
\text { boats }\end{array}$ & 1,161 & 229 \\
\hline $\begin{array}{l}\text { Commercial } \\
\text { fishing vessel } \\
\text { count }\end{array}$ & 1,106 & 212 \\
\hline $\begin{array}{l}\text { Landed value of } \\
\text { three fisheries in } \\
2016\end{array}$ & $\begin{array}{l}\$ 52.0 \text { million in } \\
2016,85 \% \\
\text { onshore }\end{array}$ & $\begin{array}{l}\$ 11.4 \text { million in } \\
2016,22 \% \text { frame }\end{array}$ \\
\hline $\begin{array}{l}\text { Mean per vessel } \\
\text { landed value of } \\
\text { three fisheries in } \\
2016\end{array}$ & $\begin{array}{l}107 \% \text { of } \\
\text { onshore }\end{array}$ & $94 \%$ of frame \\
\hline $\begin{array}{l}\text { Mean per vessel } \\
\text { trip counts in } 2016\end{array}$ & $\begin{array}{l}106 \% \text { of } \\
\text { onshore }\end{array}$ & $111 \%$ of frame \\
\hline Vessel length & average 41 feet & average 39 feet \\
\hline $\begin{array}{l}\text { Permit owner } \\
\text { residency in } 2016\end{array}$ & $\begin{array}{l}\text { Oregon for } 68 \% \\
\text { of permittees }\end{array}$ & $\begin{array}{l}\text { Oregon for } 75 \% \\
\text { of permittees }\end{array}$ \\
\hline $\begin{array}{l}\text { Principal delivery } \\
\text { port area in } 2016\end{array}$ & $\begin{array}{l}\text { Newport highest } \\
\text { number of } \\
\text { vessels }\end{array}$ & $\begin{array}{l}\text { Newport highest } \\
\text { number of } \\
\text { vessels }\end{array}$ \\
\hline $\begin{array}{l}\text { te: The three fi } \\
\text { arshore ground }\end{array}$ & es are D. crab, sc & Imon troll, and \\
\hline
\end{tabular}

Survey project response tabulations, modeling results, and inference explanations are presented in a separate document authored by the project contractor.

\section{B. Background}

Pursuant to the Oregon marine reserve legislative mandate, the project was funded by ODFW to assess Oregon nearshore fisher's perceptions and behavioral changes due to the establishment of marine reserves. ${ }^{3}$ There are currently five established marine reserves in the Oregon Territorial Sea (Map A). Management plans for the reserves restrict extractive practices and ocean development. The restriction of commercial and recreational fishing may

force fishers to forgo or shift their effort to other fishing grounds, which can result in adverse economic and social impacts. Formal research regarding fishers' behavior and perceptions due to Oregon marine reserves post-implementation is scarce.

Future studies are planned to use survey project results. For example, a survey question solicited whether or not the respondent wanted to participate in a personal interview. Those in the affirmative will be volunteers in a study for gathering additional anthropological and ecological knowledge information. Another study is planned to determine whether or not fisher stated behavioral changes align with real behavior documented with fishing logbook data. (Logbook data is available for some nearshore fisheries, but not all such as the salmon troll fishery.) The alignment analysis results will assist in creating more effective communication pathways with local fishing communities.

3. State mandates and guidelines for Oregon's marine reserves are provided in Executive Order 08-07 in 2008, House Bill 3013 in 2009, Senate Bill 1510 in 2012, administrative rules adopted by state agencies, and in the Oregon Marine Reserve Policy Recommendations adopted by the Oregon Ocean Policy Advisory Council (OPAC) in 2008. The OPAC policy recommendations provide the foundation for ODFW's monitoring of marine reserves. A description of the human dimensions monitoring plans are results is contained in biennial monitoring reports. The most recent report can be accessed at the Oregon Marine Reserve Internet portal. 
Map A

Marine Reserve Location and Relative Size Map

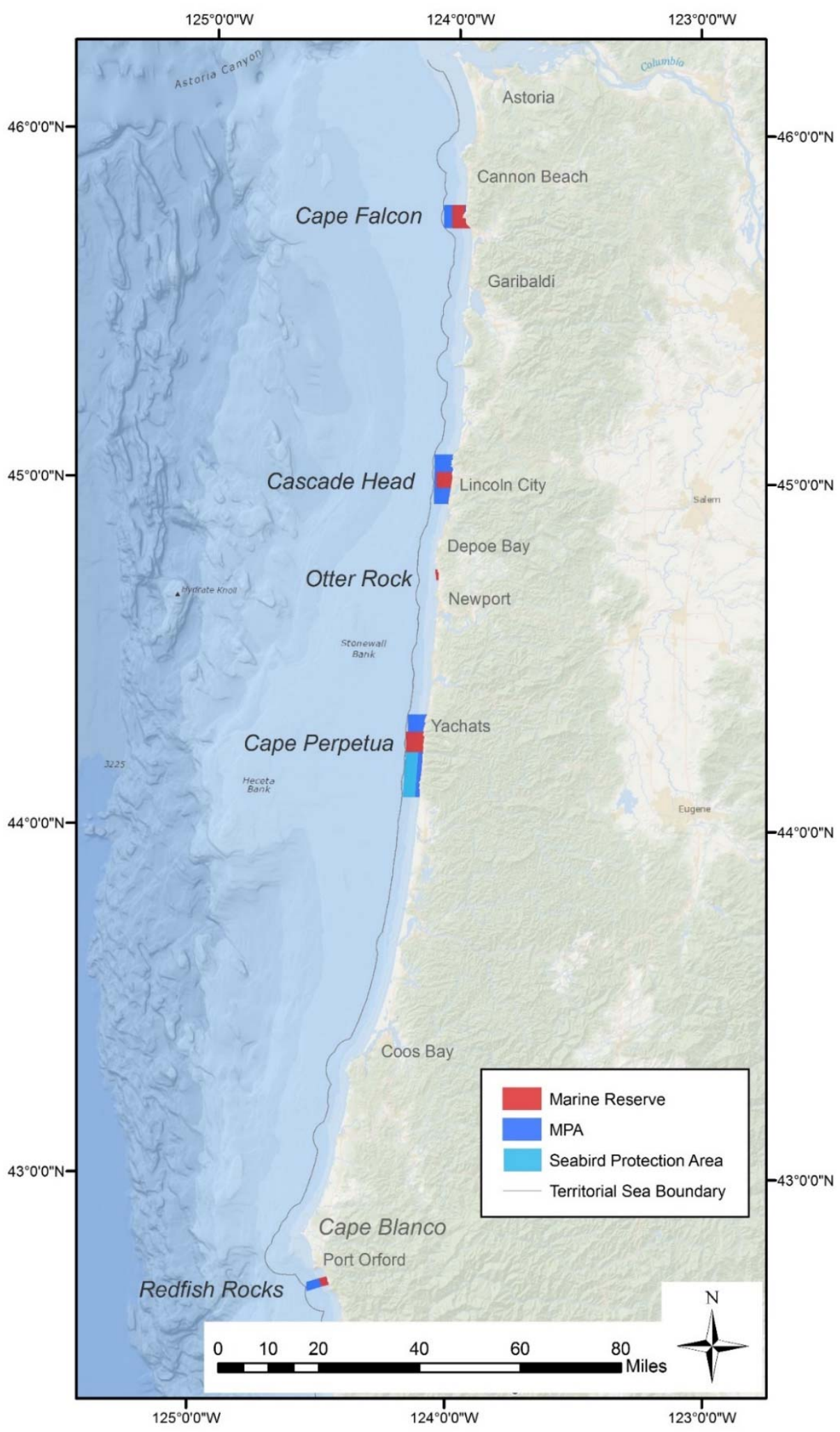




\section{Survey Project Scope}

\section{C.1. Objective}

The objective is twofold: 1) determine Oregon nearshore fisheries participation characteristics (cost and earnings, fisheries focus, effort levels, etc.), social characteristics (demographics, fishing dependence and tenure, family succession planning, etc.), and perception of marine reserve management; and, 2) determine effects from marine reserve fishing displacement.

\section{C.2. Population}

The intended population to be surveyed is participants in Oregon nearshore fisheries. These are the individuals that may have changes in their fishing activities due to establishment of marine reserves. Registrants for three commercial fishing permit types and a charter boat permit type were chosen to represent nearshore fisheries participants. The three commercial fishing permit types are Dungeness crab, salmon troll, and nearshore groundfish. These are the most important (highest landed value) nearshore fisheries. The survey project budget constraints prevented inclusion of other nearshore fisheries participants.

TRG (2018) estimated the participation levels, landed value, and economic contribution of nearshore fisheries based on species/gear definitions and fishing grounds locations. The nearshore fisheries estimates include ocean and bay fishing activities. The nearshore proportion of the commercial salmon troll fishery is estimated to be 35 percent and the nearshore proportion of the Dungeness crab fishery is estimated to be 54 percent. Recreational bay fisheries include anadromous fish in Columbia River and coastal streams.

Nearshore commercial and recreational fisheries activity is substantial. The commercial fishing onshore landed value was $\$ 157.7$ million in 2014 . There were 220.6 thousand ocean recreational trips in 2014 of which 26 percent are estimated to be via charter boat services. Nearshore commercial and recreational community economic contribution in 2014 was $\$ 103$ million. ${ }^{4}$ This represents 17 percent of Oregon total commercial and recreational fishing industry (includes distant water fisheries) which is $\$ 622$ million in 2014.

The TRG (2018) study found that the potential maximum economic impact (i.e. no replacement from fishing elsewhere) from marine reserve management is 3.6 percent of all nearshore commercial and recreational fishing economic contribution in the Oregon Territorial Sea (TS). Since the marine reserve system is less than 10 percent of the TS, it would seem likely that the 90 percent commercial harvesting and recreation angling area opportunities would provide satisfactory substitute fishing grounds for most species. However, some individual fishermen may have experience with the bottom features and water conditions at these sites, and decide not to fish elsewhere given management closures. The effort shift survey results will help determine effects from fishing abandonment, from changing locations for same fisheries, and from switching to other fisheries.

4. Economic contribution is expressed as income generated to the State level economy, includes the multiplier effect, and is stated in 2015 dollars. Dollar adjustments used the GDP Implicit Price Deflator produced by the U.S. Bureau of Economic Analysis. 
Table F shows the ten year landed value and vessel counts for the three fisheries selected to represent nearshore fisheries. The table also shows the average annual landed value per vessel. There are two trend summary statistics: 1) fisheries landed value percent variability, and 2) the Mann-Kendall test statistic that shows the strength (magnitude) and tendency (up/down direction) of a linear trend.

The period on Table $\mathrm{F}$ transcends when marine reserves were established. ${ }^{5}$ The trends are across whole fisheries and further analysis would be necessary to discern a discontinuity in effort due to marine reserves implementation.

Table F values for percent variability in fisheries landed value is greater than for vessel counts. This signals that fishers in aggregate tend to continue fishing despite conditions that may affect landing success. This may reflect participant ambivalence towards entering and exiting the fishery based solely on lost revenue opportunities. This would be consistent with habit being a meaningful social/psychological factor in fishery choice models (Van Putten et al. 2012). This observation could be extended to mean fishers reaction to management restrictions on fishing grounds in one area are simply compensated at same effort levels when there are opportunities elsewhere. Compensation in other fisheries may also occur if the fisher has the capacity and permits for other fishery opportunities.

\section{C.3. Sampling}

The survey method was to use a 100 percent sampling approach.

\section{C.4. Frame}

The survey frame included Dungeness crab, salmon troll, and nearshore groundfish permit registration holders and charter boat permit registration holders in early 2017. A commercial fishing survey unit included in the frame can hold permits for other ocean fisheries (such as halibut) and/or participate in fisheries that are not limited entry (such as albacore tuna). They might also participate in non-ocean fisheries (such as Columbia River gillnet). The survey frame contained both resident and non-resident permit owners. Survey units could be vessel owners that are not active in the fishery as well as those that do make commercial fisheries landings or make charter boat trips. While the survey frame portion related to commercial fishing encompassed most of the important nearshore fisheries, there are other lower landed value nearshore fisheries left out such as sea urchin, hagfish, groundfish trawl, sardine, and other invertebrates.

The recreational fishing survey frame was all charter boat permit owners. The survey frame did not include the private boat, bank, and diving mode for recreational fishing.

5. Marine reserves management restrictions started on January 1, 2012 for Redfish Rocks (RR) and Otter Rocks (OR); started on January 1, 2014 for Cascade Head (CH) and Cape Perpetua (CP); and started on January 1, 2016 for Cape Falcon (CF). 
The commercial fishing permit owner names from the three permit types were merged and survey unit duplicate addresses were deleted from the survey list. The result of the merging and filtering resulted in the survey frame containing 1,161 survey units.

There are cases where multiple permit owners share an address, so the merging would have precluded some owners receiving a survey instrument. There are cases where multiple vessels are associated with one owner name (highest number was discovered to be six) and a single vessel being associated with multiple owner names. To minimize respondent burden, the survey instrument contained a question asking for up to two vessel profiles.

\section{C.5. Administration}

An early instrument draft was submitted to peer reviewers within PSU and ODFW. A survey proposal was also presented at fishing industry focus group meetings that took place on the Oregon Coast in April 2017. Comments were incorporated into new versions of the instrument. The new version was used during a pretest for one-on-one interviews of a small number of fishers. Comments from the interviews were used to perfect a final questionnaire version.

The dates for survey administration were:

Prenotification date: $6 / 20 / 17$

First mailing packet date: 7/01/17

Incentive: NONE

Responses received: 121

Refusals received: 6

Second reminder date: $7 / 14 / 17$

Second mailing packet date: $8 / 4 / 17$

Incentive: $\$ 2.00$ enclosed in survey packet

Responses received: 109

Refusals received: 10

Second reminder date: $8 / 25 / 17$

Cut-off date for recording responses: 3/1/18

Total response number: 229

Total refusals: 16

Total non-deliverable mailings: 64

\section{Associating Vessels with Permit Owners}

Commercial fishing vessel identification codes were not included in the original list of permit holders pulled from the survey frame. Therefore, it was necessary subsequent to survey administration to use the ODFW fishery permit database to match the permit owner name and address in order to get the vessel identification. The vessel identification was necessary to compile fish ticket information. Table A shows the results for associating a vessel with the 
commercial fishing permit owners that received the survey questionnaire. A summary of the matching attempt is as follows.

- The columns under the title "Commercial Fishing Owner Names" exclude owners that only have a charter boat permit. There were 70 owners with a charter boat permit, but seven of them also had a commercial fishing permit $(1,098=1,161-70+7)$.

- One of the commercial fishing permit owners was not found to have a vessel match in permit registration information. While some commercial fisheries such as sea urchin are not linked to a vessel, the survey frame permits should have vessels associated with the permit owner name.

- Forty-four (=1,098-1,053-1) were matched to a vessel that was the same as another survey frame owner. The discovered 44 were assumed to be permit transfers. The earliest owner, if it could be determined, was used for the match and the other owners were ignored.

- Commercial fishing permit owner names may be associated with multiple vessels (highest discovered was six vessels). Vessel counting is exclusive of cases when more than one owner name is associated with the same vessel, resulting in 1,107 unique vessel identifications.

- The survey instrument asked for profile information for only two vessels. Therefore, delivering information was compiled for only the top two revenue generating vessels for a survey frame permit owner. One survey frame permit owner had four vessels with salmon permits, but only two had any PacFIN landings in 2016 so the other two are not used. It was the only survey frame permit owner with more than two vessels among the three fisheries that were not assumed to be transfers, and the top two by 2016 Oregon landings are included in the representativeness analysis.

- The columns titled "delivering" are counts of unique vessels discovered in fish ticket information, i.e. the vessel sold a harvested fish resource to a processor or the public in

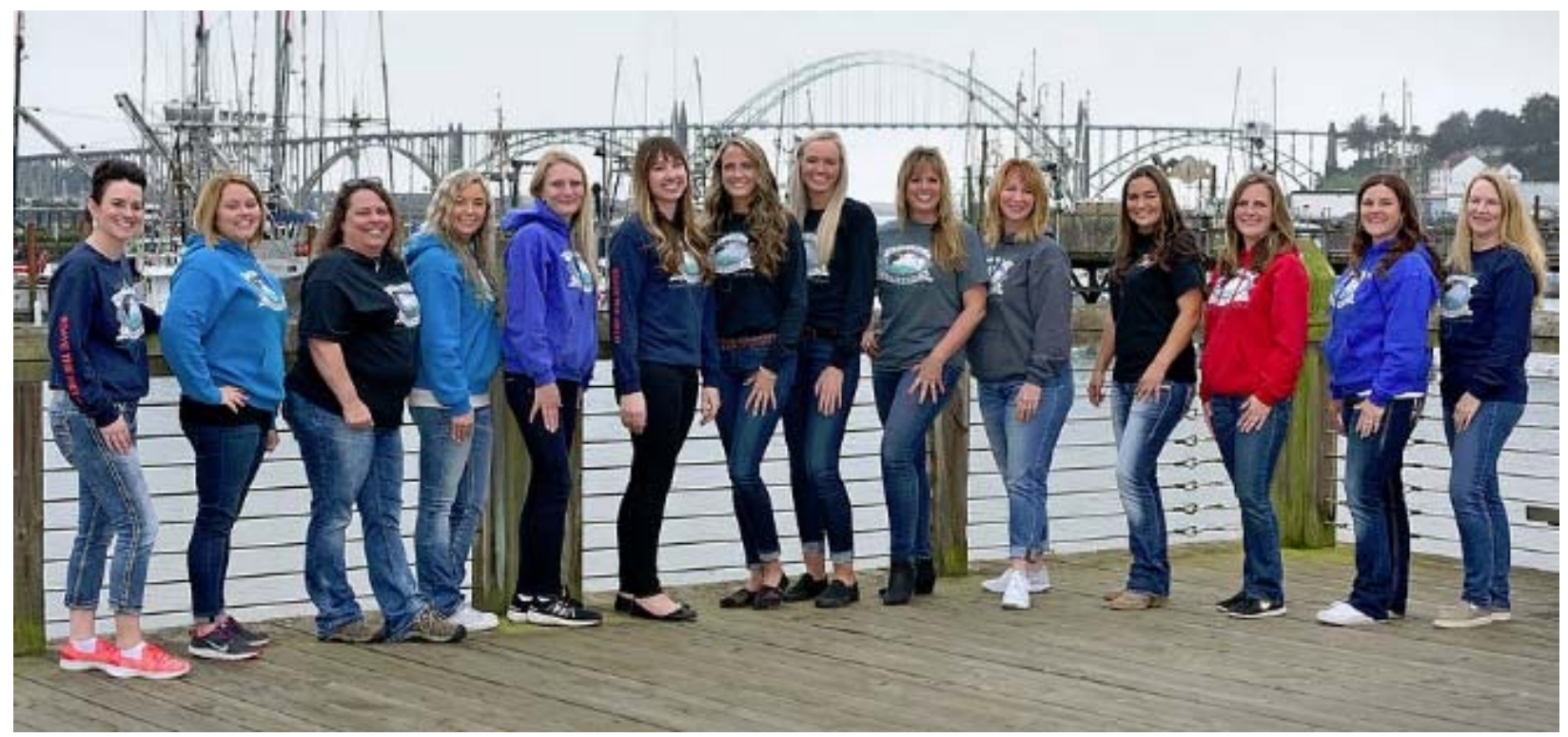

Newport Fishermen's Wives Inc. 
Oregon. Some fish tickets have no unique vessel identification associated with a delivery. For example, Columbia River tribal fisheries are not associated with a vessel identification.

- Six years of Oregon fish tickets were searched for the 1,107 vessels that were matched to the survey frame owner names. There were 861 vessels over that period that were found to have made at least one delivery. However, it could be that during the six-year period the vessel had a different owner. Further, the permit owner included in the survey frame may have owned a different vessel in a previous year. No attempt was made to reconcile the six years of all delivering vessel owner names with the survey frame owner name.

- There were 39 (=212-173) vessels found for survey respondents that had a permit for one of the three fisheries but no Oregon onshore landings for any fishery (i.e. not only the three fisheries included in the survey frame) in 2011-2016.

- There may be additional matches not found due to permit owner name or addresses having slightly different configuration. There are nine survey respondents for the missed matches. Therefore, the number of permit owner names that match at least one vessel identification is $1,053(=1,098-45)$.

- There were $480(=1,107-627)$ vessels in the survey frame that did not make Oregon deliveries in 2016. There were $76(=212-136)$ respondent vessels that did not make Oregon deliveries in 2016. The proportions of permit holders inactive in 2016 for any of the three survey fisheries are: survey frame 37 percent and respondents 23 percent.

\section{E. Respondents}

The survey frame list contained 1,161 permit owner names and the respondents were 229 . Commercial fishing owner names were 1,098 and the respondents were 213 . When the commercial fishing owner name was associated with a vessel identification, there were 1,053 matches with respondents 204. After accounting for multiple vessels per owner name and multiple names associated with one vessel, the 1,107 vessels respondents were 212 . Fish tickets

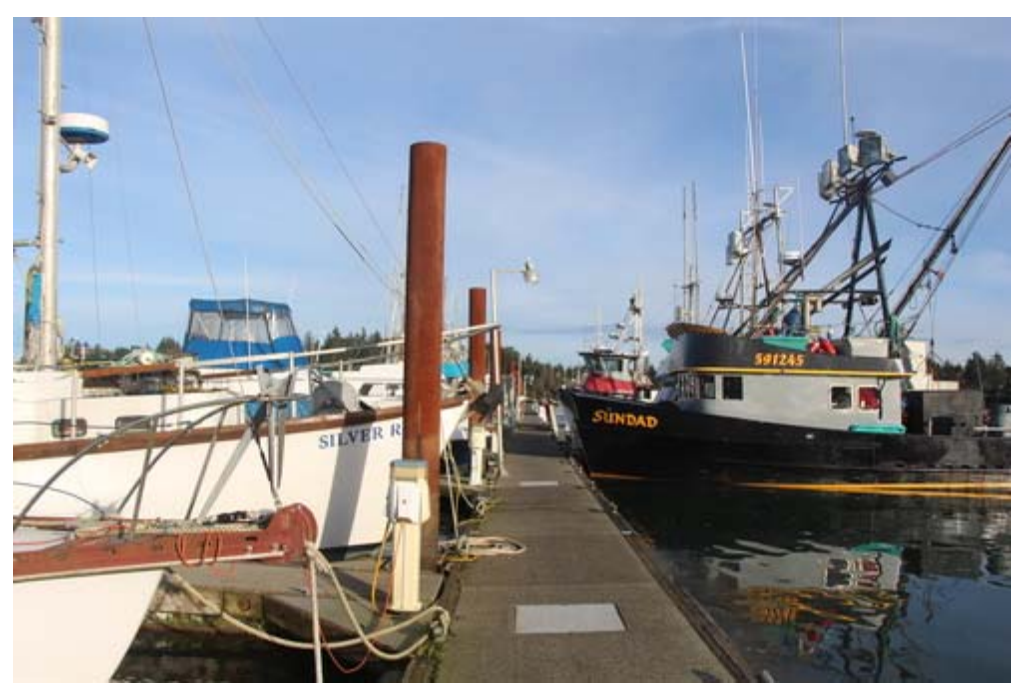

Charleston Marina were searched in years 2011-2016 for known vessel identifications and 861 were found to have landings; respondents for the vessels were 173 . Using the Council of American Survey Research Organizations (CASRO) Ninth Edition of Standard Definitions suggested formula for consideration of refusals and undeliverable instruments, the survey response rate would be 21.2 percent $(=229 /(1,161-(16+64))$. The relatively low response rate is not unusual for a natural resource 
user volunteer survey that solicits for financial performance information. A low response rate does not necessarily equate to a non-response bias (Groves 2006).

\section{F. Representativeness}

This review for representativeness is primarily based on landed value distribution. Other measures reviewed for representativeness are vessel physical size, Oregon home port, and permit owner residency.

Survey frame permit owners can have vessel revenue from deliveries in other West Coast states, Alaska, and at-sea. The out-of-state vessel revenue would be highly correlated with non-resident permit status. The out-of-state revenue was not included in the landed value tabulations. This would mean there are cases where tabulations include vessels that have none or small amounts of Oregon landings, but vessel total revenue is substantial.

Table A and Figure A and B show vessel identification matches that were found to have Oregon landings. The survey frame vessel counts were 60 percent of all onshore vessel counts in 2016 . The survey respondents represented about 13 percent (range over years 2011-2016 was 10 percent to 13 percent) of all Oregon vessel counts. The respondents represented about 22 percent of the survey frame vessel counts. Table B and Figure C and D show the survey frame landed value in 2016 was 67 percent of all onshore landed value. The respondents share of all onshore landed value was 11 percent in 2016 and 17 percent of the survey frame landed value in 2016.

Table $\mathrm{C}$ shows the landed value amounts and proportions of survey frame fisheries and incidental fisheries of the range of years 2011-2016. The percents of respondent to survey frame fisheries are 21, 29, and 26 respectively in 2016 for Dungeness crab, salmon troll, and nearshore groundfish. This percent varies significantly across the incidental fisheries. (Incidental fisheries are the other fisheries in which a survey frame permit owner participates.) Table D shows the shares by fishery for vessel counts. The shares are about 23 percent for all of the survey frame fisheries.

The distribution of respondents per vessel landed value compared to all onshore and survey frame is shown on Table $\mathrm{E}$ and Figure $\mathrm{J}$. The respondent per vessel landed value interquartile range compared to the survey frame is somewhat higher for the salmon troll and nearshore groundfish fisheries and lower for the Dungeness crab fishery.

Survey respondents are approximately equal for representation in landed value brackets (Table $\mathrm{G}$ and Figure I). The proportion of vessels in the $\$ 10$ to $\$ 50$ thousand landed value for 2016 is 25 percent for the survey frame and 26 percent for the respondents. The proportion in the $\$ 150$ to $\$ 400$ thousand bracket is 18 percent for the survey frame and 19 percent for the respondents.

Table E also shows results for comparing landed value means for the survey frame list to Oregon onshore, and for survey respondents to the survey frame. The comparison used the nonparametric Welch's t-test for two samples with heterogeneous variance between tested categories. No statistical differences ( $p$-value $<0.05$ ) in landed values were found for any of the fisheries. A 
finding of statistical difference would provide evidence that further evaluation is needed to determine whether survey calibration might be warranted.

Tables $\mathrm{H}$ and I show Oregon onshore, survey frame and respondent representativeness measures for Oregon home port and permit owner residency. Using means and proportions, the respondents deviations from survey frame are small for these other measures.

\section{G. Discussion}

The representativeness analysis purpose is to determine bias of the chosen survey frame for being inclusive of the intended survey population and investigate bias of non-response. The survey population included commercial fishing permit holders and recreational fishing charter boat permit holders. The representativeness analysis was only for the commercial fishing stratum.

The known indicators of the survey frame are from fisheries permit registrations and harvest delivery information recorded on fish tickets. There were no overt survey procedures used to track down non-respondents to determine potential bias. Therefore, and only if necessary due to a finding of misrepresentation, the known indicators could be used for creating post-survey calibration schemes to ameliorate any non-response bias.

Major findings from the representativeness analysis are:

1. If the survey population is commercial fishing participants in a traditional definition for Oregon nearshore fisheries, then survey coverage bias is introduced with the choice for the survey frame. The choice opened the survey frame list to participants whose fishing grounds are outside nearshore fisheries and there are other fishery permits that could have been included in the survey frame to be more inclusive of nearshore fisheries, such as the sea urchin fishery. The chosen survey frame does contain the most important (highest landed value generating) nearshore fisheries.

2. Concatenating survey frame list addresses and limiting respondents to providing information for only two vessels caused some loss in survey frame integrity. There were cases where multiple permit owners are associated with one address and other cases where many vessels were owned by a single registrant.

3. Not preloading the instrument with vessel and harvest history nor asking for the vessel identification number on the survey caused difficulties in verifying respondents stated behavior and supplying fish ticket delivery information to the survey results database.

4. Survey respondents were diverse and proportionally aligned with known characteristics about the survey frame universe. Known characteristic measures include vessel landed value, vessel physical length, Oregon principal port (port group where a plurality of Oregon landings are made), and permit registration in-state residency. Based on means and proportions, the respondents deviations from survey frame are small for the characteristics.

5. The proportions of permit holders active in 2016 for any of the three survey fisheries are: survey frame 63 percent and respondents 77 percent. It makes sense that a permit owner 
that is active in an Oregon fishery would be more likely to invest the time to complete a survey that is about the fisheries in which they participate.

6. Using only Oregon landed value and effort in modeling will misrepresent total vessel harvesting activity because some of the survey frame three fisheries permit holders also participate in out-of-state fisheries.

7. Response rate is low but not unexpected and unusual of other similar voluntary commercial fishing cost-earnings and preference survey studies. There were no nonresponse follow-up interviews that could be used to test similarity to respondent characteristics, behavior, and attitudes. At 229 respondents for a 1,161 survey list, an expected parametric margin of error at 95 percent confidence level for a question with a cardinal number answer that had no refusals would be plus or minus six percent.

8. More work in assessing representativeness such as comparing survey cost-earning results to mandatory reporting and other survey studies is possible.

9. Any signal of effort shift away from marine reserve due to fishing restrictions will be lost in the noise of annual landing variability. The maximum potential loss of landing value is 3.6 percent of Oregon Territorial Sea using average landings 2013-2015 (TRG 2018). The landing value variability between 2008 and 2017 has a range of 72 percent for Dungeness crab, 223 percent for salmon troll, and 23 percent for nearshore groundfish (Table F). A more spatial and temporal refined investigation would be necessary to discern a discontinuty in effort related to area fishing restrictions.

This representative analysis shows fairly close adherence to known survey frame characteristics. Therefore it is suggested that calibration schemes to improve representation may not be needed. There are no analytical standards to determine whether responses should be calibrated to reduce bias. It would be up to the project author to judge its necessity.

\section{H. Bibliography}

Deville, Jean-Claude and Carl-Erik Särndal. "Calibration Estimators in Survey Sampling." Journal of the American Statistical Association, 87:418, 376-382. 1992.

Gelman, Andrew and Thomas Little. "Post-stratification Into Many Categories Using Hierarchal Logistic Regression." Survey Methodology, v. 23, No. 2: pp. 127-135. 1997.

Groves, R.M. Nonresponse Rates and Nonresponse Bias in Household Surveys. Public Opinion Quarterly, 70(5), 646-675. 2006.

Kolenikov, Stanislav. "Calibrating Survey Data Using Iterative Proportional Fitting (Raking)." The Stata Journal, V. 14, No. 1: pp. 22-59. 2014.

Kruskal, W. and Mosteller, F. Representative Sampling IV: The History of the Concept in Statistics, 1895-1939. International Statistical Review. 1980. 
The Research Group, LLC (TRG). Interactive Model User Guide for the Broadscale Spatial Analysis of Oregon Nearshore Fisheries. Prepared for Marine Resources Program, Oregon Department of Fish and Wildlife. January 2018.

Särndal, C.E. and Lundström, S. Estimation in Surveys With Nonresponse. West Sussex, England: John Wiley \& Sons Ltd. 2005.

Van Putten, Ingrid, Soile Kulmala, Olivier Thébaud, Natalie Dowling, Katell Hamon, Trevor Hutton, and Sean Pascoe. "Theories and Behavioural Drivers Underlying Fleet Dynamics Models." Fish and Fisheries Volume 13, Issue 2. June 2012. 
Table A.1

Survey Frame and Survey Respondents Vessel Counts With Matches to Vessels Having Oregon Onshore Landings in 2011-2016

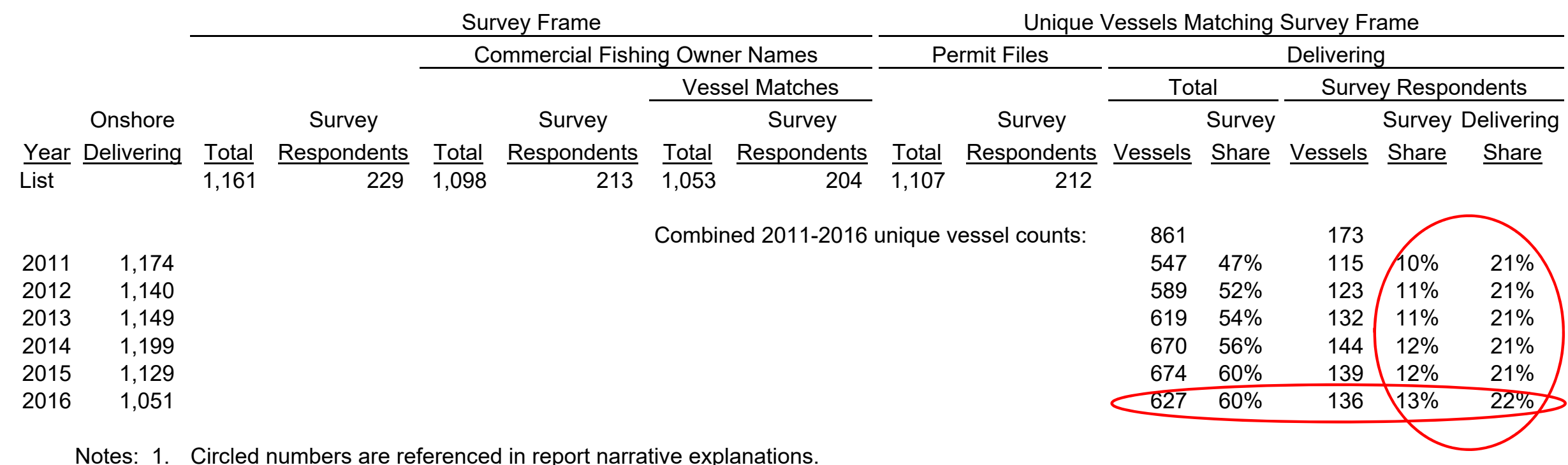

2. See report narrative for column derivation explanations.

Sources: Oregon onshore landings are from PacFIN annual vessel summary data April 2013, March 2014, April 2015, November 2016, and March 2017 extractions. Vessels matched to survey frame using ODFW fishery permit files for 2016 to 2017. 
Table A.2

Survey Frame and Survey Respondents Vessel Counts by Survey Fisheries With Matches to Vessels Having Oregon Onshore Landings in 2016

Survey frame (rows commercial fishery codes "DC", "S", "GF")

Respondents

\begin{tabular}{|c|c|c|c|c|}
\hline D. Crab & $\begin{array}{c}\text { Troll } \\
\text { Salmon }\end{array}$ & $\begin{array}{l}\text { Nearshore } \\
\text { Groundfish }\end{array}$ & $\begin{array}{l}3 \text { Survey } \\
\text { Fisheries }\end{array}$ & $\begin{array}{c}\text { All } \\
\text { Fisheries }\end{array}$ \\
\hline 374 & 886 & 99 & 1,098 & 1,098 \\
\hline 77 & 166 & 27 & 213 & 213 \\
\hline 421 & 954 & 114 & 1,197 & 1,537 \\
\hline 381 & 878 & 90 & 1,069 & 1,070 \\
\hline 78 & 163 & 27 & 209 & 209 \\
\hline 348 & 335 & 253 & 698 & 1,051 \\
\hline 292 & 293 & 170 & 553 & 627 \\
\hline 63 & 69 & 41 & 130 & 136 \\
\hline 364 & 835 & 76 & 1,107 & 1,107 \\
\hline 77 & 151 & 20 & 212 & 212 \\
\hline 307 & 302 & 97 & 598 & 859 \\
\hline 277 & 284 & 77 & 535 & 624 \\
\hline 62 & 68 & 24 & 129 & \\
\hline
\end{tabular}

Notes: 1. Circled numbers are referenced in report narrative explanations.

2. Fishery permit types include resident and non-resident. The nearshore groundfish fishery permit types are Oregon Nearshore Fishery Permit with and without a Nearshore Endorsement Permit.

3. Vessels in survey frame are determined by exact and inexact matches to permit file names and addresses, independently of codes "DC", "S", and "GF."

4. Table A.1 notes and sources apply. 
Table B

Survey Frame and Survey Respondents With Matches to Oregon Onshore Landings in 2011-2016

Oregon Landings for Unique Vessels Matching Survey Frame

\begin{tabular}{|c|c|c|c|c|c|c|c|c|c|c|c|c|}
\hline \multirow[b]{5}{*}{ Year } & & & \multirow{2}{*}{\multicolumn{4}{|c|}{ Survey Frame }} & \multirow{2}{*}{\multicolumn{6}{|c|}{ Survey Respondents }} \\
\hline & \multirow{3}{*}{\multicolumn{2}{|c|}{ Oregon Onshore Landings }} & & & & & & & & & & \\
\hline & & & \multicolumn{2}{|c|}{ Pounds } & \multicolumn{2}{|l|}{ Value } & \multicolumn{3}{|c|}{ Pounds } & \multicolumn{3}{|c|}{ Value } \\
\hline & & & & Onsh & & Onshore & & Onshore & Survey & & Onshore & Survey \\
\hline & Pounds & $\underline{\text { Value }}$ & Amount & $\underline{\text { Share }}$ & Amount & Share & $\underline{\mathrm{Am}}$ & $\underline{\text { Share }}$ & $\underline{\text { Share }}$ & unt & $\underline{\text { Share }}$ & $\underline{\text { Share }}$ \\
\hline$\overline{2011}$ & $28 \overline{5,820,628}$ & $146,485,485$ & $10 \overline{8,198,800}$ & $38 \%$ & $8 \overline{6,393,377}$ & $59 \%$ & $\overline{757}$ & $3 \%$ & $8 \%$ & 813 & $10 \%$ & $17 \%$ \\
\hline 2012 & 306,7 & $126,369,950$ & $96,422,669$ & $31 \%$ & $72,972,058$ & $58 \%$ & 625 & $2 \%$ & $8 \%$ & 238 & $9 \%$ & $16 \%$ \\
\hline 2013 & $349,390,051$ & $177,395,629$ & $134,354,197$ & $38 \%$ & $112,055,567$ & $63 \%$ & $10,495,658$ & $3 \%$ & $8 \%$ & $18,192,007$ & $10 \%$ & $16 \%$ \\
\hline 2014 & $300,362,364$ & $156,126,825$ & $127,764,366$ & $43 \%$ & $99,877,092$ & $64 \%$ & $7,208,745$ & $2 \%$ & $6 \%$ & $14,972,594$ & $10 \%$ & $15 \%$ \\
\hline 2015 & $203,885,317$ & $114,274,466$ & $74,539,342$ & $37 \%$ & $67,644,125$ & $59 \%$ & $5,033,734$ & $2 \%$ & $7 \%$ & $8,650,946$ & $8 \%$ & $13 \%$ \\
\hline 2016 & $226,918,381$ & $148,535,658$ & $87,009,197$ & $38 \%$ & $99,193,444$ & $67 \%$ & $6,599,827$ & $3 \%$ & $8 \%$ & $16,572,034$ & $11 \%$ & $17 \%$ \\
\hline
\end{tabular}

Notes: 1. Circled numbers are referenced in report narrative explanations.

2. Values are in nominal dollars.

3. Oregon onshore landings are from fish tickets that are not filtered for vessel identifications.

4. Survey frame landings are filtered for the matching vessels showing in Table A.2. The included nearshore groundfish landings are from vessels that have a Nearshore Fisheries Permit as well as incidental fishery landings from vessels that do not have. a Nearshore Fisheries Permit.

Sources: $\quad$ Oregon onshore landings are from PacFIN annual vessel summary data April 2013, March 2014, April 2015, November 2016, and March 2017 extractions. Vessels matched to survey frame using ODFW fishery permit files for 2016 to 2017. 
Table C

Survey Frame and Survey Respondents With Matches to

Oregon Onshore Landed Value by Major Fishery in 2011-2016

Survey Fisheries

Incidental Fisheries

\begin{tabular}{|c|c|c|c|c|c|c|c|c|c|c|}
\hline Year & $\begin{array}{l}\text { Ocean } \\
\text { Salmon }\end{array}$ & D. Crab & $\begin{array}{l}\text { Nearshore } \\
\text { Groundfish }\end{array}$ & $\begin{array}{l}\text { Col. R. } \\
\text { Salmon }\end{array}$ & $\begin{array}{c}\text { Other } \\
\text { Groundfish } \\
\end{array}$ & P. Shrimp & Tuna & Whiting & Sardine & Other \\
\hline & \multicolumn{10}{|c|}{ Oregon Onshore Landed Value by Major Fishery } \\
\hline 2011 & $2,403,537$ & $44,690,045$ & $1,534,618$ & $4,333,833$ & $26,904,632$ & $24,607,431$ & $18,765,949$ & $16,517,516$ & $3,191,593$ & $3,536,331$ \\
\hline 2012 & $4,248,810$ & $29,113,588$ & $1,720,643$ & $2,675,699$ & $22,113,724$ & $24,685,446$ & $15,077,265$ & $14,610,529$ & $8,976,821$ & $3,147,425$ \\
\hline 2013 & $7,607,116$ & $71,208,556$ & $1,625,231$ & $4,810,793$ & $20,697,168$ & $24,152,582$ & $16,078,899$ & $20,404,624$ & $6,299,324$ & $4,511,336$ \\
\hline 2014 & $14,828,562$ & $47,988,488$ & $1,579,699$ & $5,295,413$ & $20,230,029$ & $29,325,813$ & $11,023,484$ & $18,273,513$ & $3,521,759$ & $4,060,065$ \\
\hline 2015 & $7,334,340$ & $11,912,041$ & $1,740,992$ & $4,529,700$ & $27,047,263$ & $40,412,671$ & $9,211,747$ & $7,145,945$ & 812,687 & $4,127,080$ \\
\hline 2016 & $4,253,905$ & $55,734,874$ & $1,494,238$ & $4,053,970$ & $30,493,655$ & $25,093,253$ & $12,502,092$ & $8,693,682$ & 317 & $6,215,672$ \\
\hline
\end{tabular}

Oregon Onshore Landed Value by Major Fishery for Unique Vessels Matching Survey Frame

$\begin{array}{rrrrrrrrrrr}2011 & 2,065,484 & 35,412,530 & 790,763 & 192,540 & 17,338,988 & 16,229,219 & 8,395,380 & 4,499,793 & 0 & 1,468,680 \\ 2012 & 3,561,018 & 24,465,476 & 874,790 & 158,964 & 13,741,925 & 16,149,980 & 8,665,304 & 3,640,168 & 538,232 & 1,176,201 \\ 2013 & 6,508,484 & 59,533,639 & 861,917 & 231,157 & 12,297,158 & 16,731,516 & 7,918,707 & 5,874,195 & 939,243 & 1,159,551 \\ 2014 & 12,844,034 & 39,413,676 & 794,129 & 292,692 & 11,515,695 & 19,638,839 & 7,002,829 & 6,170,362 & 733,763 & 1,471,073 \\ 2015 & 6,491,973 & 9,990,768 & 1,034,635 & 196,176 & 16,435,299 & 25,229,662 & 5,513,137 & 964,072 & 497,663 & 1,290,740 \\ 2016 & 3,913,854 & 47,159,023 & 917,561 & 217,546 & 20,242,702 & 15,693,805 & 7,823,476 & 1,920,131 & 66 & 1,305,280\end{array}$

Oregon Onshore Landed Value by Major Fishery for Unique Vessels Matching Survey Respondents

\begin{tabular}{|c|c|c|c|c|c|c|c|c|c|c|}
\hline 2011 & 466,740 & $7,060,329$ & 300,665 & 13,543 & $3,465,850$ & $1,574,991$ & $1,214,566$ & 0 & 0 & 159,129 \\
\hline 2012 & 879,079 & $5,159,397$ & 286,084 & 9,199 & $2,331,766$ & $1,532,167$ & 1,196,207 & 0 & 0 & 97,339 \\
\hline 2013 & $1,531,885$ & $11,393,340$ & 292,061 & 17,059 & $1,539,609$ & $1,894,117$ & 1,383,996 & 1 & 0 & 139,939 \\
\hline 014 & $2,966,419$ & $7,459,684$ & 264,197 & 16,119 & $1,552,607$ & $1,410,160$ & $1,133,994$ & 0 & 842 & 168,572 \\
\hline 015 & $1,430,040$ & $2,229,060$ & 329,428 & 14,131 & $2,119,247$ & $1,364,607$ & 929,465 & 23 & 63,525 & 171,420 \\
\hline 016 & $1,144,883$ & $10,049,362$ & 237,609 & 12,012 & $2,628,731$ & 936,131 & $1,336,610$ & 7 & 0 & 226,689 \\
\hline
\end{tabular}

Share of Oregon Onshore Landed Value by Major Fishery for Unique Vessels Matching Survey Frame

$\begin{array}{rrrrrrrrrrr}2011 & 86 \% & 79 \% & 52 \% & 4 \% & 64 \% & 66 \% & 45 \% & 27 \% & 0 \% & 42 \% \\ 2012 & 84 \% & 84 \% & 51 \% & 6 \% & 62 \% & 65 \% & 57 \% & 25 \% & 6 \% & 37 \% \\ 2013 & 86 \% & 84 \% & 53 \% & 5 \% & 59 \% & 69 \% & 49 \% & 29 \% & 15 \% & 26 \% \\ 2014 & 87 \% & 82 \% & 50 \% & 6 \% & 57 \% & 67 \% & 64 \% & 34 \% & 21 \% & 36 \% \\ 2015 & 89 \% & 84 \% & 59 \% & 4 \% & 61 \% & 62 \% & 60 \% & 13 \% & 61 \% & 31 \% \\ 2016 & 92 \% & 85 \% & 61 \% & 5 \% & 66 \% & 63 \% & 63 \% & 22 \% & 21 \% & 21 \%\end{array}$

Share of Oregon Onshore Landed Value by Major Fishery for Unique Vessels Matching Survey Respondents

$\begin{array}{rrrrrrrrrrr}2011 & 19 \% & 16 \% & 20 \% & 0 \% & 13 \% & 6 \% & 6 \% & 0 \% & 0 \% & 4 \% \\ 2012 & 21 \% & 18 \% & 17 \% & 0 \% & 11 \% & 6 \% & 8 \% & 0 \% & 0 \% & 3 \% \\ 2013 & 20 \% & 16 \% & 18 \% & 0 \% & 7 \% & 8 \% & 9 \% & 0 \% & 0 \% & 3 \% \\ 2014 & 20 \% & 16 \% & 17 \% & 0 \% & 8 \% & 5 \% & 10 \% & 0 \% & 0 \% & 4 \% \\ 2015 & 19 \% & 19 \% & 19 \% & 0 \% & 8 \% & 3 \% & 10 \% & 0 \% & 8 \% & 4 \% \\ 2016 & 27 \% & 18 \% & 16 \% & 0 \% & 9 \% & 4 \% & 11 \% & 0 \% & 0 \% & 4 \%\end{array}$

Share of Survey Frame Landed Value From Survey Respondents Landed Value

$\begin{array}{rrrrrrrrrrrr}2011 & 23 \% & 20 \% & 38 \% & 7 \% & 20 \% & 10 \% & 14 \% & 0 \% & 11 \% \\ 2012 & 25 \% & 21 \% & 33 \% & 6 \% & 17 \% & 9 \% & 14 \% & 0 \% & 0 \% & 8 \% \\ 2013 & 24 \% & 19 \% & 34 \% & 7 \% & 13 \% & 11 \% & 17 \% & 0 \% & 0 \% & 12 \% \\ 2014 & 23 \% & 19 \% & 33 \% & 6 \% & 13 \% & 7 \% & 16 \% & 0 \% & 0 \% & 11 \% \\ 2015 & 22 \% & 22 \% & 32 \% & 7 \% & 13 \% & 5 \% & 17 \% & 0 \% & 13 \% & 13 \% \\ 2016 & 29 \% & 21 \% & 26 \% & 6 \% & 13 \% & 6 \% & 17 \% & 0 \% & 0 \% & 17 \%\end{array}$

Notes: 1. Notes and sources of Table B apply. Circled numbers are referenced in report narrative explanations.

2. Columbia River salmon fishery includes both non-Indian and tribal fisheries. 
Table D

Survey Frame and Survey Respondents With Matches to

Oregon Onshore Landing Vessels by Major Fishery in 2011-2016

Survey Fisheries

Incidental Fisheries

Ocean Nearshore Col. R. Other

Year Salmon D. Crab Groundfish Salmon Groundfish P. Shrimp Tuna Whiting Sardine Other

\begin{tabular}{lllllllllll} 
& \multicolumn{10}{c}{ Oregon Onshore Landing Vessels by Major Fishery } \\
\cline { 2 - 12 } 2011 & 327 & 395 & 231 & 218 & 179 & 62 & 442 & 54 & 26 & 379 \\
2012 & 391 & 357 & 245 & 187 & 196 & 64 & 447 & 51 & 35 & 372 \\
2013 & 420 & 363 & 246 & 168 & 187 & 60 & 397 & 45 & 25 & 328 \\
2014 & 515 & 371 & 224 & 183 & 174 & 60 & 379 & 40 & 32 & 285 \\
2015 & 516 & 321 & 267 & 174 & 177 & 78 & 348 & 47 & 13 & 256 \\
2016 & 335 & 348 & 253 & 175 & 182 & 75 & 367 & 57 & 17 & 253
\end{tabular}

Oregon Onshore Landing Vessels by Major Fishery for Unique Vessels Matching Survey Frame

$\begin{array}{llllrllllll}2011 & 235 & 284 & 132 & 12 & 111 & 42 & 246 & 23 & 3 & 141 \\ 2012 & 298 & 269 & 145 & 13 & 123 & 42 & 279 & 21 & 7 & 148 \\ 2013 & 327 & 284 & 155 & 9 & 123 & 40 & 237 & 19 & 5 & 129 \\ 2014 & 418 & 287 & 134 & 9 & 107 & 40 & 236 & 14 & 6 & 186 \\ 2015 & 432 & 261 & 169 & 11 & 113 & 48 & 239 & 19 & 6 & 176 \\ 2016 & 293 & 292 & 170 & 9 & 122 & 50 & 253 & 27 & 4 & 170\end{array}$

Oregon Onshore Landing Vessels by Major Fishery for Unique Vessels Matching Survey Respondents

$\begin{array}{lllllllllll}2011 & 56 & 66 & 31 & 2 & 27 & 4 & 45 & 2 & 1 & 25 \\ 2012 & 64 & 61 & 35 & 3 & 30 & 5 & 53 & 2 & 0 & 30 \\ 2013 & 76 & 65 & 43 & 1 & 33 & 5 & 42 & 2 & 0 & 24 \\ 2014 & 89 & 66 & 35 & 1 & 25 & 3 & 44 & 1 & 1 & 38 \\ 2015 & 89 & 58 & 38 & 1 & 25 & 4 & 38 & 1 & 1 & 38 \\ 2016 & 69 & 63 & 41 & 1 & 25 & 5 & 50 & 2 & 0 & 37\end{array}$

Share of Oregon Onshore Landing Vessels by Major Fishery for Unique Vessels Matching Survey Frame

$\begin{array}{lllllllllll}2011 & 72 \% & 72 \% & 57 \% & 6 \% & 62 \% & 68 \% & 56 \% & 43 \% & 12 \% & 37 \% \\ 2012 & 76 \% & 75 \% & 59 \% & 7 \% & 63 \% & 66 \% & 62 \% & 41 \% & 20 \% & 40 \% \\ 2013 & 78 \% & 78 \% & 63 \% & 5 \% & 66 \% & 67 \% & 60 \% & 42 \% & 20 \% & 39 \% \\ 2014 & 81 \% & 77 \% & 60 \% & 5 \% & 61 \% & 67 \% & 62 \% & 35 \% & 19 \% & 65 \% \\ 2015 & 84 \% & 81 \% & 63 \% & 6 \% & 64 \% & 62 \% & 69 \% & 40 \% & 46 \% & 69 \% \\ 2016 & 87 \% & 84 \% & 67 \% & 5 \% & 67 \% & 67 \% & 69 \% & 47 \% & 24 \% & 67 \%\end{array}$

Share of Oregon Onshore Landing Vessels by Major Fishery for Unique Vessels Matching Survey Respondents

$\begin{array}{rrrrrrrrrrr}2011 & 17 \% & 17 \% & 13 \% & 1 \% & 15 \% & 6 \% & 10 \% & 4 \% & 4 \% & 7 \% \\ 2012 & 16 \% & 17 \% & 14 \% & 2 \% & 15 \% & 8 \% & 12 \% & 4 \% & 0 \% & 8 \% \\ 2013 & 18 \% & 18 \% & 17 \% & 1 \% & 18 \% & 8 \% & 11 \% & 4 \% & 0 \% & 7 \% \\ 2014 & 17 \% & 18 \% & 16 \% & 1 \% & 14 \% & 5 \% & 12 \% & 3 \% & 3 \% & 13 \% \\ 2015 & 17 \% & 18 \% & 14 \% & 1 \% & 14 \% & 5 \% & 11 \% & 2 \% & 8 \% & 15 \% \\ 2016 & 21 \% & 18 \% & 16 \% & 1 \% & 14 \% & 7 \% & 14 \% & 4 \% & 0 \% & 15 \%\end{array}$

Share of Survey Frame Unique Vessels That Match Survey Respondents Unique Vessels

\begin{tabular}{|c|c|c|c|c|c|c|c|c|c|c|}
\hline 2011 & $24 \%$ & $23 \%$ & $23 \%$ & $17 \%$ & $24 \%$ & $10 \%$ & $18 \%$ & $9 \%$ & & $18 \%$ \\
\hline 2012 & $21 \%$ & $23 \%$ & $24 \%$ & $23 \%$ & $24 \%$ & $12 \%$ & $19 \%$ & $10 \%$ & $0 \%$ & $20 \%$ \\
\hline 2013 & $23 \%$ & $23 \%$ & $28 \%$ & $11 \%$ & $27 \%$ & $13 \%$ & $18 \%$ & $11 \%$ & $0 \%$ & $19 \%$ \\
\hline 2014 & $21 \%$ & $23 \%$ & $26 \%$ & $11 \%$ & $23 \%$ & $8 \%$ & $19 \%$ & $7 \%$ & $17 \%$ & $20 \%$ \\
\hline 2015 & $21 \%$ & $22 \%$ & $22 \%$ & $9 \%$ & $22 \%$ & $8 \%$ & $16 \%$ & $5 \%$ & $17 \%$ & $22 \%$ \\
\hline 016 & $24 \%$ & $22 \%$ & $24 \%$ & $11 \%$ & $20 \%$ & $10 \%$ & $20 \%$ & $7 \%$ & $0 \%$ & $22 \%$ \\
\hline
\end{tabular}

Notes: 1. Notes and sources of Table A apply. Circled numbers are referenced in report narrative explanations.

2. Columbia River salmon fishery excludes tribal fisheries because fish tickets do not reveal vessel identification. 
Table E

Frequency Distribution of Oregon Onshore, Survey Frame, and Survey Respondent Average Annual Landed Value in 2016

All Fisheries
Vessels
Minimum value
1st quartile
2nd quartile (median)
3rd quartile
Maximum value
Interquartile range (IQR)
Mean

\begin{tabular}{|c|c|c|}
\hline Oregon Onshore & Survey Frame & Survey Respond \\
\hline 1,051 & 627 & 136 \\
\hline 32 & 58 & 149 \\
\hline 6,035 & 8,390 & 6,534 \\
\hline 30,650 & 42,571 & 36,780 \\
\hline 141,557 & 171,594 & 157,388 \\
\hline $1,807,386$ & $1,734.913$ & $1,714,885$ \\
\hline 135,522 & 163,204 & 150,854 \\
\hline 138,357 & 158,203 & 121,853 \\
\hline & 0.150 & 0.090 \\
\hline
\end{tabular}

D. Crab

Vessels

Minimum value

1st quartile

2nd quartile (median)

3rd quartile

Maximum value

Interquartile range (IQR)

Mean

Two sample t-test $\mathrm{P}$-value

\begin{tabular}{rrr}
348 & 292 & 63 \\
0 & 0 & 1,154 \\
42,074 & 59,151 & 70,055 \\
120,360 & 123,445 & 103,153 \\
234,132 & 233,673 & 225,012 \\
818,458 & 805,282 & 805,282 \\
\hline 192,058 & 174,523 & 154,957 \\
\hline 160,046 & 161,504 & 159,514 \\
& 0.902 & 0.928
\end{tabular}

Salmon, troll

Vessels

Minimum value

1st quartile

2nd quartile (median)

3rd quartile

Maximum value

Interquartile range (IQR)

Mean

Two sample t-test $\mathrm{P}$-value

\begin{tabular}{rrr}
335 & 293 & 69 \\
0 & 0 & 63 \\
745 & 1,070 & 1,358 \\
4,832 & 5,894 & 7,827 \\
16,888 & 18,728 & 24,735 \\
149,071 & 149,071 & 94,507 \\
\hline 16,143 & 17,658 & 23,377 \\
\hline 12,664 & 13,358 & 16,593 \\
& 0.654 & 0.244
\end{tabular}

Nearshore groundfish

Vessels

Minimum value

1st quartile

2nd quartile (median)

3rd quartile

Maximum value

Interquartile range (IQR)

Mean

Two sample t-test $\mathrm{P}$-value

\begin{tabular}{rrr}
253 & 170 & 41 \\
0 & 0 & 0 \\
188 & 238 & 421 \\
1,522 & 1,962 & 2,439 \\
7,602 & 7,199 & 9,690 \\
71,335 & 40,976 & 40,890 \\
\hline 7,414 & 6,961 & 9,269 \\
\hline 5,887 & 5,397 & 5,795 \\
& 0.582 & 0.775
\end{tabular}

Notes: 1 . Circled numbers are referenced in report narrative explanations.

2. Oregon onshore excludes landings with no identifiable vessel. Out-of-state landed value is not included.

3. Survey frame and respondents only include vessels with Oregon deliveries in 2016.

4. The Welch Two Sample t-test is a parametric method to test the hypothesis that two subpopulations have equal means. Survey frame is compared to Oregon onshore, and survey respondents are compared to survey frame. 


\begin{tabular}{|c|c|c|c|c|c|c|c|c|c|c|c|c|c|c|}
\hline \multirow[b]{2}{*}{ Fishery } & \multirow[b]{2}{*}{2008} & \multirow[b]{2}{*}{2009} & \multirow[b]{2}{*}{2010} & \multirow[b]{2}{*}{2011} & \multirow[b]{2}{*}{2012} & \multirow[b]{2}{*}{2013} & \multirow[b]{2}{*}{2014} & \multirow[b]{2}{*}{2015} & \multirow[b]{2}{*}{2016} & \multirow[b]{2}{*}{2017} & \multicolumn{4}{|c|}{ 2008-2017 Dispersion } \\
\hline & & & & & & & & & & & Trend & Mean & $\begin{array}{c}\text { Percent } \\
\text { Variability }\end{array}$ & $\begin{array}{l}\text { Mann- } \\
\text { Kendall } \\
\end{array}$ \\
\hline & \multicolumn{12}{|c|}{ Landed Value (real, millions) } & & \\
\hline All Fisheries & 114.7 & 116.1 & 115.4 & 160.8 & 136.2 & 188.2 & 162.7 & 117.8 & 151.2 & 144.0 & & 140.7 & $52 \%$ & 1.43 \\
\hline D. Crab & 33.7 & 29.6 & 50.3 & 53.8 & 45.7 & 51.9 & 52.3 & 34.6 & 52.2 & 63.1 & & 46.7 & & 1.79 \\
\hline Salmon, troll & 0.4 & 0.4 & 3.1 & 2.6 & 4.6 & 8.1 & 15.5 & 7.6 & 4.3 & 2.1 & & 6.0 & $223 \%$ & 0.72 \\
\hline \multirow[t]{2}{*}{ Nearshore groundfish } & 1.2 & 1.4 & 1.1 & 1.3 & 1.4 & 1.3 & 1.2 & 1.2 & 1.0 & 1.0 & & 1.2 & $30 \%$ & -1.61 \\
\hline & \multicolumn{12}{|c|}{ Participating Vessel Counts } & & \\
\hline All Fisheries & 1,039 & 1,140 & 1,180 & 1,174 & 1,140 & 1,149 & 1,199 & 1,129 & 1,051 & 1,051 & & 1,125 & $14 \%$ & -0.45 \\
\hline D. Crab & 340 & 346 & 351 & 385 & 354 & 342 & 348 & 336 & 341 & 341 & & 348 & $14 \%$ & -0.63 \\
\hline Salmon, troll & 163 & 248 & 392 & 327 & 391 & 420 & 515 & 516 & 335 & 335 & & 404 & $47 \%$ & 0.63 \\
\hline \multirow[t]{2}{*}{ Nearshore groundfish } & 116 & 125 & 123 & 118 & 115 & 116 & 105 & 109 & 99 & 99 & & 113 & $23 \%$ & -2.78 \\
\hline & \multicolumn{12}{|c|}{ Average Landed Value Per Vessel (real, thousands) } & & \\
\hline All Fisheries & 110.4 & 101.9 & 97.8 & 137.0 & 119.5 & 163.8 & 135.7 & 104.4 & 143.9 & 137.0 & & 125.1 & $53 \%$ & \\
\hline D. Crab & 99.1 & 85.7 & 143.4 & 139.9 & 129.2 & 151.8 & 150.3 & 102.9 & 153.2 & 185.0 & & 134.1 & $74 \%$ & \\
\hline Salmon, troll & 2.7 & 1.6 & 8.0 & 8.1 & 11.7 & 19.2 & 30.0 & 14.7 & 12.9 & 6.4 & & 14.8 & $160 \%$ & \\
\hline Nearshore groundfish & 10.7 & 11.1 & 9.0 & 11.0 & 11.8 & 11.4 & 11.5 & 11.5 & 10.5 & 10.3 & & 10.9 & $26 \%$ & \\
\hline
\end{tabular}


Notes: 1. Circled numbers are referenced in report narrative explanations.

2. Values are real 2017 dollars adjusted using the GDP implicit price deflator developed by U.S. Bureau of Economic Analysis.

3. The Dungeness crab fisheries landed value are for a season. The season is authorized to open December 1 , however some seasons during the tables period have had delayed openings until January. To have consistent landings across the period, any landings in December of the preceding year are compiled to be in the following year.

4. The salmon fisheries in 2008 and 2009 are outliers because the fishery was essentially closed south of Cape Falcon during those years. The mean and percent variability are calculated for years 2010-2017. The Mann-Kendall statistic is calculated by repeating Year 2010 for those years. Year 2010 harvests were moderate, but representative of decade 2000's averages when salmon disaster years 2006, 2008, and 2009 harvests are omitted.

5. Oregon onshore values include those fish tickets with no unique vessel identification associated with a delivery.

6. Year 2017 data is not available for vessel counts, or for nearshore groundfish landings, so 2016 is repeated.

7. The Mann-Kendall test statistic shows the tendency for an increasing (positive) or decreasing (negative) linear trend with time using a nonparametric method. A value near zero suggests there is no significant upward or downward trend. The magnitude measures the "strength" of the trend.

8. Marine reserves management restrictions started on January 1, 2012 at Redfish Rocks (RR) and Otter Rocks (OR), January 1, 2014 at Cascade Head (CH) and Cape Perpetua (CP), and January 1, 2016 at Cape Falcon (CF).

9. Table shows only nearshore groundfish landed by vessels having Oregon Nearshore Fishery Permit with and without a Nearshore Endorsement Permit.

Source: PacFIN annual vessel summary data April 2009, March 2010, July 2011, April 2013, March 2014, April 2015, November 2016, and March 2017 extractions; and PacFIN and ODFW websites accessed April 26, 2018. 
Table G

Frequency Distribution of Oregon Onshore, Survey Frame, and Survey

Respondent Delivering Vessel Average Annual Landed Value in 2016

Vessels

Oregon onshore

Survey frame

Survey respondents

Share

Oregon onshore

Survey frame

Survey respondents

$\$ 0-500 \$ 500-10 k \quad \$ 10 k-50 k \$ 50 k-150 k$ \$150k-400k $\$ 400 k+$ Total

$\begin{array}{rrrrrrr}60 & 286 & 271 & 180 & 151 & 103 & 1,051 \\ 32 & 138 & 155 & 122 & 111 & 69 & 627 \\ 9 & 31 & 35 & 26 & 26 & 9 & 136\end{array}$

Notes: 1 . Circled numbers are referenced in report narrative explanations.

Residency of Oregon Permitted, Survey Frame, and Survey Respondent Permit Owners in 2016

All Fisheries

All Oregon permitted

Survey frame

Survey respondents

D. Crab

All Oregon permitted

Survey frame

Survey respondents

Table H

Count of Permittees

381

363

77

284
271
60

284

60

$\begin{array}{ll}897 & 627 \\ 879 & 605 \\ 165 & 126\end{array}$

292

274

39

105
92
17

$17 \%$

$19 \%$

$19 \%$

26

467

348

53

$\begin{array}{rr}10 \% & 100 \% \\ 11 \% & 100 \% \\ 7 \% & 100 \%\end{array}$

Salmon, troll

All Oregon permitted

Survey frame

$\begin{array}{lrrrrr}\text { All Oregon permitted } & 101 & 99 & 4 & 2 & 96 \% \\ \text { Survey frame } & 76 & 72 & 4 & 0 & 95 \% \\ \text { Survey respondents } & 20 & 18 & 2 & 0 & 90 \%\end{array}$

$\begin{array}{lrrrrr}\text { All Oregon permitted } & 101 & 99 & 4 & 2 & 96 \% \\ \text { Survey frame } & 76 & 72 & 4 & 0 & 95 \% \\ \text { Survey respondents } & 20 & 18 & 2 & 0 & 90 \%\end{array}$

Oregon

\begin{tabular}{rrr} 
Both & & Share \\
& \multicolumn{2}{c}{$68 \%$} \\
0 & $68 \%$ \\
0 & $75 \%$
\end{tabular}

Nearshore groundfish

Notes: 1. Table values for all Oregon permitted include all 2016 fishery permit registrants whether or not the permit was associated with a vessel that made deliveries in 2016. Names with addresses in more than one state are counted as non-Oregon for share.

2. Survey frame includes only commercial fishing permit owners, and assignments to fishery use 2016 and 2017 fishery permit files and assumptions to exclude transfers.

3. Nearshore groundfish permit types are Oregon Nearshore Fishery Permit with and without a Nearshore Endorsement Permit. 
Table I

Vessels by Principal Oregon Delivery Port Area in 2016

All Fisheries

Oregon onshore

Survey frame

Survey respondents

\section{Share}

Oregon onshore

Survey frame

Survey respondents

\begin{tabular}{|c|c|c|c|c|c|c|}
\hline Astoria & Tillamook & Newport & Coos Bay & Port Orford & Brookings & Total \\
\hline 325 & 85 & 272 & 223 & 54 & 92 & 1,051 \\
\hline 97 & 58 & 197 & 164 & 39 & 72 & 627 \\
\hline 24 & 18 & 40 & 24 & 11 & 19 & 136 \\
\hline $31 \%$ & $8 \%$ & $26 \%$ & $21 \%$ & $5 \%$ & $9 \%$ & $100 \%$ \\
\hline $15 \%$ & $9 \%$ & $31 \%$ & $26 \%$ & $6 \%$ & $11 \%$ & $100 \%$ \\
\hline $18 \%$ & $13 \%$ & $29 \%$ & $18 \%$ & $8 \%$ & $14 \%$ & $100 \%$ \\
\hline
\end{tabular}

Notes: 1. Principal Oregon delivery port area is the port group where a vessel had the most Oregon onshore landings in 2016 (not necessarily a majority). 
Figure A

Delivering Vessel Counts in 2016

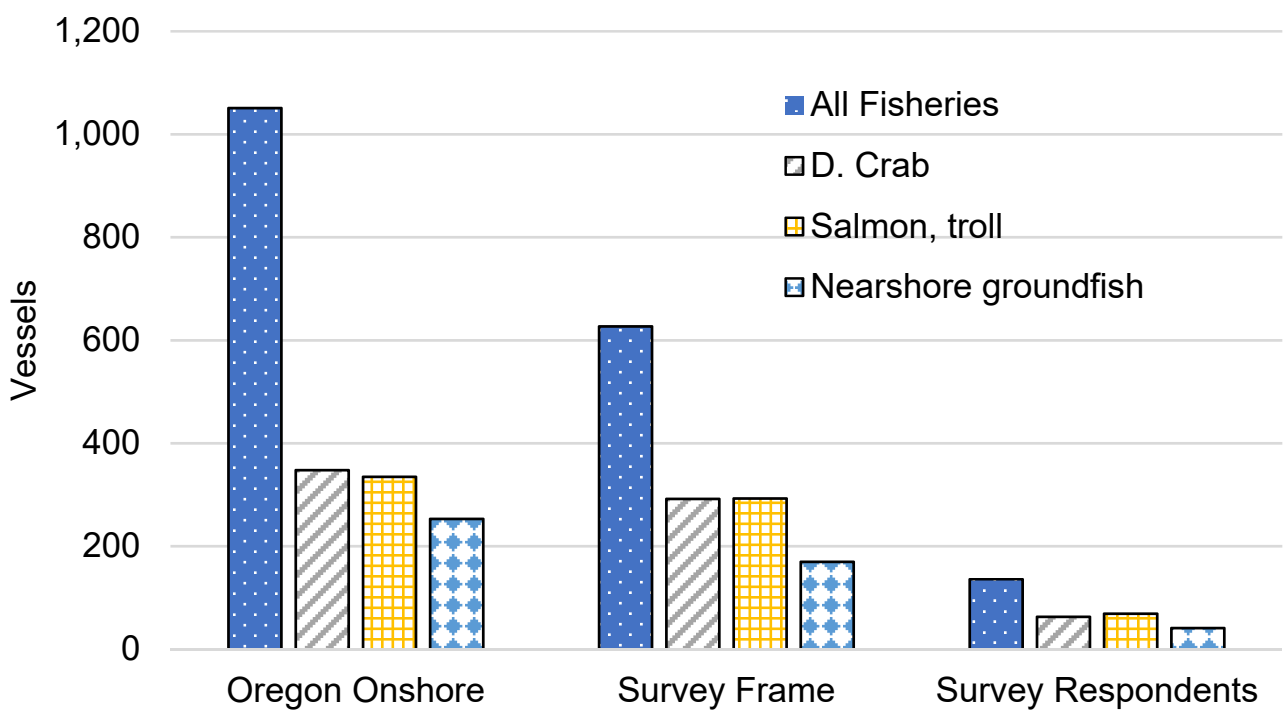

Figure B

Delivering Vessel Count Shares of

Oregon Onshore and Survey Frame in 2016

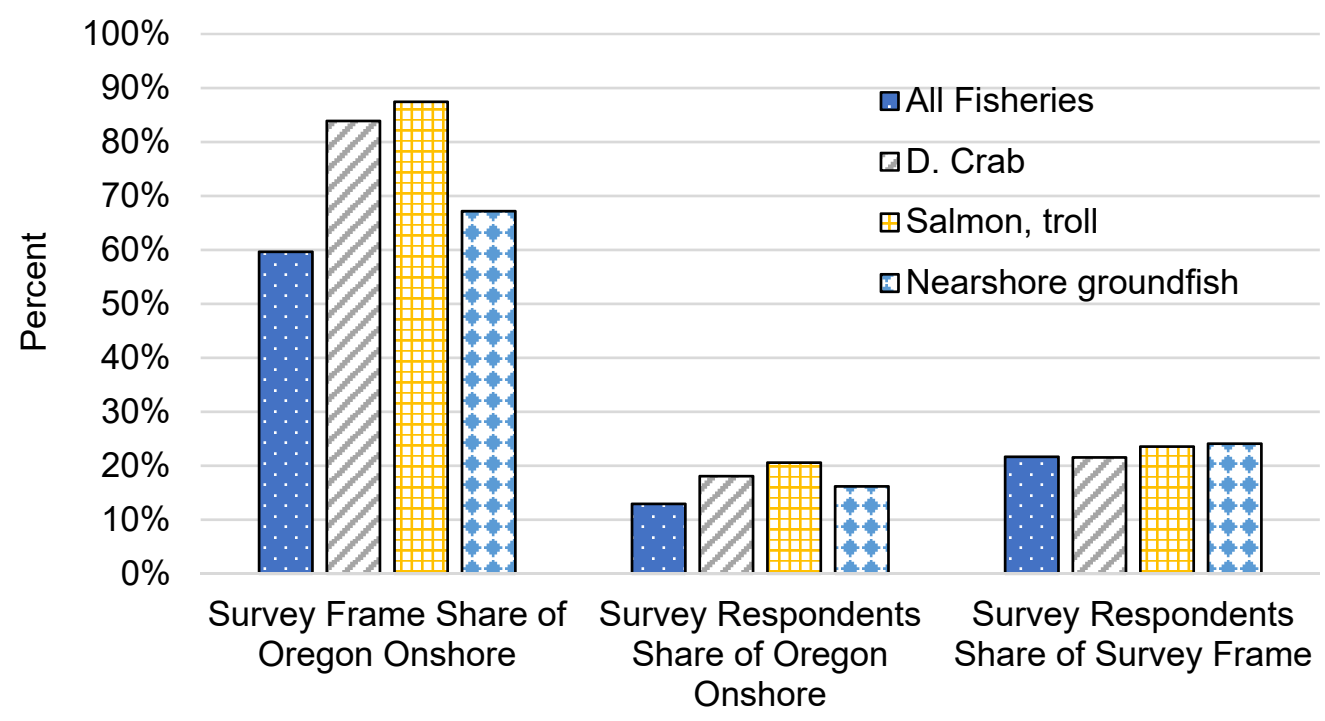

Notes: 1. Table E notes apply. 
Figure $\mathrm{C}$

Delivering Vessel Landed Value in 2016

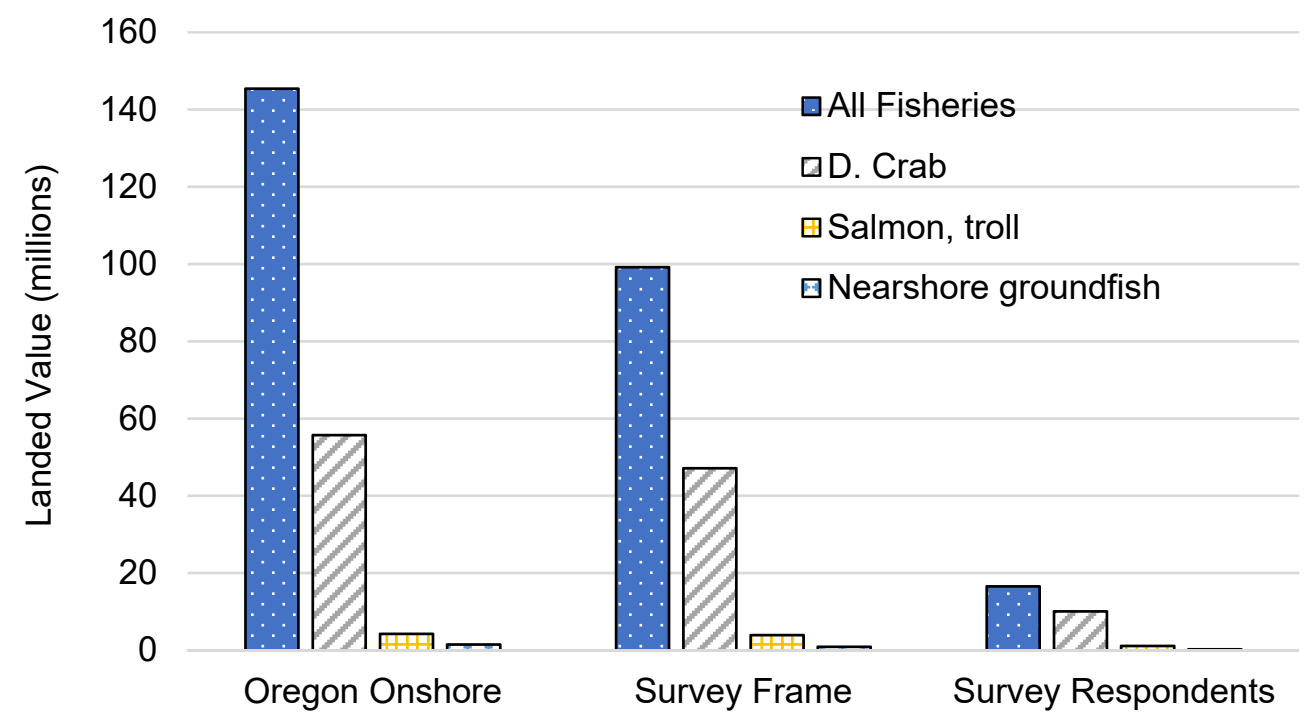

Figure D

Delivering Vessel Landed Value Shares of Oregon Onshore and Survey Frame in 2016

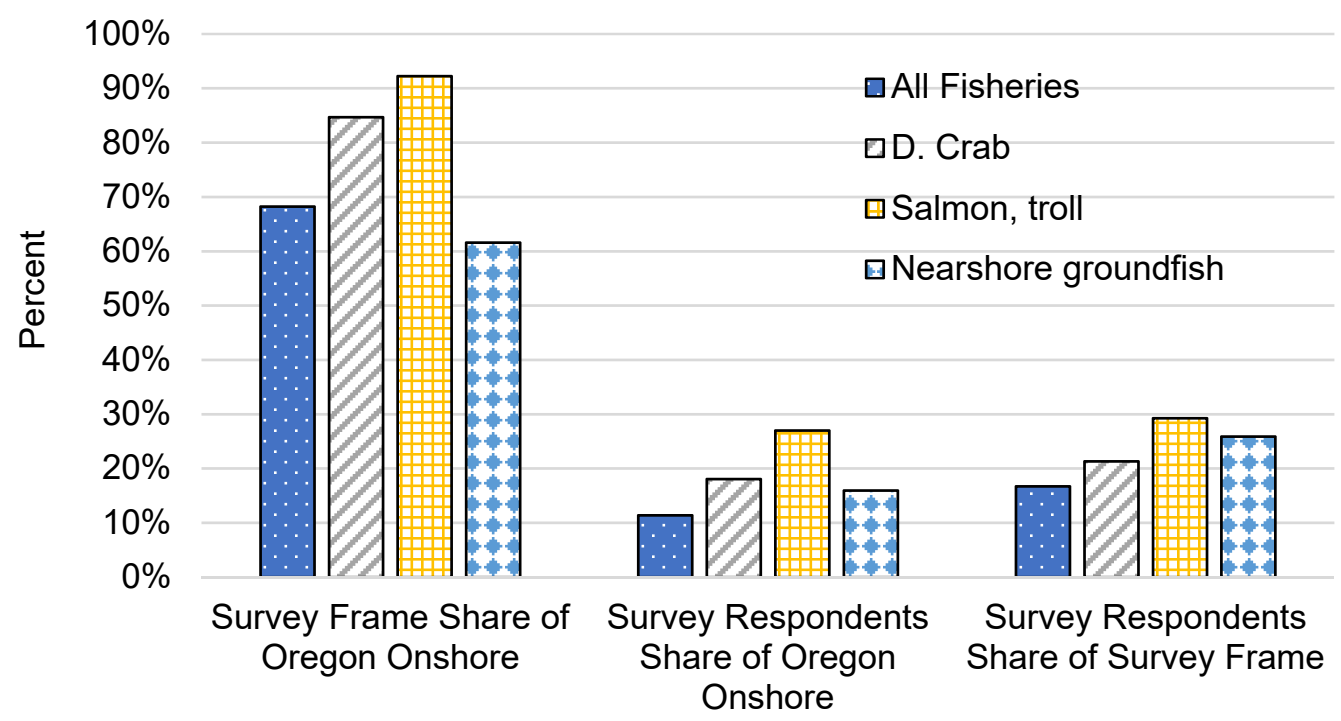

Notes: 1. Table E notes apply. 
Figure $\mathrm{E}$

Delivering Vessel Trips in 2016

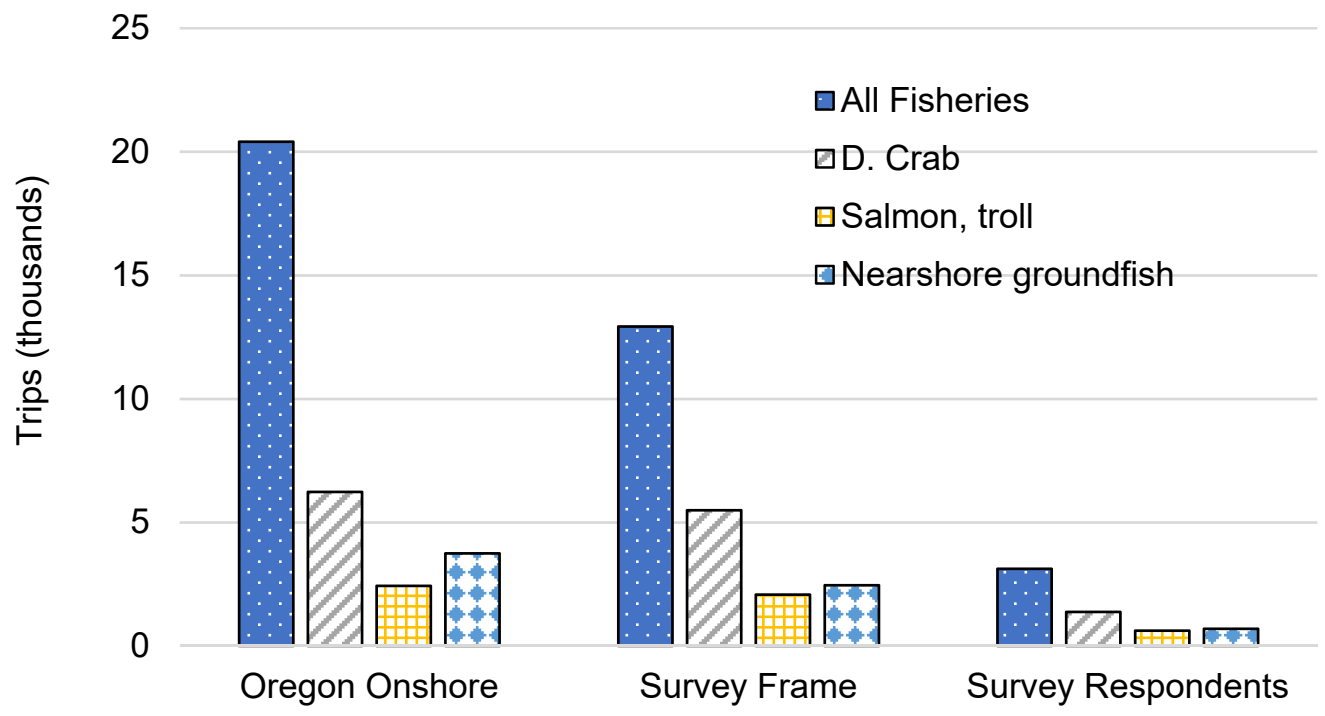

Figure $\mathrm{F}$

Delivering Vessel Trips Shares of

Oregon Onshore and Survey Frame in 2016

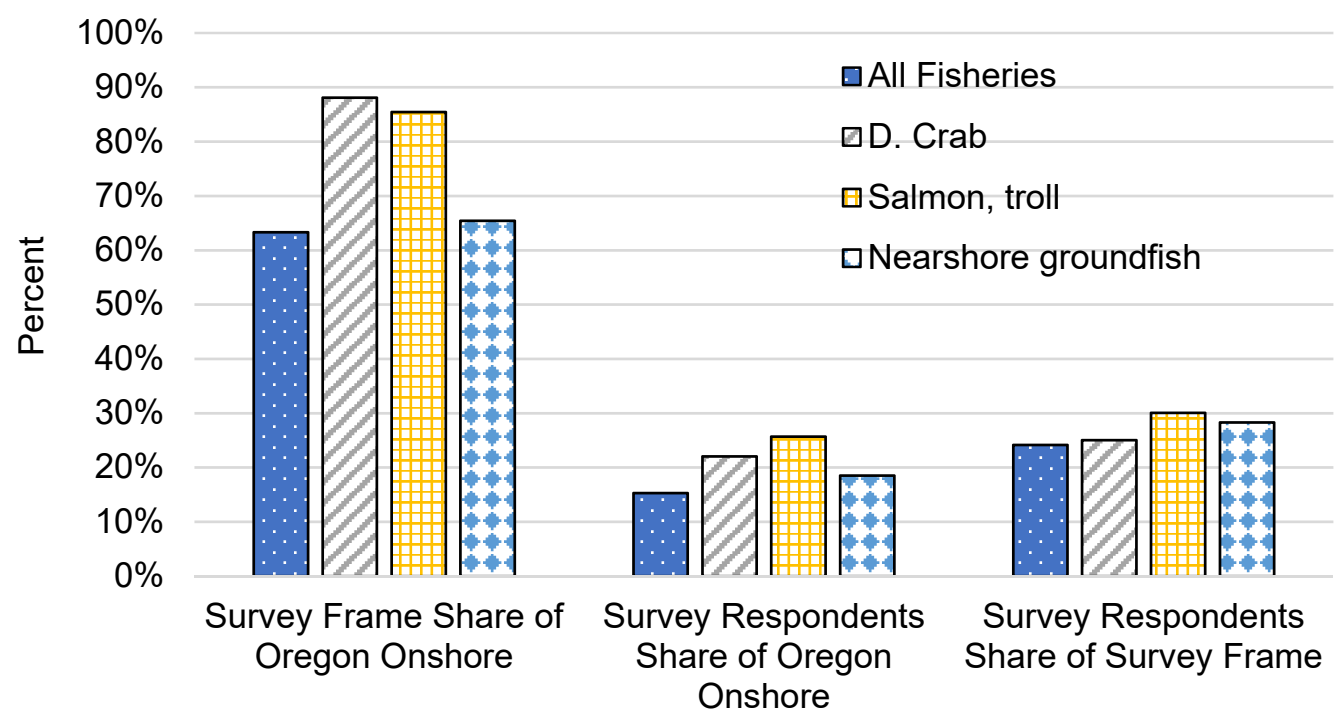

Notes: 1. Table F notes apply. 
Figure $G$

Delivering Vessel Average Annual Landed Value in 2016

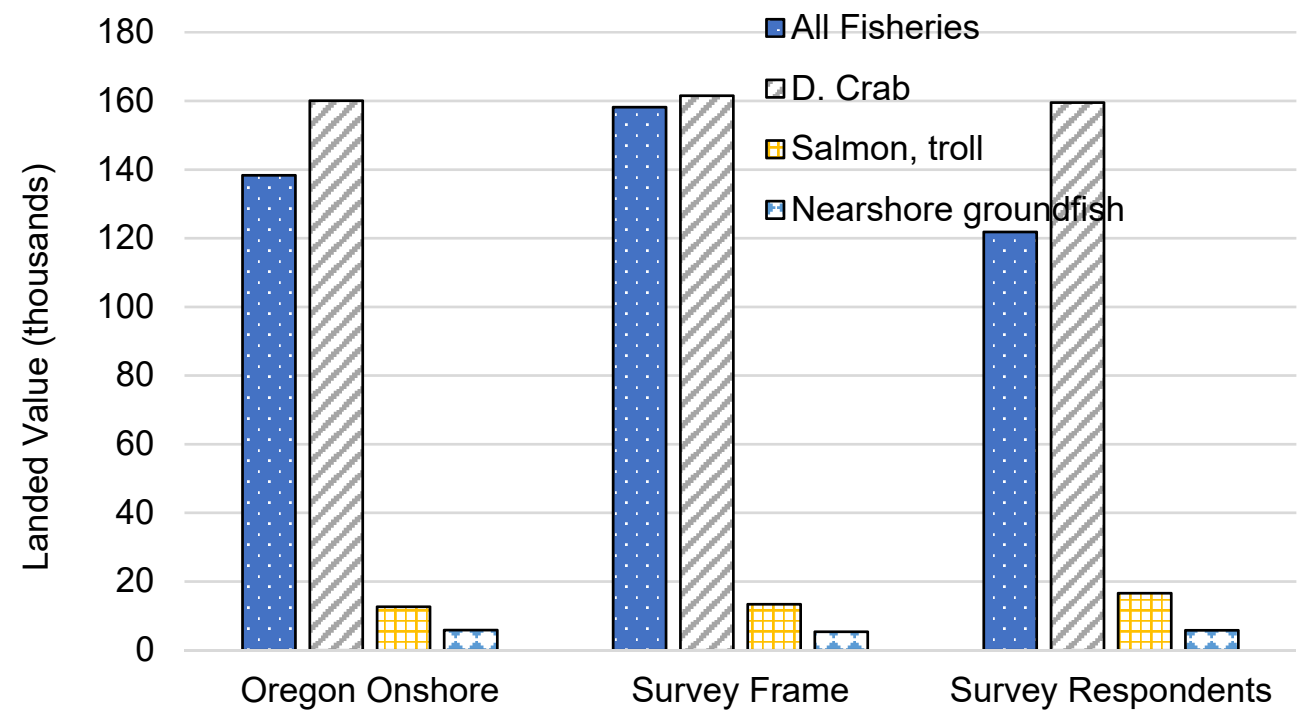

Figure $\mathrm{H}$

Delivering Vessel Average Annual Landed Value

Shares of Oregon Onshore and Survey Frame in 2016

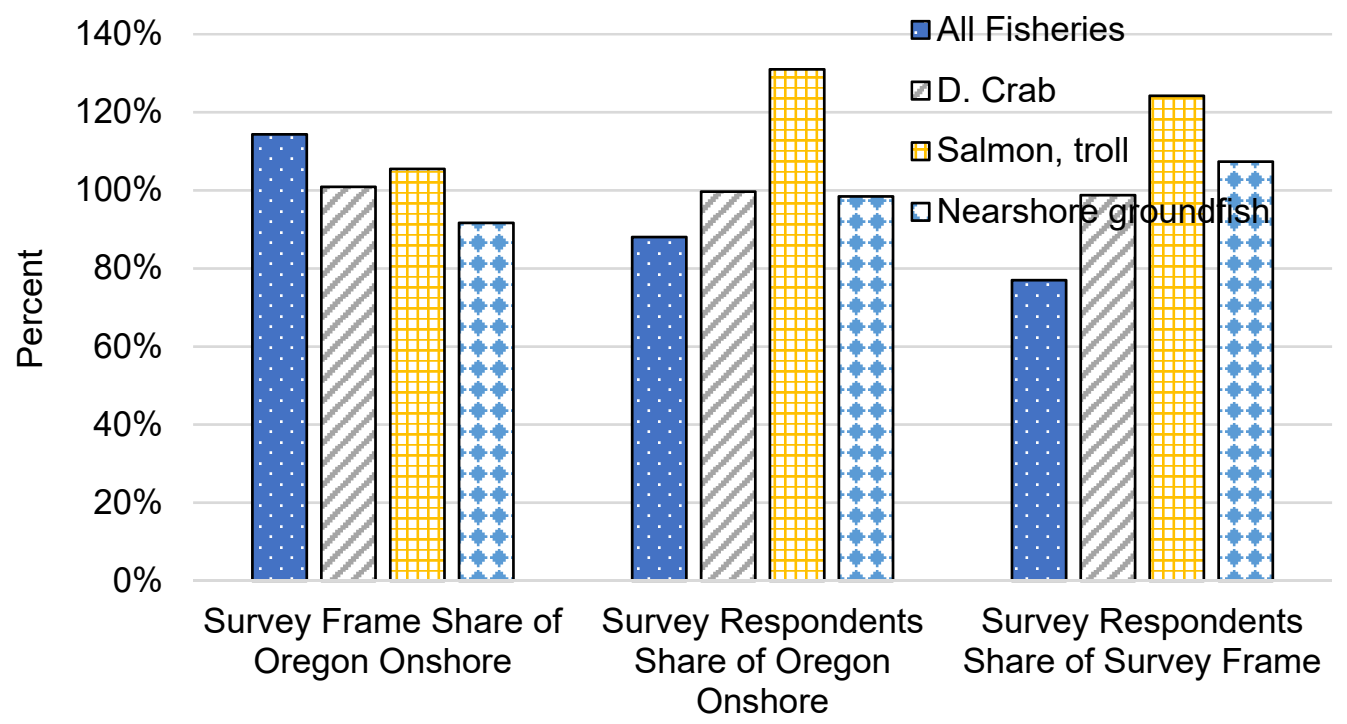

Notes: 1. Table E notes apply. 
Figure I

Histogram of Delivering Vessel Average Annual Landed Value in 2016

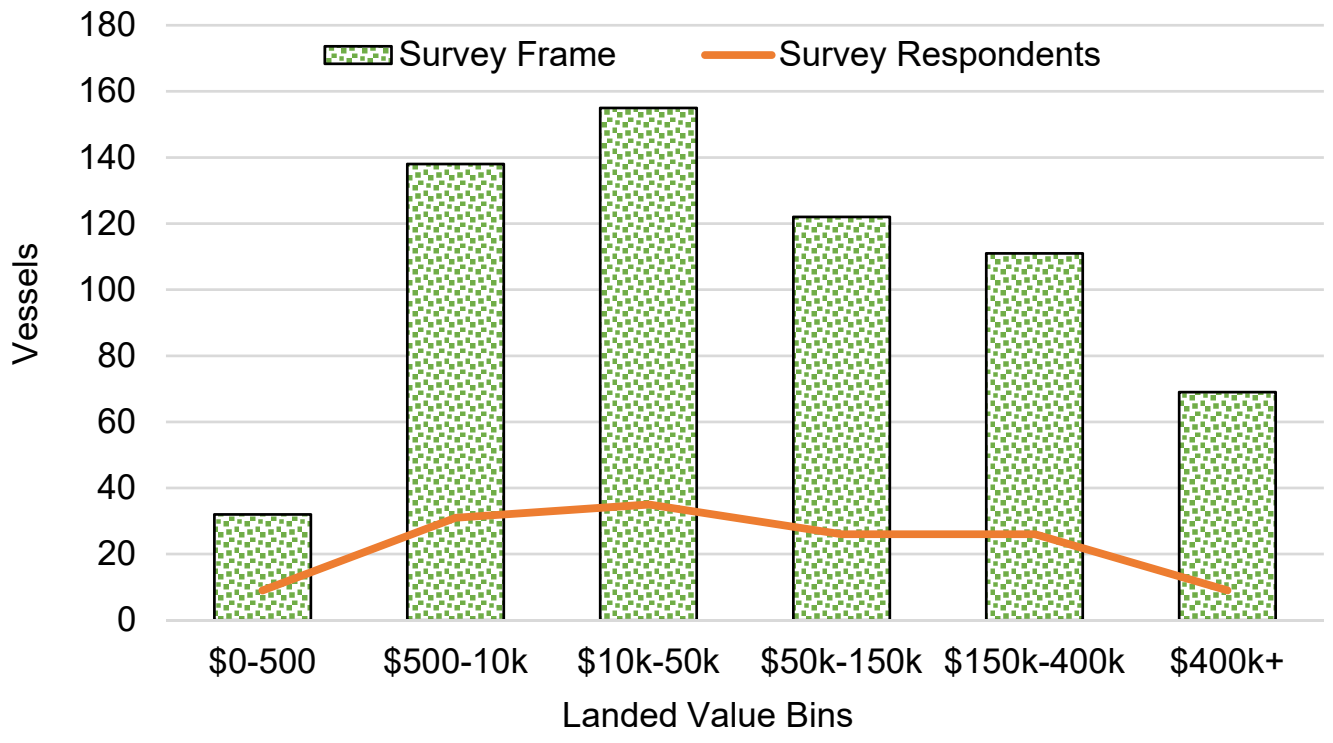

Notes: 1. Table E notes apply. 
Figure $\mathrm{J}$

Quartiles of Delivering Vessel Average Annual Landed Value in 2016

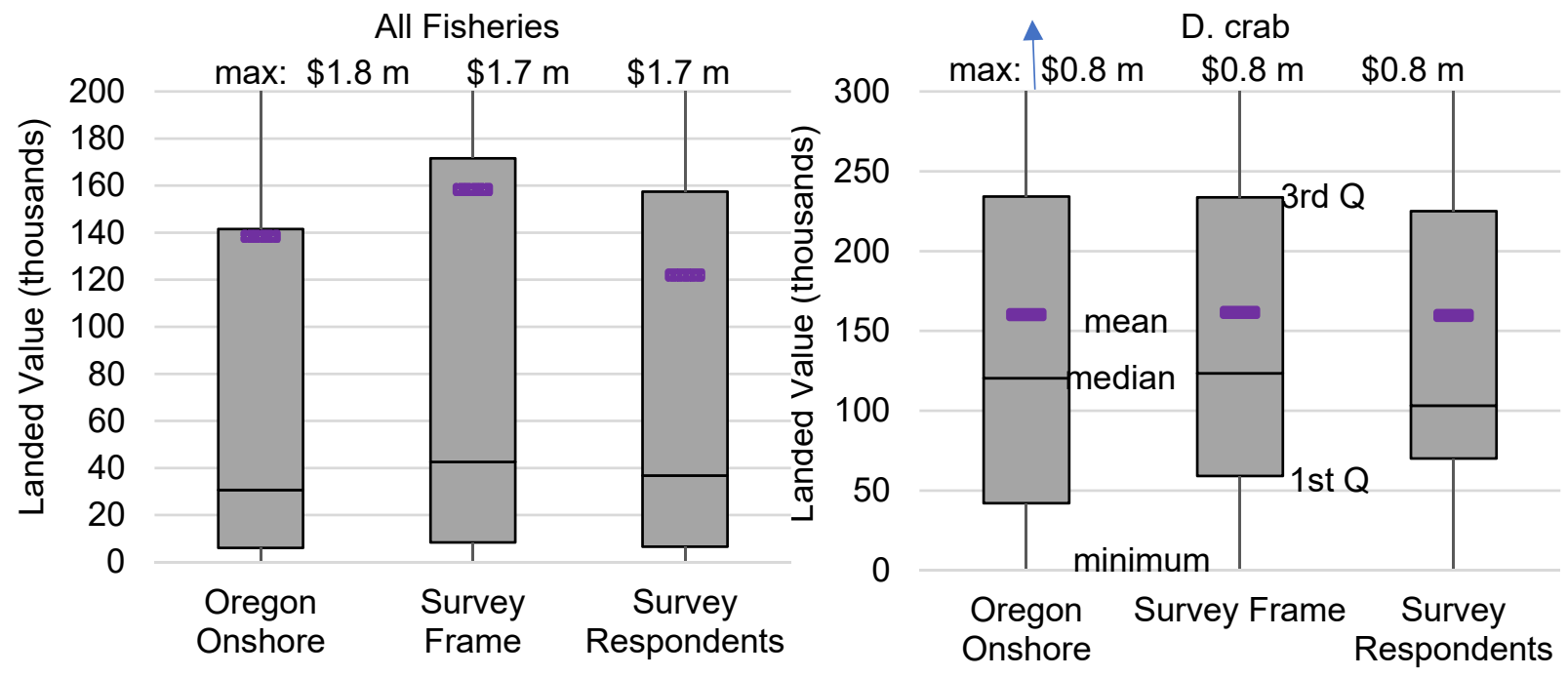

Troll Salmon

Nearshore Groundfish
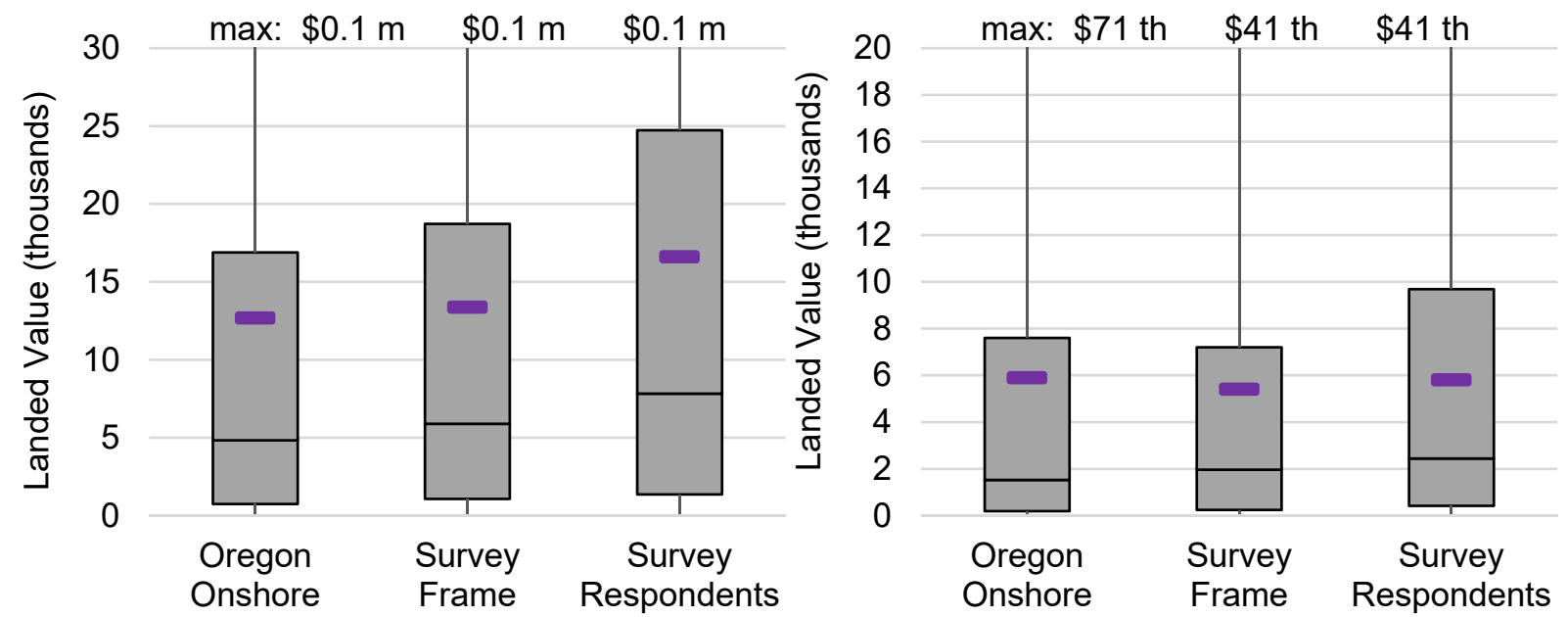

Notes: 1. Table E notes apply. 
APPENDIX 
APPEDNDIX C: Representative Analysis Summary Report 


\title{
DRAFT
}

\section{Oregon Nearshore Fisheries Effort Shift Survey Commercial Fishing Representativeness Report}

Version 3.1

\author{
prepared by \\ The Research Group, LLC \\ Corvallis, Oregon \\ prepared for \\ Marine Resources Program \\ Oregon Department of Fish and Wildlife
}

May 2018 


\section{$\underline{\text { Suggested Citation }}$}

The Research Group, LLC. Oregon Nearshore Fisheries Effort Shift Survey Commercial Fishing Representativeness Report. Prepared for Marine Resources Program, Oregon Department of Fish and Wildlife. May 2018. 


\section{Preface}

This analysis project was sponsored by the Oregon Department of Fish and Wildlife (ODFW) Marine Resources Program. The analysis was to find the degree of representativeness for respondents to a survey project being undertaken by the Department of Environmental Science and Management, Portland State University (PSU). This analysis project is one of many human dimension investigative studies being used to support ODFW's responsibilities to establish, monitor, and evaluate Oregon's marine reserve (MR) system. A more thorough description of each of the studies and data collection projects can be found in the Oregon Marine Reserves Internet portal.

This analysis project was completed by The Research Group, LLC Corvallis, Oregon. Shannon Davis was the lead author and was greatly assisted by Kari Olsen. Hans Radtke, Ph.D. needs to be recognized for his valuable input. Bryn Hudson, Master of Science Candidate, PSU has been outstanding for communicating about all matters dealing with the survey project. The authors thank ODFW staff Tommy Swearingen, Human Dimensions MR Project Leader and Cristen Don, MR Program Leader for their guidance.

Authorization is granted for this analysis project report's contents to be quoted either orally or in written form without prior consent of the authors. Customary reference to authorship is requested.

The analysis project authors and not the sponsors were responsible for generating project results. The authors do not make any warranties with respect to the project including fitness for any particular purpose. In no event shall the authors assume any liability for use of the program or derived information and shall not be responsible for any direct, indirect, or consequential damages that might arise from the application. 


\section{Table of Contents}

Preface

Table of Contents

Glossary
A. Introduction
B. Background
C. Survey Project Scope
1. Objective
2. Population
3. Sampling
4. Frame
5. Administration
D. Associating Vessels with Permit Owners
E. Respondents
F. Representativeness
G. Discussion
H. Bibliography

Maps, Tables and Figures

Map A: Marine Reserve Location and Relative Size Map

Table A: Survey Frame and Survey Respondents Vessel Counts With Matches to Vessels Having Oregon Onshore Landings in 2011-2016

Table B: Survey Frame and Survey Respondents With Matches to Oregon Onshore Landings in 2011-2016

Table C: Survey Frame and Survey Respondents With Matches to Oregon Onshore Landed Value by Major Fishery in 2011-2016

Table D: Survey Frame and Survey Respondents With Matches to Oregon Onshore Landing Vessels by Major Fishery in 2011-2016

Table E: Frequency Distribution of Oregon Onshore, Survey Frame, and Survey Respondent Average Annual Landed Value in 2016

Table F: $\quad$ Oregon Onshore Landed Value and Vessel Counts for Survey Fisheries in 2008-2017

Table G: Frequency Distribution of Oregon Onshore, Survey Frame, and Survey Respondent Delivering Vessel Average Annual Landed Value in 2016

Table H: Residency of Oregon Permitted, Survey Frame, and Survey Respondent Permit Owners in 2016

Table I: $\quad$ Vessels by Principal Oregon Delivery Port Area in 2016

Figure A: Delivering Vessel Counts in 2016

Figure B: Delivering Vessel Count Shares of Oregon Onshore and Survey Frame in 2016

Figure C: Delivering Vessel Landed Value in 2016 


\section{Table of Contents (cont.)}

Figure D: Delivering Vessel Landed Value Shares of Oregon Onshore and Survey Frame in 2016

Figure E: Delivering Vessel Trips in 2016

Figure F: Delivering Vessel Trips Shares of Oregon Onshore and Survey Frame in 2016

Figure G: Delivering Vessel Average Annual Landed Value in 2016

Figure H: Delivering Vessel Average Annual Landed Value Shares of Oregon Onshore and Survey Frame in 2016

Figure I: Histogram of Delivering Vessel Average Annual Landed Value in 2016

Figure J: Quartiles of Delivering Vessel Average Annual Landed Value in 2016

\section{Appendix}

Appendix A: Survey Instrument 


\section{Glossary}

\section{$\underline{\text { Acronyms }}$}

$\begin{array}{ll}\text { CASRO } & \text { Council of American Survey Research Organizations } \\ \text { GDP } & \text { Gross Domestic Product } \\ \text { MR's } & \text { Oregon marine reserve system sites } \\ \text { ODFW } & \text { Oregon Department of Fish and Wildlife } \\ \text { OPAC } & \text { Oregon Ocean Policy Advisory Council } \\ \text { PacFIN } & \text { Pacific Coast Fisheries Information Network } \\ \text { PSU } & \text { Portland State University } \\ \text { TRG } & \text { The Research Group, LLC } \\ \text { USPS } & \text { U.S. Postal Service }\end{array}$

$\underline{\text { Terms }}$

Dollar Where dollar values are noted to be real, the adjustment index was the adjustments GDP implicit price deflator developed by the U.S. Bureau of Economic Analysis.

Nearshore area The part of the continental shelf closest to shoreline and includes an intertidal zone. The intertidal zone extreme is the high tide splash zone and includes lower bay saline dominated estuarine waters. Some nearshore fisheries have management specifications using depth restrictions. Management depth closures can vary during the year.

Nearshore species Survey fisheries for commercial fishing are Dungeness crab, troll salmon, and nearshore groundfish. Nearshore groundfish species include selections of rockfish, roundfish, and flatfish. An estimate of the nearshore harvested portion of lingcod is included. The criteria used to select species that are nearshore groundfish is discussed in TRG (2014). The selection is inclusive of State managed nearshore species for which an Oregon Nearshore Fishery Permit is needed. There are other federal managed species in the selection that are typically caught in nearshore areas. The landings for lingcod were determined using species and gear filter queries to include open access landings with longline, other hook and line, or pot gear; and limited entry landings with longline, other hook and line, or selective FF trawl (small footrope) if it was on the same fish ticket with black or blue rockfish or certain other nearshore species. The nearshore species are listed by common name in an appendix. Some tables only show nearshore species harvests for vessels that have an Oregon Nearshore Fishery Permit. Other tables content is for all selected nearshore species determined without filtering on vessels associated with permits. 
Oregon The ocean that is three nautical miles seaward of shoreline. The seaward

Territorial Sea extent can be approximated to be the 30 fathom depth contour along the Oregon Coast.

Survey calibration Procedures to better pattern survey responses for being representative of known indicators of the survey population. Techniques include weighting response types whose numbers are deficient. Weights can be greater than one (under represented) and smaller than one (over-represented). Deville and Särndal (1992) explain the term and offer methods for survey calibration. Gelman and Little (1997) explain post-stratification procedures. Kolenikov (2014) discusses raking techniques.

Survey frame Commercial fishing permit and charter boat permit registration names. The fisheries permit types are Dungeness crab, salmon troll, and nearshore groundfish.

Survey population The intended commercial fishermen and recreational charter boat operators to receive a survey questionnaire are those likely to fish in nearshore waters sometime during a calendar year.

Commercial

Trips are approximated using fish tickets. A fish ticket represents the landing fishing trips of fish or shellfish product from one fishing trip. Ticket counts may not reflect fishing trips, because multiple tickets can be issued for a single trip when a vessel delivers to more than one dealer after returning to port, and vessels issue tickets when a sale is made directly to the public. Trip undercounts could occur in the occasion when tendering services are used because more than one vessel's harvest could be combined onto a single fish ticket. Delivery counts are not additive across fisheries because a fish ticket may include more than one species.

Recreational The mode can be charter boat, private boat, bank fishing, or diving. A charter fishing mode boat is owned by a private business which provides for-hire services on daily and fishing season schedules. The services are usually recreational fishing, but can for non-angling trips such as whale watching or just touring. The boat may make more than one trip per day depending on the distance to fishing grounds. Private boats do not provide for-hire services, although it is not uncommon that friends and relatives on the trip contribute to cost reimbursement. Bank fishing distinguishes an angling trip when the fishing opportunity will not rely on a boat. It can occur on piers and water shorelines. Dive trips can originate from a boat or shore. There are very few ocean bank or dive fishing trips in Oregon and they are not included in the analysis. 


\section{Oregon Nearshore Fisheries Effort Shift Survey Commercial Fishing Representativeness Report}

\section{A. Introduction}

An Oregon nearshore fisheries effort shift investigation was undertaken in 2017. The project used primary data collection to find related ocean commercial fishermen and recreational charter operators responses to management changes such as fishing grounds closures. The survey project contractor was Department of Environmental Science and Management, Portland State University (PSU). The survey project commenced in March 2017 and will conclude August 31, 2018. ${ }^{1}$

The survey project is to make progress on ODFW tasking to understand changes within coastal fishing communities affected by marine reserves implementation. The contractor in collaboration with the ODFW Marine Reserves Program staff sent a questionnaire via USPS mailing to nearshore fisheries permit and charter boat permit registrants as of early 2017 . There were three commercial fishing permit types and a charter boat permit type selected to cover nearshore fisheries' participants. The commercial fishing permit types are Dungeness crab, salmon troll, and nearshore groundfish. ${ }^{2}$

The survey project purpose was to solicit financial, operational, and social characteristic information as well as attitudinal information about fisheries management and other influences on fishing success. There were specific questions about fishing effort and whether the marine reserve program impacted fishing operations. Survey project questions were structured to be both objective and subjective with close-ended and open-ended wording. (An appendix to this report contains the final survey instrument.) The survey project design has a descriptive and an experimental context. The survey project contractor will use modeling to find predictive factors for fishing operation choices.

A representative analysis can be useful for developing calibration schemes for adjusting survey results to minimize any discovered non-coverage and non-response bias. Kruskal and Mosteller (1980) in a four-publication series present an extensive overview of representativeness analysis. Methods to overcome representative bias are explained by Särndal and Lundström (2005).

This report contains information about the representativeness of the survey frame and survey respondents. While the survey frame was commercial fishing nearshore fisheries permit registrants and recreational charter boat permit registrants, the representativeness analysis is only for the former. The primary measure to analyze representativeness is distribution of landed value. An inset on the next page in this report shows summaries of other indicator comparisons.

1. The project's lead author is Bryn Hudson, Master of Science Candidate. Ms. Hudson's master's degree committee members include Max Nielsen-Pincus, Ph.D. (chair), Elise Granek, Ph.D., and Thomas Swearingen, Ph.D.

2. The nearshore groundfish permit type was inclusive of permits for black/blue rockfish with and without nearshore groundfish endorsements. 


\begin{tabular}{|c|c|c|}
\hline \multicolumn{3}{|c|}{ Representative Measures } \\
\hline Measure & Survey Frame & Respondents \\
\hline $\begin{array}{l}\text { Survey size } \\
\text { including charter } \\
\text { boats }\end{array}$ & 1,161 & 229 \\
\hline $\begin{array}{l}\text { Commercial } \\
\text { fishing vessel } \\
\text { count }\end{array}$ & 1,106 & 212 \\
\hline $\begin{array}{l}\text { Landed value of } \\
\text { three fisheries in } \\
2016\end{array}$ & $\begin{array}{l}\$ 52.0 \text { million in } \\
2016,85 \% \\
\text { onshore }\end{array}$ & $\begin{array}{l}\$ 11.4 \text { million in } \\
2016,22 \% \text { frame }\end{array}$ \\
\hline $\begin{array}{l}\text { Mean per vessel } \\
\text { landed value of } \\
\text { three fisheries in } \\
2016\end{array}$ & $\begin{array}{l}107 \% \text { of } \\
\text { onshore }\end{array}$ & $94 \%$ of frame \\
\hline $\begin{array}{l}\text { Mean per vessel } \\
\text { trip counts in } 2016\end{array}$ & $\begin{array}{l}106 \% \text { of } \\
\text { onshore }\end{array}$ & $111 \%$ of frame \\
\hline Vessel length & average 41 feet & average 39 feet \\
\hline $\begin{array}{l}\text { Permit owner } \\
\text { residency in } 2016\end{array}$ & $\begin{array}{l}\text { Oregon for } 68 \% \\
\text { of permittees }\end{array}$ & $\begin{array}{l}\text { Oregon for } 75 \% \\
\text { of permittees }\end{array}$ \\
\hline $\begin{array}{l}\text { Principal delivery } \\
\text { port area in } 2016\end{array}$ & $\begin{array}{l}\text { Newport highest } \\
\text { number of } \\
\text { vessels }\end{array}$ & $\begin{array}{l}\text { Newport highest } \\
\text { number of } \\
\text { vessels }\end{array}$ \\
\hline $\begin{array}{l}\text { te: The three fi } \\
\text { arshore ground }\end{array}$ & es are D. crab, sc & Imon troll, and \\
\hline
\end{tabular}

Survey project response tabulations, modeling results, and inference explanations are presented in a separate document authored by the project contractor.

\section{B. Background}

Pursuant to the Oregon marine reserve legislative mandate, the project was funded by ODFW to assess Oregon nearshore fisher's perceptions and behavioral changes due to the establishment of marine reserves. ${ }^{3}$ There are currently five established marine reserves in the Oregon Territorial Sea (Map A). Management plans for the reserves restrict extractive practices and ocean development. The restriction of commercial and recreational fishing may

force fishers to forgo or shift their effort to other fishing grounds, which can result in adverse economic and social impacts. Formal research regarding fishers' behavior and perceptions due to Oregon marine reserves post-implementation is scarce.

Future studies are planned to use survey project results. For example, a survey question solicited whether or not the respondent wanted to participate in a personal interview. Those in the affirmative will be volunteers in a study for gathering additional anthropological and ecological knowledge information. Another study is planned to determine whether or not fisher stated behavioral changes align with real behavior documented with fishing logbook data. (Logbook data is available for some nearshore fisheries, but not all such as the salmon troll fishery.) The alignment analysis results will assist in creating more effective communication pathways with local fishing communities.

3. State mandates and guidelines for Oregon's marine reserves are provided in Executive Order 08-07 in 2008, House Bill 3013 in 2009, Senate Bill 1510 in 2012, administrative rules adopted by state agencies, and in the Oregon Marine Reserve Policy Recommendations adopted by the Oregon Ocean Policy Advisory Council (OPAC) in 2008. The OPAC policy recommendations provide the foundation for ODFW's monitoring of marine reserves. A description of the human dimensions monitoring plans are results is contained in biennial monitoring reports. The most recent report can be accessed at the Oregon Marine Reserve Internet portal. 
Map A

Marine Reserve Location and Relative Size Map

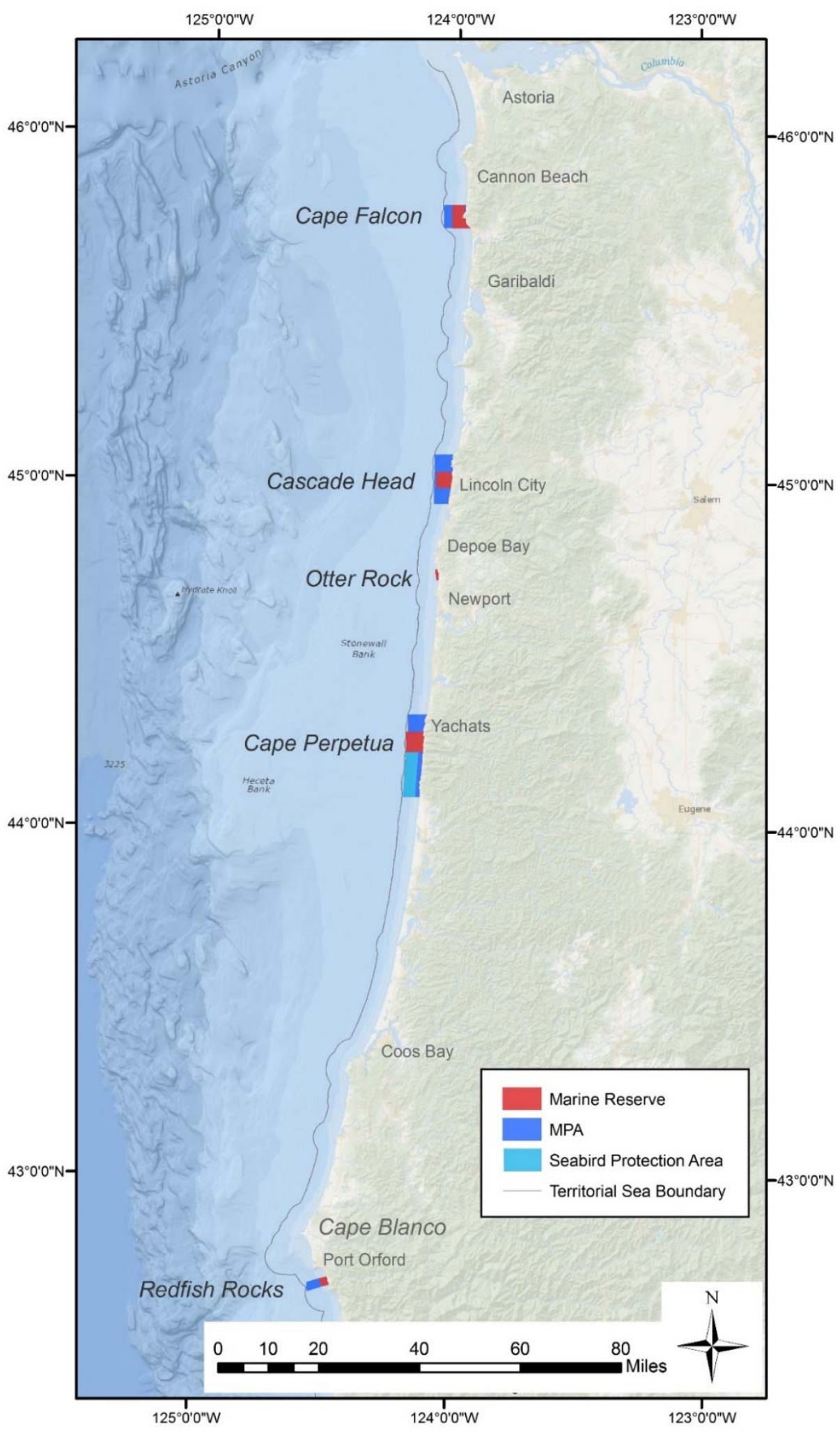




\section{Survey Project Scope}

\section{C.1. Objective}

The objective is twofold: 1) determine Oregon nearshore fisheries participation characteristics (cost and earnings, fisheries focus, effort levels, etc.), social characteristics (demographics, fishing dependence and tenure, family succession planning, etc.), and perception of marine reserve management; and, 2) determine effects from marine reserve fishing displacement.

\section{C.2. Population}

The intended population to be surveyed is participants in Oregon nearshore fisheries. These are the individuals that may have changes in their fishing activities due to establishment of marine reserves. Registrants for three commercial fishing permit types and a charter boat permit type were chosen to represent nearshore fisheries participants. The three commercial fishing permit types are Dungeness crab, salmon troll, and nearshore groundfish. These are the most important (highest landed value) nearshore fisheries. The survey project budget constraints prevented inclusion of other nearshore fisheries participants.

TRG (2018) estimated the participation levels, landed value, and economic contribution of nearshore fisheries based on species/gear definitions and fishing grounds locations. The nearshore fisheries estimates include ocean and bay fishing activities. The nearshore proportion of the commercial salmon troll fishery is estimated to be 35 percent and the nearshore proportion of the Dungeness crab fishery is estimated to be 54 percent. Recreational bay fisheries include anadromous fish in Columbia River and coastal streams.

Nearshore commercial and recreational fisheries activity is substantial. The commercial fishing onshore landed value was $\$ 157.7$ million in 2014 . There were 220.6 thousand ocean recreational trips in 2014 of which 26 percent are estimated to be via charter boat services. Nearshore commercial and recreational community economic contribution in 2014 was $\$ 103$ million. ${ }^{4}$ This represents 17 percent of Oregon total commercial and recreational fishing industry (includes distant water fisheries) which is $\$ 622$ million in 2014.

The TRG (2018) study found that the potential maximum economic impact (i.e. no replacement from fishing elsewhere) from marine reserve management is 3.6 percent of all nearshore commercial and recreational fishing economic contribution in the Oregon Territorial Sea (TS). Since the marine reserve system is less than 10 percent of the TS, it would seem likely that the 90 percent commercial harvesting and recreation angling area opportunities would provide satisfactory substitute fishing grounds for most species. However, some individual fishermen may have experience with the bottom features and water conditions at these sites, and decide not to fish elsewhere given management closures. The effort shift survey results will help determine effects from fishing abandonment, from changing locations for same fisheries, and from switching to other fisheries.

4. Economic contribution is expressed as income generated to the State level economy, includes the multiplier effect, and is stated in 2015 dollars. Dollar adjustments used the GDP Implicit Price Deflator produced by the U.S. Bureau of Economic Analysis. 
Table F shows the ten year landed value and vessel counts for the three fisheries selected to represent nearshore fisheries. The table also shows the average annual landed value per vessel. There are two trend summary statistics: 1) fisheries landed value percent variability, and 2) the Mann-Kendall test statistic that shows the strength (magnitude) and tendency (up/down direction) of a linear trend.

The period on Table $\mathrm{F}$ transcends when marine reserves were established. ${ }^{5}$ The trends are across whole fisheries and further analysis would be necessary to discern a discontinuity in effort due to marine reserves implementation.

Table F values for percent variability in fisheries landed value is greater than for vessel counts. This signals that fishers in aggregate tend to continue fishing despite conditions that may affect landing success. This may reflect participant ambivalence towards entering and exiting the fishery based solely on lost revenue opportunities. This would be consistent with habit being a meaningful social/psychological factor in fishery choice models (Van Putten et al. 2012). This observation could be extended to mean fishers reaction to management restrictions on fishing grounds in one area are simply compensated at same effort levels when there are opportunities elsewhere. Compensation in other fisheries may also occur if the fisher has the capacity and permits for other fishery opportunities.

\section{C.3. Sampling}

The survey method was to use a 100 percent sampling approach.

\section{C.4. Frame}

The survey frame included Dungeness crab, salmon troll, and nearshore groundfish permit registration holders and charter boat permit registration holders in early 2017. A commercial fishing survey unit included in the frame can hold permits for other ocean fisheries (such as halibut) and/or participate in fisheries that are not limited entry (such as albacore tuna). They might also participate in non-ocean fisheries (such as Columbia River gillnet). The survey frame contained both resident and non-resident permit owners. Survey units could be vessel owners that are not active in the fishery as well as those that do make commercial fisheries landings or make charter boat trips. While the survey frame portion related to commercial fishing encompassed most of the important nearshore fisheries, there are other lower landed value nearshore fisheries left out such as sea urchin, hagfish, groundfish trawl, sardine, and other invertebrates.

The recreational fishing survey frame was all charter boat permit owners. The survey frame did not include the private boat, bank, and diving mode for recreational fishing.

5. Marine reserves management restrictions started on January 1, 2012 for Redfish Rocks (RR) and Otter Rocks (OR); started on January 1, 2014 for Cascade Head (CH) and Cape Perpetua (CP); and started on January 1, 2016 for Cape Falcon (CF). 
The commercial fishing permit owner names from the three permit types were merged and survey unit duplicate addresses were deleted from the survey list. The result of the merging and filtering resulted in the survey frame containing 1,161 survey units.

There are cases where multiple permit owners share an address, so the merging would have precluded some owners receiving a survey instrument. There are cases where multiple vessels are associated with one owner name (highest number was discovered to be six) and a single vessel being associated with multiple owner names. To minimize respondent burden, the survey instrument contained a question asking for up to two vessel profiles.

\section{C.5. Administration}

An early instrument draft was submitted to peer reviewers within PSU and ODFW. A survey proposal was also presented at fishing industry focus group meetings that took place on the Oregon Coast in April 2017. Comments were incorporated into new versions of the instrument. The new version was used during a pretest for one-on-one interviews of a small number of fishers. Comments from the interviews were used to perfect a final questionnaire version.

The dates for survey administration were:

Prenotification date: $6 / 20 / 17$

First mailing packet date: 7/01/17

Incentive: NONE

Responses received: 121

Refusals received: 6

Second reminder date: $7 / 14 / 17$

Second mailing packet date: $8 / 4 / 17$

Incentive: $\$ 2.00$ enclosed in survey packet

Responses received: 109

Refusals received: 10

Second reminder date: $8 / 25 / 17$

Cut-off date for recording responses: 3/1/18

Total response number: 229

Total refusals: 16

Total non-deliverable mailings: 64

\section{Associating Vessels with Permit Owners}

Commercial fishing vessel identification codes were not included in the original list of permit holders pulled from the survey frame. Therefore, it was necessary subsequent to survey administration to use the ODFW fishery permit database to match the permit owner name and address in order to get the vessel identification. The vessel identification was necessary to compile fish ticket information. Table A shows the results for associating a vessel with the 
commercial fishing permit owners that received the survey questionnaire. A summary of the matching attempt is as follows.

- The columns under the title "Commercial Fishing Owner Names" exclude owners that only have a charter boat permit. There were 70 owners with a charter boat permit, but seven of them also had a commercial fishing permit $(1,098=1,161-70+7)$.

- One of the commercial fishing permit owners was not found to have a vessel match in permit registration information. While some commercial fisheries such as sea urchin are not linked to a vessel, the survey frame permits should have vessels associated with the permit owner name.

- Forty-four (=1,098-1,053-1) were matched to a vessel that was the same as another survey frame owner. The discovered 44 were assumed to be permit transfers. The earliest owner, if it could be determined, was used for the match and the other owners were ignored.

- Commercial fishing permit owner names may be associated with multiple vessels (highest discovered was six vessels). Vessel counting is exclusive of cases when more than one owner name is associated with the same vessel, resulting in 1,107 unique vessel identifications.

- The survey instrument asked for profile information for only two vessels. Therefore, delivering information was compiled for only the top two revenue generating vessels for a survey frame permit owner. One survey frame permit owner had four vessels with salmon permits, but only two had any PacFIN landings in 2016 so the other two are not used. It was the only survey frame permit owner with more than two vessels among the three fisheries that were not assumed to be transfers, and the top two by 2016 Oregon landings are included in the representativeness analysis.

- The columns titled "delivering" are counts of unique vessels discovered in fish ticket information, i.e. the vessel sold a harvested fish resource to a processor or the public in

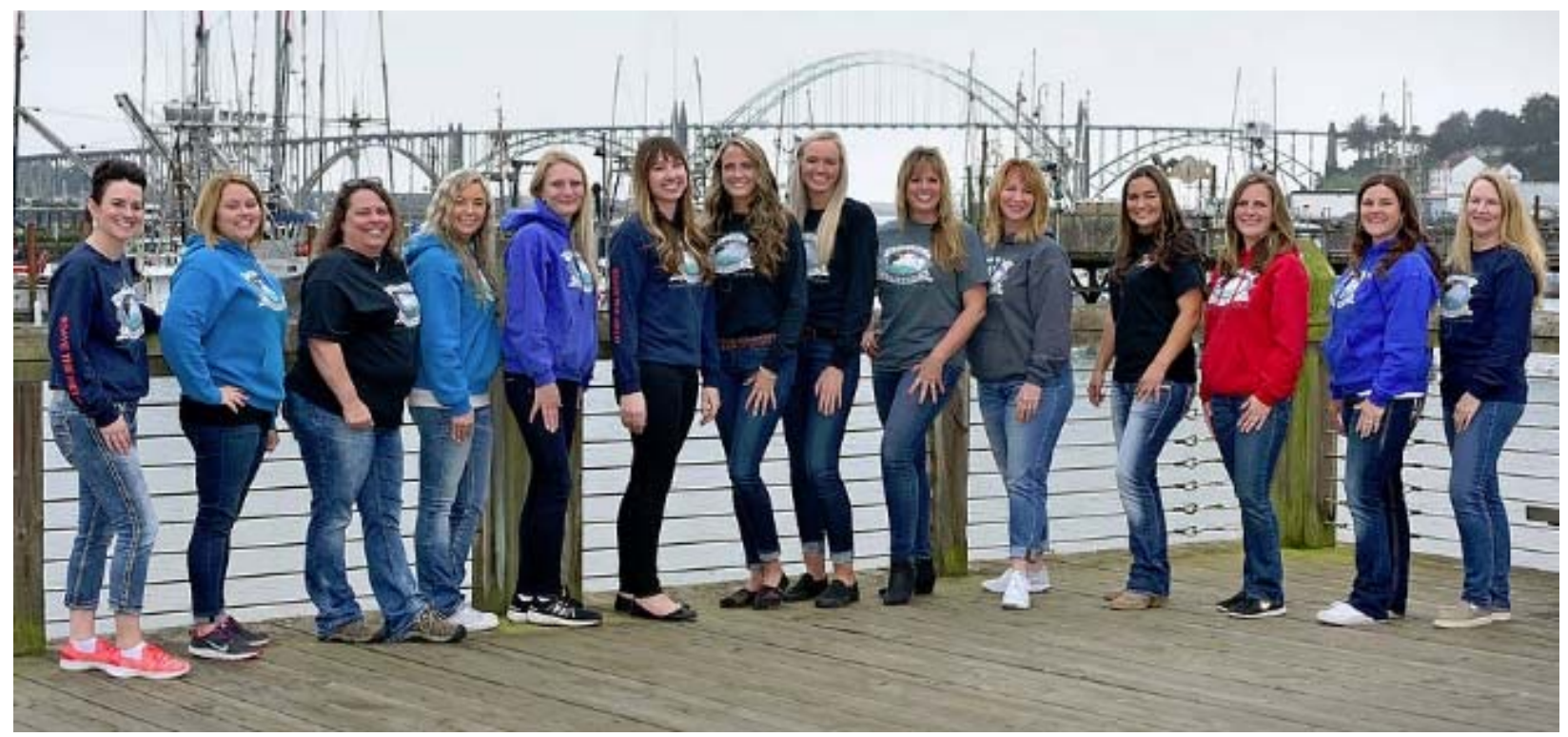

Newport Fishermen's Wives Inc. 
Oregon. Some fish tickets have no unique vessel identification associated with a delivery. For example, Columbia River tribal fisheries are not associated with a vessel identification.

- Six years of Oregon fish tickets were searched for the 1,107 vessels that were matched to the survey frame owner names. There were 861 vessels over that period that were found to have made at least one delivery. However, it could be that during the six-year period the vessel had a different owner. Further, the permit owner included in the survey frame may have owned a different vessel in a previous year. No attempt was made to reconcile the six years of all delivering vessel owner names with the survey frame owner name.

- There were 39 (=212-173) vessels found for survey respondents that had a permit for one of the three fisheries but no Oregon onshore landings for any fishery (i.e. not only the three fisheries included in the survey frame) in 2011-2016.

- There may be additional matches not found due to permit owner name or addresses having slightly different configuration. There are nine survey respondents for the missed matches. Therefore, the number of permit owner names that match at least one vessel identification is $1,053(=1,098-45)$.

- There were $480(=1,107-627)$ vessels in the survey frame that did not make Oregon deliveries in 2016. There were $76(=212-136)$ respondent vessels that did not make Oregon deliveries in 2016. The proportions of permit holders inactive in 2016 for any of the three survey fisheries are: survey frame 37 percent and respondents 23 percent.

\section{E. Respondents}

The survey frame list contained 1,161 permit owner names and the respondents were 229 . Commercial fishing owner names were 1,098 and the respondents were 213 . When the commercial fishing owner name was associated with a vessel identification, there were 1,053 matches with respondents 204. After accounting for multiple vessels per owner name and multiple names associated with one vessel, the 1,107 vessels respondents were 212 . Fish tickets

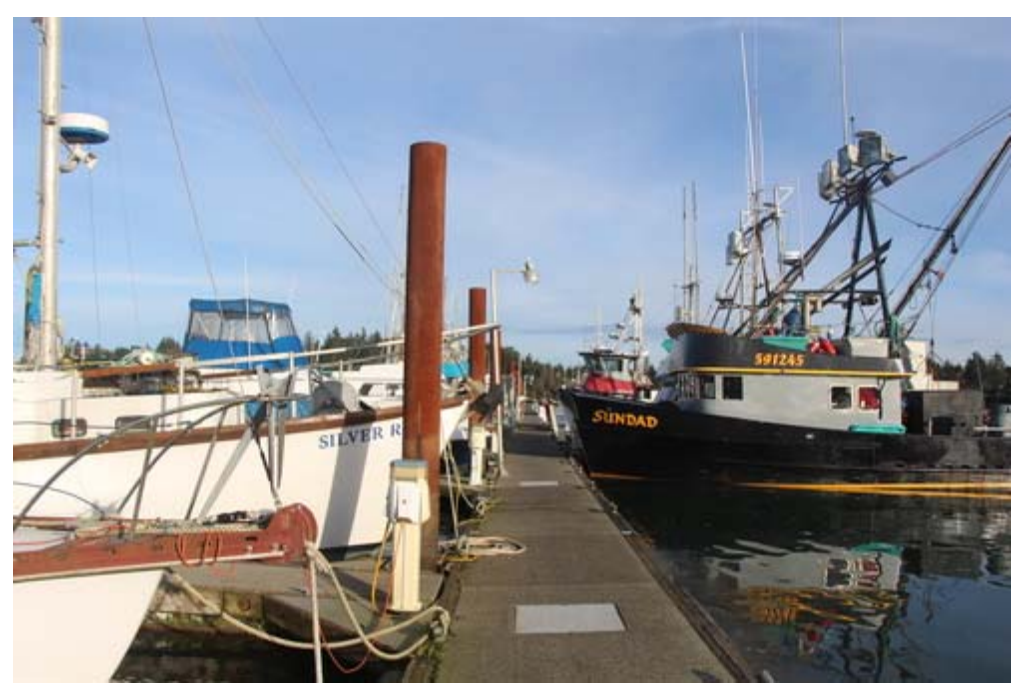

Charleston Marina were searched in years 2011-2016 for known vessel identifications and 861 were found to have landings; respondents for the vessels were 173 . Using the Council of American Survey Research Organizations (CASRO) Ninth Edition of Standard Definitions suggested formula for consideration of refusals and undeliverable instruments, the survey response rate would be 21.2 percent $(=229 /(1,161-(16+64))$. The relatively low response rate is not unusual for a natural resource 
user volunteer survey that solicits for financial performance information. A low response rate does not necessarily equate to a non-response bias (Groves 2006).

\section{F. Representativeness}

This review for representativeness is primarily based on landed value distribution. Other measures reviewed for representativeness are vessel physical size, Oregon home port, and permit owner residency.

Survey frame permit owners can have vessel revenue from deliveries in other West Coast states, Alaska, and at-sea. The out-of-state vessel revenue would be highly correlated with non-resident permit status. The out-of-state revenue was not included in the landed value tabulations. This would mean there are cases where tabulations include vessels that have none or small amounts of Oregon landings, but vessel total revenue is substantial.

Table A and Figure A and B show vessel identification matches that were found to have Oregon landings. The survey frame vessel counts were 60 percent of all onshore vessel counts in 2016 . The survey respondents represented about 13 percent (range over years 2011-2016 was 10 percent to 13 percent) of all Oregon vessel counts. The respondents represented about 22 percent of the survey frame vessel counts. Table B and Figure C and D show the survey frame landed value in 2016 was 67 percent of all onshore landed value. The respondents share of all onshore landed value was 11 percent in 2016 and 17 percent of the survey frame landed value in 2016.

Table $\mathrm{C}$ shows the landed value amounts and proportions of survey frame fisheries and incidental fisheries of the range of years 2011-2016. The percents of respondent to survey frame fisheries are 21, 29, and 26 respectively in 2016 for Dungeness crab, salmon troll, and nearshore groundfish. This percent varies significantly across the incidental fisheries. (Incidental fisheries are the other fisheries in which a survey frame permit owner participates.) Table D shows the shares by fishery for vessel counts. The shares are about 23 percent for all of the survey frame fisheries.

The distribution of respondents per vessel landed value compared to all onshore and survey frame is shown on Table $\mathrm{E}$ and Figure $\mathrm{J}$. The respondent per vessel landed value interquartile range compared to the survey frame is somewhat higher for the salmon troll and nearshore groundfish fisheries and lower for the Dungeness crab fishery.

Survey respondents are approximately equal for representation in landed value brackets (Table $\mathrm{G}$ and Figure I). The proportion of vessels in the $\$ 10$ to $\$ 50$ thousand landed value for 2016 is 25 percent for the survey frame and 26 percent for the respondents. The proportion in the $\$ 150$ to $\$ 400$ thousand bracket is 18 percent for the survey frame and 19 percent for the respondents.

Table E also shows results for comparing landed value means for the survey frame list to Oregon onshore, and for survey respondents to the survey frame. The comparison used the nonparametric Welch's t-test for two samples with heterogeneous variance between tested categories. No statistical differences ( $p$-value $<0.05$ ) in landed values were found for any of the fisheries. A 
finding of statistical difference would provide evidence that further evaluation is needed to determine whether survey calibration might be warranted.

Tables $\mathrm{H}$ and I show Oregon onshore, survey frame and respondent representativeness measures for Oregon home port and permit owner residency. Using means and proportions, the respondents deviations from survey frame are small for these other measures.

\section{G. Discussion}

The representativeness analysis purpose is to determine bias of the chosen survey frame for being inclusive of the intended survey population and investigate bias of non-response. The survey population included commercial fishing permit holders and recreational fishing charter boat permit holders. The representativeness analysis was only for the commercial fishing stratum.

The known indicators of the survey frame are from fisheries permit registrations and harvest delivery information recorded on fish tickets. There were no overt survey procedures used to track down non-respondents to determine potential bias. Therefore, and only if necessary due to a finding of misrepresentation, the known indicators could be used for creating post-survey calibration schemes to ameliorate any non-response bias.

Major findings from the representativeness analysis are:

1. If the survey population is commercial fishing participants in a traditional definition for Oregon nearshore fisheries, then survey coverage bias is introduced with the choice for the survey frame. The choice opened the survey frame list to participants whose fishing grounds are outside nearshore fisheries and there are other fishery permits that could have been included in the survey frame to be more inclusive of nearshore fisheries, such as the sea urchin fishery. The chosen survey frame does contain the most important (highest landed value generating) nearshore fisheries.

2. Concatenating survey frame list addresses and limiting respondents to providing information for only two vessels caused some loss in survey frame integrity. There were cases where multiple permit owners are associated with one address and other cases where many vessels were owned by a single registrant.

3. Not preloading the instrument with vessel and harvest history nor asking for the vessel identification number on the survey caused difficulties in verifying respondents stated behavior and supplying fish ticket delivery information to the survey results database.

4. Survey respondents were diverse and proportionally aligned with known characteristics about the survey frame universe. Known characteristic measures include vessel landed value, vessel physical length, Oregon principal port (port group where a plurality of Oregon landings are made), and permit registration in-state residency. Based on means and proportions, the respondents deviations from survey frame are small for the characteristics.

5. The proportions of permit holders active in 2016 for any of the three survey fisheries are: survey frame 63 percent and respondents 77 percent. It makes sense that a permit owner 
that is active in an Oregon fishery would be more likely to invest the time to complete a survey that is about the fisheries in which they participate.

6. Using only Oregon landed value and effort in modeling will misrepresent total vessel harvesting activity because some of the survey frame three fisheries permit holders also participate in out-of-state fisheries.

7. Response rate is low but not unexpected and unusual of other similar voluntary commercial fishing cost-earnings and preference survey studies. There were no nonresponse follow-up interviews that could be used to test similarity to respondent characteristics, behavior, and attitudes. At 229 respondents for a 1,161 survey list, an expected parametric margin of error at 95 percent confidence level for a question with a cardinal number answer that had no refusals would be plus or minus six percent.

8. More work in assessing representativeness such as comparing survey cost-earning results to mandatory reporting and other survey studies is possible.

9. Any signal of effort shift away from marine reserve due to fishing restrictions will be lost in the noise of annual landing variability. The maximum potential loss of landing value is 3.6 percent of Oregon Territorial Sea using average landings 2013-2015 (TRG 2018). The landing value variability between 2008 and 2017 has a range of 72 percent for Dungeness crab, 223 percent for salmon troll, and 23 percent for nearshore groundfish (Table F). A more spatial and temporal refined investigation would be necessary to discern a discontinuty in effort related to area fishing restrictions.

This representative analysis shows fairly close adherence to known survey frame characteristics. Therefore it is suggested that calibration schemes to improve representation may not be needed. There are no analytical standards to determine whether responses should be calibrated to reduce bias. It would be up to the project author to judge its necessity.

\section{H. Bibliography}

Deville, Jean-Claude and Carl-Erik Särndal. "Calibration Estimators in Survey Sampling." Journal of the American Statistical Association, 87:418, 376-382. 1992.

Gelman, Andrew and Thomas Little. "Post-stratification Into Many Categories Using Hierarchal Logistic Regression." Survey Methodology, v. 23, No. 2: pp. 127-135. 1997.

Groves, R.M. Nonresponse Rates and Nonresponse Bias in Household Surveys. Public Opinion Quarterly, 70(5), 646-675. 2006.

Kolenikov, Stanislav. "Calibrating Survey Data Using Iterative Proportional Fitting (Raking)." The Stata Journal, V. 14, No. 1: pp. 22-59. 2014.

Kruskal, W. and Mosteller, F. Representative Sampling IV: The History of the Concept in Statistics, 1895-1939. International Statistical Review. 1980. 
The Research Group, LLC (TRG). Interactive Model User Guide for the Broadscale Spatial Analysis of Oregon Nearshore Fisheries. Prepared for Marine Resources Program, Oregon Department of Fish and Wildlife. January 2018.

Särndal, C.E. and Lundström, S. Estimation in Surveys With Nonresponse. West Sussex, England: John Wiley \& Sons Ltd. 2005.

Van Putten, Ingrid, Soile Kulmala, Olivier Thébaud, Natalie Dowling, Katell Hamon, Trevor Hutton, and Sean Pascoe. "Theories and Behavioural Drivers Underlying Fleet Dynamics Models." Fish and Fisheries Volume 13, Issue 2. June 2012. 
Table A.1

Survey Frame and Survey Respondents Vessel Counts With Matches to Vessels Having Oregon Onshore Landings in 2011-2016

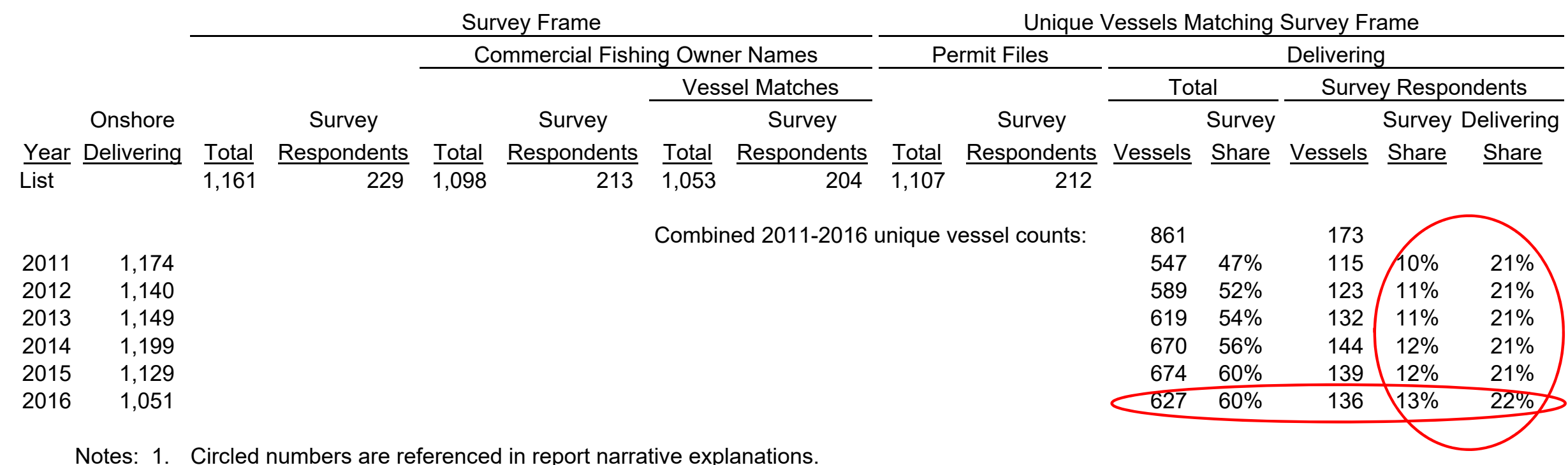

2. See report narrative for column derivation explanations.

Sources: Oregon onshore landings are from PacFIN annual vessel summary data April 2013, March 2014, April 2015, November 2016, and March 2017 extractions. Vessels matched to survey frame using ODFW fishery permit files for 2016 to 2017. 
Table A.2

Survey Frame and Survey Respondents Vessel Counts by Survey Fisheries With Matches to Vessels Having Oregon Onshore Landings in 2016

Survey frame (rows commercial fishery codes "DC", "S", "GF")

Respondents

\begin{tabular}{|c|c|c|c|c|}
\hline D. Crab & $\begin{array}{c}\text { Troll } \\
\text { Salmon }\end{array}$ & $\begin{array}{l}\text { Nearshore } \\
\text { Groundfish }\end{array}$ & $\begin{array}{l}3 \text { Survey } \\
\text { Fisheries }\end{array}$ & $\begin{array}{c}\text { All } \\
\text { Fisheries }\end{array}$ \\
\hline 374 & 886 & 99 & 1,098 & 1,098 \\
\hline 77 & 166 & 27 & 213 & 213 \\
\hline 421 & 954 & 114 & 1,197 & 1,537 \\
\hline 381 & 878 & 90 & 1,069 & 1,070 \\
\hline 78 & 163 & 27 & 209 & 209 \\
\hline 348 & 335 & 253 & 698 & 1,051 \\
\hline 292 & 293 & 170 & 553 & 627 \\
\hline 63 & 69 & 41 & 130 & 136 \\
\hline 364 & 835 & 76 & 1,107 & 1,107 \\
\hline 77 & 151 & 20 & 212 & 212 \\
\hline 307 & 302 & 97 & 598 & 859 \\
\hline 277 & 284 & 77 & 535 & 624 \\
\hline 62 & 68 & 24 & 129 & \\
\hline
\end{tabular}

Notes: 1. Circled numbers are referenced in report narrative explanations.

2. Fishery permit types include resident and non-resident. The nearshore groundfish fishery permit types are Oregon Nearshore Fishery Permit with and without a Nearshore Endorsement Permit.

3. Vessels in survey frame are determined by exact and inexact matches to permit file names and addresses, independently of codes "DC", "S", and "GF."

4. Table A.1 notes and sources apply. 
Table B

Survey Frame and Survey Respondents With Matches to Oregon Onshore Landings in 2011-2016

Oregon Landings for Unique Vessels Matching Survey Frame

\begin{tabular}{|c|c|c|c|c|c|c|c|c|c|c|c|c|}
\hline \multirow[b]{5}{*}{ Year } & & & \multirow{2}{*}{\multicolumn{4}{|c|}{ Survey Frame }} & \multirow{2}{*}{\multicolumn{6}{|c|}{ Survey Respondents }} \\
\hline & \multirow{3}{*}{\multicolumn{2}{|c|}{ Oregon Onshore Landings }} & & & & & & & & & & \\
\hline & & & \multicolumn{2}{|c|}{ Pounds } & \multicolumn{2}{|l|}{ Value } & \multicolumn{3}{|c|}{ Pounds } & \multicolumn{3}{|c|}{ Value } \\
\hline & & & & Onsh & & Onshore & & Onshore & Survey & & Onshore & Survey \\
\hline & Pounds & $\underline{\text { Value }}$ & Amount & $\underline{\text { Share }}$ & Amount & Share & $\underline{\mathrm{Am}}$ & $\underline{\text { Share }}$ & $\underline{\text { Share }}$ & unt & $\underline{\text { Share }}$ & $\underline{\text { Share }}$ \\
\hline$\overline{2011}$ & $28 \overline{5,820,628}$ & $146,485,485$ & $10 \overline{8,198,800}$ & $38 \%$ & $8 \overline{6,393,377}$ & $59 \%$ & $\overline{757}$ & $3 \%$ & $8 \%$ & 813 & $10 \%$ & $17 \%$ \\
\hline 2012 & 306,7 & $126,369,950$ & $96,422,669$ & $31 \%$ & $72,972,058$ & $58 \%$ & 625 & $2 \%$ & $8 \%$ & 238 & $9 \%$ & $16 \%$ \\
\hline 2013 & $349,390,051$ & $177,395,629$ & $134,354,197$ & $38 \%$ & $112,055,567$ & $63 \%$ & $10,495,658$ & $3 \%$ & $8 \%$ & $18,192,007$ & $10 \%$ & $16 \%$ \\
\hline 2014 & $300,362,364$ & $156,126,825$ & $127,764,366$ & $43 \%$ & $99,877,092$ & $64 \%$ & $7,208,745$ & $2 \%$ & $6 \%$ & $14,972,594$ & $10 \%$ & $15 \%$ \\
\hline 2015 & $203,885,317$ & $114,274,466$ & $74,539,342$ & $37 \%$ & $67,644,125$ & $59 \%$ & $5,033,734$ & $2 \%$ & $7 \%$ & $8,650,946$ & $8 \%$ & $13 \%$ \\
\hline 2016 & $226,918,381$ & $148,535,658$ & $87,009,197$ & $38 \%$ & $99,193,444$ & $67 \%$ & $6,599,827$ & $3 \%$ & $8 \%$ & $16,572,034$ & $11 \%$ & $17 \%$ \\
\hline
\end{tabular}

Notes: 1. Circled numbers are referenced in report narrative explanations.

2. Values are in nominal dollars.

3. Oregon onshore landings are from fish tickets that are not filtered for vessel identifications.

4. Survey frame landings are filtered for the matching vessels showing in Table A.2. The included nearshore groundfish landings are from vessels that have a Nearshore Fisheries Permit as well as incidental fishery landings from vessels that do not have. a Nearshore Fisheries Permit.

Sources: $\quad$ Oregon onshore landings are from PacFIN annual vessel summary data April 2013, March 2014, April 2015, November 2016, and March 2017 extractions. Vessels matched to survey frame using ODFW fishery permit files for 2016 to 2017. 
Table C

Survey Frame and Survey Respondents With Matches to

Oregon Onshore Landed Value by Major Fishery in 2011-2016

Survey Fisheries

Incidental Fisheries

\begin{tabular}{|c|c|c|c|c|c|c|c|c|c|c|}
\hline Year & $\begin{array}{l}\text { Ocean } \\
\text { Salmon }\end{array}$ & D. Crab & $\begin{array}{l}\text { Nearshore } \\
\text { Groundfish }\end{array}$ & $\begin{array}{l}\text { Col. R. } \\
\text { Salmon }\end{array}$ & $\begin{array}{c}\text { Other } \\
\text { Groundfish } \\
\end{array}$ & P. Shrimp & Tuna & Whiting & Sardine & Other \\
\hline & \multicolumn{10}{|c|}{ Oregon Onshore Landed Value by Major Fishery } \\
\hline 2011 & $2,403,537$ & $44,690,045$ & $1,534,618$ & $4,333,833$ & $26,904,632$ & $24,607,431$ & $18,765,949$ & $16,517,516$ & $3,191,593$ & $3,536,331$ \\
\hline 2012 & $4,248,810$ & $29,113,588$ & $1,720,643$ & $2,675,699$ & $22,113,724$ & $24,685,446$ & $15,077,265$ & $14,610,529$ & $8,976,821$ & $3,147,425$ \\
\hline 2013 & $7,607,116$ & $71,208,556$ & $1,625,231$ & $4,810,793$ & $20,697,168$ & $24,152,582$ & $16,078,899$ & $20,404,624$ & $6,299,324$ & $4,511,336$ \\
\hline 2014 & $14,828,562$ & $47,988,488$ & $1,579,699$ & $5,295,413$ & $20,230,029$ & $29,325,813$ & $11,023,484$ & $18,273,513$ & $3,521,759$ & $4,060,065$ \\
\hline 2015 & $7,334,340$ & $11,912,041$ & $1,740,992$ & $4,529,700$ & $27,047,263$ & $40,412,671$ & $9,211,747$ & $7,145,945$ & 812,687 & $4,127,080$ \\
\hline 2016 & $4,253,905$ & $55,734,874$ & $1,494,238$ & $4,053,970$ & $30,493,655$ & $25,093,253$ & $12,502,092$ & $8,693,682$ & 317 & $6,215,672$ \\
\hline
\end{tabular}

Oregon Onshore Landed Value by Major Fishery for Unique Vessels Matching Survey Frame

$\begin{array}{rrrrrrrrrrr}2011 & 2,065,484 & 35,412,530 & 790,763 & 192,540 & 17,338,988 & 16,229,219 & 8,395,380 & 4,499,793 & 0 & 1,468,680 \\ 2012 & 3,561,018 & 24,465,476 & 874,790 & 158,964 & 13,741,925 & 16,149,980 & 8,665,304 & 3,640,168 & 538,232 & 1,176,201 \\ 2013 & 6,508,484 & 59,533,639 & 861,917 & 231,157 & 12,297,158 & 16,731,516 & 7,918,707 & 5,874,195 & 939,243 & 1,159,551 \\ 2014 & 12,844,034 & 39,413,676 & 794,129 & 292,692 & 11,515,695 & 19,638,839 & 7,002,829 & 6,170,362 & 733,763 & 1,471,073 \\ 2015 & 6,491,973 & 9,990,768 & 1,034,635 & 196,176 & 16,435,299 & 25,229,662 & 5,513,137 & 964,072 & 497,663 & 1,290,740 \\ 2016 & 3,913,854 & 47,159,023 & 917,561 & 217,546 & 20,242,702 & 15,693,805 & 7,823,476 & 1,920,131 & 66 & 1,305,280\end{array}$

Oregon Onshore Landed Value by Major Fishery for Unique Vessels Matching Survey Respondents

\begin{tabular}{|c|c|c|c|c|c|c|c|c|c|c|}
\hline 2011 & 466,740 & $7,060,329$ & 300,665 & 13,543 & $3,465,850$ & $1,574,991$ & $1,214,566$ & 0 & 0 & 159,129 \\
\hline 2012 & 879,079 & $5,159,397$ & 286,084 & 9,199 & $2,331,766$ & $1,532,167$ & 1,196,207 & 0 & 0 & 97,339 \\
\hline 2013 & $1,531,885$ & $11,393,340$ & 292,061 & 17,059 & $1,539,609$ & $1,894,117$ & 1,383,996 & 1 & 0 & 139,939 \\
\hline 014 & $2,966,419$ & $7,459,684$ & 264,197 & 16,119 & $1,552,607$ & $1,410,160$ & $1,133,994$ & 0 & 842 & 168,572 \\
\hline 015 & $1,430,040$ & $2,229,060$ & 329,428 & 14,131 & $2,119,247$ & $1,364,607$ & 929,465 & 23 & 63,525 & 171,420 \\
\hline 016 & $1,144,883$ & $10,049,362$ & 237,609 & 12,012 & $2,628,731$ & 936,131 & $1,336,610$ & 7 & 0 & 226,689 \\
\hline
\end{tabular}

Share of Oregon Onshore Landed Value by Major Fishery for Unique Vessels Matching Survey Frame

$\begin{array}{rrrrrrrrrrr}2011 & 86 \% & 79 \% & 52 \% & 4 \% & 64 \% & 66 \% & 45 \% & 27 \% & 0 \% & 42 \% \\ 2012 & 84 \% & 84 \% & 51 \% & 6 \% & 62 \% & 65 \% & 57 \% & 25 \% & 6 \% & 37 \% \\ 2013 & 86 \% & 84 \% & 53 \% & 5 \% & 59 \% & 69 \% & 49 \% & 29 \% & 15 \% & 26 \% \\ 2014 & 87 \% & 82 \% & 50 \% & 6 \% & 57 \% & 67 \% & 64 \% & 34 \% & 21 \% & 36 \% \\ 2015 & 89 \% & 84 \% & 59 \% & 4 \% & 61 \% & 62 \% & 60 \% & 13 \% & 61 \% & 31 \% \\ 2016 & 92 \% & 85 \% & 61 \% & 5 \% & 66 \% & 63 \% & 63 \% & 22 \% & 21 \% & 21 \%\end{array}$

Share of Oregon Onshore Landed Value by Major Fishery for Unique Vessels Matching Survey Respondents

$\begin{array}{rrrrrrrrrrr}2011 & 19 \% & 16 \% & 20 \% & 0 \% & 13 \% & 6 \% & 6 \% & 0 \% & 0 \% & 4 \% \\ 2012 & 21 \% & 18 \% & 17 \% & 0 \% & 11 \% & 6 \% & 8 \% & 0 \% & 0 \% & 3 \% \\ 2013 & 20 \% & 16 \% & 18 \% & 0 \% & 7 \% & 8 \% & 9 \% & 0 \% & 0 \% & 3 \% \\ 2014 & 20 \% & 16 \% & 17 \% & 0 \% & 8 \% & 5 \% & 10 \% & 0 \% & 0 \% & 4 \% \\ 2015 & 19 \% & 19 \% & 19 \% & 0 \% & 8 \% & 3 \% & 10 \% & 0 \% & 8 \% & 4 \% \\ 2016 & 27 \% & 18 \% & 16 \% & 0 \% & 9 \% & 4 \% & 11 \% & 0 \% & 0 \% & 4 \%\end{array}$

Share of Survey Frame Landed Value From Survey Respondents Landed Value

$\begin{array}{rrrrrrrrrrrr}2011 & 23 \% & 20 \% & 38 \% & 7 \% & 20 \% & 10 \% & 14 \% & 0 \% & 11 \% \\ 2012 & 25 \% & 21 \% & 33 \% & 6 \% & 17 \% & 9 \% & 14 \% & 0 \% & 0 \% & 8 \% \\ 2013 & 24 \% & 19 \% & 34 \% & 7 \% & 13 \% & 11 \% & 17 \% & 0 \% & 0 \% & 12 \% \\ 2014 & 23 \% & 19 \% & 33 \% & 6 \% & 13 \% & 7 \% & 16 \% & 0 \% & 0 \% & 11 \% \\ 2015 & 22 \% & 22 \% & 32 \% & 7 \% & 13 \% & 5 \% & 17 \% & 0 \% & 13 \% & 13 \% \\ 2016 & 29 \% & 21 \% & 26 \% & 6 \% & 13 \% & 6 \% & 17 \% & 0 \% & 0 \% & 17 \%\end{array}$

Notes: 1. Notes and sources of Table B apply. Circled numbers are referenced in report narrative explanations.

2. Columbia River salmon fishery includes both non-Indian and tribal fisheries. 
Table D

Survey Frame and Survey Respondents With Matches to

Oregon Onshore Landing Vessels by Major Fishery in 2011-2016

Survey Fisheries

Incidental Fisheries

Ocean Nearshore Col. R. Other

Year Salmon D. Crab Groundfish Salmon Groundfish P. Shrimp Tuna Whiting Sardine Other

\begin{tabular}{lllllllllll} 
& \multicolumn{10}{c}{ Oregon Onshore Landing Vessels by Major Fishery } \\
\cline { 2 - 12 } 2011 & 327 & 395 & 231 & 218 & 179 & 62 & 442 & 54 & 26 & 379 \\
2012 & 391 & 357 & 245 & 187 & 196 & 64 & 447 & 51 & 35 & 372 \\
2013 & 420 & 363 & 246 & 168 & 187 & 60 & 397 & 45 & 25 & 328 \\
2014 & 515 & 371 & 224 & 183 & 174 & 60 & 379 & 40 & 32 & 285 \\
2015 & 516 & 321 & 267 & 174 & 177 & 78 & 348 & 47 & 13 & 256 \\
2016 & 335 & 348 & 253 & 175 & 182 & 75 & 367 & 57 & 17 & 253
\end{tabular}

Oregon Onshore Landing Vessels by Major Fishery for Unique Vessels Matching Survey Frame

$\begin{array}{llllrllllll}2011 & 235 & 284 & 132 & 12 & 111 & 42 & 246 & 23 & 3 & 141 \\ 2012 & 298 & 269 & 145 & 13 & 123 & 42 & 279 & 21 & 7 & 148 \\ 2013 & 327 & 284 & 155 & 9 & 123 & 40 & 237 & 19 & 5 & 129 \\ 2014 & 418 & 287 & 134 & 9 & 107 & 40 & 236 & 14 & 6 & 186 \\ 2015 & 432 & 261 & 169 & 11 & 113 & 48 & 239 & 19 & 6 & 176 \\ 2016 & 293 & 292 & 170 & 9 & 122 & 50 & 253 & 27 & 4 & 170\end{array}$

Oregon Onshore Landing Vessels by Major Fishery for Unique Vessels Matching Survey Respondents

$\begin{array}{lllllllllll}2011 & 56 & 66 & 31 & 2 & 27 & 4 & 45 & 2 & 1 & 25 \\ 2012 & 64 & 61 & 35 & 3 & 30 & 5 & 53 & 2 & 0 & 30 \\ 2013 & 76 & 65 & 43 & 1 & 33 & 5 & 42 & 2 & 0 & 24 \\ 2014 & 89 & 66 & 35 & 1 & 25 & 3 & 44 & 1 & 1 & 38 \\ 2015 & 89 & 58 & 38 & 1 & 25 & 4 & 38 & 1 & 1 & 38 \\ 2016 & 69 & 63 & 41 & 1 & 25 & 5 & 50 & 2 & 0 & 37\end{array}$

Share of Oregon Onshore Landing Vessels by Major Fishery for Unique Vessels Matching Survey Frame

$\begin{array}{lllllllllll}2011 & 72 \% & 72 \% & 57 \% & 6 \% & 62 \% & 68 \% & 56 \% & 43 \% & 12 \% & 37 \% \\ 2012 & 76 \% & 75 \% & 59 \% & 7 \% & 63 \% & 66 \% & 62 \% & 41 \% & 20 \% & 40 \% \\ 2013 & 78 \% & 78 \% & 63 \% & 5 \% & 66 \% & 67 \% & 60 \% & 42 \% & 20 \% & 39 \% \\ 2014 & 81 \% & 77 \% & 60 \% & 5 \% & 61 \% & 67 \% & 62 \% & 35 \% & 19 \% & 65 \% \\ 2015 & 84 \% & 81 \% & 63 \% & 6 \% & 64 \% & 62 \% & 69 \% & 40 \% & 46 \% & 69 \% \\ 2016 & 87 \% & 84 \% & 67 \% & 5 \% & 67 \% & 67 \% & 69 \% & 47 \% & 24 \% & 67 \%\end{array}$

Share of Oregon Onshore Landing Vessels by Major Fishery for Unique Vessels Matching Survey Respondents

$\begin{array}{rrrrrrrrrrr}2011 & 17 \% & 17 \% & 13 \% & 1 \% & 15 \% & 6 \% & 10 \% & 4 \% & 4 \% & 7 \% \\ 2012 & 16 \% & 17 \% & 14 \% & 2 \% & 15 \% & 8 \% & 12 \% & 4 \% & 0 \% & 8 \% \\ 2013 & 18 \% & 18 \% & 17 \% & 1 \% & 18 \% & 8 \% & 11 \% & 4 \% & 0 \% & 7 \% \\ 2014 & 17 \% & 18 \% & 16 \% & 1 \% & 14 \% & 5 \% & 12 \% & 3 \% & 3 \% & 13 \% \\ 2015 & 17 \% & 18 \% & 14 \% & 1 \% & 14 \% & 5 \% & 11 \% & 2 \% & 8 \% & 15 \% \\ 2016 & 21 \% & 18 \% & 16 \% & 1 \% & 14 \% & 7 \% & 14 \% & 4 \% & 0 \% & 15 \%\end{array}$

Share of Survey Frame Unique Vessels That Match Survey Respondents Unique Vessels

\begin{tabular}{|c|c|c|c|c|c|c|c|c|c|c|}
\hline 2011 & $24 \%$ & $23 \%$ & $23 \%$ & $17 \%$ & $24 \%$ & $10 \%$ & $18 \%$ & $9 \%$ & & $18 \%$ \\
\hline 2012 & $21 \%$ & $23 \%$ & $24 \%$ & $23 \%$ & $24 \%$ & $12 \%$ & $19 \%$ & $10 \%$ & $0 \%$ & $20 \%$ \\
\hline 2013 & $23 \%$ & $23 \%$ & $28 \%$ & $11 \%$ & $27 \%$ & $13 \%$ & $18 \%$ & $11 \%$ & $0 \%$ & $19 \%$ \\
\hline 2014 & $21 \%$ & $23 \%$ & $26 \%$ & $11 \%$ & $23 \%$ & $8 \%$ & $19 \%$ & $7 \%$ & $17 \%$ & $20 \%$ \\
\hline 2015 & $21 \%$ & $22 \%$ & $22 \%$ & $9 \%$ & $22 \%$ & $8 \%$ & $16 \%$ & $5 \%$ & $17 \%$ & $22 \%$ \\
\hline 016 & $24 \%$ & $22 \%$ & $24 \%$ & $11 \%$ & $20 \%$ & $10 \%$ & $20 \%$ & $7 \%$ & $0 \%$ & $22 \%$ \\
\hline
\end{tabular}

Notes: 1. Notes and sources of Table A apply. Circled numbers are referenced in report narrative explanations.

2. Columbia River salmon fishery excludes tribal fisheries because fish tickets do not reveal vessel identification. 
Table E

Frequency Distribution of Oregon Onshore, Survey Frame, and Survey Respondent Average Annual Landed Value in 2016

All Fisheries
Vessels
Minimum value
1st quartile
2nd quartile (median)
3rd quartile
Maximum value
Interquartile range (IQR)
Mean

\begin{tabular}{|c|c|c|}
\hline Oregon Onshore & Survey Frame & Survey Respond \\
\hline 1,051 & 627 & 136 \\
\hline 32 & 58 & 149 \\
\hline 6,035 & 8,390 & 6,534 \\
\hline 30,650 & 42,571 & 36,780 \\
\hline 141,557 & 171,594 & 157,388 \\
\hline $1,807,386$ & $1,734.913$ & $1,714,885$ \\
\hline 135,522 & 163,204 & 150,854 \\
\hline 138,357 & 158,203 & 121,853 \\
\hline & 0.150 & 0.090 \\
\hline
\end{tabular}

D. Crab

Vessels

Minimum value

1st quartile

2nd quartile (median)

3rd quartile

Maximum value

Interquartile range (IQR)

Mean

Two sample t-test $\mathrm{P}$-value

\begin{tabular}{rrr}
348 & 292 & 63 \\
0 & 0 & 1,154 \\
42,074 & 59,151 & 70,055 \\
120,360 & 123,445 & 103,153 \\
234,132 & 233,673 & 225,012 \\
818,458 & 805,282 & 805,282 \\
\hline 192,058 & 174,523 & 154,957 \\
\hline 160,046 & 161,504 & 159,514 \\
& 0.902 & 0.928
\end{tabular}

Salmon, troll

Vessels

Minimum value

1st quartile

2nd quartile (median)

3rd quartile

Maximum value

Interquartile range (IQR)

Mean

Two sample t-test $\mathrm{P}$-value

\begin{tabular}{rrr}
335 & 293 & 69 \\
0 & 0 & 63 \\
745 & 1,070 & 1,358 \\
4,832 & 5,894 & 7,827 \\
16,888 & 18,728 & 24,735 \\
149,071 & 149,071 & 94,507 \\
\hline 16,143 & 17,658 & 23,377 \\
\hline 12,664 & 13,358 & 16,593 \\
& 0.654 & 0.244
\end{tabular}

Nearshore groundfish

Vessels

Minimum value

1st quartile

2nd quartile (median)

3rd quartile

Maximum value

Interquartile range (IQR)

Mean

Two sample t-test $\mathrm{P}$-value

\begin{tabular}{rrr}
253 & 170 & 41 \\
0 & 0 & 0 \\
188 & 238 & 421 \\
1,522 & 1,962 & 2,439 \\
7,602 & 7,199 & 9,690 \\
71,335 & 40,976 & 40,890 \\
\hline 7,414 & 6,961 & 9,269 \\
\hline 5,887 & 5,397 & 5,795 \\
& 0.582 & 0.775
\end{tabular}

Notes: 1 . Circled numbers are referenced in report narrative explanations.

2. Oregon onshore excludes landings with no identifiable vessel. Out-of-state landed value is not included.

3. Survey frame and respondents only include vessels with Oregon deliveries in 2016.

4. The Welch Two Sample t-test is a parametric method to test the hypothesis that two subpopulations have equal means. Survey frame is compared to Oregon onshore, and survey respondents are compared to survey frame. 


\begin{tabular}{|c|c|c|c|c|c|c|c|c|c|c|c|c|c|c|}
\hline \multirow[b]{2}{*}{ Fishery } & \multirow[b]{2}{*}{2008} & \multirow[b]{2}{*}{2009} & \multirow[b]{2}{*}{2010} & \multirow[b]{2}{*}{2011} & \multirow[b]{2}{*}{2012} & \multirow[b]{2}{*}{2013} & \multirow[b]{2}{*}{2014} & \multirow[b]{2}{*}{2015} & \multirow[b]{2}{*}{2016} & \multirow[b]{2}{*}{2017} & \multicolumn{4}{|c|}{ 2008-2017 Dispersion } \\
\hline & & & & & & & & & & & Trend & Mean & $\begin{array}{c}\text { Percent } \\
\text { Variability }\end{array}$ & $\begin{array}{l}\text { Mann- } \\
\text { Kendall } \\
\end{array}$ \\
\hline & \multicolumn{12}{|c|}{ Landed Value (real, millions) } & & \\
\hline All Fisheries & 114.7 & 116.1 & 115.4 & 160.8 & 136.2 & 188.2 & 162.7 & 117.8 & 151.2 & 144.0 & & 140.7 & $52 \%$ & 1.43 \\
\hline D. Crab & 33.7 & 29.6 & 50.3 & 53.8 & 45.7 & 51.9 & 52.3 & 34.6 & 52.2 & 63.1 & & 46.7 & & 1.79 \\
\hline Salmon, troll & 0.4 & 0.4 & 3.1 & 2.6 & 4.6 & 8.1 & 15.5 & 7.6 & 4.3 & 2.1 & & 6.0 & $223 \%$ & 0.72 \\
\hline \multirow[t]{2}{*}{ Nearshore groundfish } & 1.2 & 1.4 & 1.1 & 1.3 & 1.4 & 1.3 & 1.2 & 1.2 & 1.0 & 1.0 & & 1.2 & $30 \%$ & -1.61 \\
\hline & \multicolumn{12}{|c|}{ Participating Vessel Counts } & & \\
\hline All Fisheries & 1,039 & 1,140 & 1,180 & 1,174 & 1,140 & 1,149 & 1,199 & 1,129 & 1,051 & 1,051 & & 1,125 & $14 \%$ & -0.45 \\
\hline D. Crab & 340 & 346 & 351 & 385 & 354 & 342 & 348 & 336 & 341 & 341 & & 348 & $14 \%$ & -0.63 \\
\hline Salmon, troll & 163 & 248 & 392 & 327 & 391 & 420 & 515 & 516 & 335 & 335 & & 404 & $47 \%$ & 0.63 \\
\hline \multirow[t]{2}{*}{ Nearshore groundfish } & 116 & 125 & 123 & 118 & 115 & 116 & 105 & 109 & 99 & 99 & & 113 & $23 \%$ & -2.78 \\
\hline & \multicolumn{12}{|c|}{ Average Landed Value Per Vessel (real, thousands) } & & \\
\hline All Fisheries & 110.4 & 101.9 & 97.8 & 137.0 & 119.5 & 163.8 & 135.7 & 104.4 & 143.9 & 137.0 & & 125.1 & $53 \%$ & \\
\hline D. Crab & 99.1 & 85.7 & 143.4 & 139.9 & 129.2 & 151.8 & 150.3 & 102.9 & 153.2 & 185.0 & & 134.1 & $74 \%$ & \\
\hline Salmon, troll & 2.7 & 1.6 & 8.0 & 8.1 & 11.7 & 19.2 & 30.0 & 14.7 & 12.9 & 6.4 & & 14.8 & $160 \%$ & \\
\hline Nearshore groundfish & 10.7 & 11.1 & 9.0 & 11.0 & 11.8 & 11.4 & 11.5 & 11.5 & 10.5 & 10.3 & & 10.9 & $26 \%$ & \\
\hline
\end{tabular}


Notes: 1. Circled numbers are referenced in report narrative explanations.

2. Values are real 2017 dollars adjusted using the GDP implicit price deflator developed by U.S. Bureau of Economic Analysis.

3. The Dungeness crab fisheries landed value are for a season. The season is authorized to open December 1 , however some seasons during the tables period have had delayed openings until January. To have consistent landings across the period, any landings in December of the preceding year are compiled to be in the following year.

4. The salmon fisheries in 2008 and 2009 are outliers because the fishery was essentially closed south of Cape Falcon during those years. The mean and percent variability are calculated for years 2010-2017. The Mann-Kendall statistic is calculated by repeating Year 2010 for those years. Year 2010 harvests were moderate, but representative of decade 2000's averages when salmon disaster years 2006, 2008, and 2009 harvests are omitted.

5. Oregon onshore values include those fish tickets with no unique vessel identification associated with a delivery.

6. Year 2017 data is not available for vessel counts, or for nearshore groundfish landings, so 2016 is repeated.

7. The Mann-Kendall test statistic shows the tendency for an increasing (positive) or decreasing (negative) linear trend with time using a nonparametric method. A value near zero suggests there is no significant upward or downward trend. The magnitude measures the "strength" of the trend.

8. Marine reserves management restrictions started on January 1, 2012 at Redfish Rocks (RR) and Otter Rocks (OR), January 1, 2014 at Cascade Head (CH) and Cape Perpetua (CP), and January 1, 2016 at Cape Falcon (CF).

9. Table shows only nearshore groundfish landed by vessels having Oregon Nearshore Fishery Permit with and without a Nearshore Endorsement Permit.

Source: PacFIN annual vessel summary data April 2009, March 2010, July 2011, April 2013, March 2014, April 2015, November 2016, and March 2017 extractions; and PacFIN and ODFW websites accessed April 26, 2018. 
Table G

Frequency Distribution of Oregon Onshore, Survey Frame, and Survey

Respondent Delivering Vessel Average Annual Landed Value in 2016

Vessels

Oregon onshore

Survey frame

Survey respondents

Share

Oregon onshore

Survey frame

Survey respondents

$\$ 0-500 \$ 500-10 k \quad \$ 10 k-50 k \$ 50 k-150 k$ \$150k-400k $\$ 400 k+$ Total

$\begin{array}{rrrrrrr}60 & 286 & 271 & 180 & 151 & 103 & 1,051 \\ 32 & 138 & 155 & 122 & 111 & 69 & 627 \\ 9 & 31 & 35 & 26 & 26 & 9 & 136\end{array}$

Notes: 1 . Circled numbers are referenced in report narrative explanations.

Residency of Oregon Permitted, Survey Frame, and Survey Respondent Permit Owners in 2016

All Fisheries

All Oregon permitted

Survey frame

Survey respondents

D. Crab

All Oregon permitted

Survey frame

Survey respondents

Table H

Count of Permittees

381

363

77

284
271
60

284

60

$\begin{array}{ll}897 & 627 \\ 879 & 605 \\ 165 & 126\end{array}$

292

274

39

105
92
17

$17 \%$

$19 \%$

$19 \%$

26

467

348

53

$\begin{array}{rr}10 \% & 100 \% \\ 11 \% & 100 \% \\ 7 \% & 100 \%\end{array}$

Salmon, troll

All Oregon permitted

Survey frame

$\begin{array}{lrrrrr}\text { All Oregon permitted } & 101 & 99 & 4 & 2 & 96 \% \\ \text { Survey frame } & 76 & 72 & 4 & 0 & 95 \% \\ \text { Survey respondents } & 20 & 18 & 2 & 0 & 90 \%\end{array}$

$\begin{array}{lrrrrr}\text { All Oregon permitted } & 101 & 99 & 4 & 2 & 96 \% \\ \text { Survey frame } & 76 & 72 & 4 & 0 & 95 \% \\ \text { Survey respondents } & 20 & 18 & 2 & 0 & 90 \%\end{array}$

Oregon

\begin{tabular}{rrr} 
Both & & Share \\
& \multicolumn{2}{c}{$68 \%$} \\
0 & $68 \%$ \\
0 & $75 \%$
\end{tabular}

Nearshore groundfish

Notes: 1. Table values for all Oregon permitted include all 2016 fishery permit registrants whether or not the permit was associated with a vessel that made deliveries in 2016. Names with addresses in more than one state are counted as non-Oregon for share.

2. Survey frame includes only commercial fishing permit owners, and assignments to fishery use 2016 and 2017 fishery permit files and assumptions to exclude transfers.

3. Nearshore groundfish permit types are Oregon Nearshore Fishery Permit with and without a Nearshore Endorsement Permit. 
Table I

Vessels by Principal Oregon Delivery Port Area in 2016

All Fisheries

Oregon onshore

Survey frame

Survey respondents

\section{Share}

Oregon onshore

Survey frame

Survey respondents

\begin{tabular}{|c|c|c|c|c|c|c|}
\hline Astoria & Tillamook & Newport & Coos Bay & Port Orford & Brookings & Total \\
\hline 325 & 85 & 272 & 223 & 54 & 92 & 1,051 \\
\hline 97 & 58 & 197 & 164 & 39 & 72 & 627 \\
\hline 24 & 18 & 40 & 24 & 11 & 19 & 136 \\
\hline $31 \%$ & $8 \%$ & $26 \%$ & $21 \%$ & $5 \%$ & $9 \%$ & $100 \%$ \\
\hline $15 \%$ & $9 \%$ & $31 \%$ & $26 \%$ & $6 \%$ & $11 \%$ & $100 \%$ \\
\hline $18 \%$ & $13 \%$ & $29 \%$ & $18 \%$ & $8 \%$ & $14 \%$ & $100 \%$ \\
\hline
\end{tabular}

Notes: 1. Principal Oregon delivery port area is the port group where a vessel had the most Oregon onshore landings in 2016 (not necessarily a majority). 
Figure A

Delivering Vessel Counts in 2016

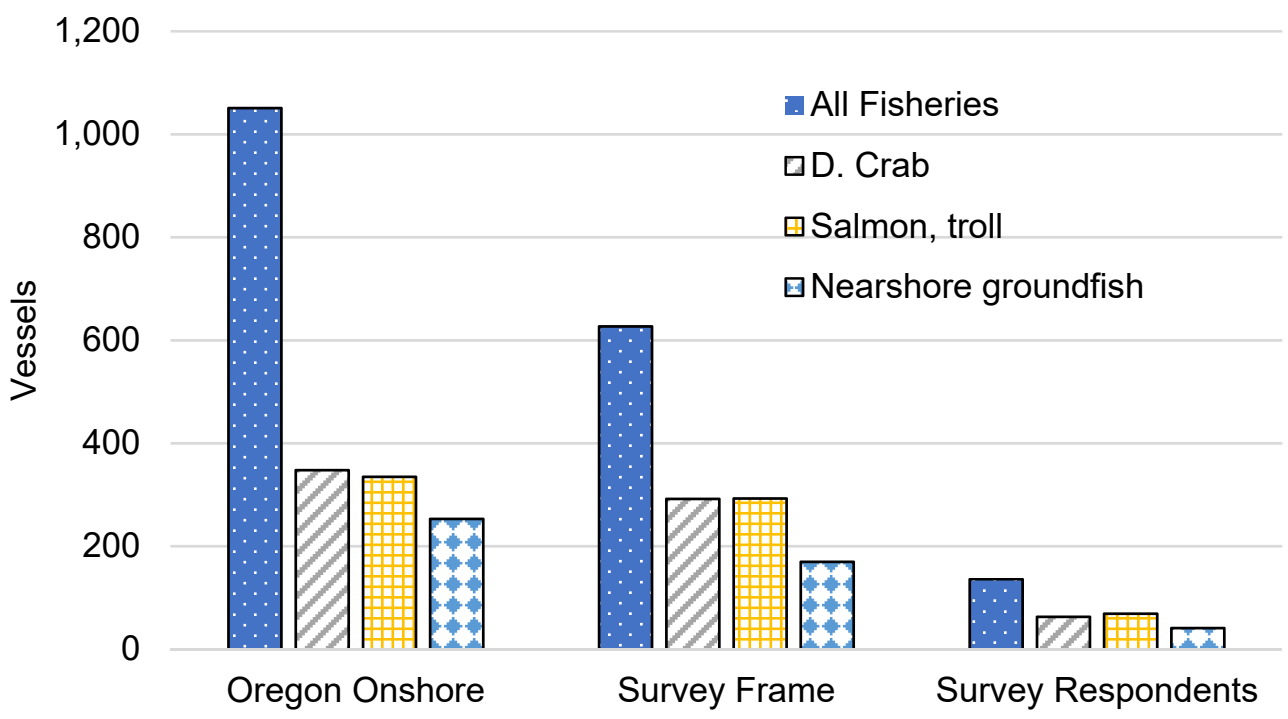

Figure B

Delivering Vessel Count Shares of

Oregon Onshore and Survey Frame in 2016

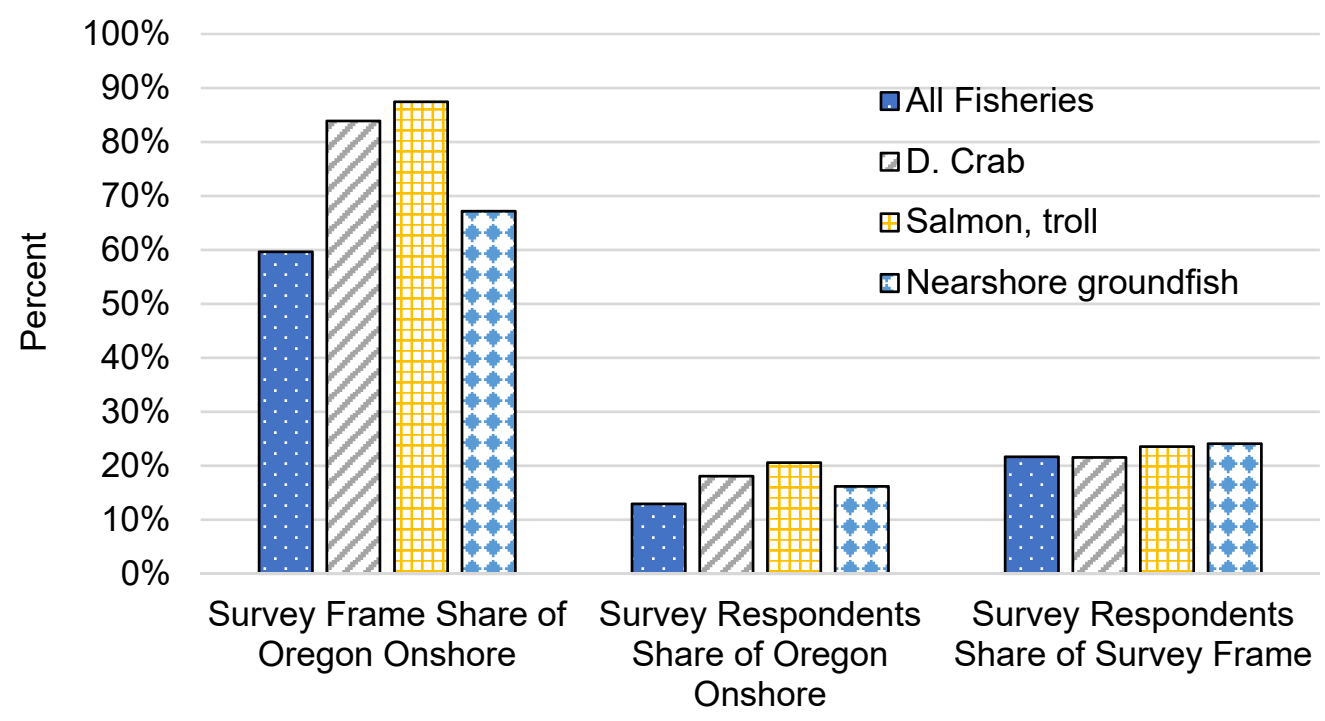

Notes: 1. Table E notes apply. 
Figure $\mathrm{C}$

Delivering Vessel Landed Value in 2016

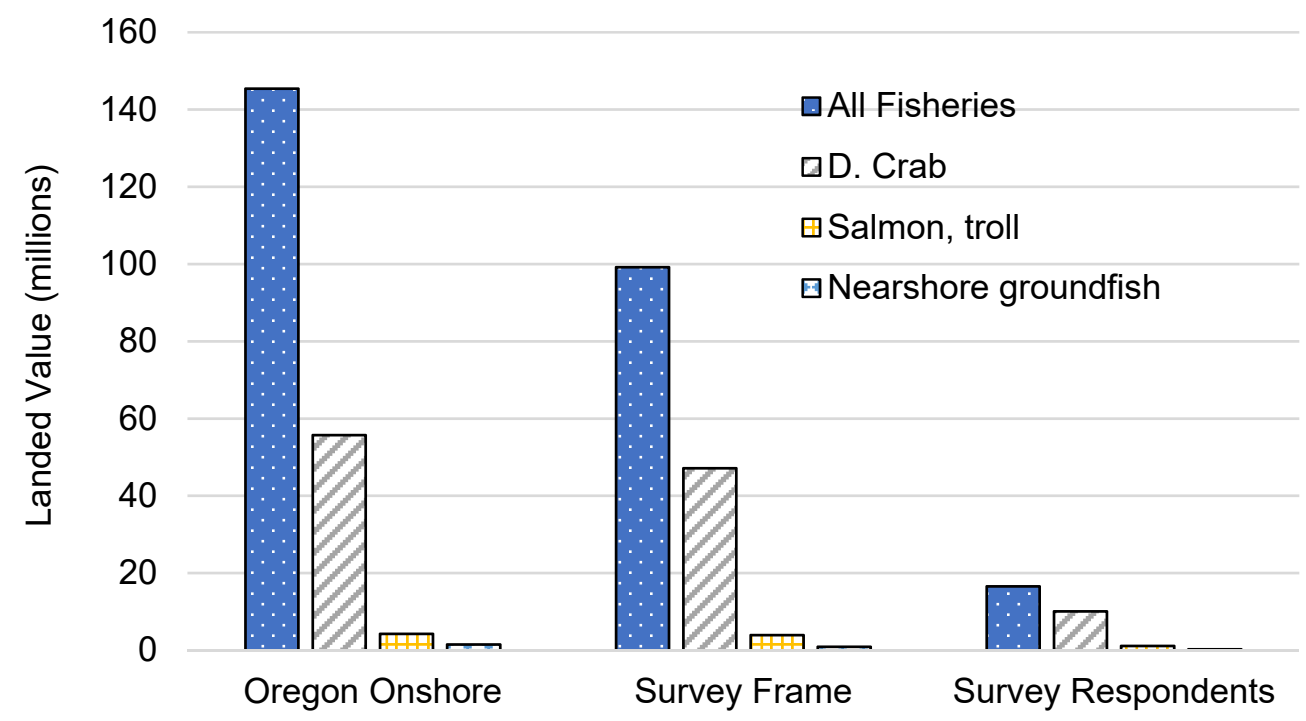

Figure D

Delivering Vessel Landed Value Shares of Oregon Onshore and Survey Frame in 2016

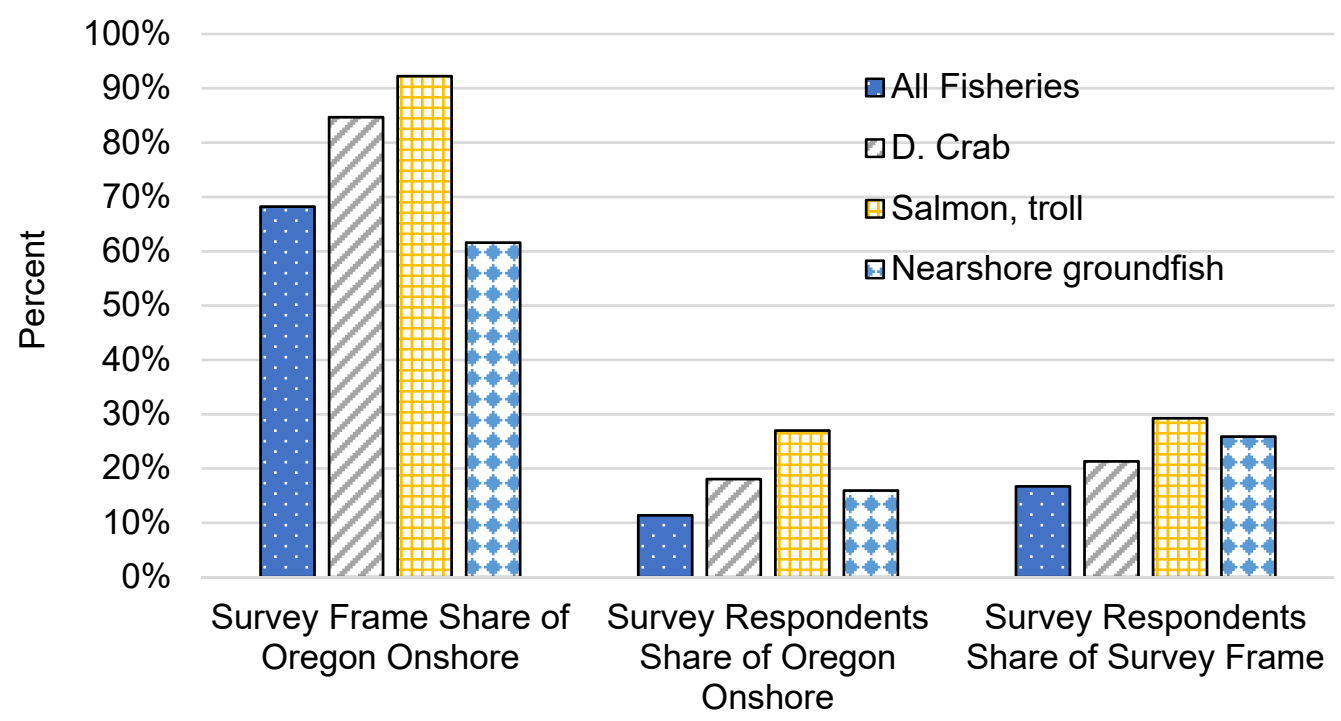

Notes: 1. Table E notes apply. 
Figure $\mathrm{E}$

Delivering Vessel Trips in 2016

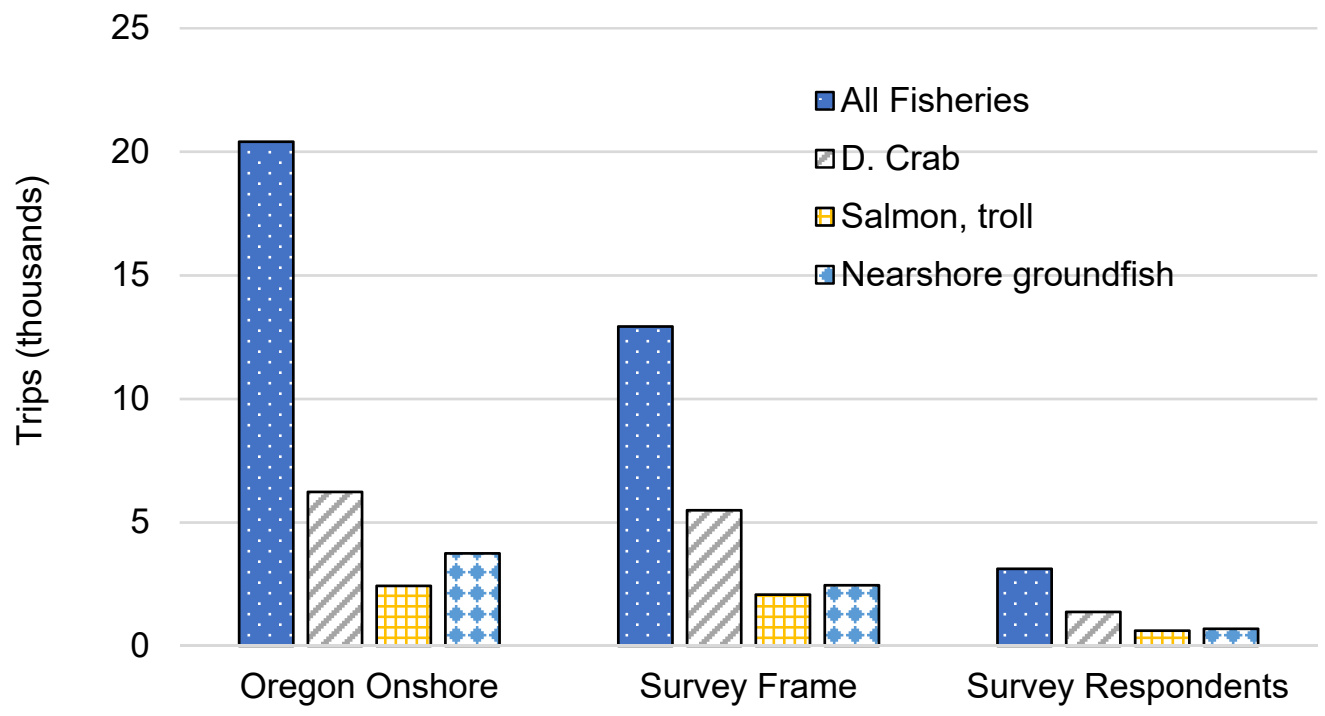

Figure $\mathrm{F}$

Delivering Vessel Trips Shares of

Oregon Onshore and Survey Frame in 2016

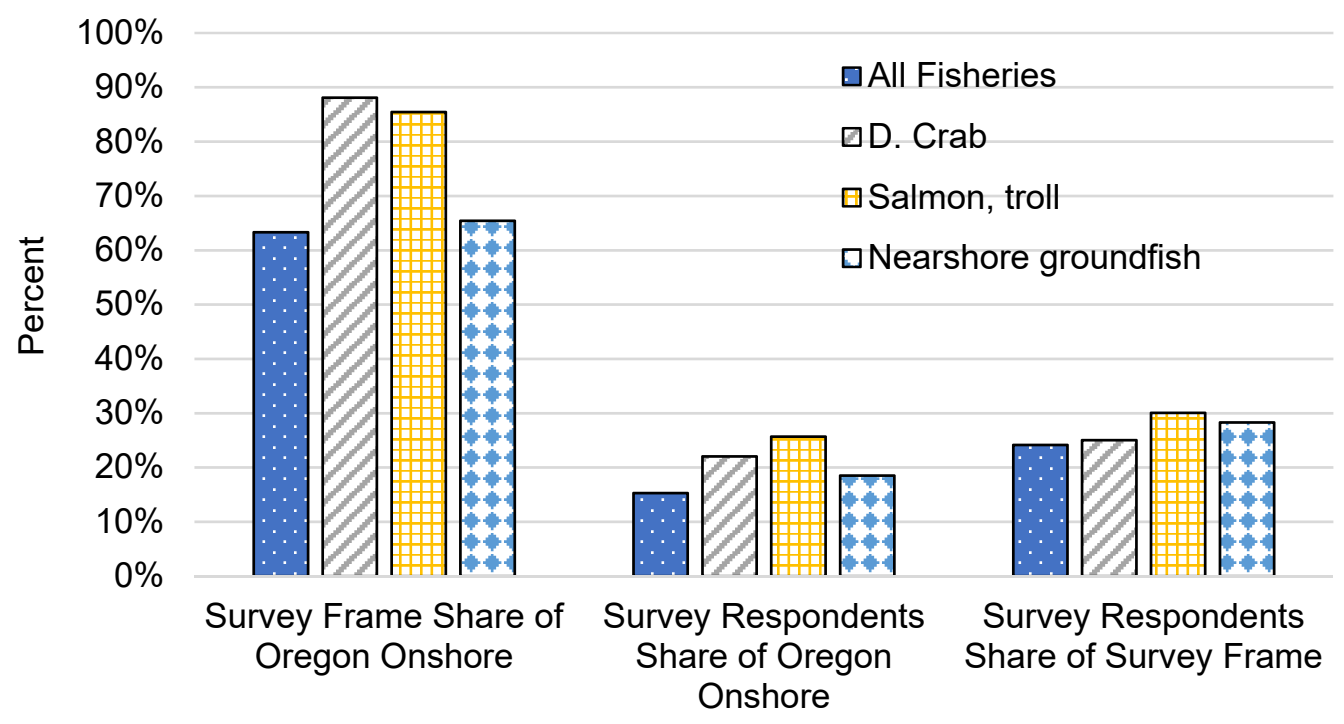

Notes: 1. Table F notes apply. 
Figure $G$

Delivering Vessel Average Annual Landed Value in 2016

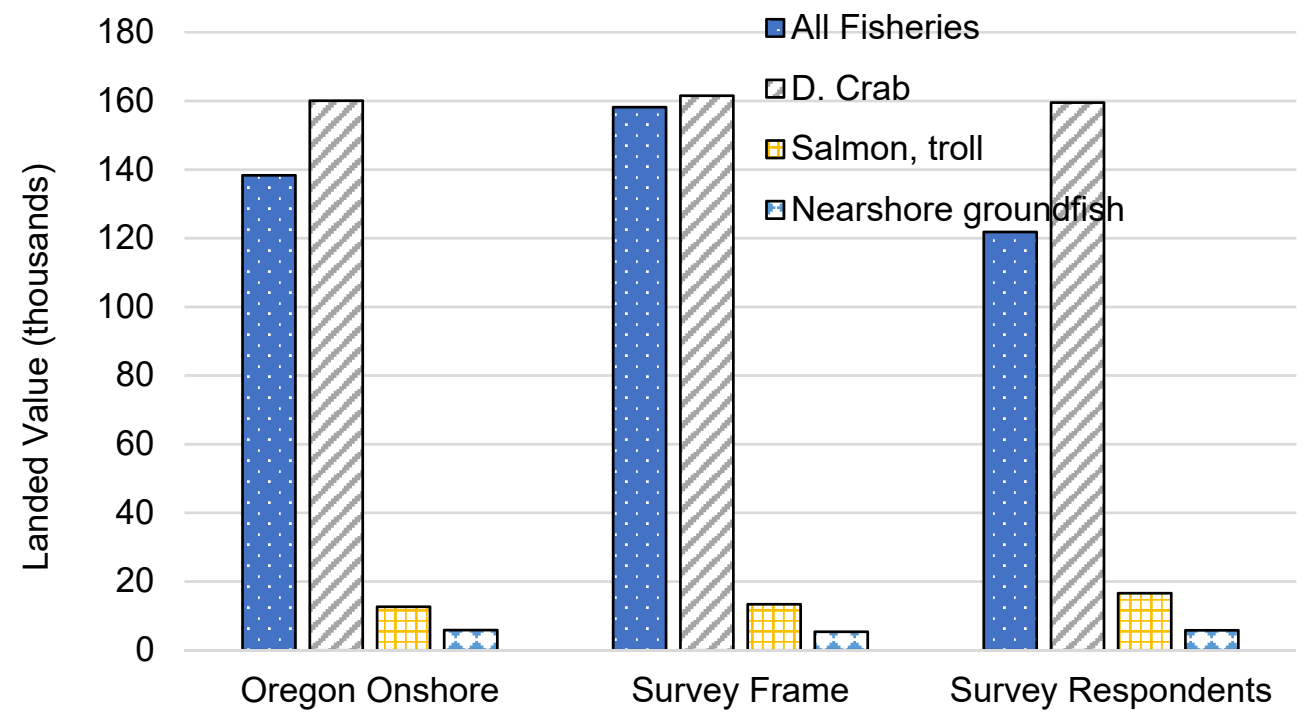

Figure $\mathrm{H}$

Delivering Vessel Average Annual Landed Value

Shares of Oregon Onshore and Survey Frame in 2016

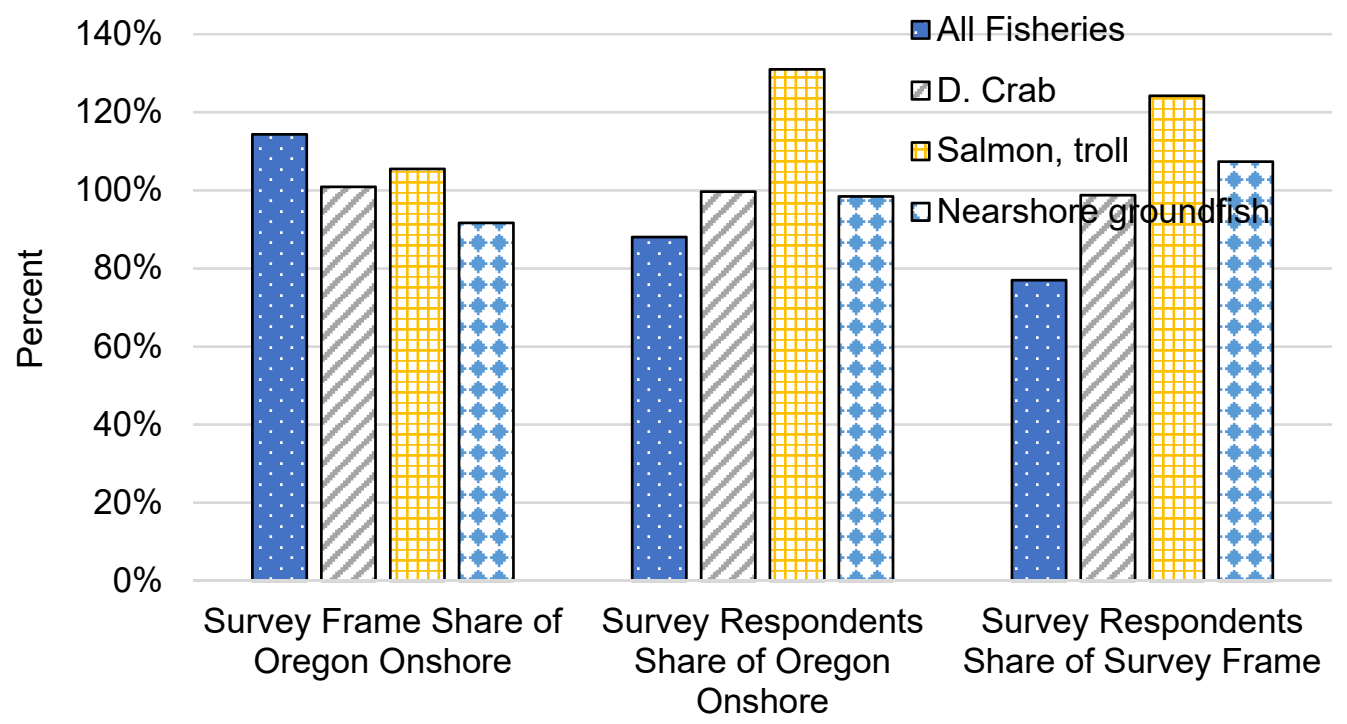

Notes: 1. Table E notes apply. 
Figure I

Histogram of Delivering Vessel Average Annual Landed Value in 2016

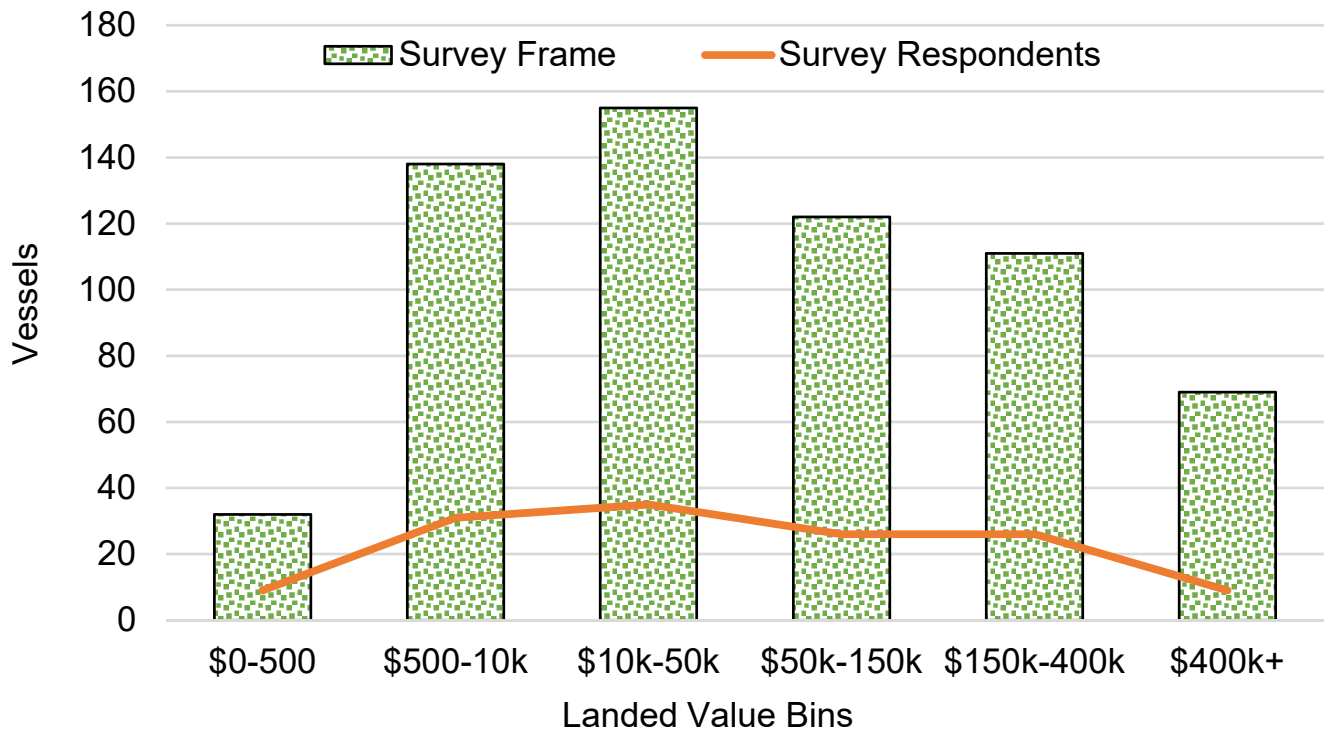

Notes: 1. Table E notes apply. 
Figure $\mathrm{J}$

Quartiles of Delivering Vessel Average Annual Landed Value in 2016

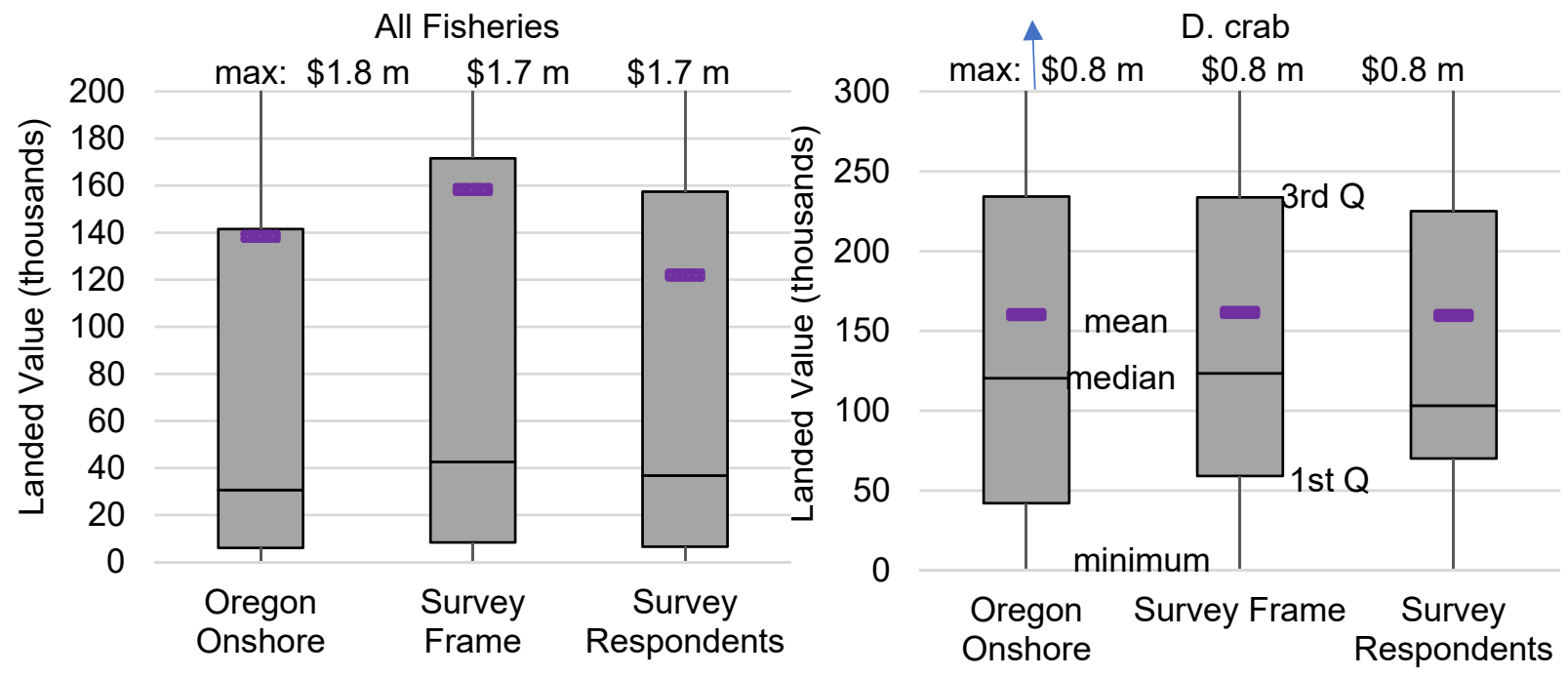

Troll Salmon

Nearshore Groundfish
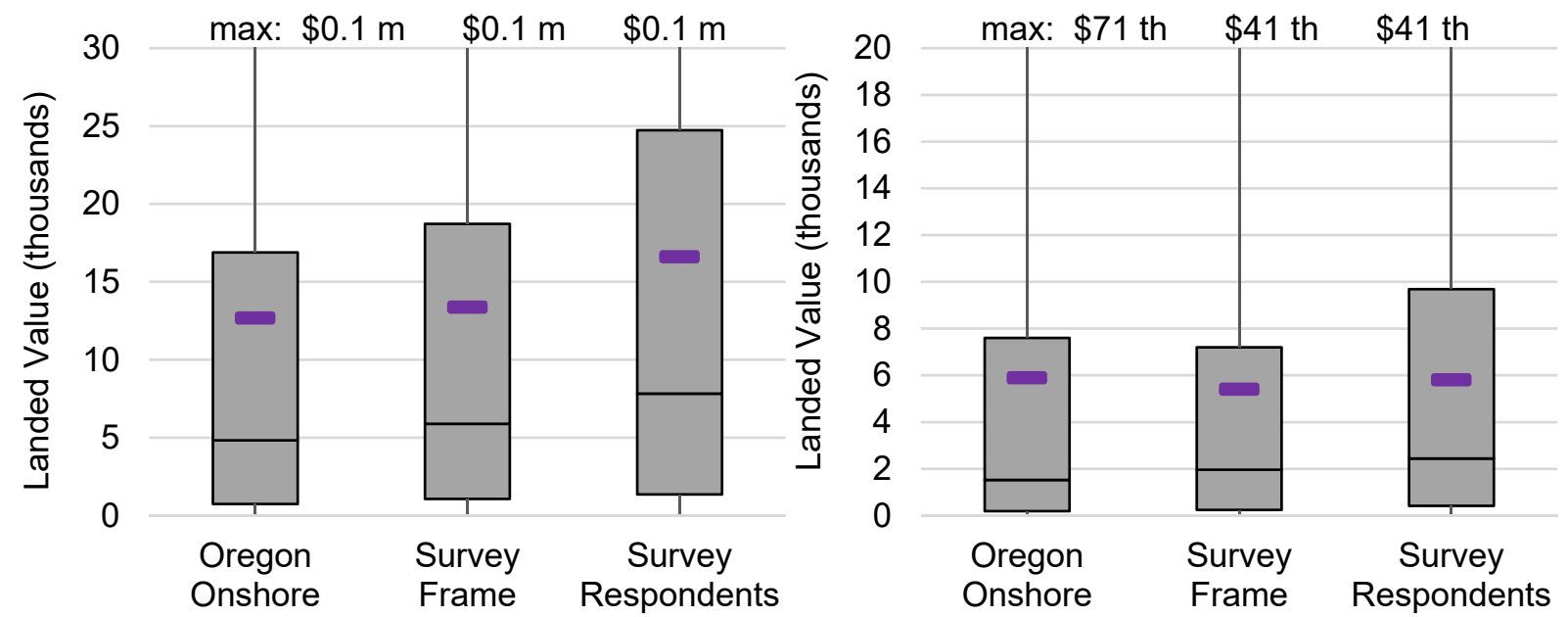

Notes: 1. Table E notes apply. 
APPENDIX 


\section{APPENDIX D: Human Subjects Approval}

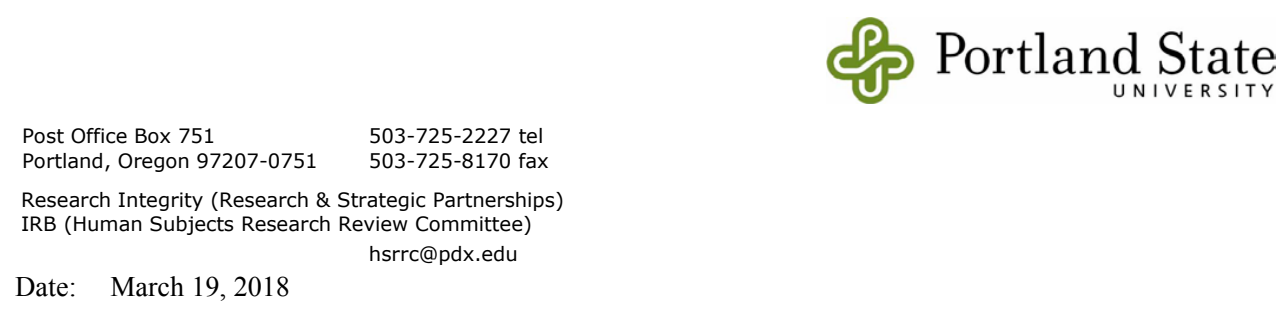

To: $\quad$ Elise Granek / Bryn Hudson, Environmental Sciences and Resources [SPA Awards]

From: Lindsey Wilkinson, IRB Chair

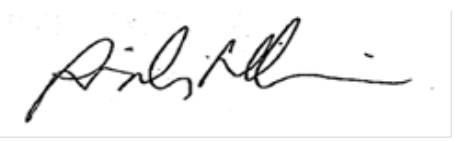

Re: $\quad$ IRB approval for continuation of your protocol \# 174098, entitled: "Spatial and Temporal Shifts in Oregon Fishery Efforts.” [Oregon Department of Fish and Wildlife, PIAF/grant \#170249]

Approval-Expiration: March 19, 2018 - March 26, 2019

Notice of IRB Review and Approval - Continuing Review Expedited Review Category 8 (c); as per Title 45 CFR Part 46

The continuation report for the project identified above has been reviewed and approved by the PSU IRB (Human Subjects Research Review Committee) and the Research Integrity office using an expedited review procedure. This is a minimal risk study. The IRB is satisfied that your provisions for protecting the rights and welfare of all subjects participating in the research are adequate. Please note the following requirements:

Approval: You are approved to conduct this research study only during the period of approval cited above, and the research must be conducted according to the plans and protocol submitted (approved copy enclosed).

Consent: Consent is no longer required as enrollment and data collection are completed. No consent document is approved for this period.

Changes to Protocol: Any changes in the proposed study, whether to procedures, survey instruments, consent forms or cover letters, must be outlined and submitted to the IRB immediately. The proposed changes cannot be implemented before they have been reviewed and approved by the IRB.

Continuing Review: This approval will expire on 03/26/2019. It is the investigator's responsibility to ensure a Continuing Review Report is submitted to the IRB two months before the expiration date, and that approval of the study is kept current. The Continuing Review Report is available on the Research Integrity website.

Adverse Reactions and/or Unanticipated Problems: If any adverse reactions or unanticipated problems occur as a result of this study, you are required to notify the Research Integrity office within 5 days of the event. If the issue is serious, approval may be withdrawn pending an investigation by the IRB.

Completion of Study: Please notify the IRB as soon as your research has been completed. Study records, including protocols and signed consent forms for each participant, must be kept by the investigator in a secure location for three years following completion of the study (or per any requirements specified by the project's funding agency).

If you have questions or concerns, please contact the Research Integrity office in Research \& Strategic Partnerships at hsrrc@pdx.edu or (503) 725-2227. 


\section{APPENDIX E: Community Partner Reflection}

Working with the Oregon Department of Fish and Wildlife was overall a wonderful experience. I received tremendous support from the Marine Reserves Program and from ODFW staff members outside of the program. Staff members provided contacts within the fishing community that aided in survey development and outreach process prior to survey distribution. One of the main challenges that I faced was not necessarily with ODFW, but more the association that my research had with the department. I noticed that during the outreach process, fishers became wary and less willing to collaborate after I prefaced that my work was being funded in part by ODFW and the Marine Reserves Program. I mainly saw this as a desire to withhold information from management agencies. The main complaint that I heard was in regards to the "weaponzing of scientific data". To remediate this problem, I took the stance that ODFW was funding this research in order to help marginalized or impacted groups share their views and opinions in a quantifiable way. After gaining the trust of many local community members, I found that the outreach process and discussions around management were much more comfortable and open. 